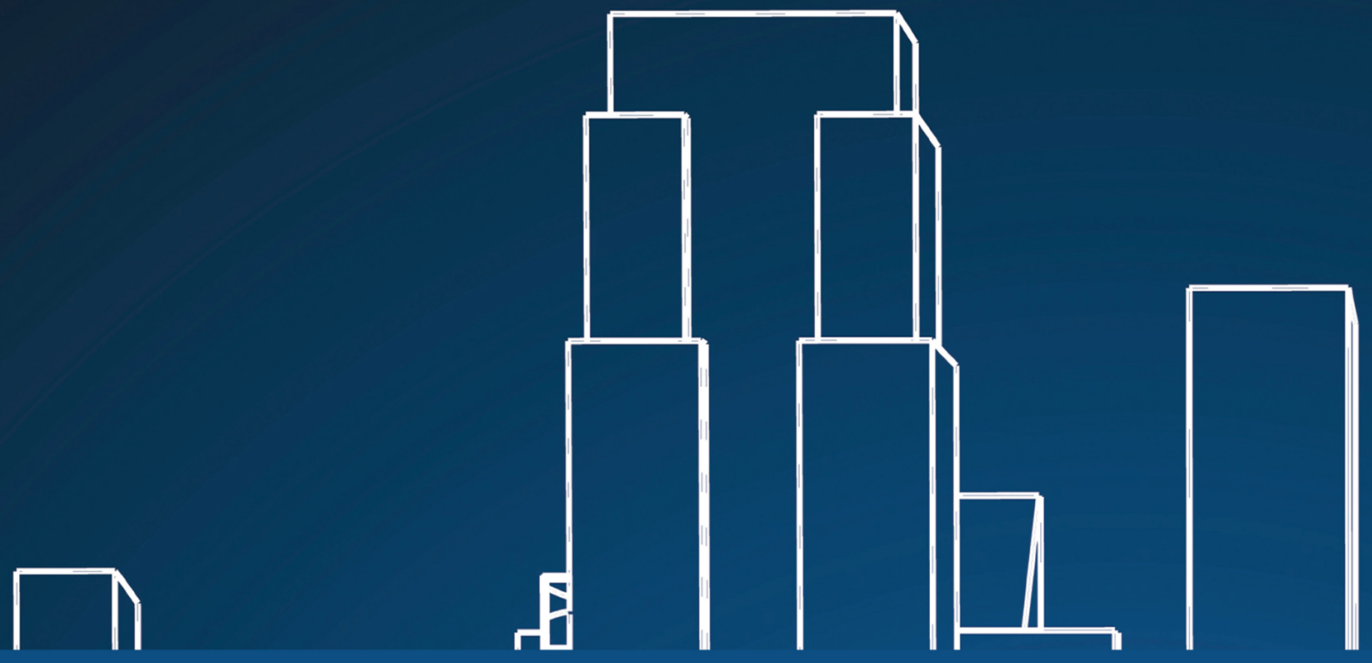

Classical and Contemporary Social Theory

\title{
THE UNIVERSITY REVOLUTION
}

OUTLINE OF A PROCESSUAL THEORY OF MODERN HIGHER EDUCATION

Eric Lybeck

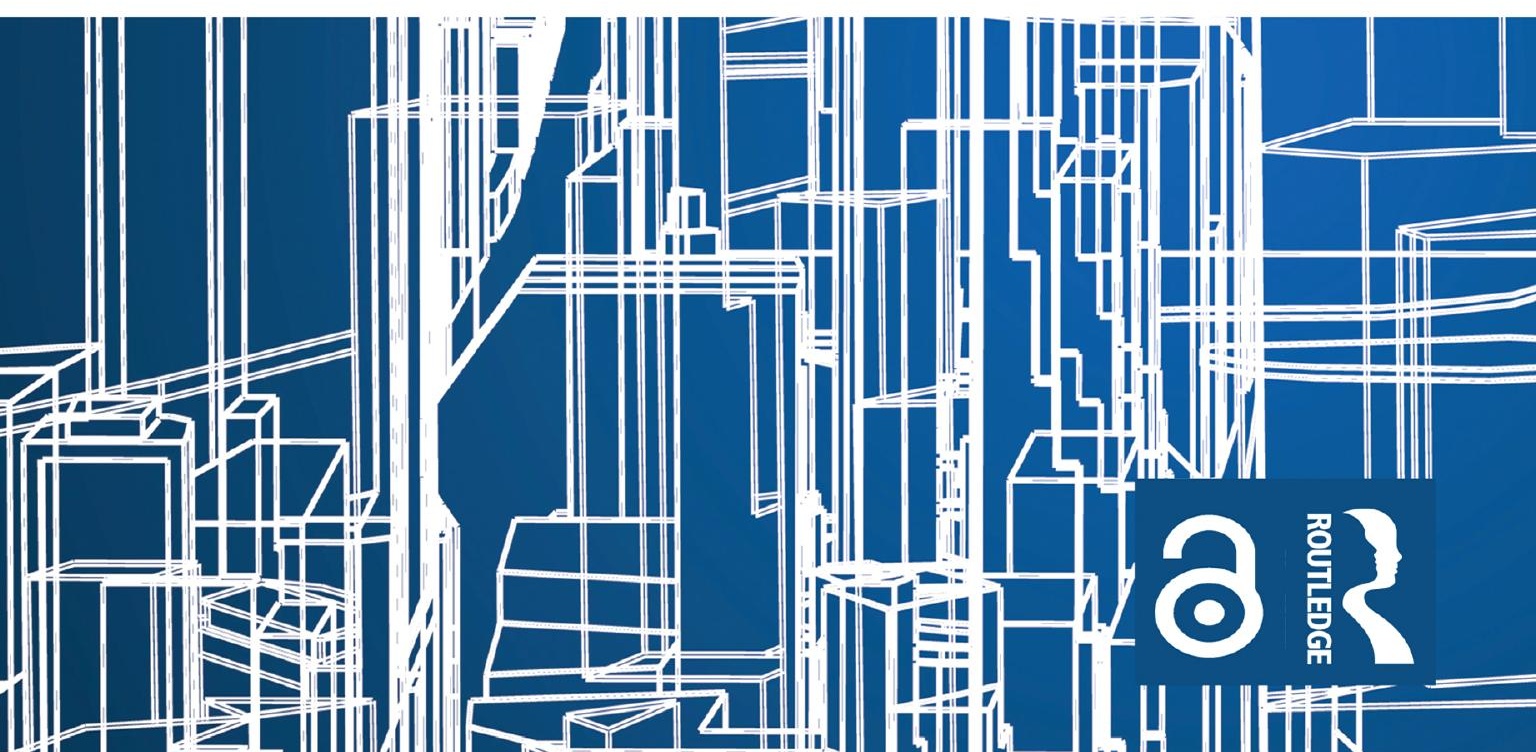


"This is an important and timely book. The modern university was formed in the last decades of the 19th century. However, its collegial organization facilitated a later adaptation of knowledge and culture toward democratic purposes. Lybeck shows how recent re-organization along managerial lines has shifted the university toward private interest in human capital and service to the knowledge economy. It represents an educational counter-revolution with profound implications for society and culture."

John Holmwood, University of Nottingham, UK 
$\Longrightarrow$ Taylor \& Francis

Taylor \& Francis Group

http://taylorandfrancis.com 


\section{The University Revolution}

Few institutions in modern society are as significant as universities, yet our historical and sociological understanding of the role of higher education has not been substantially updated for decades. By revisiting the emergence and transformation of higher education since 1800 using a novel processual approach, this book recognizes these developments as having been as central to constituting the modern world as the industrial and democratic revolutions. This new interpretation of the role of universities in contemporary society promises to re-orient our understanding of the importance of higher education in the past and future development of modern societies. It will therefore appeal to scholars of social science and history with interests in social history and social change, education, the professions and inequalities.

Eric Lybeck is Presidential Fellow at the University of Manchester, UK, and co-editor of Sociological Amnesia: Cross Currents in Disciplinary History. He is editor-in-chief of the open-access journal, Civic Sociology. 


\title{
Classical and Contemporary Social Theory
}

\author{
Series Editor
}

Stjepan G. Mestrovic, Texas A\&M University, USA

Classical and Contemporary Social Theory publishes rigorous scholarly work that re-discovers the relevance of social theory for contemporary times, demonstrating the enduring importance of theory for modern social issues. The series covers social theory in a broad sense, inviting contributions on both 'classical' and modern theory, thus encompassing sociology, without being confined to a single discipline. As such, work from across the social sciences is welcome, provided that volumes address the social context of particular issues, subjects, or figures and offer new understandings of social reality and the contribution of a theorist or school to our understanding of it.

The series considers significant new appraisals of established thinkers or schools, comparative works or contributions that discuss a particular social issue or phenomenon in relation to the work of specific theorists or theoretical approaches. Contributions are welcome that assess broad strands of thought within certain schools or across the work of a number of thinkers, but always with an eye toward contributing to contemporary understandings of social issues and contexts.

\section{Titles in this series}

\section{The Detective of Modernity}

Essays on the Work of David Frisby

Edited by Georgia Giannakopoulou and Graeme Gilloch

Global Economic Crisis as Social Hieroglyphic

Genesis, Constitution and Regressive Progress

Christos Memos

\section{The University Revolution}

Outline of a Processual Theory of Modern Higher Education

Eric Lybeck

For more information about this series, please visit:

https://www.routledge.com/sociology/series/ASHSER1383 


\section{The University Revolution Outline of a Processual Theory of Modern Higher Education}

\section{Eric Lybeck}


First published 2021

by Routledge

2 Park Square, Milton Park, Abingdon, Oxon OX14 4RN

and by Routledge

52 Vanderbilt Avenue, New York, NY 10017

Routledge is an imprint of the Taylor \& Francis Group, an informa business

(C) 2021 Eric Lybeck

The right of Eric Lybeck to be identified as author of this work has been asserted by him in accordance with sections 77 and 78 of the Copyright, Designs and Patents Act 1988.

The Open Access version of this book, available at www.taylorfrancis.com, has been made available under a Creative Commons Attribution-Non Commercial-No Derivatives 4.0 license.

Trademark notice: Product or corporate names may be trademarks or registered trademarks, and are used only for identification and explanation without intent to infringe.

British Library Cataloguing-in-Publication Data

A catalogue record for this book is available from the British Library

Library of Congress Cataloging-in-Publication Data

Names: Lybeck, Eric Royal, author.

Title: The university revolution : outline of a processual theory of modern higher education / Eric Lybeck.

Description: Abingdon, Oxon ; New York, NY : Routledge, 2021. |

Series: Classical and contemporary social theory | Includes bibliographical references and index.

Identifiers: LCCN 2020057015 (print) | LCCN 2020057016 (ebook) |

ISBN 9781138497900 (hardback) | ISBN 9781351017558 (ebook)

Subjects: LCSH: Education, Higher-Aims and objectives. | Universities and colleges-History. | Educational change.

Classification: LCC LB2322.2 .L93 2021 (print) | LCC LB2322.2 (ebook) | DDC 378-dc23

LC record available at https://lccn.loc.gov/2020057015

LC ebook record available at https://lccn.loc.gov/2020057016

ISBN: 978-1-138-49790-0 (hbk)

ISBN: 978-1-032-02032-7 (pbk)

ISBN: 978-1-351-01755-8 (ebk)

DOI: $10.4324 / 9781351017558$

Typeset in Times New Roman

by Taylor \& Francis Books 


\section{Contents}

List of figures viii

Preface $\quad$ ix

Acknowledgements $\quad \mathrm{x}$

1 The university revolution; or the academization process 1

2 The systemic evolution of universities: Ben-David's 'centers of learning' as world-systems analysis $\quad 24$

3 The ideological organization of university systems: A theoretical framework

4 Paradoxes of the academization process: Foreign and classical language education since 1864

5 Women and higher education: Two ideas of equality in 19thcentury Britain

6 'Without any reason for being': Interdisciplinarity at the 1904 World's Fair

7 Conclusion: Reconstructing the academic profession

References

Index 


\section{Figures}

1.1 Temporal dimensions and corresponding dimensions of social power.

2.1 Approaches in the sociology of science. 27

2.2 Workplaces of leading scientists, 16th-19th centuries. 39

2.3 19th-century networks of scientific practice. 41

2.4 18th-century networks of scientific practice. $\quad 42$

2.5 Growth of the 'scientific community'. 42

2.6 Distribution of German university students over the faculties and subject areas, 1830-1914 (in rounded percentages by column). 49

3.1 Dimensions of IEMP power. $\quad 67$

3.2 Ideology: General and special. $\quad 78$

3.3 Dimensions of meaning. $\quad 89$

3.4 AGIL model of the American university. 92

3.5 Nested subsystems of knowledge. $\quad 99$

3.6 Fractal distinctions in sociological methods. 99

3.7 Fractal cycling. $\quad 100$

3.8 Fractal divisions of science/ideology. 104

3.9 Four functions of the university. 105 


\section{Preface}

I began writing this book in 2016 with a simple question: Why do we have modern universities at all? At some point, a handful of monks and priests attended the cloisters of medieval colleges. Today, over a billion people have higher degrees. We take this very much for granted, and yet this huge expansion of higher learning is among the few aspects of modernity that are truly unprecedented in human history. So, I returned to that history to find out why this happened in the first place.

In doing so, I realised that much history and sociology of education makes an error - many think the history of education is primarily about exclusion and domination. Education does, of course, exclude at times; and the institutional expansion of modern universities would not have occurred without the pressures of imperialism and class conflict. But, at root, the history of education is the history of expanding access to education - that is, increasing the social fund of knowledge.

This means that education began somewhere - it had a centre; an elite; a tradition - and that exclusive system became something else over time. Our current system is in the process of becoming something else right now and will be different again tomorrow. More students will be educated. More knowledge will be produced, changed and forgotten.

Universities represent the promise that we might someday get a handle on that knowledge. We might obtain the truth. We won't. What we can learn is how to use knowledge as a means of orientation - as an aid in our own collective and individual actions. But, in producing knowledge at such a pace and with such complexity, we cannot help but produce ignorance at the same time - ignorance of facts and things, but also of one another.

I thought I could answer the question I set out to address - but, I regret to say, I have not found the truth. I have, however, found a way of orienting myself to the history of modern higher education and its place within modern society. This may or may not be useful to others, but I have recorded some of my initial thoughts here for reference, assistance, criticism, dialogue and correction. With any luck - nay, inevitably - I will know more tomorrow. I can therefore only apologise for any errors and oversights in the meantime. 


\section{Acknowledgements}

I am grateful to discussants at the University of Cambridge's Faculty of Education, Lancaster University's Department of Educational Research, and the University of Manchester's Institute of Education for comments on the overall argument of the book.

Each of the other chapters were presented and discussed as works in progress: Chapter 1 at the American Sociological Association meeting in Philadelphia in 2018; Chapter 2 at the Social Science History Association meeting in Vancouver, Canada, in 2012; Chapter 3 at the British Sociological Association's Early Career Theorists' meeting in London in 2013; Chapter 4 at the University of Surrey Understanding the Contemporary University Student seminar in 2016; Chapter 5 at the Social Science History Association meeting in Chicago in 2019; and Chapter 6 at the Social Science History Association meeting in Chicago in 2016. I am grateful to all who commented and helped refine the book's arguments, theory and evidence.

Figures 2.2-2.5, which are reprinted/adapted by permission from Springer Nature, were originally published in Minerva (Taylor et al. 2008).

Chapter 7 was published previously as 'Reconstructing the Academic Profession' in On Education: Journal for Research and Debate (Lybeck 2018a) and is reproduced with permission. 


\section{The university revolution; or the academization process}

\subsection{Theorising the university}

Few institutions in modern societies are as taken for granted as universities, which pursue advanced teaching and research in the arts and sciences, graduate ever wider and more diverse populations of students, and occupy extensive acres and buildings at considerable public and private expense. Even as student tuition fees and debt skyrocket, and governments and businesses encourage more technology and innovation to stimulate economic growth, and students, administrators and faculty try to balance the pursuit of social justice with freedom of speech and enquiry, the following questions are rarely asked: Why do universities exist in the first place? Where did this institution come from? And, why does it exist in its current form?

We will address these questions historically and sociologically - that is, processually - noting that the university has gone through a series of phases in several national contexts. Each of these historical moments left an imprint on the content and character of this fundamentally 'modern' institution. Indeed, I will argue that the emergence of the modern university was at least as important in establishing the conditions of modern society as the industrial and democratic revolutions. Further, this was no accident, for the university resolved a number of tensions, contradictions and conflicts surrounding the dramatic social, economic and political transformations of the 19th century in Europe and America.

The long-term rise of the university must therefore be considered a central process within the broader shift from traditional, medieval societies to contemporary, modern (or postmodern) societies. Since 1800, we can trace the contours of an 'academization process' that occurred in two phases: first, the shift from a medieval university to a modern, elite university; and second, the shift from an elite to a mass university. Of the two phases, the former established the structure and culture of the modern university, while the latter reproduced and extended the paradoxes and contradictions embedded in the former.

Many factors contributed to this transition, which began in the 19th century, but the most important were: 


\section{The university revolution}

1 Changes in class structure - in particular, the rise of the bourgeois middle classes and the decline of the aristocracy, resulting in a 'new class' of academics and professionals.

2 Displacement of religion - in particular, the decentring of the clergy and Theology as the core profession and discipline in the university, resulting in the overall secularization of abstract knowledge.

3 Imperial competition - in particular, intra-imperial competition within the 'core' imperial states, especially those fearful of the rapid rise of the German Empire, whose academic system was emulated isomorphically.

4 Changing status of women and children - in particular, the consolidation of the educated, adult male as citizen and resistance to this designation by suffragists and others, especially those involved in social work, public health and philanthropy.

5 Rise of science and technology - the prevailing influence of industrialism, medical science, engineering and related activities was undoubtedly important in justifying and resourcing the modern university, but this investment should also be understood in relation to the other dynamics, particularly professionals' interest in claiming the authority of 'science'.

We will explore each of these factors in detail within the chapters below. Undoubtedly, other dynamics were significant as well. However, following a review of the present, common-sense understanding of what universities are and were for, which tends to imply that only factor 5 (science) was historically significant, we shall see that the rise of the modern university was an emergent phenomena of several unplanned social processes interacting with one another to produce, initially, an elite university dedicated to specialized research and advanced teaching within a range of professions and, subsequently, a widened, massified university system that tries to include ever more populations. All the while, universities and politicians have remained unreflective about the limits of this project due to the consolidation of the elite university system at the end of its first phase of development.

The risk of any generalization is that it is incomplete and glosses over particulars. This is all the more risky for a generalization about the entire history of modern academia, which is almost equivalent to claiming to account for the history of modern thought tout court. No single scholar can ever obtain such a quantity of knowledge him or herself. Thus, outside the history of the early modern era (Burke 2000), the historiography of universities has tended towards either specific national cases (Geiger 2014; McClelland 1980; Weisz 1992) or compendiums of multi-author, multi-volume edited collections recounting the range of activities that have occurred within universities (e.g., Brock and Curthoys 1997; Rüegg 2004). These are remarkable resources for historians and sociologists and have been consulted in making the proposed generalization; however, many remain rooted in mid-20th century metanarratives, as we shall see. It is, however, worth admitting from the start that, while historical, the present book is not a work of history; rather, this is 
historical sociology and, even more specifically, a work of historically grounded sociological theory. Other scholars have defended this form of research from critics (Mann 1994; Mouzelis 1994; Münch 2000) insofar as our goal is not necessarily to add new historical data to the picture, but rather to develop new ways of thinking, heuristic frameworks and conceptual tools through which we might re-approach the relevant historical and archival material anew. The historical references should therefore be considered as indicative examples encountered in the course of developing the theory, which suggests further interrogation of these issues, events and processes would be useful in filling out and potentially revising aspects of the theory and our view of the past, present and future.

Unlike popular notions of 'theory' as something akin to an 'opinion', one should recall that even a theory like Darwin's analysis of evolution does not stand or fall on a single or a few observations (Putnam 1981). Rather, the value of the theory lies in its capacity to produce generative hypotheses; whether a range of old and new observations can be usefully drawn together and explained within the general theoretical framework thereby encouraging the accumulation of knowledge. The 'academization process' theory elaborated below is by no means as general or revolutionary as that of natural selection; rather, it provides a 'middle-range' explanation for the emergence and dynamics of particular institution - the university - in the context of modern societies, which it co-produced alongside the capitalist economy, national states, mass media and so on (see Merton 1957 on middle-range theory). Accordingly, the book should be understood as the beginning of a scientific process of discovery rather than a culmination of an extended career's worth of historical scholarship. Indeed, such grand theorising is not normally the province of early career scholars, who, like myself, cannot know everything there is to know about a field as large as modern university history. Still, as the discussion below will reveal, both within the specialized field of higher education research and as an academic profession generally, we often retain today a woefully inadequate picture of the major macro-sociological dynamics that produced the institution in which we work, which continues to expand in influence and centrality across our contemporary, globalised, knowledge-based economies and societies.

Indeed, working within the emerging field of Critical University Studies (Petrina and Ross 2014), I have encountered a range of early career scholars coming from several interdisciplinary backgrounds - English, History, Theology, STS, Philosophy, Politics and so on - who began researching a particular topic in their disciplinary field. In my case, this was the history of sociology, which led to a question about universities as an institutional context and a realisation that the central metanarratives surrounding universities (especially about the 19th century) have not been substantially revised since the post-war era. Each of us in our own specialist spheres turned our attention from an original topic of interest to the history of universities in general, uncovering a range of activities and phenomena that have hitherto been 


\section{The university revolution}

largely ignored or, if studied, have been disconnected from mainstream accounts of what universities are and were for. Since the early 2010s, scholars have designated this emerging field as 'Critical University Studies' (Morrish and Sauntson 2019; Newfield 2011; Petrina and Ross 2014); however, we might more broadly define it as 'new university studies' - or simply 'university studies' - including the processual approach offered here as well as post-critical, civic and historical sociological modes of analysis and more (Hodgson et al. 2020; Stevens and Gebre-Medhin 2016).

For we desperately need new ways of thinking. From the point of view of theory, we are still using the spectacles and lenses crafted in the mid-20th century for more or less ideological purposes. This does not make such observations entirely untrue; but in turning our heads from one horizon to another, we confront the hazy outlines of a much wider field of vision in our periphery. In doing so, we realise that we may have hitherto mistaken a single effect of the multidimensional academization process - the rise of science, technology and innovation - for its core and central cause.

\subsection{The triple revolution since 1800}

Sociologists and historians are familiar with the notion of a 'dual revolution' that began in Europe, especially Britain, in the late 18th century. In his Age of Revolutions, Hobsbawm traced the contours and effects of the French Revolution of 1789 and the contemporaneous British Industrial Revolution, suggesting that these shifts toward democratisation and the industrialisation of state and society gave birth to the modern world (Hobsbawm 1969). Similar notions informed the mid-20th century debates over 'Late Capitalism' versus 'Industrial Society'. For example, Giddens's 'post-Marxist' critique of historical materialism suggested the two major forces of modernity were the nationstate and capitalist market (Giddens 1985; Adorno 2003; Dahrendorf 1959). Political sociologists have since articulated refined theories of the state from both Marxian and neo-Weberian perspectives to emphasize the 'relative autonomy' of state institutions from the dominant economic class of bourgeois capitalist owners (Block 1994; Poulantzas 1969; Mann 1993; Evans et al. 1985). Indeed, a further 'third wave' of historical sociologists have added the cultural dynamics that influenced politics and society in their new interpretations and analyses of the modern world (Steinmetz 1999; Adams et al. 2005; Reed 2011). Within this 'cultural turn', one might include insights drawing on the work of Bourdieu, postcolonial scholars and Science, Technology and Society (STS) scholars, drawing our attention to the role of knowledge and various forms of expertise that have informed the West's hegemonic domination of the rules of the game within and beyond nationstates (Bhambra 2010; Bourdieu 2015; Gilman 2007; Go 2013; Gorski 2013; Steinmetz 2013; Zimmerman 2012).

These lines of research are essential to our understanding of 'modern' market societies, states, culture and knowledge as well as the dynamics linking 
these to one another in interdependent, but relatively autonomous ways. However, I wish to return to the premise of the 'dual revolution' and make a more radical claim insofar as the dual revolution was, in fact, triple. In addition to the democratic and industrial revolutions, there was a third emergent process - called here 'the academization process' - in which the modern university system was established beginning in the 19th century, which provided core elements, structures and agents of modern society irreducible to either industrialisation or democratisation. Indeed, the modern university system has played a fundamental role in integrating and mitigating the contradictions of democratic industrial societies. This functional role explains the tremendous growth in higher education since its origins at the University of Berlin in 1810 to such an extent that, at present, around 2.8 per cent of the world's population is currently enrolled in higher education (UNESCO IIEP 2017); meanwhile, vast amounts of professional training, human rights and social justice work, and economic and technical innovation are mediated through interactions within what scholars have termed the 'triple-helix', or 'government-university-industry' complex (Etzkowitz and Leydesdorff 1996, 1998; Block and Keller 2009; Slaughter and Rhoades 2009; Münch 2014; Bromley and Meyer 2015; Meyer and Bromley 2013). My argument here is that we cannot understand 'modernity' as such without including the constitutive role the university system has played in organizing modern societies and social power, locally, nationally and globally.

\subsection{Classical sociological approaches to the triple revolution}

The notion of a triple revolution was, in fact, often implied and sometimes articulated by classical sociologists. Marx and Engels, for example, drew on Heine's analysis of the emergence of German idealism in parallel to the French Revolution to describe a 'philosophical revolution' occurring alongside the democratic and industrial changes in the early 19th century - though their materialist criticism rejected the notion that this could have significance beyond the realm of 'pure thought' until Hegel was 'turned on his head' (Engels 2005; Marx and Engels 1970; Leopold 2007). Weber, on the other hand, noted the existence of a stratum 'peculiar to the West, especially on the European continent, [that] was of crucial importance for its whole political structure: the university-trained lawyers' (Weber 2008: 171). In Economy and Society he wrote:

Formally elaborated law constituting a complex of maxims consciously applied in decisions has never come into existence without the decisive cooperation of trained specialists ... Only indirectly is this development influenced by general economic and social conditions. The prevailing type of legal education, i.e., the mode of training of the practitioners of the law, has been more important than any other factor.

(Weber 1968: 775-76) 


\section{The university revolution}

Weber's position is clear: legal rationalization is the product of universitytrained lawyers, which is an observation with compelling significance when connected with his interpretations of the significance of legal rationality for the growth of capitalism (Ewing 1987).

Durkheim was, in fact, at his most historical when tracing the evolution of educational institutions and thought in his Evolution of Educational Thought (Durkheim 2013). Explaining changes in educational theories from medieval to modern times, he wrote:

There is no immutable form of education, that yesterday's cannot be that of tomorrow, that while on the one hand, the systems are in a state of perpetual flux, these continual changes (at least when they are normal) connect at any given moment in time with a single fixed and determining reference point: namely, the condition of society at the relevant moment.

(Durkheim 2013: 9)

These changes in education are then socialised into generations of students, who henceforth respond to shared 'social facts' and, in turn, reshape the world. Indeed, by the end of the 19th century, Durkheim credited modern schools with instilling the all-important 'cult of the individual' as both a producer of modern selves, but equally as the legacy and product of the long trends in educational theory running from Romanesque cathedrals through medieval universities, Renaissance classicism and so on. He noted, 'In each one of us, in differing degrees, is contained the person we were yesterday ... It is just that we don't directly feel the influence of these past selves precisely because they are so rooted within us' (Durkheim 2013: 11).

Accordingly, the role of education was of considerable importance to classical sociologists working to understand the central dynamics of modern societies. But, none went as far as Parsons, who explicitly articulated the view that mass higher education was 'the most critical single feature of the developing structure of modern society' (Parsons and Platt 1974: vi). Universities contributed to the shift from traditional to modern societies by encouraging allocation of social status according to achievement rather than ascription. The professional ethics of the businessmen, lawyers and scientists who enter society as graduates involves the adoption of the affective neutrality and instrumentalism of the specialist.

In so far as the doctrine is upheld that in general the 'leading men' of the society should be educated men in the modern sense, their elite status carries with it commitment to a value-system of which the values of the scientist, and the valuation of his activities and their results, form an integral part.

(Parsons 1951: 342)

Unfortunately, Parsons and the modernization theorists who drew the structural-functionalist interpretation into higher education studies and 
science policy developed a rather 'static', evolutionary notion of the development of universities in modern societies. As we will see in Chapter 2, Edward Shils and his student, Joseph Ben-David, produced an historical account of the emergence of modern higher education in 19th-century Germany based on a theory of competition drawn from Milton Friedman and others working at the University of Chicago (Ben-David 1960, 1971, 1977; Shils 1962, 1989). Their historical account incorrectly suggested that natural scientists and academics were themselves responsible for the embedding of 'value-neutrality' in universities based on the 20th-century outcome of a positivist science system projected back in time as an origin myth. Even Shils noted as much in his annotations on Ben-David's manuscript for 'The Scientific Role' article for Minerva:

Most important for the future revision of this book is the need to document from biographies and correspondence and other personal records the facts of the emergence of the 'scientific identity'. It is entirely taken for granted here. It is, in fact, inferred from the increase in the density and intensity of scientific activity in the 19th and 20th centuries. You do not present in this chapter any evidence that there had been such a change in self-conception. I myself have always believed that such a change took place, but I am only a dilettante, not writing a scholarly book on the subject. ${ }^{1}$

In fact, more recent scholarship in the history of German universities suggests the emergence and consolidation of the university was driven by state-centralisation processes and the need for a rational civil service (Ash 2006; Habinek 2010; Lybeck 2017; McClelland 1980). While this interpenetration with state power might discount the thesis presented here - that universities represented an autonomous basis of power in the process of modernization the critical challenge for functionalist evolutionism consists in recovering the actual social science: the humanistic, professional and, indeed, religious bodies of knowledge other than natural science present during the birth of the modern university system. We cannot merely project the present conditions of the knowledge economy back to the early 19th century and presume the outcomes were the same as the sociogenetic causes.

Unfortunately, even critical sociologists assessing the relationships between state, capitalism and higher education maintain the same rear-view model of positivist science promoted by modernization theorists - only adding a critical negation to suggest this was the natural ideological superstructure for global capitalism. Immanuel Wallerstein (2004), for example, draws on C.P. Snow's notion of the 'two cultures' separating arts and science to suggest scientists led this bifurcation. While partially true insofar as scientists did respond to incentives, institutions and resources universities provided, this explanation is insufficient insofar as the universities are taken-for-granted as a context, rather than being explained within very particular historical conjunctures in 


\section{The university revolution}

German-speaking states reacting to the invasion of French Revolutionary armies during the pre-Napoleonic and Imperial phases of the revolution (Lybeck 2018c).

Indeed, even more recent attempts within the 'new sociology of knowledge' and related practice-oriented approaches informed by STS, the Cambridge school of political thought, Bourdieusian and related approaches emphasizing local interactions amongst knowledge-makers, fail to update the narrative of the macro-level development of the university system overall (Camic and Gross 2004; Knorr-Cetina et al. 2000; cf. Lybeck 2019a). Frickel and Gross, for example, offer a general theory of scientific and intellectual movements (SIMs) which suggests that the establishment of successful ideas follows the same patterns exhibited in successful social movements (Frickel and Gross 2005). And yet their 'general' theory already explicitly acknowledges the following:

Because our theory is designed primarily to explain SIMs in modern scientific and intellectual fields, our examples - almost all North American and Western European - are taken from the historical period beginning in the 1830 s with the organizational bureaucratization of research in German universities (Ben-David 1971).

(Frickel and Gross 2005: 206).

As the quote reveals, again Ben-David's account of the scientist's role in society is used as the historical basis for subsequent knowledge development. Here, the institution of the modern 'Western' university is assumed to be a fixed context in which the general theory of SIMs applies.

\subsection{Contemporary trends in historiography and historical sociology}

Meanwhile, historians of universities are beginning to revisit the traditional narratives in which universities emerged, particularly in Germany - a central case for the 19th century. Wellmon, for example, situates the innovation of the university - and specifically the disciplined university graduate - as a technology for 'organizing enlightenment' in light of late 18th-century concerns about the proliferation of books, which is not dissimilar from our contemporary fears about information overload (Wellmon 2015). Clark tracks changes in the bureaucratization of teaching under pressures of more and more students from wider segments of the population, especially those training for civil service examinations, which resulted in a rationalization of 'academic charisma' (W. Clark 2006). Outside German historiography, Whyte has identified an alternative local and regional basis for the emergence of civic universities in Britain, flipping the traditional narrative that Oxbridge set the terms of higher education from its hierarchical centre (Whyte 2015). And, several volumes of the Perspectives on the History of Higher Education series edited by Roger Geiger have articulated a 'revisionist' account of the late 
19th-century American history of universities as well as in other periods (Geiger 2013; Geiger et al. 2017).

These histories are only a few examples of the range of new historical material that can be integrated within the recently emerging body of scholarship Stevens and Gebre-Medhin term a 'political and historical sociology' of the higher education sector (Stevens and Gebre-Medhin 2016). In their review article, the authors identify three separate organizational patterns developing over time: 'an associational configuration, nascent in the early republic and elaborated through to World War I; a national service configuration, developed through the middle decades of the 20th century; and a market configuration, still in evolution' (Stevens and Gebre-Medhin 2016: 122). To grasp these dynamics, the principles, methods and explanatory logics developed especially within the field of comparative-historical sociology have begun to be applied to the study of higher education. Recent works exemplifying this approach include Berman's analysis of the market university developing from changes in regulation, patent law and biotechnology, ultimately rooted in economists' ideas of 'innovation' (Berman 2011). The authors also highlight work in the 'academic capitalism' tradition that draws Marxian analysis of capitalist production and consumption into our understandings of how contemporary universities are working increasingly as extractive industries as much or more than as institutions of higher learning (Marginson and Considine 2000; Slaughter and Leslie 1997; Slaughter and Rhoades 2009).

However, without diminishing the significance of this developing research, we should reconsider whether a new narrative - or perhaps metanarrative might be necessary to fully account for the interrelationships involved within the triple revolution ongoing since the 19th century. For if political sociologists are correct in identifying the 'relative autonomy' of the state vis-à-vis the market, should we not also note the autonomy of the academy over the same period? Even the trends identified by Stevens and Gebre-Medhin occurred after the university revolution was well underway - in part due to their American focus, which leaves out much of the prehistory and prefiguration of American academe in German universities (Lybeck 2016). The academic capitalism school remains rooted in a dual revolution notion in which industrial capitalism extracts from universities, ultimately in the interests of bourgeois capitalist exploitation (Heller 2016). The university remains part of the ideological superstructure rather than being constitutive of social power as such.

Instead, not unlike scholars working in the 'triple-helix' perspective on the contemporary government-university-industry complex, we want to track the systemic and linked interactions between at least three processes, rather than viewing it as a dual revolution with universities thrown in as an epiphenomenal symptom. In fact, insofar as neither the industrial or democratic revolutions happened overnight - that is, these were also long-term processes occurring over centuries and several generations - we can term what would otherwise be called in parallel a 'university revolution' as, instead, amounting 
to an 'academization process' alongside an industrialisation process and democratisation process; none of which, it should be noted, has culminated or is complete. I will, accordingly, outline a theoretical framework developed from synthesis of the work of especially Andrew Abbott, Isaac Reed and Norbert Elias, which can be termed a general 'processual' theory of society (Lybeck 2019b). We can then apply this to the history of universities, the state and society to see what difference this makes in further refining and consolidating our knowledge of the triple revolution or 'academization process'.

\subsection{Toward a general processual theory}

\subsubsection{Linking ecologies}

In recent years, Andrew Abbott has developed a 'processual' theory of social phenomena drawing on pragmatism and the Chicago School 'ecological' tradition. His most recent collection of theoretical essays demonstrates several aspects of the approach that challenge traditional sociological understandings of individuals, social order, inequality, normativity and more (Abbott 2016). In line with historical sociology, in general, processual sociology emphasizes the significance of time, sequence and processes (Abbott 2001b). The ontology of the social world assumes everything social is constantly 'making, remaking and unmaking itself (and other things), instant by instant' (Abbott 2016: ix). In contrast to the structural functionalist static tradition, processualism considers stability to be the thing that needs to be explained insofar as 'all is change'.

Drawing on Mead (1932), Abbott suggests the only thing that really exists is the present, into which the past and future are 'encoded'. Individuals are encoded through memories, narratives and embodied habits, thought patterns, etc., just as the past is also encoded in archives, institutional and organizational structures, collective memories and so on.

The utility of the idea of encoding is that it gets us out of the trap presented by the fact that the past is well and truly gone, the fact that there can be no effect at a historical distance. The concepts of historicality and encoding get us out of that trap by reminding us that certain parts of the past are continuously (re)encoded into the present synchronic social structure, in the sense of thereby acquiring historicality - the appearance of endurance in time.

(Abbott 2016: 14)

Even 'big structures' of the kind historical comparativists study are at risk of rapid and contingent change (Tilly 1984), yet these have the appearance of long, durable objects due to both actually recurrent synchronic causal patterns as well as the cultural concepts we use to demarcate 'capitalism' and the 'state' as distinctive historical things. We know from history that both the 
relations and forces of production change - indeed, within Marxian and Schumpeterian analyses, these deep structural changes are precisely what causes financial crises and business cycles (Paolucci 2009; Schumpeter 1939). With each iteration, capitalist regulation is remade into something qualitatively newer (or 'later') (Jessop 1995; Mandel 1975).

We might say the same about the 'university' insofar as we are aware of a type of organization dedicated to the study of advanced knowledge that has 'survived' from the European Middle Ages, all the while exhibiting considerable variation in form from institution to institution and across time; yet, we often speak of 'The University' as an idea or ideal that provides conceptual unity to these temporal and synchronic variations. Indeed, as we shall see in Chapter 2, among the insights worth retaining from the modernization theorists' view of 'centers of learning' shifting between national university cores and peripheries is that the 'idea of the university' produces substantive causal effects in the global organization of knowledge - such that Germany could set the standard of what academic knowledge should be in the 19th century, whereas America does this in the 20th and 21st centuries (Ben-David 1977; Taylor et al. 2008).

Abbott's development of the concept of 'linked ecologies' begins to connect his earlier work on the 'system of professions' and the chaotic, fractal structure of academic disciplinary developments within the university (Abbott 1988, 2001a, 2005b; Lybeck 2019a). He challenged the linear assumption of the sociological idea of 'professionalization', in which every profession follows a particular sequence of legitimation via articulation of principles emphasizing scientific and technical rationality, the establishment of training and legal protections to control entry into the profession and so on. Instead, a jurisdictional model of interprofessional competition highlighted the ways in which the processual development of any one profession depended on the activities, interests and conflicts in and between other professions. Through jurisdictional claims over particular kinds of work, professions define subjective boundaries between objective problems, thereby distinguishing tasks within their remit and expertise from others, including lower status semi-professions, interlopers and amateurs (Etzioni 1969; Gieryn 1983). These claims are regulated through affirmation amongst various audiences, including the state, public and, importantly for our purposes, the academy. Because abstract notions of scientific and technical competence are central to the legitimation of professional claims, the status of professional knowledge within the university can lead to a range of proxy conflicts at a higher level of abstraction.

These proxy jurisdictional disputes occur alongside and within the interprofessional turf wars amongst the academic profession itself, that is, between disciplines, which Abbott has explored elsewhere (Abbott 1999, 2001a). In this analysis, disciplines mark fractal distinctions between, for example, 'hard' and 'soft' forms of science, both within and between themselves, which become 'bundled' at the level of the university as a whole. Again, the idea of 'the university' as a unified entity is important for denoting coherence in an 
otherwise chaotic and disorganized proliferation of constantly revised notions of 'truth'. I have argued that we can synthesize Abbott's work on professions and academia by noting that the academic profession has a particular, special position within the system of professions unlike any other insofar as academics claim a (tenuous) monopoly on the ultimate rights of abstraction i.e., truth. This does not mean truth is ever settled - quite the contrary - but the functional role of academia as audience for jurisdictional claims positions universities as the central institution demarcating which kinds of abstract knowledge are allowed and which can be deemed 'pseudoscience' or 'ideology'. Thus, as professionals increase their power, authority and roles across modern societies, the role of the university also increases in significance even when the paradoxical outcome of anti-expert populism appears to be ascending from Great Britain to Brazil (Streeck 2017).

In Abbott's own work, linkages between 'ecologies' - state, universities and professions - suggest certain kinds of settlement and stability are reached for particular durations, but not necessarily for the same reasons within each ecology, each of which operates according to different time scales. Thus, political actors might see value in assenting to or undermining a profession, say psychiatry, due to budget pressures, which might connect with academic criticism of psychiatric authority from radical or existentialist points of view. This might, in turn, connect with the relatively low status of psychiatrists working in asylums vis-à-vis others promoting forms of care rooted in prescription medication and short-term behavioural adjustment via outpatient care. The three interests combine in a process, or series of events, resulting in the shuttering of asylums (Taylor 2011; see Sewell 2005 on events).

While this ecological explanation is straightforward enough - and could, perhaps, be equally well demonstrated using a Bourdieusian or organizational theory of 'fields' (Bourdieu 1977; Fligstein and McAdam 2015; Martin 2003; cf. Abbott 2005a) - the processual approach effectively highlights the inadequacies of the teleological approaches of both structural-functionalists and critical sociologists. Returning to the explanation for the rise of the university, the outcome of the positivist, scientific, liberal university of the post-war American period was projected back upon the history of early German universities to suggest scientists themselves - as the beneficiaries of this trend - were also the prime movers of this institutionalization. Rather, as the linked ecologies framework recommends, we should explore the multiple dynamics occurring in different ecologies for different reasons, using different logics according to different timescales. We should, accordingly, track each ecology's development across the period of interest noting what went on for which reason, while remaining attentive to those points of integration and disintegration between linked, interdependent 'spheres', 'fields' or 'ecologies', depending on one's favoured terminology.

This is precisely what the turn to practice advocated by the new sociologists of ideas recommends (Camic and Gross 2004; Camic et al. 2011); and yet, as noted, by orienting attention largely within the academy, the incentive to 
overhaul the overall history of the modern university system is not ready to hand. Further, because the new sociology of ideas was articulated so strongly in opposition to the 'old sociology of knowledge' represented by Mannheim, Gouldner, Marcuse and other scholars, who supposedly overemphasized functionalist, macro-sociological explanations for the development of ideas (Camic and Gross 2002), it becomes difficult to retain view of the factors developing in what we have hitherto called the 'dual revolution' - that is, the broader context of industrialisation and nationalisation - and how these have impacted the success or failure of ideas and practices within and beyond the academy (cf. Gross 2018).

\subsubsection{Bringing power back in}

Abbott's sociology of professions and disciplines, while useful in unpacking the fractal structure of discourse and social institutionalization, unfortunately lacks a robust theory of power. Though Abbott attends to, for example, differentiation between elite researchers and non-elite teachers, a fully elaborated model of power would add to our analysis relating to the macro-sociological dynamics beyond the professions. Reed (2013) recently reformulated a range of theories of power to note three dimensions: relational, discursive and performative. He engages with two standing debates within sociological theories of power - one emphasizing various 'sources' of power (Hall and Schroeder 2006; Mann 1986; Poggi 2000), and another emphasizing 'dimensions' of power (Lukes 2004). In addition, there persists a cross-cutting discussion of the distinction between 'power to' (capacity) and 'power over' (domination) (Dahrendorf 1959; Mills 1999; Parsons 1957). Drawing on hermeneutics and strong-programme cultural sociology (Alexander 2003), which he elsewhere terms 'intepretivism' (Reed 2011), Reed demonstrates that every theory of power mobilizes different models of causality. Historical materialists, for example, engage with notions of 'totality', while behaviourists rely on methodological individualism. Developing a typology, Reed distinguishes 'relational-realist', 'discursive-hermeneutic' and 'performativepragmatist' epistemological-ontological constructs, which are typically understood as mutually-exclusive paradigms.

Of the three, the last is the least well understood in political sociology. Sociologists following the pragmatism of G.H. Mead and his contemporary interpreters (Gross 2009a; Joas 1996; Mead 1934) emphasize the role of 'creative action' mediated by habit. These neopragmatists note that 'performance' or 'performativity' can create social power 'rather than just expressing those power relations that already exist' (Reed 2013: 203; see also Alexander et al. 2006). Furthermore, neopragmatists' attention to situated action and temporality root causality in 'events' constructed out of intersubjective practices in which sequence and ordering matter (Abbott 2001b; Sewell 2005). Power can be 'delegated' to both future and past events, while motivating creative action in the present. Among the achievements of the article, Reed integrates the performative dimension with more familiar relational and discursive power. 
By shifting his level of abstraction to ontology, Reed translates the typology into a multidimensional theory of power. Relational power derives from positions within a structure of social relations. 'Sources' approaches - for example, Mann's 'organizational materialism', Bourdieusian field theory and Luhmannian systems theory - tend to imply this dimension when differentiating 'capitals', 'institutions', 'resources' and so on. However, as hermeneutics reveal, diffuse discursive power works through symbolizations, significations, hegemonic assumptions and the reification of social objects and categories. Scholars working in the Bourdieusian tradition may imply this differentiation when 'symbolic capital' or 'doxa' are distinguished from 'social', 'cultural' and 'economic' forms of capital - the latter being relational, the former being discursive (Swartz 1997). Integrating the performative dimension enables empirical consideration of the varying effectiveness of all three - by indexing the "degree to which capacity and domination are traceable to the situated effectiveness of acts themselves as movers of the world' (Reed 2013: 207). The State of the Union address made by the US president every year, for example, is most certainly a performance of power, but it is almost entirely heteronomous with the existing structure-action dialectic insofar as existing power remains constant before and after the event. In other words: nothing changes.

Marking an important distinction within the definition of ideological power, Reed avoids conflating dimensions with sources. In Mann's IEMP framework, for example, ideology is said to derive from the human need to find ultimate meaning in life, to share norms and values and to participate in aesthetic and ritual practices (Mann 1986). Ideologies can be 'sociospatially transcendent' and/or provide 'immanent morale' to existing power; however, in order to become effective, ideological power must be institutionalized. Mann's emphasis on institutions and organizations of ideological power, while essential for mapping the relational distribution of sources, such as art and religion, fails to adequately address the discursive dimension 'potentially present, in empirically variable ways, in any sphere of activity' (Reed 2013: 212). Retaining the realist contribution to analysis of relational structures, Reed accounts for the presence of discursive formations within all institutional sources of power. And yet, all power must be performed, whether actively, as in the 'founding act' of a national constitution, or unconsciously and passively, as in the routine reproduction of structures.

The routine sense of performance, evident in the State of the Union example above, demonstrates a further connection to Mann's IEMP formulation, which Reed does not engage with directly. In his most recent volumes, Mann has added to his classic definition of ideological power a form which is neither transcendent nor immanent. Rather, 'institutionalized ideologies' are minimally present within routinized, disenchanted institutions, 'often lurking in the sub-conscious. They are thus conservative, endorsing values, norms and rituals that serve to preserve the present order' (Mann 2012a: 7). ${ }^{2}$ The inclusion of passive, institutionalized ideologies suggests a general, latent (functional?) role within all sources of power 
insofar as structures and organizations are reproduced in the course of traditional, habitual, routine action.

As in cultural studies generally, Reed's formulation engages the connection between performance and discourse at the agential interface. However, the pragmatist temporalization of creative action can be extended to the level of structure to highlight the long-term performance of relational structures and systems. This durability of structure can be explained with reference to the 'institutionalized ideology' concept, reflecting passive, unthinking performance of existing institutions. When aggregated up to the level of durable structure, events can be processes - that is, long-term events consisting of multiple, multidimensional short-term events. This amounts to a radical temporalization of the structure/agency dilemma - an ontological move I am presently developing in other theoretical work. ${ }^{3}$

For the purposes of sociological research, Abbott's (2001b) processual sociology can be connected ontologically with Elias's figurational approach, distinguishing three dimensions of time: natural history, sociological history and individual history (Elias 1983). 'The sequences denoted by terms such as "biological evolution", "social development" and "history" form three distinct but inseparable layers in a process encompassing the whole of mankind, the seed of change being different at each level' (Elias 1983: 13).

The whole discussion of the relationship between sociology and history is impeded by the fact that up to now even scholarly studies have generally neglected to define clearly both the difference and the relationship between biological evolution, social development, and history ... How much the development of human societies, social development, differs from biological evolution is shown by the fact that the former, unlike the latter, can in a certain respect be reversed.

(Elias 1983: 12)

We perceive natural history as static because we have the most distance from it; the processes at work have been going on for billions of years, presumably since the Big Bang. This provides us with greater detachment from these seemingly universal laws (Elias 1987a). But note this reflects not a question of time, but rather a question of analytic scale. By 'zooming in' to the level of individual action, one can highlight 'agency', whereas 'zooming out' reveals the durability of structure (see also Fuchs 2001). ${ }^{4}$

Elias's three temporal dimensions can be related to Reed's multi-dimensional theory of power as in Figure 1.1. As historical sociologists, our research should outline the contours of communicative discourses (e.g., systems, codes, signs and so on) and relational structures (i.e., power networks, fields, institutions, markets, states and so on) as they evolve processually in sociological time, occurring across generations. These structures and discourses, however, are always the codetermined products of performances occurring at the temporal level of the 
Dimensions of

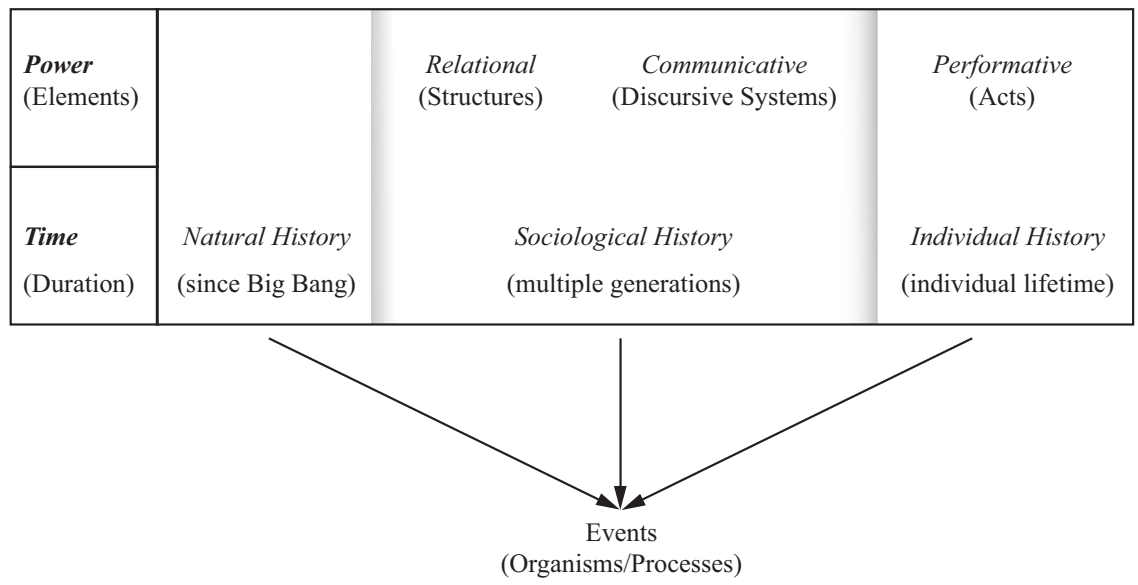

Figure 1.1 Temporal dimensions and corresponding dimensions of social power.

individual. ${ }^{5}$ Causation occurs contingently within events - being the products of three mutually-interpenetrating temporalities. ${ }^{6}$

Social structures are durable objects and differ from natural objects insofar as knowledge establishes relations in the course of human action and signification. Knowledge embodies a process exhibiting structural forms and content - prime material for the historical sociologist. Indeed, insofar as knowledge is a collective resource with clearly relational, discursive and performative dimensions, it is an ideal object of study within the 'sociological' dimension of temporal and analytic scale. Elias's conception of knowledge was not an unfolding of truth perceived by a transcendental subject. Rather, discovery is a combination of individual insights based on the historical accumulation of knowledge as exists as context within a particular point in time.

Sociological theories of knowledge have to break with the firmly entrenched tradition according to which every person in terms of her or his own knowledge is a beginning. No person ever is. Every person, from the word go, enters a pre-existing knowledge stream. He or she may later improve and augment it. But it is always an already existing social fund of knowledge which is advanced in this manner, or perhaps made to decline. These theories of knowledge can thus accommodate the observable fact that knowledge, like the language in which it is couched, is group specific, even though the same knowledge can be symbolically represented by different languages.

(Elias 1987a: xvii)

This group-specific, social fund of knowledge is historically contingent, like an agent's performance of gender. However, as an attribute of a collectivity, 
the social fund of knowledge precedes the individual's agential action within events and processes, even as discovery and innovation push knowledge 'forward' or 'backward' within individual lifetimes. The social fund of knowledge provides what Elias termed humans' 'means of orientation', providing a basis upon which contingent action could occur - action that nonetheless conforms to predictable patterns within processes, that is, according to 'process universals'.

Further complicating this multidimensional temporalization, we can follow Abbott in observing that individuals are themselves the durable carriers of 'historicality', having experienced several momentous societal changes in their increasingly long lifetimes (Abbott 2016).

In a world of which it can be said that social change is happening faster and faster, it must be the historical continuity of individuals that provides the sinew linking past and present. It is the historicality of individuals that enables us - even forces us - to know social change.

(Abbott 2016: 5)

Recognition of the relations and dimensions of ideological power - now expanded to include passive institutionalized ideologies, durable structures (and durable individuals) and the social fund of knowledge - compels a reconsideration of the role of education and ideology within both macrosocial processes and particular historical events.

\subsubsection{The road to new class power}

We can identify the university as an institution of ideological power. This can be interpreted as being the central ideological institution within modern society, as Parsons suggested. Here we may qualify this significance to say: universities are the central ideological institution for the ascendant New Class (Gouldner 1979; King and Szelenyi 2004; Konrad and Szelenyi 1979). The university organizes ideological power on behalf of professionals and academics, with institutional connections to other relational sources of power: in politics (the state, courts, diplomatic service, etc.), economics (businesses, consumers, banks, etc.), military (armed forces, intelligence, etc.) as well as other ideological sources of power (mass media, art, secondary schools, etc.). However, recognition of the university's relational power does not necessarily imply an identical discursive organization of ideology. Indeed, multiple ideological discourses may be in competition with one another within and without the university. The distinction between 'science' and 'ideology', I will argue in Chapter 3, provides one means through which these discourses are attributed and allowed to compete without ever being settled.

There is nothing that disqualifies scholars in the Abbottian or new sociology of ideas tradition from studying all three of the dimensions identified by Reed however, the 'practice turn' and analytic interest in localism incentivises a greater 
awareness of the contingent and dynamic interactions at the performative level of events compared to the longer and more durable structures, including capitalism, nation-statehood, imperialism or even globalization and neoliberalism. These are more often positioned in studies as taken-for-granted contexts, referenced, by and large, when a particular effect occurs within the academy or laboratory. Again, this is acceptable within the contingent ontology provided by processualism, but it amounts to an analytic choice: suspending processual analysis of the macro-sociological context in order to study local effects (which do, in turn, aggregate up and partly constitute macro-processes). However, ironically, insofar as the processual approach is characterised by its historicality and attention to temporality, this hesitation to reconstruct the macro-level can lead to what Norbert Elias called the 'retreat into the present' (Elias 1987b; Inglis 2014).

This makes sense within an ontology that considers only the synchronic present to be 'real', in which the past and future are encoded in multidimensional ways that can be reconfigured through cultural reworking of memory, narrative and so on. However, as Elias noted, this can result in projection of present political and normative concerns onto the past in ways that distort the much more contingent and complex interdependencies at play within multiple long-term processes (many more than even the three suggested here in the case of the triple revolution). Indeed, Elias used the example of academic conflicts between structural-functionalism and neo-Marxism to demonstrate the way proxy political disputes occurred within sociology, not unlike the dynamics Abbott highlights that occur in the field of professions vying for academic recognition:

The two types of theories represent a projection into the social sciences of the political division in society at large between conservatives and liberals on the one hand and socialists and communists on the other ... Thus Parsonianism and neo-Marxism, as the two most prominent schools of theoretical thought in sociology, fought out an attenuated version of the class struggle within the setting of an academic discipline.

(Elias 1987b: 224-25)

We have already encountered the outcomes of this precise division in the field of university studies resulting in the two flawed metanarratives noted above. Yet, the solution to this problem of normativity provided by the new sociologists of ideas and STS - i.e., ideology - is to adopt a relativistic 'non-normative' approach that avoids such conflicts in the name of something akin to exploration of 'what really happened', again largely in terms of localist interactions (Camic and Gross 2009; Gross 2009b).

Elias's figurational sociology provides us with an alternative approach which nonetheless remains processual: he identifies a spectrum running between 'involvement' and 'detachment', initially articulated as a spectrum between 'subject-oriented' vs. 'object-oriented' forms of knowledge (Elias 
1971a, 1971b, 1987a). Historical sociological research provides a means of detaching from present conditions and outcomes to reconsider the long-term processual dynamics present at earlier stages in the emergence of a system; Elias called this a 'sociogenetic' approach. Once these sociogenetic processes developed and acquired stability, one might then be able to account for what he called 'process universals' - that is, generalizable theories related to events, structures and actions within an otherwise contingent process. His work on the civilizing process demonstrated the utility of this approach by connecting changes in the habitus of elite, court society (Elias 1983), particularly as manifested in table manners, to macro-sociological dynamics of state centralization processes, including the monopoly of violence and the state (Elias 2000). Well after the decline of court society, these standards of etiquette and taste continue to inform our notions of what is considered civilized and proper behaviour.

If we follow this line of analysis, the specifics of Elias's account of the emergence of the modern state provides us with essential historical content through which we can begin to reconsider the dual revolution before extending this to our analysis of the university revolution. ${ }^{7}$ Beginning with the emergence of absolutist states - or 'survival units', as he termed them (Kaspersen and Gabriel 2013) - Elias explored the incentive structures that produced larger and larger states ruled by monarchs employing standing armies at the expense of weaker states that retained feudal, aristocratic protection systems (see also Tilly 1990). Cash payments to soldiers and navies as well as the need to raise these funds introduced currency into societies, particularly in cities, eventually stimulating the emergence of modern taxation systems and the gradual ascendance of the bourgeois class. Monarchs adapted the role of the aristocracy from a warrior class to a courtier class in the course of their monopolization of violence. Aristocracies adopted new patterns of consumption, style and manners, while economically benefitting from an absence of taxation, which the bourgeoisie resented, particularly in societies like France, where their social position was actually very near that of the privileged nobility.

The French Revolution and the turn toward 'democracy', in general, was interpreted by Elias as the claim of the bourgeois classes for public control of the monopoly of taxation in order to rationalize accounting and avoid costly wars and investments steered by absolutist monarchs and their unaccountable cabinets. In France, this latter cohort included the 'noblesse de robe', university-trained advisors who represented the middle classes in the estates general (see also Bourdieu 1996, 2015; Fowler 2015). This positioned these educated professionals and advisors in what Wright (1985) would call a 'contradictory class position' insofar as the intellectual class had an interest in preserving some privileges (for themselves) and thus the old regime, but at the same time, the noblesse de robe identified with the rationalization interests and developmentalist economic agendas of the industrial capitalist middle classes. ${ }^{8}$ 


\section{The university revolution}

Gouldner (1970) argued that the French polytechnicians represented an early iteration of the 'new class' of academics, professionals and technocrats, which explains why sociology emerged when it did as a conservative-progressivist discourse to reform society using science and industry while avoiding the chaos of revolution (see also Therborn 1976). However, my research into German legal science suggests an earlier and more robust articulation of this conservative social scientific 'new class' worldview was institutionalized in German-speaking countries responding to French imperial invasion (Lybeck 2018c). Indeed, it was within Germany - not France - that the modern university system was developed according to a schema articulated by Kant in his essay on the 'Conflict of the Faculties' (Kant 1992). Kant's goal of promoting members of the philosophical faculty to the rank of doctor suited the interests of civil servants, Stein, Hardenburg and other state reformers wanting to restructure the monarchical legal order without displacing their own authority as educated experts (Levinger 2000; Nipperdey 1998).

Accordingly, we can date the 'origin' of the modern university to the foundation of the University of Berlin in 1810, which conferred the first doctorate in Philosophy, thereby promoting the discipline of Philosophy to equivalence with the higher faculties of Theology, Law and Medicine. Thereafter the dynamics of the academic profession, differentiated by specialized disciplines, become more and more autonomous. But, again, contrary to the narrative of the modernization theorists and the critical sociologists (often focused, like Gouldner, on France or, later, the USA) the reason the modern university developed as and when it did was not due to scientists' will to power; rather, dynamics across linked ecologies - particularly those between the state, academia and law, in Germany - aligned for contingent reasons through multiple processes that could collectively be referred to as the 'academization process'. As we shall see, in Britain - identified by Ben-David as a consistent 'secondary centre' with its own idiosyncratic development - a series of linked interests aligned amongst clergy, academics, politicians and industrialists to produce a similar outcome amongst both the emerging civic universities and Oxbridge later in the 19th century.

In each instance, Germany and Britain, we can interpret the university system as being the product of a particular form of liberal conservatism, or conservative liberalism - indeed, even more so, a kind of 'progressive conservatism' - which became institutionalized and reproduced within the emerging elite, modern university. This modern university was founded and functioned as a useful mechanism of progressive reform that avoided the risks of revolution during an era in which the urban working classes, immigrants and corrupt politicians were considered to be becoming a 'problem' domestically. At the same time, imperial interests to include populations and territories overseas (or across Eastern Europe as in the German, AustroHungarian and Russian Empires) led to affirmation of higher education as a resolution to the contradiction - that is, hypocrisy - of colonists' expressed commitments to 'self-government', by suggesting dominated peoples needed 
to be educated before taking up this role for themselves. In effect, this conceit created a temporal lag between present domination supposedly in a population's 'best interest', and a distant future when this population would presumably thank their oppressors for their foresight. As we will see, this justification was most significant for the colonisers themselves, allowing them to wake up in the morning thinking they were good people. Most of us living and educated in advanced industrial nations have learned to perform this genre of self-delusion more or less out of habit, avoiding confrontation with the many ways in which we benefit from the domination of largely unseen and ignored others on a regular basis.

Again, Elias's analysis of the civilizing process provided a means to understand these two bourgeois interests in education - domestic and imperial - as part of the same piece insofar as the assimilation and adaptation of aristocratic 'civilized' ideals into the bourgeois class habitus led to their self-conception as standing at the end of a teleological process: civilization. All working classes and colonial subjects needed to do to become civilized themselves was adopt the standards of knowledge and behaviour of the civilized world. They would learned how to do this through education (see also Gellner 1983). Thus, historians have identified efforts to turn 'peasants into Frenchmen' (Weber 1976), and analysed the way technology was used as a 'measure of men' (Adas 1989). In a sense, we should not treat domestic and imperial domination as separate processes. These were one and the same, ultimately imperialist forms of assimilation via culture and ideological power as much as via economic and political integration. That we have not hitherto seen this effect of our ascent in this way is a reflection of the way the academization process was disguised and justified historically, not least via the flawed affirmative (and critical!) metanarratives noted earlier.

Unfortunately, Elias himself did not study the sociology of education in depth, and so I have only just begun exploration of what a figurational sociology of education would look like (Lybeck 2019b). Most importantly, commitment to processualism and historical dynamics positions his approach as a viable alternative to the more familiar approaches of Bourdieu, Foucault and others in the sociology of education (Ball 1990, 2013; Gale and Lingard 2015; Murphy 2013). If we further connect his political sociology of mostly European societies to the historical sociology of universities recommended by Mitchell and Gebre-Medhin, focused largely on the US, we can begin to sketch the outlines of broader 'academization process' emerging in early 19thcentury Europe, precisely at the same point identified as the start of the dual revolution (ca. 1800). With this in view, we can reformulate our presentist assumptions about the dynamics driving local interactions ongoing within the academic environment and the contemporary triple-helix. Just as in the past, science and capitalism are not the only factors at play within the structuration of higher education; so too are complex, intra-elite, imperialist, gender-related and other issues impacting us today. 


\section{The university revolution}

The linked-ecological accounts of professions, academics, politicians and industry can thereby be rooted in longer-term power dynamics that have led to the position of a particular class of knowledge workers drawing status from a growing university system. This 'new class' position neither embodied and projected the value-neutral view from nowhere, as the functionalists argued, nor is it identical to the 'old class' of bourgeois capitalists (Gouldner 1979). It is, however, the viewpoint or vantage from which we sit ourselves as working academics. As Elias noted, we are inherently 'involved' in this system - and this explains, perhaps, why the triple revolution has hitherto been identified as 'dual'. We have inadequately accounted for ourselves within the broader process of modernization, thinking we were merely independent, autonomous observers. But this is an ideological delusion.

In what follows, we will reject this assumed autonomy, while still seeking more 'object-oriented' knowledge; through historical and processual analysis we might begin to 'detach' from our present position and reconsider the sociogenesis of the modern university system anew. Rather than exploring a 'civilizing process' or 'industrialisation' and 'democratisation', we can identify a distinct 'academization process' through which the university, the academic profession and professionals, in general, have become ever more central in constituting the modern world.

\section{Notes}

1 Shils to Ben-David, University of Chicago Library, Special Collections Research Center, Minerva Records, Box VI, 13.

2 Though Mann does not pursue the full significance of the addition, he points toward both the discursive and performative roles of ideology as necessary for preservation and reproduction of powerful institutions in general. Yet, as in political sociology more broadly, Mann's original model only associates causal power with positive, empirical and visible power, as manifested in existing organizations and structures of power - typically, the state (Steinmetz 2004).

3 This theoretical work has thus far only been presented at conferences, initially termed 'critical organicism' to distinguish my temporalization of structure from the 'stratified' ontologies of critical realism as well as the 'flat ontology' of neopragmatism. The term 'organicism' refers to the philosophy of organism developed by A.N. Whitehead $(1925,1930)$ and the organic historical sociology of Lewis Mumford (1963, 1973). Increasingly I term this approach as simply 'processual sociology' to highlight the theoretical links and legacies of Abbott and Elias's work (Lybeck 2019b, 2019a).

4 Padgett and Powell well express this dynamic process between structure, agency and 'temporal size': 'in the short run, actors create relations; in the long run, relations create actors' (Padgett and Powell 2012: 3).

5 This does not necessarily imply supra-individual entities cannot engage in performative action; only that the performance - of the market, for example - is experienced, recognized and acted through at the level of involved individuals during their own life-histories.

6 This ontology requires further elaboration than space here allows. I have written several conference papers composed as elements within my projected 'critical organic' approach. The ontology broadly draws on A.N. Whitehead's philosophy of 
organism, which is related to Norbert Elias's process sociology. This is reflected in Figure 1.1, suggesting events are also processes, which are also organisms.

7 A more extensive summary of Elias's analysis of the rise of nations and capitalism can be found in (Lybeck 2019b) as well as part III of The Civilizing Process itself (Elias 2000).

8 This was typical of 'enlightened' bureaucrats rationalizing and modernizing the civil service both before and after the French Revolution (Raeff 1975; Rosenberg 1958; Steinmetz 1997b). 


\section{The systemic evolution of universities \\ Ben-David's 'centers of learning' as world- systems analysis}

\subsection{The rise of national higher education systems}

In the previous chapter, I introduced the five factors or causes of the academization process during its first phase of development:

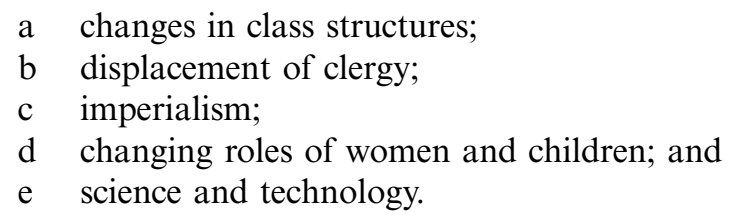

This chapter will take the last cause first, while acknowledging the merits of the functionalist analysis of 'centers of learning' (Ben-David 1977) as well as aspects of the critical, neo-Marxist world-systems analysis (WSA) of science. Interestingly, Abbott himself suggested that WSA amounted to an 'ecological' understanding of the entire global capitalist system (Abbott 2005b), although, as we shall see and have noted in the previous chapter, this critical approach is also limited in different ways.

In reviewing these analyses, we will also assess the role and position of each of four central nations - France, Germany, Britain and the United States - across the period of interest: around 1800 to the present. France set the ball rolling as part of the Revolution, but the modern university we are familiar with was born in Germany. Higher education was a central element in the conservative, Romantic reaction to the French Enlightenment (Lybeck 2018c). In Germany, and later within nations which copied their innovations, the university enabled rational social reform without requiring either revolution or, indeed, popular participation. The German academic system provided a mechanism through which descending aristocrats and learned professionals could socialize and assimilate ascending middle-class children into their norms and behavioural patterns. The result was a new form of culture - academic culture - which emphasized the disinterestedness of science alongside claims about the universal value of Western civilization.

DOI: $10.4324 / 9781351017558-2$ 
The German model of the university took hold around the world, but nowhere with as much vigour as in the United States. Yet, because no adequate national system of secondary education then existed, American 'universities' were institutionalized as graduate schools on top of existing undergraduate colleges with legacies from the British colonial past. Thus the American university combined the structure and culture of two national educational systems: British and German. Indeed, throughout the period, Britain figured as a 'secondary center', adapting toward a similar pattern, but often one or two generations later, and then with much greater rapidity. One can still see this, for example, in Britain's rapid shift toward mass participation since 1997, or in the 2011 introduction of $£ 9,000$ fees paid by student loans (Lybeck 2018b). Even earlier, during the 1860s, educational reformers replaced the classical curriculum with more 'modern' forms of study, thereby reproducing the overall structures of the academization process in its own idiosyncratic ways.

Accordingly, it makes sense to retain a world-systemic or emerging global view of the academization process, in which central national systems set the pace for others on the semi-periphery and periphery. However, we will see that it was not science or scientists alone that encouraged these changes, but rather the involvement of consolidating states themselves that encouraged the establishment of universities within the core nations for the range of reasons we have identified as central causes of the academization process. In each national context, the dynamics were not identical, and yet some were similar and shared due to nations' involvement in the other macroprocesses of industrialism, democratisation, geopolitics and so on, as well as the transnational isomorphic processes of the rise of science and its eventual link with the institution of the university, especially beginning in Germany.

\subsection{Ben-David's sociology of science}

The sociologist of science, Joseph Ben-David, produced a well-known institutional account of the historical development of 'the scientist's role in society'. Ben-David followed the emergence and institutional consolidation of science beginning in Renaissance Italy and early modern Britain. Ideal social conditions encouraged expansion of the science system as a whole, while at the same time stimulating a geographic shift between 'centers of learning', which moved from Britain to France to Germany to the United States by the 20th century. This chapter suggests that Ben-David's analysis is epistemologically homologous with WSA. WSA, particularly as outlined by Immanuel Wallerstein and Giovanni Arrighi, not only adheres to a similar 'global' model of a single system, but also contains an analysis of the rise of science. Recognition of the limits of both approaches points toward new historical interpretations of the evolution of scientific disciplines and global political economy highlighting the determining role of codified knowledge in the organization of material power. 


\section{The systemic evolution of universities}

After summarizing the epistemological frameworks and findings of each sociology of science, I review geographic data published by Peter Taylor, Michael Hoyler, and David Evans (2008), who tested Ben-David's analysis of the scientist's role in society within a world-systems framework. Though the authors suggest their evidence confirms Ben-David's and WSA's descriptions of the rise of science, I argue that a substantial shift occurred during the 19th century when science became institutionalized in the university. Because BenDavid and WSA position this 'university revolution' within a trend of longer durée, they neglect the emergence of novel patterns in scientific and social organization induced by this institutional transformation.

I conclude by referencing evidence indicating that the developments BenDavid and WSA credit to scientists were, in fact, promoted first within the legal faculty. Recognizing the earlier development of legal sciences in Germany reverses the chronological order of influence between the natural and social sciences and, more importantly, establishes a mechanism through which scientistic, rational thought penetrated society. Because Ben-David's and WSA's functionalist models conflate outcomes with causes, they neglect the actual causal factors which led to the institutionalization of the university in 19 th century Germany as well as science within it.

\subsubsection{Sociologies of science}

In 1971, Joseph Ben-David intended to write an introductory textbook on the sociology of science but instead produced a landmark monograph, The Scientist's Role in Society (Ben-David 1971). Though he had already produced several works establishing himself as a leading scholar in the field (Ben-David 1960; Ben-David and Collins 1966; Ben-David and Zloczower 1961), the author had not concisely outlined how his approach to the sociology of science differed from other traditions (see also Ben-David and Sullivan 1975).

He noted two dimensions along which sociological approaches to science could be broken down. The first distinction is between approaches which claim that social conditions only influence the behavior of scientists and those which claim that social factors can also influence the basic concepts and logical structure of scientific knowledge itself. The second difference lies between 'interactional' and 'institutionalist' approaches. One could produce a four-field table which includes the variations of these orientations, as in Figure 2.1.

Ben-David positioned and defended his own approach in contrast to the flawed 'interactionist' and 'sociology of knowledge' orientations. The former began with Michael Polanyi's work emphasizing the 'scientific community' and the social aspects of scientific consensus, but came to prominence in the wake of Thomas Kuhn's research on scientific revolutions (Polanyi 2000; Kuhn 1962). However, Kuhn's model implied too much insulation from external social influence, as normal scientists only relate to self-referential traditions except during scientific revolutions. Though Ben-David credited the 


\begin{tabular}{|c|c|c|}
\hline $\begin{array}{l}\text { Social } \\
\text { influence } \\
\text { on science }\end{array}$ & Orientation \\
\hline Behavioral & $\begin{array}{c}\text { Interactional } \\
\text { Interactionist } \\
\text { (practices) }\end{array}$ & $\begin{array}{c}\text { Institutional } \\
\text { (roles) }\end{array}$ \\
\hline Conceptual & Constructivist* & Sociology of knowledge \\
\hline
\end{tabular}

Figure 2.1 Approaches in the sociology of science.

* Ben-David claimed that the constructivist position was not publicly acknowledged by anyone at the time (1971); yet, his description of this logically-possible orientation corresponds with the Edinburgh strong programme, which would emerge later in the decade much to his chagrin (Ben-David 1981).

Source: Ben-David 1981: 2.

interactionist approach for providing useful conceptualizations of 'paradigms' and the 'scientific community,' which limit and define the boundaries of science, ultimately, an institutional perspective is necessary to account for external influences, particularly cultural and organizational factors outside the logic and practice of science itself.

At the same time, Ben-David refused to accept the institutional explanation provided by scholars in the sociology of knowledge tradition, because this would suggest that social factors could influence the content of scientific knowledge. Because science is not a type of behaviour; rather, it is a system of thought that can be 'written down, forgotten, and learned again, with its form or content remaining unchanged', social influences, particularly ideological predispositions reflective of social class position, cannot determine the content of scientific knowledge (Ben-David 1971: 1). Ideological commitments for example, 19th-century German enthusiasm for Naturphilosophie - could move science forward initially when the corpus of knowledge was vague and indeterminate. Eventually, however, these non-scientific ideologies slowed substantive scientific growth until they were replaced by valid, logical and empirical knowledge.

Although ideological bias (socially determined or not) might have played some role in the blind alleys entered by science, the philosophical assumptions that had become part of the living tradition of science were selected by scientists from the array of competing philosophies for their 
usefulness in the solution of specific scientific problems and not for any socially determined perspective or motive.

(Ben-David 1971: 11)

In place of the sociology of knowledge approach, he suggested an institutionalist sociology of scientific roles to uncover the conditions that determine the level of scientific activity by shaping the organization of scientists in different countries at different times. The persistence of a role-pattern indicates social acceptance, recognition and legitimation of an activity and the functions it performs. Growth of science does not happen automatically, but occurs only when societies accept and, ideally, positively support scientific activity. Ben-David's role-theory enabled comparison across contexts, including historical sites in which the term 'scientist' did not exist (Ben-David 1965). For example, Ben-David's study includes Italian artists, like DaVinci, and British mathematicians, like Newton, but not Greek philosophers, who, according to him, did not separate their moral, religious and magical beliefs from their commitment to systemic thought.

\subsubsection{The scientist's role}

What specific qualities define the scientist's role? Ben-David indicated that experimental attention to empirical reality is an important distinction in the patterned activity which separates science from speculative philosophy or religion. However, empiricism alone is not sufficient, since this would not explain the difference between Europe and China, which also valorized empirical reality. Thus, a logical method of reasoning from first principles - in other words, theoretical science - was equally necessary for the emergence and extension of the scientific role. Finally, a commitment to value-neutral science was necessary to establish the 'autonomy of science', allowing empirical data to unfold according to its logical ordering. None of these rolefeatures - experimentation, logic and value-neutrality - on their own were sufficient to generate the scientific role, since traces of each can be found in other cultural contexts, for example, ancient Greece, China and medieval Europe. The scientific role emerges only as a complex combination of practices when experimental data is synthesized according to logical principles and accumulated into authoritative systems of knowledge.

The normative commitment of value-neutrality encourages the accumulation of knowledge and, indeed, figures as the most important cultural contribution to the growth of science. Acceptance of the scientific role implies a change in social values, modifying philosophical and religious authority, raising the dignity of technological knowledge and establishing new norms of intellectual freedom (Ben-David 1965: 17). The freedom of secular philosophical discourse in relation to theological authority, in particular, was an important precondition for scientific growth. Individual scientists commit themselves to the norm of value-neutrality in an effort to avoid emotional 
involvements which would discourage them from recognizing universally valid standards of evidence (Merton 1938). Of course, no individual can embody this ideal, but scientific growth occurs when collectivities allow the accumulation of empirical findings without the influence of non-scientific goals, interests and biases. In this way, science as a system of knowledge achieves a standard of objectivity no individual could achieve alone.

Note that this definition of the scientific role corresponds with an ideal of 'pure science', and Ben-David often distinguished other responsibilities scientists might have - for example, general education, applied research and professional training - from the practice of science itself. The growth of science, therefore, implies the growth of experimental, scientific research.

\subsubsection{Competition and decentralization}

Influenced by Milton Friedman's theories of competition (Schott 1993), BenDavid explained the well-known success of German science in the 19th century by highlighting the competitive field provided by a decentralized university system (Ben-David 1960). Since in previous eras Britain and France led in science, some difference in the external organization of science must have given Germany the upper hand after 1800. Typical studies highlighted three possible German advantages:

1 better quality laboratory equipment for scientific use;

2 unique features of German university education, including the Habilitation, teacher and student freedom, and a commitment to research output;

3 the large number of institutions which allowed academic mobility and competition.

Ben-David cited this third cause as the most significant, since it also encouraged the development of the other factors.

Because no single institution was able to lay down the standards for the system of universities overall, scholars were able to move and develop their ideas with relative autonomy. Competition encouraged specialized, experimental research, which generated knowledge within existing and novel disciplines, such as psychology, which emerged out of philosophy and physiology (Ben-David and Collins 1966). Only when the number of professorships in Germany stopped expanding in the late 19th century - in effect, closing the system - did this competitive condition subside, providing an advantage to the United States, which claimed the pre-eminent position in science during the years that followed (Ben-David and Zloczower 1961).

\subsubsection{Centers of learning}

In a series of papers leading up to the publication of The Scientist's Role in Society, Ben-David had elaborated this competitive model of scientific 
growth. When social conditions developed so that scientists became free to innovate and develop their ideas autonomously, systems of knowledge emerged in accordance with scientific norms. Thus, by explaining the success of German science in the 19th century, he further explained why the United States became dominant during the 20th century insofar as a similarly decentralized system emerged there.

Yet, while the competitive model explained the substantive growth of scientific knowledge, it did not necessarily explain the growth in organizational support for the scientific role. The United States, for example, not only provided a broader competitive field for autonomous scientific activity, it also expanded the provision of institutional resources. Ben-David addressed this compounding institutionalization of the scientist's role by incorporating the concepts of 'center' and 'periphery', which situated all active national contexts within a single developing organizational field (Ben-David 1977). As centers of knowledge moved geographically, for example, from Germany to the United States, accumulated advantages for the science system in general carried into the next context. In this way, the overall system adapted and upgraded itself over time.

Ben-David's mentor, Edward Shils, had insisted that his protégé develop the categories of center and periphery in his analysis of the university and science. With typical humility, Shils remarked that 'most of the persuasion usually ran from me to him rather than the other way round' (Shils 2006: 156). It is, therefore, worth summarizing what Shils meant by these categories (Shils 1982: 93-109): A society's center is not primarily a geographic location, but is, rather, a central value-pattern which all members of society must minimally accept (see also Parsons and Shils 2001). This social value adheres to elites and central societal subsystems insofar as their status positions them closest to the perceived center. Via charismatic recognition of this central authority, societies establish an embodied order; groups become integrated through tacit, enthusiastic or critical engagement with the ideals, persons and institutions located in the center. The identity of the primary group - its 'collective self-consciousness' - solidifies further when others, outside the group or in the periphery, affirm the identity of the center.

In the hands of Ben-David, applied to science and the university, the concepts of center and periphery enabled an explanation of the historical growth of the scientific community as a single system:

In the centers ... the social structure of science developed on the basis of the patterns of the previous center and innovations related to the conditions prevailing in the new center. Elsewhere, however, much of what happened was a response to, imitation of, resistance to, or competition with the center. Because of the unity of the world's scientific communities, members in the peripheral countries used the situation at the center as their frame of reference in thinking about their own conditions of work.

(Ben-David 1971:19) 
The value orientation of peripheral nations emulating the center provided some unity to the system as a whole, even though variation persisted throughout and centers rose and declined. Wherever organizational innovations emerged, they were assimilated into the central science system.

\subsubsection{Institutionalization of science in the university}

The center/periphery model came to the fore when Ben-David's research shifted from the scientist's role in general toward comparative assessment of university systems for the Carnegie Commission on Higher Education (BenDavid 1972a, 1977). ${ }^{1}$ While the general premises of the scientist's role remained in the background, focused comparison of higher education systems in Centers of Learning steered Ben-David toward a more complex analysis of the social conditions which contributed to the organization of science within the particular institution of the university.

The university and science fulfilled different functions for different strata of society, and the modern university still contains the legacy of these functions, including professional training and general 'liberal' education. According to Ben-David, three groups revolutionized higher education in France, Germany and England: philosophers, scholars and administrators. England was further influenced by professionals, including businessmen and some public figures. Still, in general, the university is said to have reformed in response to needs and pressures emanating from within the academic community.

Science, when left to its own devices, tends toward specialization and a logical division of labor; and, indeed, in the initial wave of reforms in Napoleonic France, specialized schools were promoted, rather than the archaic medieval universities which had been dismantled by the revolution. Two major contributions to the global pattern were added while France stood at the center of learning:

1 state-sponsorship secured a stable basis of finance and authority; and

2 meritocratic evaluation procedures opened social access to higher education (cf. Bourdieu 1996).

England, at this time, unhurriedly extended professional status to new fields and new technical colleges, but these changes were not government sponsored and did not amount to university reform.

The shift of centers from France to Germany in the 19th century institutionalized the scientific role in the decentralized, competitive research university. Ben-David noted that the movement for reform in Germany was entirely promoted by philosophers and scholars. 'Occupational groups aspiring to professional status played no role in the movement' (Ben-David 1977:19). Humanistic intellectuals glorified the university in general in the ideological language of the unity of all knowledge. Thus, state support for 


\section{The systemic evolution of universities}

higher education was steered into the declining medieval universities scattered around German lands. And, although the German state's instinct was to control everything, it left universities alone out of conservative Romantic sentiments, unthreatened by the status of academics in an aristocratic society.

Philosophers did not promote the natural sciences or encourage experiment at this time, but did add an essential ingredient to the global pattern: 'The university was to be a prestigious and even privileged institution, but this privilege was to be based on true scholarly merit, not on traditional status bolstered by a general, and usually shallow, humanistic learning' (Ben-David 1977: 20). In time, bounded competition in an academic marketplace managed to differentiate knowledge into different disciplines effectively within a single institutional form. This exchange of truth content was possible due to the overall homogeneity of a single type of university across the region, allowing the transfer of credentials. Ben-David credits an absence of middle classes and the 'relative lack of articulation of German society' for this homogeneity (Ben-David 1977: 21; cf. Walker 1998).

German professors contributed to the sum of scientific knowledge in this period as the state rapidly industrialized and enthusiasm for technical progress marked the European cultural landscape (Salmi 2008). Yet, according to Ben-David, Germany's primary contribution to the global university system was as a model, first for Britain, then the United States. Though English educational reform lagged in the early part of the century, eventually Oxford and Cambridge recognized the threat posed by new colleges in London and elsewhere. The ancient universities' elitism, however, led to a reform justified according to Germanic ideals of research excellence, thereby ignoring the very existence of Oxbridge's local competitors (Ashby 1967; cf. Rothblatt 1981). 'The result was an actually improved version of the original Humboldtian university ideal' (Ben-David 1977: 23).

In America, European models were drawn upon, especially the German and (now Germanized) English systems. 'The foremost purpose of the reform was to catch up to European higher education. Dissatisfaction with the existing state of affairs did not arise from internal disputes, but from contact with superior foreign models' (Ben-David 1977: 25). On the one hand, incorporation of best practices led to the ideal institutionalization of science. On the other hand, since the social bases of reform in the young nation were different from the rigidly hierarchical Old World, European models were adapted to local conditions, generating further innovations and improvements, for example, the separation of teaching and research functions into undergraduate and graduate education. Unlike the English dons, meritocratic Americans openly acknowledged the diversity of functions scattered throughout the system as a whole, thereby encouraging scientific achievement in all its facets. This success has led to the ascendancy of the United States as the center of global learning, representing an ideal to which the periphery aspires and adapts. 


\subsection{World-systems analysis of science}

\subsubsection{The capitalist world-system}

As in Ben-David's model of centers of learning, WSA also sought to explain the compounding growth of a single system across centuries. Initiated by Immanuel Wallerstein in 1974, WSA challenged the triumphalist modernization theory (MT) of political economic development by synthesizing MT histories of 'core' nations with Marxian historiography, including debates surrounding the transition from feudalism to capitalism (Aston and Philpin 1985; Holton 1981), and dependency theory, which highlighted the 'development of underdevelopment' in colonial economies (Baran 1957; Frank 1989; Prebisch 1959). Drawing on the Annales School, especially the work of Fernand Braudel (1996), which emphasized structural changes across a 'longue durée', Wallerstein positioned the origins of capitalism in the 'long sixteenth century', 1450-1640.

Once stimulated in the 15th century by explorations off the Iberian Peninsula, capitalism grew in cyclical patterns of accumulation followed by consolidation of institutional gains. To the extent financial and mercantile interests were satisfied within core regions, capital accumulated, while lowcost production of single commodity 'monocultures' developed in the periphery to satisfy core markets. By including both core and periphery in a single system, Wallerstein forced a reinterpretation of MT narratives, which had implied capitalism emerged within core nations alone due to domestic conditions (So 1990). Wallerstein effectively 'internationalized' analysis of the development of capitalism, enabling connections drawn from varied regional contexts to be related to the growth of a single systemic form.

\subsubsection{Hegemony}

A world-economy can be distinguished from world-empires, neither of which necessarily encompasses the entire globe. Rather, each represents a 'world' unto themselves. Though establishment of world-empires was attempted by Charles VI in the 16th century, Napoleon in the 18th and Hitler in the 20th, these efforts failed, so that the most a state could achieve was hegemony within an increasingly interconnected (capitalist) world-economy.

What allows us to call them hegemonic is that for a certain period they were able to establish the rules of the game in the interstate system, to dominate the world-economy (in production, commerce, and finance), to get their way politically with a minimal use of military force ... and to formulate the language with which one discussed the world.

(Wallerstein 2004b: 58)

This definition of hegemony reflects the economic, political and ideological dimensions of capitalist power. States which managed to secure hegemony 
attained market advantage until the expense of maintaining supremacy in geopolitics, economics and culture outstripped the distance between rivals. Crises, typically interstate wars, contribute to the ascendance of a new, more powerful hegemon, which provides a new center within the capitalist core.

Arrighi (2010) identified two logics of accumulation: one financial and another territorial. The modern world-system developed according to long secular, Kondratieff cycles of extensive (expansive) and intensive (internalizing) growth (Goldstein 1988). Each successive cycle reflects an overall 'pattern toward regimes of increasing size, scope and complexity', although the 'agencies, strategies and structures' of each cycle of accumulation were different. (Arrighi 2010: 375). The outcome has been a trajectory from a capitalist system centered in a particular city-state (Genoa) to one organized as a world-state in the 20th century under the United States. With each movement from capital to capital, the system acquired new characteristics and internal relations, while ultimately maintaining structural equivalence, since the cyclical logic of capital accumulation followed by crisis remained.

Each historical movement of a hegemon, therefore, also implies a new stage within the system's overall growth. In presenting his multi-volume Modern World-System, Wallerstein assumed the continuation of the processes, institutions and structures outlined in previous installments, and novel structures are presented according to the historical period in which they emerged and became salient. Volumes I and II cover the creation of the world-economy and the consolidation of Dutch hegemony during a 'B-phase' (downturn) of the global economy (Wallerstein 1974, 1980). A key outcome of this period was the 'Franco-British rivalry' over succession to Dutch hegemony, which drove the next century's colonial expansion, covered in volume III (Wallerstein 1989). Wallerstein explains both the industrial and democratic revolutions as 'normal' outcomes of cyclical growth, comparable to other times and places, though on a larger scale. The French Revolution is interpreted as the end phase of the Franco-British rivalry, initiating few radical changes to French domestic institutions, but culminating in British ascendance as hegemon in the 19th century.

In the recently published volume IV, however, the French Revolution does figure prominently as a novel and important event which led to the ideological reconfiguration of the capitalist system (Wallerstein 2011). The revolution normalized social change, allowing the disjunction between the political economy of the capitalist world-system and its discursive rhetoric to be overcome. Three major secular ideologies were formed in this context: conservatism, liberalism and radicalism. The second managed to convert its right and left wings into 'avatars' of itself and eventually institutionalized a liberal 'geoculture' built around three pillars: the nation-state, citizenship and the historical social sciences (Wallerstein 1990). 


\subsubsection{Social science between the arts and sciences}

Wallerstein's identification of the institutionalization of the historical social sciences as one of three pillars of liberalism is striking in the context of such major macro-social phenomena as the industrial and democratic revolutions. However, a model of the university and disciplinary divisions of knowledge has been embedded in the logic of WSA for several decades, though rarely commented upon in secondary literature (Lee and Wallerstein 2005; Wallerstein 1990, 2001, 2004a, 2004b; Wallerstein et al. 1996). Using C.P. Snow's (2012) notion of 'two cultures', which separates humanists and natural scientists, Wallerstein interpreted the division of knowledge as a functional element in the ideological organization of liberal geoculture.

He writes,

Once upon a time, in Europe as elsewhere, there was only one knowledge culture - the search for the true, the good, and the beautiful. It was not divided into differing and opposed epistemologies. Rather, there was a continual struggle as to who would control this single knowledge culture.

(Wallerstein 2011: 221)

This unity changed as liberals invested in education, part of a broader agenda of reform via specialists, rather than conservative reaction or radical revolution.

Since every educated person was a specialist in something, it followed that those who would be allowed to exercise the role of citizen were those who were educated and were therefore specialists. Others might eventually be admitted to this role, when they had received the proper education to permit them to join the society of rational, educated men.

(Wallerstein 2004b: 63)

Liberals invested in practical, useful knowledge, especially science, since 'the imperative of endless accumulation of capital had generated a need for constant technological change, a constant expansion of frontiers - geographical, psychological, intellectual, scientific' (Wallerstein 2004b: 2).

Directing attention toward the institutionalization of science in the university, Wallerstein suggests that scientists themselves led the division between themselves and the humanities.

The organizational objective of the natural scientists ... was to secede from the combined blur of knowledge activity and create a haven for certain kinds of activity from which others were due to be excluded. The natural sciences presented themselves as the sole guardian of the search for truth ... to succeed in this intellectual 'divorce', the natural scientists needed to secure an 
institutional base. They began to ensconce themselves in the universities and to create organizational niches in newly created faculties of natural science.

(Wallerstein 2011: 223)

As the social sciences emerged later in the 19th century, a 'battle' ensued between scientists and humanists trying to assimilate social scientific disciplines into their humanistic or scientistic camps.

Wallerstein focuses on historical methods developed in Germany under Leopold von Ranke, who tried to represent history as 'scientific'.

This shrinking of the analysis of politics to 'events in the narrowest sense' served well the interests of the centrist liberals. For, when generalizations were shunned, historical writing became, for the first time in the 19th century, a 'National religion'.

(Wallerstein 2011: 239)

Wallerstein and his colleagues follow the trajectory of this scientistic mode of historical research through the so-called Methodenstreit between 'nomothetic' social sciences, interested in uncovering universal laws, and 'ideographic' traditions, emphasizing cultural particularity (Lee and Wallerstein 2005; Wallerstein et al. 1996: 55-73). The ideographic method is represented as an 'antisystemic' trend due to its affiliation with the German Historical School surrounding left-wing economists, Schmoller, Brentano, and others.

However, like antisystemic movements beyond the academy - radical workers', women's, and anti-colonial movements - the epistemological challenge to scientism was eventually assimilated into the liberal mainstream.

What the antisystemic movements have done, if one considers their global activities over 150-odd years, has been essentially to turn themselves into the fulfillers of the liberal dream while claiming to be its most fulsome critics ... The fetishism of science by the antisystemic movements ... was a natural expression of the post-1789 triumph of Enlightenment ideas in the world-system.

(Wallerstein 1990: 52)

Only the 'revolutions' of 1968 have opened a window of opportunity, as the world-system has now gone into terminal crisis. In science, complexity studies have challenged the Newtonian worldview of science, while in the humanities, cultural studies have attacked the same determinism and universalism which obscure the paradoxes of liberal ideology.

\subsubsection{Science redefined}

Drawing on both antisystemic epistemological traditions, but especially the complexity theory of Ilya Prigogine (1997), Wallerstein promotes a vision of 
social science which is not 'scientistic' or 'deterministic'. Rather, he emphasizes the chaos and unpredictability of human developments implying an 'end of certainty' (Wallerstein 2004a; see also Arrighi and Silver 1999). Though this recognition undermines the Newtonian worldview of an ordered universe, every unit of natural and social phenomena maintains an historical trajectory, an 'arrow of time'. The task of both natural and social scientists, therefore, is to understand the basic regularities of processes interacting with complex environments. This requires a distinction between 'minor' and 'major' uncertainties; the former Braudel called the 'dust' of events, while the latter can be identified only in the longue durée of persistent interactions. Prigogine's theory of chaotic determinism, in which both time and duration are central, and structures are constantly constructed and reconstructed, provides a metaphysics which enables the identification of durable processes during 'normal' systemic operations, while also allowing for non-equilibrium conditions during which systemic bifurcations occur, perhaps only once every 500 years.

In order for us to speak of a systemic bifurcation, we would have to identify a moment (in the past) ... when this system came into systemic crisis. In short we would need to analyze three different time periods: the period of genesis; the period of the normal operation and evolution of the system; the period of bifurcation, or systemic crisis.

(Wallerstein 2004a: 41)

This is precisely what WSA claims to have uncovered. By identifying cyclical patterns related to economic expansion and consolidation, the movement of hegemonic centers and the divisions and crises in academic disciplines, WSA captures the normal operation of the capitalist system evolving according to an elementary substantial form, which emerged in early modern Italian city-states and has expanded toward its logical outcome covering the entire globe. This analysis enables the identification of the normal trajectory of this system, and the contemporary observation that this logic has run its course and has entered systemic bifurcation, that is, crisis. Where this will lead us is uncertain, but our only chance of steering humanity's fate according to informed decisions will come from a collective intellectual discussion transcending the 'two cultures' - 'a reunification of the methods of enquiry across the fields of knowledge, and one in which the terrain of social science will now be central, if not all encompassing' (Wallerstein 2004a: 55).

\subsection{Science, or science in the university?}

\subsubsection{Epistemological homologies}

Both Ben-David and WSA developed internally consistent models of a single system operating and developing across a longue durée. While broadly comparative across time and place, each interprets historical developments in 
relationship to an emergent global pattern. At the systemic level, institutional arrangements compound over time, especially in the course of geographic displacement of the 'center' or 'core.' As one state overtakes another as the hegemonic center, previous advantages are transferred to the new, more powerful center, which adds further innovations into the global system.

Similarly, a fundamental durability of basic structural form is maintained in each system. For Ben-David, the scientist's role emerged in the 16th century and gradually asserted itself in the modern research university. The activity and the content of science itself remain unchanged by the process, only the scale of research increased. In the same way, once initiated, the capitalist world-system developed according to the cyclical logics of capital and territorial accumulation. Analytic recognition of this durable persistence of form allows comparison across time, so that similar configurations, mechanisms and processes in early modern Holland can be related to 19thcentury Britain to uncover the most important institutional patterns common to each. In WSA, these include an unequal exchange between core and periphery regions, national hegemony and Kondratieff cycles of accumulation followed by crises. In Ben-David's sociology of science, the scientist's role, competition and decentralization, and, again, the structural relationship between 'center and periphery' are especially important causal factors.

\subsubsection{Geohistorical analysis}

Of course, a major difference between the two is their primary system of reference; Ben-David focuses on the science system, while Wallerstein primarily focuses on the capitalist economy. However, each system occurred in the same place, Europe, during the same period following the Italian Renaissance, ca. 1450. Therefore, we can position Ben-David's narrative of the rise of science within Wallerstein's analysis of the capitalist world-system to examine further correspondence between the two approaches.

Much of the empirical work until 1900 has been done by geographers Peter Taylor, Michael Hoyler and David Evans (2008), who tested Ben-David's analysis of the scientist's role in society within a world-systems framework. Using data on one thousand 'leading scientists' from 1450 to 1900 , collected and catalogued by Robert Gascoigne (1987), the authors map the 'rise of science' identified by both Ben-David and Wallerstein (see Figure 2.2). The figure, derived from a matrix cross-listing scientists and their places of work, immediately provides graphic demonstration of Ben-David's account of the movement of natural scientists, the so-called centers of learning. 'Science' moved from Padua in the 16th century, to London in the 17th, to Paris in the 18 th, and to Germany in the 19th.

The geographers generally affirm the two accounts of the rise of science, although they lend more explanatory credence to WSA. While their data introduce interesting findings - for example, most scientific centers lay outside metropolitan, multifunctional cities, suggesting scientists encouraged "company 

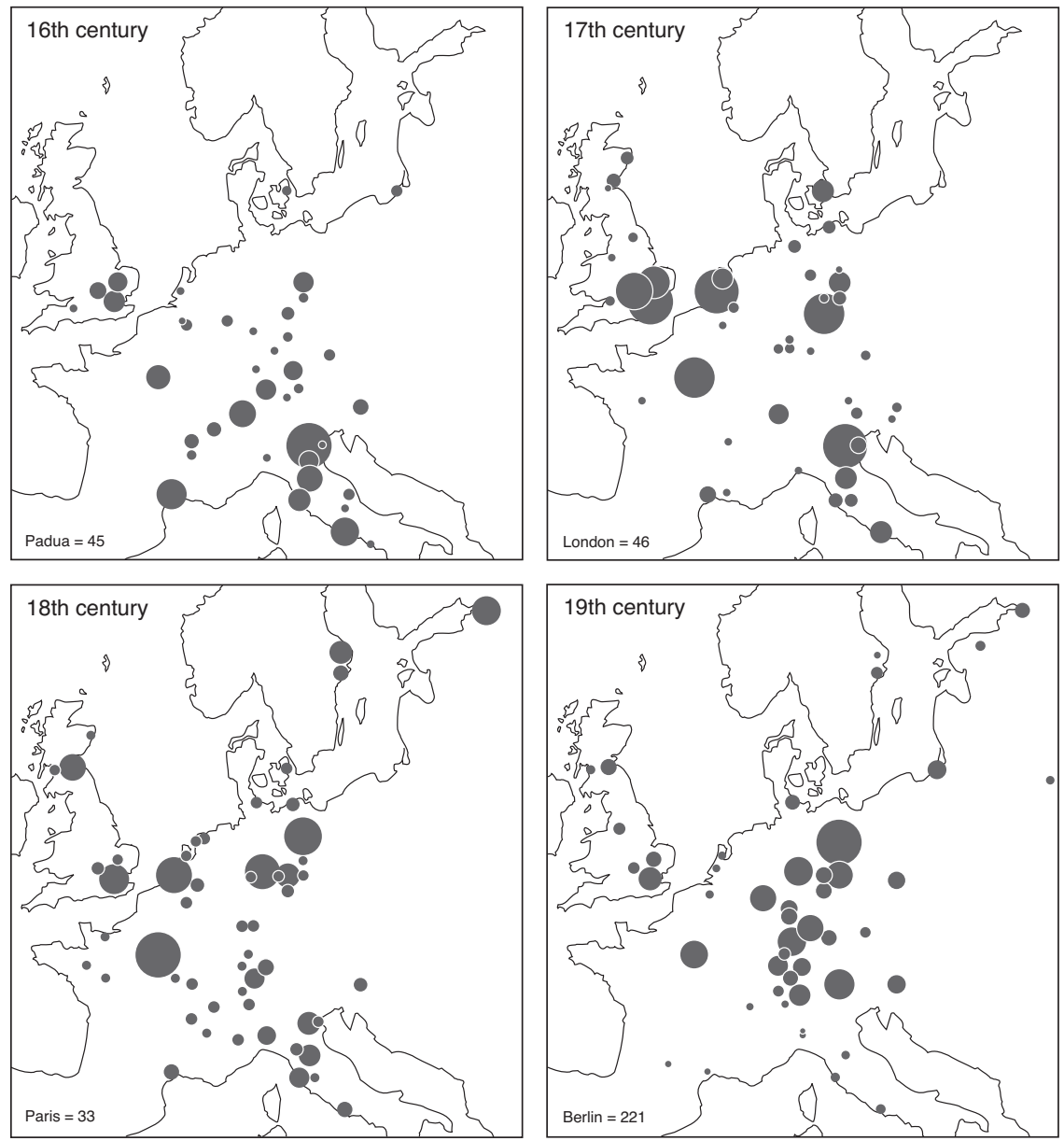

Figure 2.2 Workplaces of leading scientists, 16th-19th centuries.

Source: Taylor et al. 2008.

towns' - for the most part, their analysis fails to go beyond Wallerstein's broad interpretation of science.

The relevance of 'science' to social needs emanating from the endless accumulation of capital, the differentia specifica of the modern worldsystem, has encompassed both materialist reproduction (the work of science underpinning technology) and ideological reproduction (the idea of science underpinning progress).

(Taylor et al. 2008: 392)

Thus, science functions as a 'core-making' activity across the modern period. However, a closer look at the data yields a more complex picture. 
Most obviously, the centers of learning and the centers of capital do not move together. Though there is some overlap during the 16th and 17th centuries as capital moved from Italy to the Low Countries, by the 18th century, science is positioned in Paris, while Britain is on its way to securing victory in the Franco-British rivalry. This could indicate that ascendance to the center of science is a quality which adheres to hegemonic aspirants, perhaps an investment made by societies seeking to compensate for secondary status in economic power through the cultural glory of scientific achievement? Such a hypothesis would at first seem to adhere to the next movement from France to Germany, which figures in WSA as the hegemonic aspirant trailing Britain in the 19th century. However, outside of these maps, at the end of the period lies the United States, which did not follow this pattern. The US assumed the mantel of scientific center, then actually became hegemon and remained scientific center despite competition from the Soviet Union.

These observations lead the authors to suggest that 'structures of knowledge are integral to the reproduction of the modern world-system in their own right, they do not simply mirror leading material and technological processes' (Taylor et al. 2008: 408). However, this leaves the fundamental change beginning in 1800 unexplained. For example, in the maps above, the cities, Padua, London and Paris serve as centers until the end of the 18th century, while, in the 19th the entire nation of Germany appears as center. While Berlin is still the capital of science, in fact, the Rhine valley as a whole contains a vast complex of scientific centers up the spine of Europe. Perhaps this indicates that Ben-David's competitive field was located along a thoroughfare running from Göttingen to Bonn to Heidelberg to Tübingen at the skirts of Prussian borders?

But this was likely not the case, as Figure 2.3 demonstrates. The map of network ties from Taylor and his co-authors (2008), which is derived from analysis of scientists' movements between locations, shows that Berlin functioned as the head of an octopus, sending and receiving scientists who did not move across the periphery as often as they went to the capital. Even more striking is the difference between this network map and that of the 18th century in Figure 2.4.

The 18th-century network was, in fact, highly polycentric and decentralized, with many different national sub-networks. In many ways, it was not a system at all. Following the university revolution in Germany, however, one observes a veritable vacuum of scientific activity anywhere else, with England completely isolated and France dependent upon Paris as the only access point to the outside world. Of course, scientific discourse travelled trans-nationally as mass communications technologies spread throughout the period (Thompson 1995); still, as an indication of professional resettlement patterns, one can observe an enclosure process through which scientific practice became isolated from broader social patterns of the upper classes. Science became professionalized within academia in this period, generating a considerable increase in scientific activity within highly-contained national networks. Figure 2.5 indicates the scale of this increase in activity. 


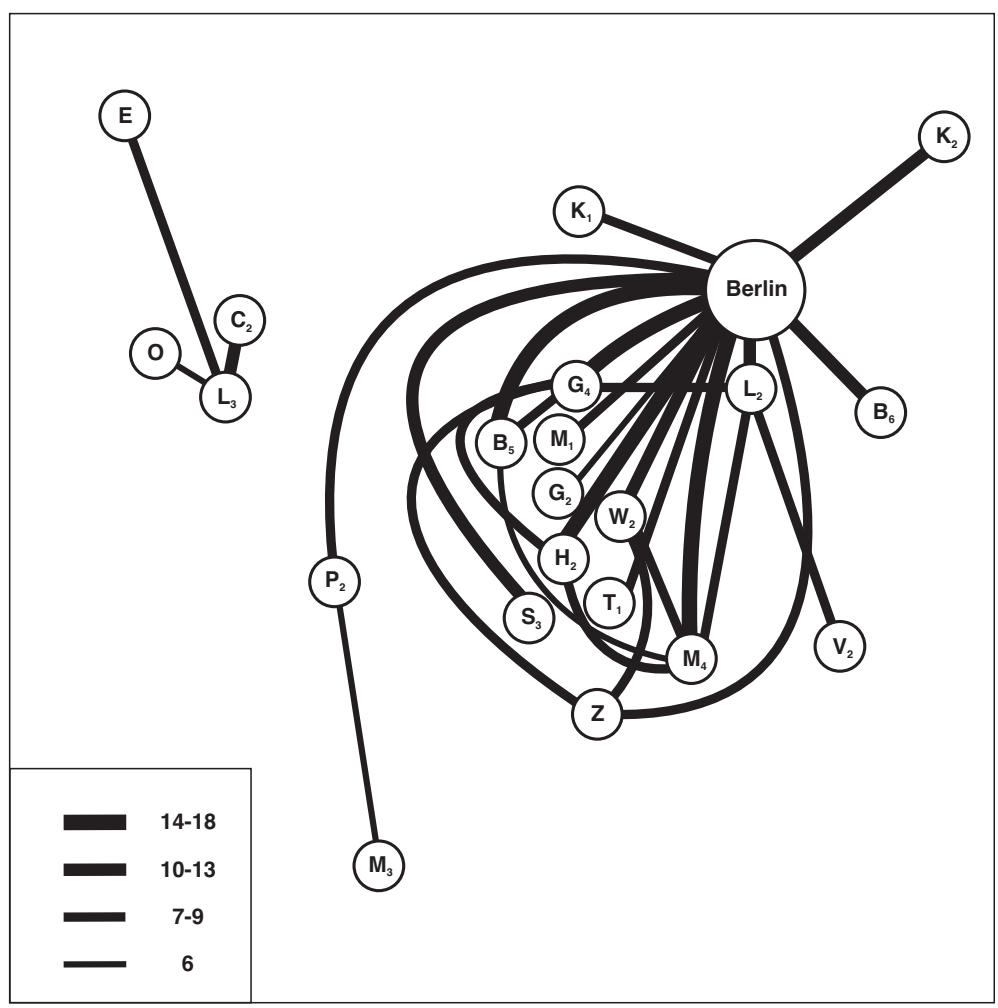

Figure 2.3 19th-century networks of scientific practice.

Note: City codes: A1 Amsterdam; A2 Avignon; B1 Basel; B2 Bath; B3 Berlin; B4 Bologna; B5 Bonn; B6 Breslau; C1 Caen; C2 Cambridge; C3 Copenhagen; D Dijon; E Edinburgh; F1 Ferrara; F2 Florence; F3 Freiburg; G1 Geneva; G2 Giessen; G3 Glasgow; G4 Göttingen; H1 Halle; H2 Heidelberg; H3 Helmstedt; J Jena; K1 Kiel; K2 Königsberg; L1 Leiden; L2 Leipzig; L3 London; L4 Lyons; M1 Marburg; M2 Modena; M3 Montpellier; M4 Munich; N Nuremberg; O Oxford; P1 Padua; P2 Paris; P3 Pavia; P4 Pisa; R Rome; S1 St. Petersburg; S2 Stockholm; S3 Strasbourg; T1 Tübingen; T2 Turin; U Uppsala; V1 Venice; V2 Vienna; V3 Vienne; W1 Wittenberg; W2 Würzburg; Z Zurich.

Source: Taylor et al. 2008.

\subsubsection{Explaining science in the university}

But, nothing about the data provides an explanation for this increase, and we must return to the center-periphery models for answers. Ben-David suggested the university provided a stable organizational home for scientific research to increase in scale under decentralized competitive conditions. However, as Figure 2.3 indicates, the field was still highly consolidated around Berlin as a center within the center. This highlights the extremely important role of the state in the organization of this system. Ben-David did argue that this material and organizational support, especially state protection of academic 


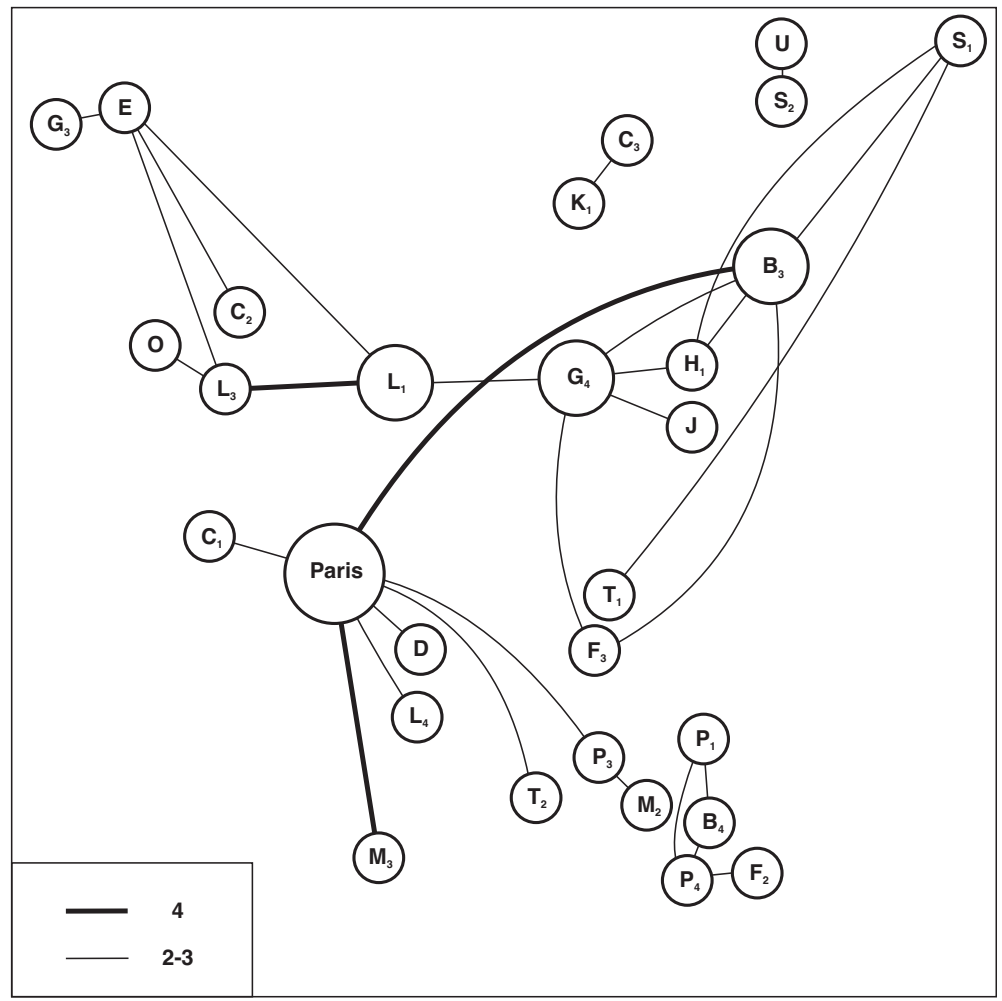

Figure 2.4 18th-century networks of scientific practice.

Source: Taylor et al. 2008; City codes: see Figure 2.3.

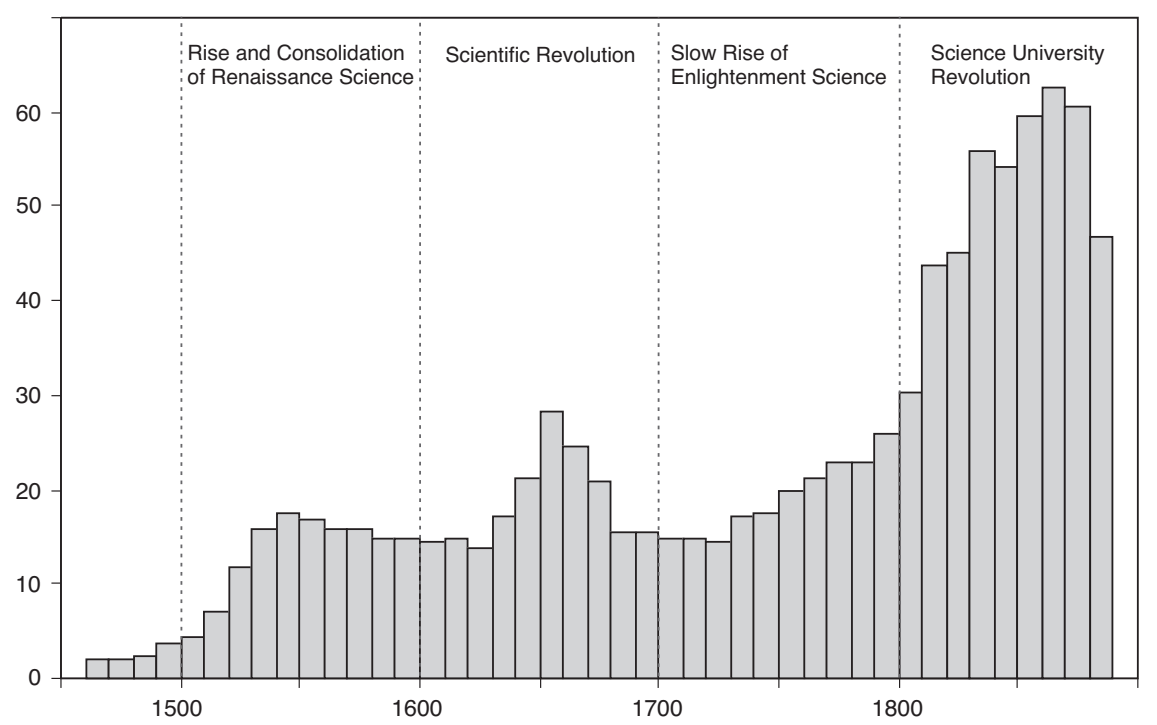

Figure 2.5 Growth of the 'scientific community'.

Source: Taylor et al. 2008; Gascoigne 1987. Number of 'leading scientists' by decade of 'career' start (three-decade moving average). 
autonomy, was instrumental in accelerating scientific activity. However, he is less convincing on the reasons why the German state offered so much, more or less implying that because France was investing in higher education, so did Germany. Wallerstein argues that this novel investment in science served an ideological function within the world-system and was encouraged by liberals seeking practical, specialist reform. And yet, this too is unconvincing when one considers that the novel institutional growth of the university occurred in Germany. To dismiss the growth of science and the university as an orthogonal development, which only later proved ideologically useful to capitalists, evades the core questions: Why was there a university revolution?; and, Why did science become institutionalized within the university?

\subsection{Particularities of German university history}

\subsubsection{Why universities?}

Both Ben-David and WSA position the 'university revolution' within broader trends of longer durée and thereby neglect the emergence of novel patterns in scientific and social organization induced by this institutional transformation. Wallerstein interprets the rise of science in the university as ideological cover for the expansive, capitalist world-system. Ben-David interpreted the institutionalization of universities within the story of the growth of science, which emerged in modern form in 17th-century Britain (see also Merton 2002). Once developed, scientific practice moved to whichever centers provided the most ideal institutional preconditions. Because Ben-David assumed that peripheral states emulated the center, he focused exclusively on the 'central part of the world system' at a given time, with some exception paid toward 'England as a durable secondary center' (Ben-David 1977: 5). Since further system development was achieved by incorporating and emulating successful models, Germany is only relevant to the analysis during its successful period, and primarily in terms of what outside observers in England and America thought about German universities. Only the establishment of German higher education in its 'ideal home', the university, needs explanation, since this model was later copied by the rest of the world.

According to Ben-David, selection of the archaic university institution was an accident of fate, since the small, fragmented German countries could not afford to construct French-style institutions and had to work with what they had ready to hand. Another happenstance, Napoleon's invasion of Germany, led to the removal of universities' ecclesiastical and financial bases, so that the reconstructed universities became reliant on state support (Anderson 2004). The state's competitive interest in modernization, which had been constrained by theological control in centuries past, meant neo-humanist philosophers, like Wilhelm von Humboldt, were charged with reforming the university according to their ideals emphasizing teacher and student freedom (Lernfreiheit and Lehrfreiheit), the unity of teaching and research (Einheit von 
Lehre und Forschung), the unity of science and scholarship (Einheit der Wissenschaft) and the primacy of 'pure' science (Bildung durch Wissenschaft) over specialized professional training (Ausbildung) (cf. Ash 2006).

Of course, the guiding administrators, scholars and philosophers did not reform the university with the natural sciences in mind. Rather, they were inspired by the ideological conviction of the 'unity of knowledge', according to Ben-David. Growth of scientific knowledge only occurred after the ideological unity of knowledge subsided and was replaced by mathematical-experimental methods by the 1830s. Once German universities established relative autonomy for philosophy and science within their walls, natural scientists were able to lead further developments themselves, including the sub-division of labor, which led to biology's success.

\subsubsection{The education state}

Ben-David's analysis suggesting university reform was internally driven, however, ignores the actual external factor of contemporaneous state reform in Germany. As Jacob Habinek has well documented, even Ben-David's paradigmatic success story, biology, cannot be explained by the autonomous effort of scientists striving for truth (Habinek 2010). University reforms did encourage focusing on basic research to the relative exclusion of traditional subjects, but scholars themselves were not responsible for disciplinary specialization.

Instead, the incorporation of universities into state civil service bureaucracies, political integration of the German territories under Prussian control, and expanding university enrolments due to increased demand for teachers and bureaucrats were necessary conditions for the formation of specialized disciplines. These conditions encouraged disciplinary specialization by restricting the power of university faculties to resist external influences, and by encouraging the partitioning of established scientific jurisdictions among more and more professors.

(Habinek 2010: 5)

The separation of the disciplines was but one element within a broader state effort to break the stranglehold of organized familial patronage networks, which effectively controlled academic appointments, just as all guild privileges were being undermined throughout Germany in the course of economic and political unification (Blackbourn 2003). Though professorial privilege enabled academic mobility across Germanic-speaking regions, this had been allowed since 1229, when a Papal Bull formally recognized the rights of studium generale (universities) to only hire teachers holding the title of 'master' from a similarly accredited university (Rashdall 1895).

In the 19th century, the movement of scholars within Germany tended toward politically-centralized regions in the emerging second Reich - Prussia, 
Baden and Bavaria - which provided the most resources. Thus, external variations of power drove the mobility of scholars, not the autonomous pursuit of truth. And, while state authority replaced ecclesiastical privileges, more importantly, steady payment of cash salaries replaced the hand-to-mouth household economies academics scraped from church property and their right to collect tutorial fees from students in their homes (W. Clark 2006; McClelland 1980). Salaries and legal titles made professors bureaucratic appointees of the state (Weber 1968). Meanwhile, the expanding population of lecturers (Privatdozenten) subsisted on a combination of private means and similar tutorial fees promoted directly to the public. This meant, on the one hand, that lecturers and professors were still drawn from wealthy elites capable of sustaining long periods of waiting in the wings. On the other hand, Privatdozenten had to balance careerist allegiance to their professorial mentors with popular appeal, often leading to exaggerated publicity regarding the significance of research findings.

But why was the public willing to receive these revelations? In 1808, the Prussian state ministry enacted the 'Municipal Ordinance' (Städteordnung) changing the category of 'citizen' (Bürgher) to include all persons owning a house and practising a municipal trade (C. M. Clark 2006: 334). This reform, motivated by rising state debt and the need for new taxation, effectively ended the privileges of corporate bodies, such as guilds. It is interesting to note that, in this context, university professors did not lose these guild privileges and continued to monopolize the market for education. For other citizens seeking status recognition, the only route of access was via the state, achievable either through military service or higher education. Education became a marker of distinction in a way that was not the case in any other nation analyzed by Ben-David or WSA. Only after World War II did German society begin to assimilate the more common Western European pattern of conspicuous consumption as status symbol (Münch 1992; Veblen 1924). Thus, instead of a 'traditional' bourgeois class on the English and French model, Germany developed an 'educated' bourgeoisie, the so-called 'Bildungsbürghertum' (Kocka and Mitchell 1993; Koselleck 2002).

This educated middle class was no accident. Following the humiliating defeat at the hands of Napoleon in 1806, Prussian state reforms were entrusted to aristocratic ministers, Karl vom Stein and Karl von Hardenberg, in an attempt to fully rationalize the state bureaucracy (Beamten) (C. M. Clark 2006; Levinger 2000). This 'revolution from above' has often been interpreted as a failed attempt at liberal reform, but, such an analysis misses the philosophical motivation behind the Stein and Hardenberg reforms. As Thomas Nipperdey related,

The Prussian reform movement was deeply influenced by philosophy; it was an idealistic and moralistic movement. This went beyond rhetoric, tone or superstructure, it also characterized its concrete goals ... In the realm of political ideas and morality, reform centers on autonomy and responsibility; it seeks a neuer Mensch, a 'reborn', a 'refined' human 
being. This new man was not only the goal of the reforms; he was needed to carry them out. In this respect, it was much more than an institutional reform; it was, in the widest sense, an educational reform.

(Nipperdey 1998: 22; emphasis added)

Whereas Ben-David insisted that 'the movement for reform of higher education consisted entirely of philosophers and scholars', he neglected that the state itself consisted of like-minded philosophers (Ben-David 1977: 19). These philosopher king's ministers were, in fact, the driving force behind university reform in the first decades of the 19th century.

\subsubsection{The conflict of the faculties}

Wilhelm von Humboldt was not a natural scientist, but a philologist; nor was he formally an academic. He was hired by Stein to run the state's Section for Religion and Public Instruction in 1809. His reforms extended across the entire range of education, not only universities, which were to acquire a single, standardized system of public instruction. In any event, he only helmed the University of Berlin and the ministerial post for a very short time, and other figures, including Fichte, Schleirmacher and Kant, were more widely influential at this time (Bruch 2006). Humboldtian ideals defining the proper role of the university were discovered by academics at the turn of the 20th century.

As Ash (2006) recounts, the 'Humboldtian myth' gave threatened professors cause to complain about the fivefold increase of students, from 13,000 in 1850 to 64,657 in 1914, which had led to overcrowded lecture halls, and the development of an unemployed, 'intellectual proletariat,' causing a 'research exodus' from the university. When the state threatened to expand accreditation to specialized, technical schools - that is, scientific research institutes - professors framed this as a betrayal of Humboldt's vision of teacher-researchers dedicated to pure science. This enabled academics to maintain their professional jurisdiction over higher education conferred by university privileges, as specialized research was added as post-doctoral fellowships at the Kaiser-Wilhelm-Gesellschaft, now the Max Planck Society.

Though Ben-David admitted that Humboldt's vision was more ideal than reality, he nonetheless credited the 'scientist' for institutionalizing competition and autonomy within the university (Ben-David 1971: 117). Many of these structural conditions were, indeed, instituted in the early 19th century, but Humboldt's contribution is best understood as a summary of the earlier Kantian argument, which inspired the state ministers who instituted them.

Kant (1992) argued in 'The Conflict of the Faculties' (Der Streit der Fakultaten), published in 1798, that the 'businessmen' (Geschäftsleuten) of the higher faculties, theology, law and medicine, were too constrained by their practical duties. Only the philosophical faculty was unbound by the directives of external power, and they were therefore able to criticize the higher faculties 
according to the free-judgment of 'Reason'. The university should recognize this value and give the philosophical faculty the autonomy it needed to fulfill its critical mission.

Kant's text should be placed in the 18th-century context of his own struggle to repeal censorship of his recent anthropological work, deemed threatening to the jurisdiction of theologians and jurists. Further, Kant's personal conflict with the faculties must be put into the context of a century-long struggle by 'masters' of philosophy seeking recognition as 'doctors', a title reserved only for the higher faculties (W. Clark 2006).

Philosophy was a primarily a teaching discipline, on the level with 'masters of music', but nonetheless popular with the aristocratic students attracted to the 'modern' universities of the 18th century, Halle and Göttingen (McClelland 1980). On the one hand, this meant that philosophers indeed covered 'all parts of human knowledge', as Kant claimed, including historischen Erkenntnis, historical knowledge (history, geography, philology and the humanities, and the natural sciences) as well as 'Bernnufterkentnisse' [sic], pure rational knowledge (pure mathematics and pure philosophy, the metaphysics of nature and of morals) (Kant 1992). On the other hand, the appeal of 'science' in this context should be understood as a component of the aristocratic culture of the French Enlightenment, emphasizing Reason and moral science (Heilbron 1995). As Weber would later admit, 'the scientific training that is traditional in German universities, which we should be providing, is a matter of the aristocratic spirit, and we should face up to this' (Weber 2008: 30; emphasis in original).

Kant's 'Conflict of the faculties' was an appeal aimed directly at the monarch and his aristocratic ministers, circumventing the censorship of the theological and legal faculties. In this professional conflict, the faculty of law was much more significant than theology, since it was they who prevented the ascendance of the lower faculty. This power of jurists can only be understood within the legal framework of the Holy Roman Empire, where academic jurists functioned in a manner we would recognize today in the American Supreme Court. The Holy Roman Empire had several layers of legal authority, including Roman law, Imperial law, local state law and customary law, all of which needed to be weighed. Since the days of Christian Wolff, the juridical faculty aspired to ground their authoritative decisions in 'natural law' based on abstracted, atemporal interpretations of Nature and the human condition. Kant's claim that philosophy could challenge these interpretations according to Reason, anthropology and the moral progress of History challenged the very foundations of German legal authority.

Kant's argument that philosophy should be autonomous did not imply that philosophy would be authorized to freely criticize the state. Rather, philosophers should remain autonomous to resolve conflicts between the other higher faculties. If the state wished to push society toward progress, it must be able to hear the uncensored writings of the 'free professors of law' in philosophy. This did not imply freedom of speech for the masses, but rather a retrenchment of the authority of professors to interpret natural and social rights 
according to the principles of republican government, treating 'the people according to the principles which are commensurate with the spirit of libertarian laws ... although they would not be literally canvassed for their consent' (Kant 1992: 165). Kant's political position seems authoritarian, but it was the philosophical inspiration for modernizing state reformers in the early 19 th century, who wished to force their people to be free.

\subsubsection{German legal sciences}

The ascendance of the more 'bourgeois' Prussian King Frederick William III in 1797 enabled the publication of Kant's tract, but it was not until Frederick William sought council from his Kantian ministers, Stein and Hardenberg, that his vision of philosophical autonomy was institutionalized at Humboldt's University of Berlin in 1810, the first institution to award a PhD in philosophy. But this institutionalized autonomy was not the product of the ministers' quaint, nostalgic attitude for their former university days, as Ben-David suggested. Rather, these modernizing reformers required the removal of the static Wolffian vision of natural law. From this angle, the promotion of philosophy was actually a demotion of the law faculty, which now had to prove its merit. Its first task was to figure out what the actual law was, not only in Prussia, but in the several lands now incorporated into the state following Napoleon's dismantling of the Holy Roman Empire. Other medium-sized German states, similar products of the post-revolutionary international order, faced comparable problems of legal interpretation.

Jurists, no longer able to reference 'Nature', assimilated Kantian epistemology to develop Rechtswissenschaft, legal science. A full description of the history of legal science is impossible in this short paper (see Reimann 1989). But, reference can be made to the work of Friedrich Savigny, Georg Puchta, Jacob Grimm and Rudolph Jhering, which reveal, on the one hand, an increase in scientism as legal scholars sought to ground their authority in adequate theoretical 'systems', and a grounding of these analyses in 'history'.

To look at law as a historical phenomenon meant to consider its positive, as opposed to metaphysical, side ... here, 'history' did not refer to tradition, but to legal facts. Facts are by their very nature 'historical' in the sense that all data are: as something that is already given and thus already part of the past ... The system was the inherent order of positive law ... Based on positive, historical material, it was objective and thus truly scientific.

(Reimann 1989: 879, 880)

Once initiated in 1803, legal science split into a number of sub-divisions, including a 'Romanist' school, emphasizing the universalism of Roman law, and a 'Germanist' school, emphasizing the cultural particularity of German culture and custom (Lybeck 2015). The Romanist school broke down further 
into those emphasizing Justinian's Institutiones and the Pandects, or commentaries. Legalist attention to history led to the emergence of the historical sciences themselves, since archival work could be managed by classical philologists within the upgraded philosophical faculties. More importantly, they also led to the emergence of the social sciences as jurists emphasized the indirect social influences on formal law in the second half of the century.

Indeed, the 'Methodenstreit' Wallerstein highlights as the social sciences' fall from grace occurred much later in the century within economics. These debates in the proto-social sciences over universal laws versus cultural particularism were largely prefigured in the legal scientists' arguments over which was most important: theoretical 'system' or historical particularity. And, while Wallerstein claimed the Methodenstreit was never 'resolved', one should recognize its function as a teaching exercise, weighing one position against another to stimulate critical thinking in upper-level seminars. Actual social scientific research, such as that conducted by Karl Marx and Max Weber, both of whom were trained in the legal faculty, moved back and forth between the universal and particular (Whimster 2017). The same educational approach was institutionalized within 19th century American law and business schools, inspired by German Rechtswissenschaft to develop legal realism and the 'case-method' of professional training (Reimann 1989).

Ben-David's and WSA's neglect of the continued development of the higher faculties contributes to a highly selective historical account of the university. Indeed Ben-David went so far as to say 'occupational groups aspiring to professional status played no role in the movement' to reform universities, and that the universities were 'devised for the training of professional teacherresearchers' (Ben-David 1977: 19, 49). This only applies if one leaves out the state civil service as a professional group! In fact, the legal faculty still educated a considerable portion of German university students throughout the 19th century. Figure 2.6 shows the slow decline in enrollment in law, which was less than theology, while the gain in sciences was comparable to the gain in the humanities.

Legal scientists undoubtedly idealized some version of science and history in the 19th-century 'Age of Progress'. However, recognition that these were

\begin{tabular}{lccc}
\hline & $\mathbf{1 8 3 0 - 1 8 6 0}$ & $\mathbf{1 8 6 0 - 1 8 9 0}$ & $\mathbf{1 9 1 1}$ \\
\hline Theology & 30 & $\mathbf{2 0}$ & $\mathbf{1 0}$ \\
Law, Government & 30 & 25 & $\mathbf{2 0}$ \\
Medicine & 15 & 20 & 20 \\
Humanities & 15 & 15 & 25 \\
Sciences & 5 & 10 & 15 \\
Minor Fields & 5 & 10 & 10 \\
\hline
\end{tabular}

Figure 2.6 Distribution of German university students over the faculties and subject areas, 1830-1914 (in rounded percentages by column).

Source: Ringer 1979: 60. 
professional disciplines directly connected to the state draws attention to the penetration of scientific, rational legal domination in society itself. For example, the historian Theodore Hamerow discredited the epithet applied to the do-nothing Frankfurt Parliament of 1848 - at the time called the 'parliament of professors' - by noting that of the 392 parliamentarians only 49 were university professors (Hamerow 1958: 124). Never mind that 200 were jurists! And, when the German civil code was drafted from 1874 to 1896, it was drawn extensively from the Pandectist legal scholar, Bernhard Windscheid's, textbook, so that it was described as 'a Windscheid Pandect treatise in statutory form' (Reimann 1989: 867).

Though Ben-David focused attention on the role of professional training in Centers of Learning, this was treated as an 'external' factor to the science function of the university (cf. Abbott 1988; Fourcade 2009) ${ }^{2}$ Neither he nor WSA examined the development of the content of what was taught within the professional faculties at this time. As Scheppele (1994) argues, this is typical of sociologists today, who remain oblivious to contemporary legal theory. However, in the case of 19th-century German university history, this neglect leads to the misrecognition of a basic chronology: that legal science and legal history developed before the natural sciences. This contradicts Wallerstein's argument that aggressive natural scientists were responsible for the ideological break-up of knowledge.

\subsubsection{Transfer of German model to the United States}

The institution of the Kaiser-Wilhelm-Universität is an interesting case, insofar as the university was part of an imperial nation-building mission following the annexation of Alsace-Lorraine in the Franco-Prussian War (Craig 1984). The construction of the first university since the University of Bonn (1818) provided an opportunity for academics, officials and the public to submit comments on their vision of the 'ideal university'. Academics, especially humanistic scholars, including Wilhelm Dilthey and Heinrich von Treitschke, lobbied the state to divide the philosophical faculty in two. At the same time, the establishment of social science chairs was institutionalized for the first time. Though positivists were selected for these initial social science chairs, since these value-neutral historians would not offend the colonized Alsatian elites, this was not typical of the broader German pattern. Empiricist, methodical social science did not come into its own until the German academic model migrated to the US (Fleck 2011).

Though not in direct imitation of Kaiser-Wilhelm-Universität, the public discussion over the model university encouraged considerable reforms to universities across the unified German Empire, which was consumed in the nationalist spirit of victory, triumph and chauvinism. Later, when US academics and reformers came to Germany to learn the secrets of their scholarly success, they encountered men like Friedrich Althoff, who had a dual role at the Kaiser-Wilhelm-Universität as a professor of law and as a key official 
under the Badenese Baron Franz von Roggenbach during the university's founding (Brocke 1991; Sachse 1928). Althoff went on to become the Cultural Minister of the Higher Education Section of the Prussian State from 18821907, overseeing a massive increase of university funding. During his tenure, state authority over university decisions greatly increased as university policy became centralized in Berlin under what would become called the 'Althoff system'.

Reflecting his nation-building experience in Strasbourg, the Cultural Minister began promoting German scholarship internationally, including academic exchanges with the United States, justified explicitly as a cultural imperialism. Visiting American scholars - including most of the first generations of sociologists (Small 1924) - confronted an idealized version of the German system, a combination of what Althoff observed and what he wished he could forge (e.g., Flexner 1994). This idealized model, including the arbitrary division of arts and sciences, was enthusiastically institutionalized in the first graduate schools at Johns Hopkins (1876) and Clark University (1887) (Reuben 1996).

But the university was situated in an extremely different political economic situation in 19th-century America. The goal of capitalists in this era was control of government-business relations at the federal, rather than state-level (Fligstein 1993; Kolko 1977). Local particularities of law made it difficult to monopolize markets. At the same time, agrarian populism and urban muckraking raised the threat of anti-monopolistic congressional legislation. The progressive state of Roosevelt, Taft and Wilson emerged gradually as a means through which corporations 'voluntarily' cooperated with executive commissions and separate governmental departments, which could be corrupted more efficiently and reliably.

Social science promised the fulfilment of several functions for the political and business classes in the Reconstruction and Progressive eras. The elitist 'Mugwump' ethic of proto-social scientists like Henry Adams, Lester Ward and Thorstein Veblen sought the removal of corrupt party 'machines', which would be replaced by the authority of intellectuals and technocrats (Rafferty 2003). In this period (1884-1930), modern universities emerged under the direction of Mugwump presidents like Daniel Coit Gilman (Johns Hopkins) and Charles Eliot (Harvard). The most important of these new institutions, the University of Chicago, was funded by John D. Rockefeller as a philanthropic enterprise which would have the side benefit as a professional school for corporate managers, politicians, civil servants and economists (who were explicitly encouraged to write social scientific propaganda to counter muckraking journalism). This mission in fact failed, as many of the new educated elites used their skills to found new enterprises in competition with the large firms Robber Barons had hoped they would lead. Not until these elites started filling the government commissions established during the New Deal did this 'state nobility' begin to fill its purpose (Bourdieu 1996; Galbraith 1978).

The considerable Rockefeller endowment made Chicago the most advanced university in the country and institutionalized a number of new disciplines, 


\section{The systemic evolution of universities}

including sociology under Albion Small. Because Chicago also established the first university press, which published the flagship journals of the emerging disciplinary associations (Abbott 1999), the disciplinary divisions made at Chicago became standard nationwide, including the division of 'political economy' into three separate disciplines: sociology, political science and economics. Political economy had already split from the disciplines contained in the American Social Sciences Association, founded in 1867, which had also included education, health and jurisprudence. Though the establishment of graduate and professional education was fraught with counter-trends until World War II, the foundations of the US academic system were laid in the period between 1880 and 1920 .

The development of university departments maintaining internal control, while individual academics were evaluated by external disciplinary associations, journals and private foundations, meant that a centralized 'national' university system did not emerge (Abbott 2001a). By the time federal agencies, including the Air Force and National Science Foundation, invested directly in research after 1945, the autonomy of academics vis-à-vis the state was well entrenched in tradition. This enabled disciplines and professional associations to maintain stable positions which could not be directly controlled by the state or even the market. This stability has contributed to a differentiated distribution of authority internally and externally, which reproduces the structural properties of the European guild system for these professions.

Guild privileges imply recognition before the law; they allow for the monopolization, and therefore capitalization, of particular services. According to Andrew Abbott, the system of professions is largely organized by professionals themselves competing for jurisdiction (Abbott 1988). However, these must also orient their jurisdictional claims to particular audiences within their social and cultural environments. The former includes the law and the market. Within the latter are the public and the academy.

The ability of a profession to sustain its jurisdictions lies partly in the power and prestige of its academic knowledge. This prestige reflects the public's mistaken belief that abstract professional knowledge is continuous with practical professional knowledge ... it is therefore not surprising that jurisdictional assaults are often directed at the academic level.

(Abbott 1988: 54)

As a rule of thumb, the more 'abstract' one's professional knowledge, the higher one's prestige. Thus, even though a weak to non-existent national legal framework existed to protect the scores of professions and disciplines that securely work across state - and now national - borders, common recognition of their academic knowledge provided these actors with the ability to monopolize and capitalize on their academic distinctions. 


\subsection{The recursive influence of science, ideology and the university}

Much of the above historical detail is lost in Ben-David's and WSA's systemic models of the growth of science and the university. Each model produces a range of descriptive, historical data which are always connected to an underlying linear narrative. Though their compounding system models allow for the incorporation of subsequent reconfigurations and adaptations of the system when and where they emerge, the end result is ultimately the same: the contemporary capitalist system or the post-war American university. Though the causal narratives are told 'forwards', their historical focus is always a backward projection of the present.

Both begin their stories in the Renaissance, specifically Italian city-states, where they find the first identifiable kernels of their systems. From this point on, their systems are operational in essentially unchanged form. For Ben-David, substantial growth is grounded in the external order of empirically observable Nature. As Thomas Kuhn noted in his review of The Scientist's Role:

If, as Professor Ben-David argues ... society can alter only the quantitative growth of science, not influence its nature, and if such alterations are merely responses to varied modes of supporting the scientific role, then that role must be given once and for all, fixed in some timeless Platonic heaven. In addition, it must be single and unified, the scientific role.

(Kuhn 1972: 177)

Thus, Ben-David's institutional analysis contains not only a sociological assumption, but, in fact, reflects a metaphysical assumption: that Nature is itself fixed and ordered to the extent that empiricist experiment and rationalist analysis automatically lead to the substantive growth of objective knowledge. This positivist assumption enables a retracing of history to find glimpses of a singular scientific role, working backwards from the outcome of the ideal science system in the decentralized United States with the post-war American scientist as archetype.

For Wallerstein, the social, but no less static, mode of capitalist accumulation determines the direction of systemic development. As William H. Sewell recognized, Wallerstein ultimately posits a 'big bang' in the 15th century, beginning in the age of exploration, 'a primal cosmic event that determined the subsequent character and evolution of the universe' (Sewell 2005: 87). In Arrighi's hands, WSA reduces the dynamics of capitalism to a cyclical pattern of intensive and extensive growth and the rise and fall of hegemons, as critical Marxist scholar Moishe Postone suggests.

His approach substitutes a description of a pattern for an analysis of what grounds the dynamics, and does so in a way that also brackets consideration of the ongoing structuring and restructuring of labour and more generally, of social life in capitalism.

(Postone 2010: 16) 


\section{The systemic evolution of universities}

WSA and Ben-David provide linear narratives explaining a steady rise of capitalism and the natural sciences. But, these two trends are not adequately considered together, on the one hand, as occurring within the same times and places, and on the other, as having become integrated together as a single process following the university revolution. 'Capitalism' rises and 'Science' rises, but there is no substantive interpenetration between the two processes. The institutionalization of science does not do anything to society.

And yet, my own historical sketch above suggests that, once connected and considered relationally as causally significant factors upon each other, the synthesis of these two developments within the university figures as a fundamental transformation of both knowledge and power. University privileges enabled the capitalization of knowledge, extending academic guild privileges to the self-organized system of professionals. Though justified according to philosophical arguments, often post-hoc, the institutionalization of this knowledge-based status structure occurred first within the German state, not the market or the laboratory. By the end of the process of international diffusion of this model, a new mode of hierarchical distinction had been developed, so that academics and professional elites recognize themselves within a second-order, abstract system, which is then enacted upon the world (Callon 1998; Fourcade 2009; Meyer et al. 1997; Mitchell 2005).

\subsubsection{The function of science for Ben-David and WSA}

WSA comes closer to this recursive recognition by identifying the growth of science as a 'core-making' process. However, Wallerstein primarily references British and French intellectuals in his analysis of the division of knowledge. His account, which jumps from the definition of 'science' in French salons to the 'humanities' as promoted in British elite schools to 'history' as practiced in German universities, to say nothing of 'social science' as defined in post1945 United States, misses all of the complex particularities in which these divisions of knowledge were actually determined.

This is the product of a functionalist tendency to conflate outcomes and functional conveniences with motives and actors. Indeed, even Shils noted as much in his annotations on Ben-David's manuscript quoted in Chapter 1.

Most important for the future revision of this book is the need to document from biographies and correspondence and other personal records the facts of the emergence of the 'scientific identity'. It is entirely taken for granted here. It is, in fact, inferred from the increase in the density and intensity of scientific activity in the 19th and 20th centuries. You do not present in this chapter any evidence that there had been such a change in self-conception. I myself have always believed that such a change took place, but I am only a dilettante, not writing a scholarly book on the subject. ${ }^{3}$ 
Shils's recommendation in 1965 is as valid today: the history of the university and the emergence of the scientific role cannot be inferred from the growth of science and technology in society. Rather, we must reconstruct the actual motivations of those responsible for the emergence of a new role - the professional academic - and a new institution - the modern research university as it emerged in Germany, America, Britain and, to a lesser extent, France (which followed the emergent European - that is, German - model by the end of the 19th century) (Anderson 2004; Weisz 1992).

While WSA's negative evaluation of the ideological effect of the division of knowledge in the university may be a valid criticism from the angle of the late capitalist world-system (Harvey 1989; Jameson 1991; Lash and Urry 1987), Wallerstein failed to locate the enlightened aristocratic reformers and legal scholars in 19th-century Germany who were actually responsible for institutionalizing these structural divisions. Rather, like Ben-David, he suggested scientists intentionally segregated themselves.

Though claiming to focus on 'external' factors, Ben-David dedicated little to no attention to the actual historical particularities of German history outside the academy. The cultural backwater appears to have 'unintentionally' struck upon the ideal institution for modern science in the medieval university (Ben-David 1960: 839). The 'Germany' upon which Ben-David derived key elements of his competitive model of scientific growth was, in fact, the imago of Germany, as it functioned in modernization theory more broadly, suggesting the nation followed a distorted, 'special path' (Sonderweg) to modernity (Dahrendorf 1969; Parsons 1934; Taylor 1946; cf. Blackbourn and Eley 1984; Steinmetz 1997a). Describing German society as homogeneous and authoritarian, Ben-David missed the actual external developments enacted by the modernizing Prussian state and the internal developments within the legal faculties who populated the future German state - an educationbased state which was enthusiastically assimilated into American elite power constellations before World War I.

The Sonderweg assumption that Germany was an aberrant nation, which industrialized late, lacked democratic traditions and, therefore, encouraged militaristic, irrational ideologies, implies the historical existence a non-aberrant norm: an idealized, ahistorical version of Britain, France and the United States (Blackbourn and Eley 1984). These 'liberal' countries presumably were properly democratic, did not have militaristic tendencies and successfully modernized according to the interests, values and freedoms of the enlightened bourgeois classes. Ben-David incorporated this 'normal' modernization path into his center/periphery model by suggesting German innovations in higher education were mediated by the assimilation of the German model into British and American universities. In his view, the actual conditions and consequences of German development become irrelevant, since Anglo-Saxons adapted Humboldtian ideals into their own liberal democratic way of life by the end of the 19th century anyway.

Ben-David's vision of the autonomous university promoting the non-ideological, value-neutral scientific role must be understood as a fundamental 
component of classical modernization theory developed by his mentor Edward Shils. Nils Gilman (2007) has suggested that the modernization synthesis within post-war US social sciences consisted of three key ingredients:

a a stage theory of history moving from 'traditional' to 'modern' societies;

b a Schumpeterian elite theory of democracy (Schumpeter 2008); and

c a thesis suggesting the 'end of ideology' (Aron 2001; Bell 1960; Shils $1955,1958)$.

The ideal of autonomous social scientific experts advising powerful corporate and state interests from their ivory tower was part and parcel of a new definition of democracy that emphasized bounded freedom for intelligent elites. Modernization theory, in this sense, was an American variant of Kantian republicanism. In order for social scientists to justify themselves with respect to those in power, they generalized the value of the academy as the ideal setting for inter-subjective truth to emerge according to Humboldtian commitments to value-free research and teaching.

The significance of Ben-David's historical account was, therefore, to cast these ideals into the historical record, suggesting that the autonomy of science actually emerged in 19th-century German universities, and, more importantly, that it had reached its pinnacle in the post-war United States. Instead of referencing themselves as experts, modernization theorists referenced the entire historical transition from 'traditional' to 'modern' societies, running from Renaissance Italy through to British scientific societies, the French Enlightenment, the Humboldtian university of Germany and eventually culminating in contemporary American society composed of ethical professionals, cheerful masses and value-neutral scientists.

Wallerstein largely assimilated this triumphant liberal narrative into his own story, simply redefining the growth of science as a negative, rather than positive, development to be rectified by reuniting the sciences, humanities and social sciences. But it is unclear, from Wallerstein's analysis, why this should matter. If the unity of knowledge split in 19th-century universities, and social sciences emerged fragmented within them, did this change anything about the character of capitalism itself? If the fundamental economic structures have been reproduced unchanged since the 14th century, how would a 'unidisciplinary' reorganization of the social sciences change anything (Wallerstein et al. 1996)?

As Michael Burawoy has argued in reference to the Gulbenkian commission chaired by Wallerstein in the 1990s to 'open the social sciences', Wallerstein's turn to epistemological divisions seems to have been motivated by the lack of success his analysis had within academic discourse (Burawoy 2005b, 2008). Rather than return to the drawing board to rework his heavily criticized model (Skocpol 1977; Zeitlin 1984), he externalized WSA flaws as a problem with the audience; scholars did not understand WSA because they have been distorted by their disciplinary divisions. Furthermore, by crediting the antisystemic revolutions of 1968 with stimulating the conditions through which knowledge can finally be unified in the 
social sciences, Wallerstein positions himself and his generation as heroic figures fighting against the awful 19th-century Newtonian worldview (see Wallerstein 1971).

Though the two approaches are clearly distinguishable in terms of the content of their ideological orientations - one liberal, the other Marxist each shares a wilful organization of the historical past to 'prove' the arguments they wish to make with respect to the present and future development of the academy. Even more striking, both land on essentially the same recommendation: social scientists should advise both university and social reformers (provided they are bred in the authors' ilk). Neither identifies themselves as individuals claiming such authority and power. Rather, they reference the validity of their historical analyses as properly (social) scientific. By redefining science itself, WSA and modernization theorists deflect the ideological agendas driving analytic outcomes. In Wallerstein's case, Newtonian science was a distorted representation of the natural world as static, rather than chaotic. Natural scientists destructively split knowledge up into disciplines and, in the process, prevented recognition of the capitalist worldsystem. In Ben-David's case, experimental natural science is defined as valueneutral, the only non-ideological way to truth.

As the example of the Kaiser-Wilhelm-Universität indicates, the social sciences did emerge at the same time the arts and sciences were split. However, this was not done at the bequest of scientists, who have rarely verbalized a claim for power themselves. Even Wallerstein's C.P. Snow, who regaled the 'two cultures' in the post-war British academy, was challenging elitism of humanistic Oxbridge tutors (Ortolano 2005). Ben-David's and Wallerstein's ideological biases promote the misrecognition of themselves within this philosophical teaching faculty, institutionalized to critique the state without influencing it. In this regard, each sociologist reproduces the functional role the academic doctors of philosophy have played throughout the modern period: generating an ideal of the university which can be drawn upon when external forces threaten to undermine academic autonomy. The irony is that both scholars neglect the very faculties and professions that have actually enacted science and abstracted social systems upon the world, thereby missing the recursive influence the university has had in producing a novel form of hierarchy within knowledge-based capitalism.

\subsection{From nature to progress: A history of the future}

Of more contemporary sociologists, Niklas Luhmann noted the significance of the change historical legal science engendered in constituting modernity as a form of 'second-order observation' (Luhmann 1988a, 1988b, 1995a). Within the legal system, Luhmann identified a fundamental paradox: the 'third question' - not whether a law is just or unjust, but whether the distinction between legal/illegal is just or unjust in itself (Luhmann 1988b). The impossibility of jurists assessing justice as such was precisely Kant's justification for the ascent of 'free professors in law': 
The jurist, as an authority on the text, does not look to his reason for the laws that secure the Mine and Thine, but to the code of laws that has been publicly promulgated and sanctioned by the highest authority ... the jurist must straightaway dismiss as nonsense the further question of whether the decrees themselves are right.

(Kant 1992: 40-42)

Avoidance of the unquestioned right of judges to decide right and wrong, "which led a series of "gaps", was initially resolved within the Theological worldview by identifying the genesis of human authority and social order as the emanation of God. When the Protestant Reformation undermined this absolute assumption, legal theory shifted toward the Natural Law tradition and the grounding of Law in the abstract principles of Reason. The state and legal order were 'contracts' rooted in an ahistorical state of Nature, which decontextualized human beings into abstract 'subjects'. Following Hobbes's assertion that humans are 'naturally' violent - a distinction between 'society' and 'nature' emerged to separate the artificial constructions of Law as a form of protection from inner human instincts and the vicissitudes of nature (Latour 1993).

Precisely this shift toward Natural Law made the whole philosophical structure vulnerable to historical and comparative research in the 19th century. Luhmann cited the historical school for undermining the Kantian 'inflation of hopes regarding the foundations of law' (Luhmann 1988b: 159). Once the historian searched for the state of nature in the historical record, it became immediately apparent no such state ever existed, except in the mind of the rationalists. Two options opened themselves up: first, one could adopt the perspective of the lawyers and their historical experience, allowing the law to evolve or remain according to juridical practice. Alternatively, one could reform the basis of the constitutional state so that legislation could lead us into the future. During the reactionary Vormärz period in Germany, the first option was employed as historians dug deeper and deeper into the actual historical particularisms, channelling the essence of the legal system along its course of development. In adopting this course, the abstract principles of natural law were fully undermined - there was no 'state of nature', no 'natural rights' - only historical privileges and traditions. Not until the next period, following the Revolutions of 1848 and the Wars of Unification from 1864-1871, did the second tack come fully into its own:

The paradox now disguises itself as the splendid future of divine mankind, the future of freedom and equality, the future of emancipation and democratic constitutions, or the future of the greatest happiness of the greatest number of people, and finally as the future of the communist society as the new state of nature, the state after the state, after property, after all divisions and distinctions. The paradox prevents observations and descriptions, the future being unobservable by itself anyway. The 
future becomes the grand excuse for all the misdeeds of the new industrial society, the grand excuse for applying the law which the society itself produces according to a calculus of interest and, increasingly, as a reaction to its own self-created problems.

(Luhmann 1988b: 159)

A similar observation was made by Alvin Gouldner, who noted that the horrors of the Revolution and frustration with the Counter-Revolution produced St. Simonian Positivism in France (Gouldner 1970: 98). The breakdown of the Church's traditional 'maps', which identified the 'sources' of authority for the Old Regime, attenuated the traditional image of the social order along with its social identities. This necessitated a 'Romanticization' of the present, which was nonetheless compatible with new 'scientific' methods and apolitical principles of 'objectivity'. In France, the new social sciences were not produced by the emerging, propertied middle-classes, but rather, were the project of a 'dispossessed aristocracy'; not-yet-arrived strata, including engineers; and socially-stigmatized groups, including Jews, adulterers, bankrupts and bastards. Sociological Positivism, in its original formulation, did not appeal to the middle classes beating back the Restoration. In Gouldner's analysis, the science of society would not become useful until the latter half of the 19th century.

Only where and when the institutional requirements of commercial industrialism were fully established; only when the middle class was secure from the restoration of old elites; only when it therefore did not look upon the past as a threat and did not believe the future required anything radically different: only then could the middle class relinquish a cultural lag theory that explained away present social tensions as due to old institutions grown archaic.

(Gouldner 1970: 107)

Gouldner's argument is compelling in light of Luhmann's observation that the contradictions of the legal 'third-question' shifted the justification of hierarchical authority into the unobservable capacity to predict and shape the future. However, Gouldner's shorthand attempt to connect French Positivism to German Romanticism is less historically convincing and neglects the fundamental role of legal science as the midwife of social science (Lybeck 2015). Savigny and the historical legal scientists were not out-groups on the fringes of bourgeois society. Indeed, as German historians never fail to remind us, the bourgeois middle classes (as traditionally defined in relation to the capitalist mode of production) were minimally present.

How did Romantic historicism - a backward looking, anti-modern ideology - result in progressive teleology? First, note Luhmann's identification of two options following the breakdown of Natural Law: one historicist, one teleological. The two trends were separated chronologically in the first and 


\section{0}

The systemic evolution of universities

second halves of the 19th century. But, the Germanists developed their constitutional tradition under the duress of censorship. Theirs was not, in fact, the ideology of the status quo. The more reactionary impulse limiting free expression emanated from the Viennese internationalism of Prince Metternich of Austria. The Germanist idealizations of the Gemeinwesen were rooted in the Black Forest communities of equals and rapidly vanishing hometowns (Walker 1998). Theirs was the nationalism of a Kleindeutsch Germany, which would become reality in the wake of the Wars of Unification (Lybeck 2018c).

Legally, Germanists and Romanists resisted efforts to codify the law and were differently oriented to 'science' as defined by French polytechnicians (and Austrian absolutists). The historical school were committed anti-naturalists, which Mannheim identified as a fundamental 'cornerstone' of one type of conservative ideology: Romantic historicism, analytically distinguishable from ahistorical conservative bureaucratism (Mannheim 1986). The latter shared with bourgeois capitalists an affinity with the Natural Law thinking Savigny negated. He and the Romantics not only threw scepticism upon the doctrine of the 'state of nature', the 'social contract' and 'inalienable Rights', they further rejected the characteristic mode of natural law thinking. The historicist conservative affirmed 'history', 'life' and 'nation'; contrasted thinking and being, giving primacy to the later; and confronted the problem of 'irrationality' as constitutive of human life and fundamental to 'individuality'. Most importantly, Romantics rejected 'mechanistic' rationalism in favour of holistic conceptions of 'organic unity' and 'organisms'.

The idea of the social organism is put forward by the conservatives to counter the idea of the universal applicability of political innovations to any historical and national entity. This 'category' has a special significance, since it arose from the conservative impulse to stem the spreading tide of the French Revolution by pointing out that political institutions can only develop organically and cannot be arbitrarily transferred from one national organism (Nationalkörper) to another.

(Mannheim 1986: 109)

A further emphasis on the 'qualitative' over the 'quantitative' and 'abstract' grew from the same impulse, as did a dynamic conception of Reason. Methodologically, the conservative resisted any attempt to construct collective representations as aggregated individuals and, instead, began from the standpoint of totality. One could not understand any phenomena without understanding its relation to other entities and its relation to the whole of which it was a part.

Still, Mannheim noted that the chronology of this emergence following the French Revolution left a latent mirror-image of Enlightened Reason embedded in the new modes of conservative, historicist thinking. The result was an ideology constructed as the 'opposite' of ideology (natural law) - an antiEnlightenment. In expressing an objective interest in facts, rather than 
theories, the conservative Romantic historian learned a habit which denied his own engagement with the object - History - while at the same time seeking to master it. The aggregation of historical research produced material useful 'for its own sake', which is to say, useful to anyone with sufficient historical knowledge. The assumption underlying the utility of history, therefore, presupposed a knowledgeable elite who would carry research insights into positions of power. Thus, despite the suppression of values during the reactionary period, the German historical school did not conflict with the institutional structure constructed by the Kantian ministers one decade earlier. During the Wars of Liberation, Stein, Hardenberg, Humboldt and their peers resisted the centralizing tendencies of their French enemies, replacing the Revolutionary road to modernization with the gradual inculcation of a neuer Mensch via education. The retreat into history presupposed the continuation and expansion of these elites, but provided them with a new academic ethos which denied the politics underlying the higher education project.

Consider Humboldt's original, primary intention in unifying teaching and research as a means of preserving the modern authority of secondary school teachers. In fact, the historical model for this Neohumanist secondary education came from neither Rome nor Germany, but Greece. As La Vopa describes, a valorization of Hellenism contributed to the Bildungsbürgertum elitist disdain for utilitarianism, insofar as every member of the learned profession had to first navigate the rigorous Classicism of the Gymnasium.

The new concept of Wissenschaft accommodated its practitioners to academic and bureaucratic realities even as it promised to negate or transcend them, and that was its ideological significance. ... The Hellenism of schoolmen gave all this a new specificity. Like the leisured self-cultivation of the old-style aristocrat, the classicist's scholarship was practiced for its own sake, as something intrinsically noble, rather than extrinsically utilitarian. Yet this liberal pursuit could and indeed must be derived by a relentless work discipline, eminently suitable to the bureaucratic environment that schoolmen occupied and most of their pupils would enter.

(La Vopa 1990)

From the perspective of the student - future academic or bureaucrat school and higher learning acclimatized and socialized them chronologically from Greece to Rome to Medieval Germany, imprinting the history of Europe on the individual student. Throughout, the difficult tasks of reading ancient Greek or navigating archaic Roman legal codes created a separation from everyday experience. The civil servants came to live in a different world, that of history. The graduate was provided with an elitist point of view, the property of an elect class of knowledge workers. But, note the paradoxical constitution of the new, bureaucratic self: he denies the 'mechanical' and 'rationalist' world of utilitarian bureaucrats. In other words, he denies and devalues himself and the very work he is tasked to pursue. 
In the deconstruction of the Holy Roman Empire and the Restoration following the French Revolution in Germany, Savigny's historical legal science suited a widespread rejection of French Enlightenment, particularly in the form of legal codes. Yet, even Mannheim's analysis, which interprets Savigny as a 'free-floating intellectual' who attached himself to conservatism rather than progressivism, neglected the underlying liberalism and constitutionalism of Savigny and Romanists, to say nothing of the more nationalistic and republican Germanists. If we situate Savigny and the historical school in the local context of the university as a whole, the historicist discourse more precisely articulates with a New Class of learned professionals. A new form of authority rooted in mastery of historical fact is visible in the Hellenism of the secondary school teachers, along with a cognitive separation from the everyday world via technical philological methods. Yet, this new elitism was paradoxical insofar as the jurists' authority was historically grounded in the 'people' - the Volksgeist - which must be studied on its own terms, according to its 'Eigentum', its irreducible particularity. Further, this elitism denied its own existence: an anti-elitist elitism.

The authority Savigny renewed was not that of the venal, landholding aristocrat, but the medieval guildsmen - what would later be called the 'Mittelstand'. The learned professions shared with this class political interests that needed law, but not necessarily centralized state power and constant revision of historic rights and privileges. In other words, each needed the Old Regime, but only certain elements, principally the right to local self-governance. Norbert Elias plausibly argued that the university provided a middle-class counterweight to the French court. In France, overturning of the courtly tier produced the extension of the franchise via bourgeois revolution tied to a new meritocratic 'State-nobility' (Bourdieu 1996, 2015). In Germany, where the educated civil service was thin and scattered across the territory, the intellectuals remained 'floating in the air'.

What legitimized the middle-class intelligentsia to itself, what supplied the foundation of its self-image and pride, was situated beyond economics and politics. It existed in what was called for precisely this reason das rein Geistige (the purely spiritual), in books, scholarship, religion, art, philosophy, in the inner enrichment, the intellectual formation (Bildung) of the individual, primarily through the medium of books, in the personality.

(Elias 2000: 25)

Historical legal scholars rooted their ideal communities in fragmentary medieval constitutions, in the Roman codes adapted to local Germanic customs. The essential distinction we should hold in mind is not, therefore, between aristocratic authority and bourgeois enlightenment. Rather, beginning around 1810, one can observe the emergence of a new form of academic authority rooted in a new professional position in a new institutional complex. These scholars denied their own political interests, translating these interests into concepts rooted in historical fact. 
The self-justification of academics and jurists became the justification for aristocratic, bourgeois and bureaucratic elites who could not adequately construct ideologies for themselves - certainly not without the redundancy and adaptive capacities necessary within a modern society undergoing rapid social transformation. Again, the bourgeois Enlightenment set the initial challenge through the legal universalism of Natural Law discourse. According to Gouldner, this amounted to a generalization of bourgeois interest against the Old Regime. The bourgeoisie's blocked ascendance was translated into a series of concepts drawing attention to 'injustice' attributed to all forms of 'irrational', historical institutional configurations, especially the Church, Monarchy and Landed Aristocracy.

Enlightenment ideologies at first united all social classes under the rubric of the 'nation', as a social entity apart from and against the old regime priesthood and aristocracy. Correspondingly, the development of antiEnlightenment ideologies sought a symbolic rubric for a new solidarity of classes within the nation. They sought ideologies that would include the aristocracy and reestablish its hegemony over the other and newer classes. In both cases, what was needed was an ideology that could contribute to the blurring of certain, but in each case different, class differences and to the consolidation of new polities.

(Gouldner 1982a: 207)

In France and the more traditionally 'Western European' nations, the result was a public contest between differing conceptions of the nation. This ideological duel became markedly contradictory when the bourgeois classes became satisfied with the limited extension of the franchise providing legal and political rights to property-holding men. Indeed, as Therborn highlighted, the bourgeoisie became fearful of further extension of suffrage to women, lower classes and ethnic minorities as well as limited further democratization, despite counter-hegemonic frames employing similar universal concepts of equality, liberty and nation (Therborn 1977).

Unlike in France and England, where a liberal public sphere was sanctioned, central European censorship did not encourage publicity outside the academic texts legible only to those scholars trained in a classical Gymnasium. This meant that academic 'ideological services' were rendered on behalf of the counter-revolution or alternatively smuggled into fairy tales and legal antiquarianism. Initially, university education required considerable income and was therefore de facto restricted to elites, so that the aristocrats remained important members of the cohort being socialized into the modern German university. In the latter half of the century, as industry and commerce maturated, producing new economic elites, the university became a means of reproducing inherited privileges. But this story lies well in the future. Initially, the new 'non-ideological' ideologists served only two clients: aristocrats and bureaucrats - and it is their vision which inflects the historical image of 19th- 
century Germany as a 'feudal' society run by a powerful centralized state bureaucracy. The reality was far more contested, but the academics served their state sponsors, both ideologically and practically. In the decades to come, the German mode of political organization via educated elites contributed to the most rapid economic, legal, military and cultural modernization project of the age, an achievement which other nations strove to replicate, even as the edifice crumbled from within.

The emergence of the university in the aftermath of the French Revolution produced a number of novel, unprecedented changes which would take decades to bear fruit. Particularly significant was the consolidation of a new standpoint of academic authority. The invention of this non-ideological ideology retained the contradictions of its period and place of origin. Just as Kant envisioned, academics were positioned as expert advisors to the ruling classes, provided they expressed no political opinions of their own. The construction of the Kantian university, a fundamental component within a political project that sought to engender and socialize a neuer Mensch, was almost immediately supplanted by a more conservative, Romantic ethic emphasizing historical particularity under conditions of intense censorship.

As a form of practice, directly connected to legal order and legal reform, the New Class authority Savigny established for jurists contributed to the unification project that was to come (Lybeck 2017). Legal training in Roman jurisprudence provided a means through which particulars could be stripped to their essence without submitting subjects to universal categories. The adaptation of Romantic nationalism into comparative historical scholarship provided deep historical justification for the Kleindeutsch German Empire, which was consolidated in 1871. By establishing a vision of the future in the past, the Germanists inspired not only the nation being forged in blood and iron, they simultaneously inspired external observers seeking to reproduce the successes of the Teutonic phoenix rising from the ashes of the great French mistake.

\section{Notes}

1 See Commission Research, New York, Columbia University, Rare Books and Manuscript Library, Carnegie Foundation for the Advancement of Teaching, 19051979 (CFAT), VI.HE, VI.C, Box 115, 119.

2 Ben-David did deal with professional education as a separated function of universities (Ben-David 1972b, 1977; see also Parsons and Platt 1974). However, as Abbott (1988: 196) argues, he essentially equates professional education with practical knowledge acquisition; hence, he manages to distinguish the professional faculties from pure scientific research. He does not consider the conjunctural historical differences between professional systems in Germany, France, the US and especially Britain, where professional training in law, for example, continued to occur outside the university until the late 20th century (Burage 1993).

3 Shils to Ben-David, Minerva papers, Box VI, 13. 


\title{
3 The ideological organization of university systems
}

\author{
A theoretical framework
}

\subsection{Introduction}

If we compare the age in which we live to, for example, the decades following World War II or the belle époque of the late 19th century, one might observe that we seem to have lost our faith in science (Latour 2004). Whether as academics confronted with various crises of representation, or as citizens confronted with populism, post-truth and anti-expertise, we seem to have lost the grounding that science provided past generations (Beck 1992; Wagner 2008). However, this narrative of a declining faith in 'science', like the triumphalist metanarrative of progress which preceded it, fails to capture the way in which science continues to function as the ideological basis of modern civilization.

Since at least the 19th century, social scientists have posited an end or decline of ideology within modern society, noting the diminution of religious faith and the disavowal of secular metanarratives on the political left and right (Durkheim 2001; Weber 1958; Bell 1960; Shils 1955). And yet, as the recent surge in evangelical influence in American power and the rise of the New Left during the 1960s and 1970s make clear, such observations of decline were fundamentally flawed. No one today would argue that the United States is a non-ideological nation. The failure of these predictions could lead to one of two conclusions: (a) the trend had been one of decline, but conditions changed so that ideology was now again on the ascendance; or, (b) the scientific observation of ideological decline was, in fact, ideological - that is, incapable of reflecting on the unity of the distinction between science and ideology. Here the latter argument is assumed, and thus the historical decline of ideology is redefined as the replacement of traditional (religious) ideological authority with a modern (scientific) ideological system.

This modern ideology suggests that productivity is dependent on science and technology and that society's problems are solvable on a technological basis. Theories presupposing the decline of ideology assume that the rise of science is equivalent to the rise of non-ideology. In refusing to concede this non-ideological ground to science, I observe that the declinist theories and theorists themselves are most reflective of the actual organization of scientific

DOI: $10.4324 / 9781351017558-3$ 
ideology in modern societies. The very distinction between science and ideology is, in fact, the binary code upon which science maintains its own ideological purity.

After outlining what I mean by ideology, which is somewhat different from traditional uses, I describe the ways in which the binary distinction between 'science/ideology' functions as the organizing principle within the modern university system. Since ideologies must be organized within institutions to obtain social power, the research university is identified as the central institution in this modern, scientific mode of ideological organization. This chapter outlines a theoretical framework for the study of university systems derived from the systems theory of Niklas Luhmann and Talcott Parsons, supplemented by Alvin Gouldner's critical theory and Andrew Abbott's analysis of professions and disciplines.

The argument can be summarized as follows:

a ideologies, in general, can be defined by their relative intellectualization, which allows ideas to become systematic and structured at the social level;

b organized ideologies consist of meaningful combinations of distinctions and justifications, most significantly among powerful elites;

c the distinction between science/ideology functions as the operative code of the university system by externalizing 'ideology' as a special, exogenous mode of justification lacking the self-grounded authority of 'science';

$\mathrm{d}$ this operative code is distributed across and within disciplines and faculties, but it is 'bundled' at the level of the university as a whole; and

e systematic ignorance of the science/ideology distinction justifies academic autonomy inside the university while also reinforcing the authority of professionals working outside the academy.

The emergent contradiction between elite authority and self-grounded justification is the dominant and operative paradox of contemporary knowledgebased capitalism.

\subsection{Traditional ideology vs. the ideology of technology}

\subsubsection{Mann's IEMP model}

For two reasons I direct attention to Michael Mann's impressive account of the origins and evolution of social power up to the modern era. First, the overall validity of his IEMP model of social power, including both the heuristic value of differentiating mixed but autonomous ideological, economic, military and political powers as well as the historical observations contained within the Sources of Social Power: Volume II (1993) are presupposed. However, second, my intention in addressing Mann's historical sociology is to fundamentally revise his declinist account of ideological development during 
the 19th century. Without disqualifying his findings, my argument, following Alvin Gouldner (1982a), asserts that the decline of religious authority was not a decline in ideology, but rather reflected the rise of the scientific critique of ideology.

In Mann's 'organizational materialist' formulation, four sources of social power - ideological, economic, military and political - mix impurely and chaotically in different socio-spatial contexts and determine social structures historically. At a general level, power is broken down into a number of dimensions, illustrated in Figure 3.1.

Power can be distributive or collective. The former typifies Weberian notions of power emphasizing the hierarchical power of actor A over B. To the extent A's will can be achieved despite the resistance of B, A has more power. The second type, derived from Parsons, emphasizes the ability for actors to work together for shared ends, as in A + B's influence over C (Parsons 1999: 220-36). Furthermore, power may be either extensive, capable of organizing large numbers of people over far-flung territories, or intensive, capable of mobilizing a high level of commitment from participants. Finally, power may be authoritative, comprising willed command by a (usually collective) actor, or diffused, in that it is not directly commanded.

The most effective exercises of power combine all these types. The organization of military power, for example, is intensive in its organization to preserve life and inflict death, and extensive in that it can organize many people over large socio-spatial areas. Yet, relative to other sources of power, military organization tends to be the most authoritative in that it concentrates coercion, providing disciplined, routinised control. In modern societies, this military power tends to be monopolized by the state, but this condition is historically unusual and never absolute, since, for example, a military coup can overthrow political authority. Thus, politics and military power overlap, especially in the geopolitical system, but are not identical. Similarly, politics overlaps with economics, ideology with politics and so on. While these are analytical distinctions for heuristic purposes, the real autonomy and multidimensionality of these powers explains why no single power source is capable of determining the overall structure of society.

By differentiating and addressing the autonomous significance of military, economic and ideological power, Mann establishes a political sociology that represents the various interests, groups, and institutions, which become organized within the state. Political power is characterised by its centralised and binding power over a delimited territory. IEM power resources are located outside the state and must be drawn upon. Contrasting his position against
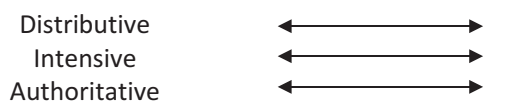

Collective

Extensive

Diffuse

Figure 3.1 Dimensions of IEMP power.

Source: Mann 1986, 1993. 
the Marxian, pluralist, 'true-elitist' and institutionalist theories of the modern state, he defines the state as an 'active place' rather than an actor or place (Mann 1984, 1993: 44-91). The state contains two dualities: 'it is place and person and center and territory' (Mann 1993: 56). To the extent state institutions are differentiated, undertaking different functions for different interest groups, states increasingly penetrate societies, especially when they become bureaucratically rationalised.

Prior to the modern era - for example, during the spread of Christianity during the decline of the Roman Empire - ideological power provided political authorities with infrastructural power (Mann 1984, 2008). Mann, however, notes that ideological power declined during the long 19th century (1760-1914), and in volume II of his magnum opus he dedicates most of his attention to economic, military and political power, especially in reference to national-states and economic classes (Mann 1993). In Mann's framework, ideology derives from the human need to find ultimate meaning in life, to share norms and values, and to participate in aesthetic and ritual practices. Ideologies can be sociospatially transcendent and/or provide immanent morale to existing power. Accordingly, he defends his decision to focus on 'EMP', rather than 'I', during the 19th century because ideology was primarily immanent rather than transcendent in this period.

Several scholars, particularly those representatives of the culturalist 'thirdwave', have criticised Mann's neglect of ideological power (Adams et al. 2005; Gorski 2006; Reed 2013). Indeed, the notion that ideology declined is a dubious claim in itself within an era R.R. Palmer described as the 'advent of the isms':

An 'ism' (excluding such words as 'hypnotism' or 'favoritism') may be defined as the conscious espousal of a doctrine in competition with other doctrines. Without the 'isms' created in the thirty-odd years after the Peace of Vienna it is impossible to understand or even talk about the history of the world since that event.

(Palmer and Colton 1965: 431)

Between 1815 and 1850, one finds the first conscious espousals of such 'isms' as liberalism, socialism, conservatism, individualism, constitutionalism, humanitarianism, monarchism, nationalism, communism, positivism and capitalism - each of which were transcendent ideological movements interested in changing the world.

However, according to Mann, for ideologies to become socially powerful they must become organized within institutions; again, the classic example is the Christian church. Therefore, ideology is not most important in terms of its statements or belief structure, but in terms of its practical effects on social structures, especially those most powerful institutions becoming centralised within the modern state. In this sense, perhaps, one could concede that conservatism and socialism were most relevant as immanent morale, that is, as 
ideological justification for existing political, military and economic institutions and classes.

But how do we treat the rise of science and technical knowledge? Ralph Schroeder (2007), for example, has criticised Mann's neglect of science in modern social organization and has suggested that science and technology represent a fifth form of autonomous social power. In a reply to critics, Mann conceded that his neglect of science and technology should be recognized, but that science is still contained within IEMP.

Science ... played a major role in European development ... Though most of the major inventions did not come from scientists, but from the 'micro-technologies' of engineers and artisans, it has now been shown that they had absorbed the general principles of scientific theories, and they shared a common technical vocabulary and method. They had imbibed the ideology that natural phenomena were orderly and predictable, mastered by means of a scientific method of exact measurement and reproducible experiment ... This especially puts more ideological power into my explanation of the later stages of the European breakthrough.

(Hall and Schroeder 2006: 375)

However, he has most recently argued that 'science ... differs from true ideologies in its aspiration to be emotionless, and it is always subject to cold scientific refutation, unlike ideologies' (Mann 2012a: 8; emphasis added). Furthermore, scientists are always involved in clientelistic relationships with the state, market and other powers:

Science is actually distinct, anomalous, among forms of knowledge. It has emergent properties in increasing the collective powers of human groups, but it has very little distributive power, for it places itself at the service of those who wield other sources of social power.

(Mann 2012a: 8)

These concessions and clarifications, however, should be related to a new type of ideology within Mann's definition of ideological power, namely, 'institutionalized ideologies', which are neither transcendent nor immanent, but are rather minimally present within routinised, disenchanted institutions. 'They are often lurking in the sub-conscious. They are thus conservative, endorsing values, norms and rituals that serve to preserve the present order' (Mann 2012a: 7). Indeed, within many theories of ideology, for example, those emphasizing false consciousness or legitimations of the status quo (e.g., Mannheim 1985), these habitualised, unconscious presuppositions lying behind social action in traditional institutions are ideology tout court.

But, let us here assume that Mann is correct in stating that science does not provide transcendent social action, nor does it encourage immanent morale, 
as it is subjected to the logic of cold calculation on behalf of more powerful clients. In this sense, it would still be a deflationary ideology, leading to what Max Weber (1958) called the 'disenchantment of the world', or what Herbert Marcuse (1991) called the 'ideology of one-dimensional man'. By reducing the ability for values to enter or change existing organizations, science encourages the unthinking conservation of institutionalized ideologies, and the maintenance of organizational rules become ends in themselves (Habermas 1970). And yet, as Mann rightly acknowledges, because of the connection between science and technology, science is able to materially change the world - that is, produce growth of and for itself - as well as determine and reproduce the conditions of its own growth. In this sense, science is socially powerful indeed.

Thus, the growth of science, as science and ideology, has enabled the general expansion of social organization itself. Not only does science encourage the adaptation of social power according to non-transcendent ideological authority, but it also encourages an increasingly systemic penetration of organized IEMP power in society - that is, infrastructural power in general. Whereas Mann insists that IEMP refers to the chaotic, multi-dimensional and non-systemic mix of autonomous social power, I argue that science makes social power more systemic in modern societies. Science provides the ideological 'base' upon which modern society has grown, including the extension of capitalism, national states and the so-called 'decline' of traditional authority.

\subsubsection{Gouldner's account of the ideology of technology and the emergence of the New Class}

Whereas for Mann and other modernization theorists, ideology can be associated with traditional religion, Gouldner was one of the few social theorists to recognize, on the one hand, that modern ideologies are different from traditional religious ideology, and, on the other, that social scientists fail to observe the differentia specifica of modern ideology, since social scientists are among the most radical adherents to this very ideology. The sociological myth of scientific 'value-freedom', or 'objectivity', is treated by Gouldner as 'the ideology of a working group' (Gouldner 1964: 199). Marxism and academic sociology overlap in their claim to critique ideology as a 'pseudo-science', as something that others do or have. Meanwhile, both sociological traditions limit their own reflexivity by denying this powerful social force has an influence on themselves and their 'science'. Gouldner's earliest critique of sociological value-freedom in 'Anti-Minotaur' (1964) was challenged at the time and since by critics who administered surveys to sociologists to demonstrate their left-leaning, but by no means irrational, politics; others have suggested that Gouldner was a loose cannon with ulterior political agendas (Lipset and Ladd 1972; Camic and Gross 2002). However, critics consistently fail to recognize that in a range of publications produced during the 1970s, including especially the Dark Side of the Dialectic trilogy (Gouldner 1979, 1982a, 1982b), Gouldner generalized his observations of sociologists to 
include an entirely 'New Class' of professionals and academics (Chriss 1999). That is to say: Gouldner's theory of the New Class and his analysis of sociology as ideology are components within a critical social theory of modern scientific ideology in general.

Most importantly in terms of Mann's account of the decline of ideology in the 19th century, Gouldner argued that traditional ideology has been replaced with a new ideology of technology. 'This new ideology suggests that productivity is dependent on science and technology and that society's problems are solvable on a technological basis, and with the use of educationally acquired competence' (Gouldner 1982a: 24). The new ideology was initially embodied by a relatively undifferentiated middle class during the Enlightenment, but it has now become institutionalized within the modern research university and is embodied in the New Class elite of (technocratic) professionals and (humanistic) intellectuals (Gouldner 1979).

The New Class is differentiated by occupational roles, the former often working as experts outside education, while the latter work inside primary, secondary and tertiary educational institutions. But New Class factions are unified through their capitalisation of culture derived from certificates of advanced education: cultural capital. Unlike in Bourdieu's $(1988,1996)$ analysis of cultural capital as distinct from economic capital, however, Gouldner connects the New Class to their income streams.

Culture becomes capital when it is 'capitalized' which means when incomes are set aside for those possessing culture or certain forms of it, while denying these incomes to those lacking it ... the great growth in cultural capital since [the mid-19th century] calls for a new general theory of capital, for a political economy of culture, and for a theory of a New Class as culture-privileged, and where private ownership is seen as only a special case of 'capitalism'.

(Gouldner 1979: 25-27)

Gouldner's 'cultural capital' is nearer to Bourdieu's more specific concept of 'institutionalised' cultural capital (Bourdieu 1986). In contrast to objectified cultural capital, which includes materialized media such as paintings, musical performances or other intellectual properties requiring knowledge to both produce and consume, institutionalized capital for Bourdieu consists of formally sanctioned higher educational qualifications. Higher education degrees neutralize the properties derived from embodiment in a biological individual, enabling exchange amongst official position holders. Importantly, degrees distinguish academic cultural capital from that of the autodidact, courtier or bohemia - the scientist from the amateur (see also Gieryn 1983; Lamont and Molnár 2002) Increasingly, the value of the degree comes to be decoupled from current cultural capital value and instead reflects future income and exchange value on the professional labor market. Gouldner (1979) noted that the objectification of knowledge in higher education 


\section{2}

The ideological organization of systems

credentials is necessary to secure higher incomes - indeed, this is the premise behind higher education policy emphasizing the so-called 'graduate premium' students will obtain across their life-course. However, only through the withholding or threat of withholding a capital object can the bearer extract rents. Elias makes a similar point with regard to the monopolization of violence, status and knowledge - the significance of power is manifest most often when an actor has the power to withhold, for example, wages, health, food, favour, social position, etc. (Elias 2000; Lybeck 2019b; Mennell 1998). Also like Bourdieu, Gouldner noted the importance of New Class retention of both the means of production and consumption of cultural capital. One only knows how to consume the objects following 'proper' education.

Drawing on Fisher (1906), Gouldner marks a distinction between wealth (material), property rights (to use material) and capital (value of future income). The essence of New Class capital is the capacity to secure future incomes - not productivity - though he acknowledges that higher productivity may be a by-product of professional and academic practice (cf. Collins 1979). Again, this is similar to Bourdieu's notion that, once degrees become tied to particular occupations they secure a capital value, which is decoupled from current cultural capital and, instead, reflects the value of future income (Bourdieu 1986). Likewise, as many Bourdieusians neglect, Bourdieu argued that cultural capital and 'disinterestedness' only come into being within capitalism, when economic capital presupposes a contrast between 'self-interest' and 'disinterest'. It is within this context that the elite can no longer pass down their hoards of economic capital across generations without first laundering self-interest off of the child. Only years of schooling - 'knowledge for its own sake' - can replace the economic advantages of a child with a designation of 'merit' derived from a combination of her own effort and biological capacities.

The New Class's occupational positions provide academics and knowledge professionals with special and particular interests. In the Western welfare states and the Soviet Union at the time of Gouldner's writing, this interest in cultural capital accumulation lent itself toward support for the state, which would provide expanded employment opportunities as teachers within public education and policy positions as consultants and professionals. Socialism and left-wing politics are thus connected to these interests, though they are justified according to universalistic criteria.

In addition to this economic interest, the New Class has a further stake in maximising its members' own autonomy, and thus it rejects the authority of old class bureaucrats, including those within the university and state. 'This quest for autonomy expresses a political impulse toward that self-management of work characteristic of (at least) skilled and "professional" workers seeking to control the terms, conditions and content of their work for guild reasons' (Gouldner 1979: 34). This emphasis on autonomy and self-groundedness encourages the final commonality between the technocratic and humanistic members of the New Class: the culture of critical discourse (CCD). 
A particular linguistic variant differentiates a 'New Class' of academics and professionals from other classes, including the old bourgeois capitalist class (Bernstein 1973; King and Szelenyi 2004).

The New Class's special speech variant ... stresses the importance of particular modes of justification, using especially explicit and articulate rules, rather than diffuse precedents or tacit features of the speech context. The culture of critical speech requires that validity claims be justified without reference to the speaker's societal position or authority. Here, good speech is speech that can make its own principles explicit and is oriented to conforming with them, rather than stressing context-sensitivity and context-variability. Good speech here thus has theoreticity.

(Gouldner 1979: 28)

CCD discourages justification according to external authority (including oneself). And yet, the two factions of the New Class - professionals and intellectuals - are employable because they have been dubbed as authorities possessing special knowledge and skills (cultural capital). This creates an inversion of the normative functioning of ideology in that power is now justified according to the critique of ideology, i.e., science. Whereas in traditional societies, power and particularist interests could be justified according to existing authorities - for example, the church or monarchy - in modern societies, rational-empirical science indicates the limits of validity claims according to inter-subjectively verifiable observations of reality.

Scholars in the sociology of professions have criticized Gouldner's characterization of the New Class as a unity of academics and professionals. Steve Brint, for example, has demonstrated inconsistent articulation of critical discourse and coherent political interests across the professions (Brint 1996). Rather than a unified class consciousness, professionals and academics closer to the public sector manifest the qualities Gouldner noted, while those employed in the private sector adopt different patterns of discourse and expertise. Similarly, Marxist sociologists follow Maurice Zeitlin in declaring the separation of ownership and management a 'pseudo-fact', evidenced by the retention of familial control in banking and interlocking directorships (Domhoff 2010; King and Szelenyi 2004; Zeitlin 1974, 1989). Each of these criticisms, however, ignores Gouldner's argument denoting the New Class a possibility, not an actuality. It is most important to observe the underlying long-term trend:

Is the New Class now the ruling class? Certainly not. Will the New Class someday become the ruling class? Conceivably. If they are on their way to rule, what is taking them so long about it? But why assume it is taking them 'long'? How long did it take the old class to come into power? It had been emerging with urbanization and the waning of the 'spiritual' power since perhaps the fourteenth century.

(Gouldner 1979: 15) 


\section{The ideological organization of systems}

Gouldner identified a 'cultural lag' between the interests and political preoccupations of students on the New Left and the mainstream sociological paradigm of structural-functionalism - this is 'the crisis'. Second, as discussed in Chapter 2, he described the origins of sociology not in Parsons, but in relation to the class conflicts of Restoration France, during which Comtean positivism aggregated the dissatisfactions of a 'declassed nobility' with an ascendant class of engineers enrolled at the polytechnics.

Both the cultural lag in 1968 and the aspirations of the declassed nobility and engineers exhibit his essential motivational mechanism - 'blocked ascendance':

Relative to the old class and men of moneyed property, the New Class of intellectuals and intelligentsia are in general blocked ascendents. Being relatively well educated, the New Class has by that fact alone already begun its upward mobility. ... Blocked ascendance produces an increase in the political activity of the New Class and in open acts of confrontation with authority.

(Gouldner 1979: 63)

As blocked ascendents, the New Class resists economic and political limits to their ascent into higher positions of social prestige - in Shils's terminology, blocked movement toward the centre. Durable blockage contributes to alienation, which may manifest outright protest unless channelled discursively and institutionally. For example, a New Class actor might make trade-offs - balancing income against autonomy and critical culture - thereby exhibiting some of the differential observed by Brint: higher-paid, less-critical consultants versus lowerpaid, more-critical public school teachers. ${ }^{1}$ Blocked ascendance might manifest protest, or it might take the discursive form of 'objectivity' or value-neutrality. 'Non-normative' scholars detach from society to observe social values from the outside. However, this non-ideological commitment is a political choice, which academic social science has made into a profession.

Deriving their own authority from self-grounded justifications, the New Class's grievances tend to become generalized - often by adopting the standpoint of a similarly blocked or dominated group. This explains the declassed old regime's articulation with the ascendant polytechnicians or the case of Marxist vanguards drawn from the bourgeois middle class, who were often doubly-blocked Jewish youths (see Alexander 2008: 486-88). Mann, for example, analysed the background of the Bolshevik party committees in 1917,

Of the sixty-one whose parental backgrounds are known, only nineteen were worker or peasant ... They were the intelligentsia attracted to general ideologies, but more dropped out of university or technical institute than graduated. ... they were also disproportionately Jewish or from Russia's ethnic minorities. 
This articulates precisely with Marx's own background, recently retrieved by Jonathan Sperber: a German-Jewish student whose father and supervisor suddenly died, necessitating Marx's disenrollment, after which his abstract Epicurean philosophizing shifts toward economic emancipation from compulsory wage labor (Sperber 2013). Not wanting to work in a factory for a low wage, these ex-students translated their own grievances and alienation into the working class in general. Denoting this lower class as the 'universal subject', these middle-class intellectuals thereby denied their own subjectivity within the historical process (Gouldner 1982b; Lukács 1971). In this way, the interests of the New Class are externalized from themselves and self-grounded in the 'reality' of their objects or 'cases'.

Since the radical 1960s until now, especially following the feminist transposition of standpoint from the working class to women (Harding 2004), a plurality of 'oppressed' social objects - every intersectional identity from transgender to migrant 'precariat' (Standing 2011) - can be identified to disguise middle-class students and academics from themselves. This does not mean the oppression and injustices identified in conferences and student meetings are not real - but, the function of the infinite 'panels', 'symposia', lectures and film series on such topics is not primarily to help ameliorate these injustices. Rather, by pretending to 'act' politically by giving talks to a few comrades based on textbook understandings of 'neoliberalism' or 'gender trouble', critical scholars disguise their own alienation from the power complex they have consciously and actively resisted integration with. At the same time, by 'giving voice' to the wretched of the earth, (often) white, middle-class academics justify their own elitism with respect to their most immediate neighbours, stepping over homeless on their way to the demo to free Palestine.

For, regardless of the moral worth of these causes, none changes the reality that, within the academization process, historical evolution from feudal hierarchical distinctions toward alternative systems of official titling established the distributive control of ranks within higher education institutions. This control of qualifications within the university contributes to a functionally differentiated society which is still compatible with hierarchical power at the core. The university is where ideology is authoritatively organized via the arts and sciences. Gouldner writes:

The university today is the key modern institution for the training of ideologues: it is also that single institution from which most modern ideologues derive their livings. Indeed, the university today is the single largest producer both of technocrats and ideologues, of both science and ideology.

(Gouldner 1982a: 185)

This authoritative organization of ideology is all the more important to the extent that culturally- and legally-recognized certificates of cognitive competence now provide the narrow bridges of access to positions of power. Through higher 
education institutions, experts gain officially sanctioned status and knowledge distinctions that enable them to convert different types of capital across different system boundaries.

Unlike Mann, Gouldner recognized with considerable specificity the long historical emergence of a New Class in the 19th and 20th centuries, of which post-war sociologists were a particularly representative case. This class is not identical to any old class - neither capitalists, laborers, nor old-line bureaucrats - and analysis of their role in modern society and their ideological organization requires novel consideration of (a) their ability to capitalize on cultural competence objectified within higher education credentials, (b) their political interest in maximizing autonomy and (c) their linguistic modes of justification requiring the self-groundedness of authoritative claims. As will become clear below, the ability to ground authority objectively within 'science' becomes of the utmost importance for the functional organization of this New Class ideology.

\subsubsection{Ideology as intellectualization}

Before considering the particularities of this organization of ideology within the modern research university, I first outline a more broad - that is, general theory of ideology which provides the conditions of observing and redescribing scientific ideology 'from the outside'. This general theory of ideology considers the distinguishing element of ideologies, contrasted against practices and fragmentary ideals, in that ideologies are intellectualized.

Modern ideologies can be differentiated from beliefs, in general, through their conscious reference to empirical reality and their aggregation into collective self-consciousness (and systemic unconsciousness) (Shils 1982). As Gouldner notes,

Ideology makes a diagnosis of the social world and claims that it is true. It alleges an accurate picture of society and claims (or implies) that its political policies are grounded in that picture. To that extent, ideology is a very special sort of rational discourse by reason of its world-referring claims. It defends its policies neither by traditionalistic legitimation nor by invoking faith or revelation.

(Gouldner 1982a: 31)

Ideologies are thus coeval with social theories which begin with assertions of what the world is, what the world should be and an established connection between theory and practice. Thus, in principle, ideologies are rational intellectual constructions.

This notion of ideologies as intellectual constructions homologous to social theories does not originate with Gouldner, but, indeed, with Parsons himself (drawing on Pareto), who recognized that theories are ideologies (Parsons 1937: 178-293; Pareto 2003). In explicating the nature of ideology within The 
Social System (not coincidentally with reference to the institutionalization of science in modern societies), Parsons wrote:

Where the primary reference is empirical we may speak of ideology. The only difficulty with this term is that it refers primarily to the belief system shared by the members of a collectivity ... when the individual actor is the point of reference we shall try to avoid this difficulty by speaking of a 'personal ideology'. Finally, when the primary reference is non-empirical we may ... speak of religious ideas, as distinguished from philosophical. According to this view, then, there is a fundamental symmetry in the relations, on the one hand, of science and ideology, on the other of philosophy and religious ideas.

(Parsons 1951: 331-32)

Here Parsons distinguishes between the personal ideology of the individual within the action frame of reference, and that of the ideology of a collectivity. He provides a helpful way of relating each to 'rationalization' in the Freudian psychological sense - ideologies are the collective version of personal psychic rationalization - that is, the collective organization and avoidance of internal contradiction. Internally, ideologies provide collective identity while projecting contradictory particulars externally, producing both the collective conscience and the collective unconscious. Ideologies establish a relative unity in the field of collective representations of the world. Ideologies are ideals which have been thought through - at least, in part - especially in terms of internal logical consistency, consistent use of terminology and meaningful connections between the general and the particular. It is this intellectualized feature which gives ideologies salience in everyday life, discursive engagement and political mobilization.

In Parsons's view, social science - particularly systematic, theoreticallygrounded social science - provides the possibility to see beyond these collective blinkers to a more objective empirical reality. In contrast, I argue that ideology is inescapable. Humans cannot avoid some means through which contingent experiences can become integrated into a broader narrative constituting one's life. Socially, ideologies become salient when they are organized into coherent sets of common assumptions which connect individuals to primary and secondary groups. Ideologies therefore have both a social and personal function, being one of the core means through which the social and the individual co-construct one another.

Of course, ideologies may lack the formal methodological rigour of the scientific method, but this suggests only that ideologies obtain at a lower order of intellectualization, rather than that they lack systemically structured knowledge. Because ideologies are often more connected to political practices, morals and values, the overall logical consistency among assumptions is less important than in scientific practice. 'It is by the nature of the case that empirical elements should be combined with and shade off into non-empirical 


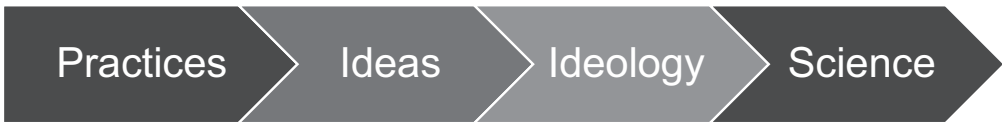

Figure 3.2 Ideology: General and special.

elements at the points where justification of the ultimate goals and values of collective action become involved' (Parsons 1951: 350).

And yet, once intellectualization becomes the criterion upon which ideologies are defined, the argument naturally unfolds to cover science as the most ideological of all, as represented in Figure 3.2.

Here, a general ideological scale increases across all categories, with 'more' present as a fragmentary idea pops into mind, relative to routine, habitualised practices and behaviour. Ever more 'ideology' obtains when these ideals become organized in terms of existing or new categories; that is, when they become organized within a system. At the individual level, this integration may be entirely idiosyncratic and eclectic. The ideologue need not be consistent. However, when aggregated to the level of social systems - as a social fund of knowledge - ideologies have form and some degree of logical consistency. These ideologies then form the structural basis of an 'idolum', worldview or cultural environment, which individuals and societies confront and integrate into themselves (Mumford 1973).

From this point of view, there is no necessity that a higher ideological level exists above ideology; that is, science. Accordingly, as Elias noted, religion and magic are more than sufficient as a means of orientation - that is, as organized 'knowledge'. However, by encouraging practices and methods that allow the coordinated discussion, evaluation and integration of novel findings, science encourages greater systematicity for those ideals which would otherwise remain particularistic. Science can be interpreted as a cognitive technique that allows complex external environments to become simplified through the marking of factual distinctions and self-reference. The operative advantage of science is that it establishes rules and techniques which extend the intellectual coherence of the social system.

Science generalizes and universalizes claims while also establishing cognitive maps through which exceptions can be explained. Of course, science does not achieve this ideal in practice - that is, by definition, no fundamental 'Truth' can be established for all times and places. What are secured, however, are common assumptions that can remain 'given', providing stability for further statements (Kuhn 1962). Highlighting this quality of science does not undermine, for example, the validity of the physical laws of the known universe. Science here is both science and ideology. Scientific theories and ideologies, defined by their relative intellectualization, both establish 'simplifications that work', which aggregate fragmented ideals into coherent, socially-recognizable systems of 
thought (Luhmann 2002; see also Pareto 2003). As Niklas Luhmann argued, 'scientific theories and technologies, converge in their use of simplifications that is, simplifications in the sense of disregarding other things whose reality remains undisputed' (Luhmann 2002: 70).

On the one hand, the institutionalization of scientific ideology has enabled the proliferation of technologies and the emergence of the 'knowledge-based economy', a 'strong-anticipatory' system, dually layered as a network of institutional relations and a complex of differentiated functions (Leydesdorff 2006). On the other hand, systematic ignorance of that which is left outside the science system organized around the code 'truth/untruth' - produces what Luhmann (1998) called an 'ecology of ignorance'. In other words - and this is a central paradox in the academization process that expands access to higher education (Trow 1972) the more 'science' that is produced, the more ignorance is produced amongst the population, who become less and less capable of accessing these highly specialized forms of knowledge. Science, however, is self-referenced as 'truth', while 'untruth' occurs somewhere else, outside the indexically defined system. When these truth/untruth distinctions become durable and integrated within broad systems of power - via elite socialization, instrumental rationality and self-grounded public discourse - they function as elements within an ideological system. A functionally-differentiated society maintains the hierarchical basis upon which cultural capitalization can occur by securing authoritative control of these distinctions and justifications in educational institutions, 'a dense-infrastructure at whose centre there is the Western university' (Gouldner 1979: 57).

\subsection{Distinctions and justifications}

Niklas Luhmann's (1995b) non-essentialist systems theory will be related directly to Gouldner's understanding of scientific ideology as a set of distinctions. To review what has been uncovered above, I follow Mann in arguing that ideologies must be organized within institutions to obtain social power. Here, the research university is identified as the central institution in this modern mode of ideological organization. In particular, the university provides a complex system of distinctions and justifications that is both highly adaptive and highly conservative. However, since Luhmann's systems approach is often misinterpreted as a form of systems essentialism, rather than an epistemological orientation to sociologically meaningful information organized through reference to observing observers, I will briefly review some of Luhmann's theoretical assumptions before supplementing the systems frame of reference with an elite theory of ideology which reconnects with Parsons's and Gouldner's analysis of the university and the New Class.

\subsubsection{Luhmann's theory of autopoietic systems}

Though rarely used by many English-speaking sociologists, who find his sociology too abstract, an advantage in Luhmann's systems approach is that 
he does not assume a priori that actors have agency within communicative systems. That is an empirical question. In the case of sociological discourse, actors are certainly held 'constant' - analytically at least - so we can observe the latent 'structures' occurring out of sight behind their backs. 'Action' is an attribution psychically necessary for 'individuals' contained within an identifiable body. But, social communication has no such identity; it is decentred. It is, therefore, a fallacy for sociologists to assert that all social organization must be reducible to actors. This basic humanist assumption, common to the majority of social research, amounts to saying that computers make no calculations on Wall Street. That does not mean that society has not been organized by humans, or that humans are not relatively autonomous participants in history. More often than not, however, social systems are intentionally organized to make actors the 'environment' of a situation. Social systems seek to reduce the impact and input (i.e., agency) of humans. Hence, treating humans as interchangeable, average units - homo economicus, or similar often proves most efficient in managing the majority of social action, reserving mitigating efforts for exceptions and outliers.

Accordingly, we can begin by agreeing with Luhmann's very simple ontology: 'There are systems'. There are natural systems, and there are social systems. Often Luhmann is misunderstood in Anglophone sociology as having suggested that social systems are organized in the same way as natural systems, in part, because of his emphasis on the notion of autopoiesis (self-organization). The notion of autopoietic systems was initially derived by biologists Humberto Maturana and Francisco Varela, who observed that the input/output model within traditional cellular biology did not capture the synchronic elements of self-organizing systems (Seidl and Schoeneborn 2010). For example, an antibody is often represented in biological science as 'coming in' to attack pathogens that have wrongfully entered a system. But without pathogens there would be no antibodies. The existence of one implies the other, and the two emerge together, like Hegel's 'Master/Slave'. And yet, though he was inspired by Maturana and Varela's biological systems theory, Luhmann explicitly argued that psychic systems and social systems are uniquely organized around meaning. 'Whereas biological systems can provide meaning to information, they cannot exchange the meanings thus generated among themselves because they cannot be expected to develop meaning into codified meaning or discursive knowledge that can be exchanged' (Leydesdorff 2006: 133).

Meaningful communications are organized along three dimensions: factual, temporal and social (normative), none of which can appear in isolation from the other. Each correspond to a type of generalization upon which expectations are grounded: generalization over time (zeitlich), generalization over a plurality of objects (sachlich) and generalization over a plurality of subjects (sozial) (Luhmann 1982: xiv).

In order to constitute structures, expectations about behaviour must acquire lasting validity, such as will persist even when such expectations 
are not verified in individual cases. Here he who sticks to the expectations in spite of such disappointments is safe from blame. This contra-factual stabilisation of expectations is the function of normative experience. Furthermore the expectations about behaviour must be arranged into roles which are sachlich consistent, that is, which remain practically performable in the face of changes in the situation ... And finally, expectations about behaviour must to some extent become institutionalized, and thus made the object of consensus.

(Luhmann 1974: 42-43)

By recognizing social systems as fundamentally contingent systems of meaning, which must constantly reproduce the structural elements and relations of themselves, Luhmann provides us with a model of both structure and structural change. Strictly speaking a 'system', which is composed of events, cannot change, but systems are often identified with their most durable elements, namely structures, which do change (Luhmann 1995b: 278-356). We can note here that this ontology is remarkably similar to Abbott's processual metaphysics wherein 'all is change', and it is stability that needs to be explained (Abbott 2016). Although social science has tended to emphasize teleological or motivated changes, these are, in fact, especially rare compared to the more common morphogenetic adaptations which build new structures on top of existing system structures (see also Archer 1995). Indeed, only when modern techniques of organization were developed to control expectations through planning have social systems developed the capacity to increase complexity through the intentional contraction of the time it takes to switch to a new structure.

This achievement occurs through functional differentiation, that is, the generation of complexity and redundancy, which increases the possibility of successful structural selections. According to Merton (1957), functions do not derive from the needs of the entire system in its totality. Rather, functions are most noticeable locally when they begin to break down, generating a form of cognitive dissonance among actors and institutions. Manifest (conscious) functions, therefore, should not be ignored, as they reflect the motivated actions that produce social structure much of the time (see also Martin 2011; Reed 2011). Latent functions, on the other hand, could be potentially infinite in number, and they are impossible to know or observe with certainty. Functions are not necessarily 'there', but, like hierarchy, the term provides unity on the level of observations (first and second order). Luhmann suggested that functional integration works due to the creation of redundancy, allowing different courses of action to become functionally equivalent (Luhmann 1995b: 299). Greater complexity increases the likelihood that specialized functions will find a structural home, while orientation toward function offers a certain amount of security against failures of performance.

The significance of complexity and functional differentiation relates to the university, as the autonomy of science has allowed this differentiation of 
functions to occur both internally and externally. In the process of university expansion and integration with society, which has ensured increasing selectivity among redundant structures and discourses, the institution has also provided stability to the capitalist system and the nation state. In other words, ideological power systems (organized knowledge) add to the collective power of all modern systems of social power. By providing the conditions for the autonomous reproduction of complexity, universities, in particular, allow disciplines and professions to become 'closed systems' - what Elias called 'scientific establishments' or monopolies (Elias et al. 1982). Operational closure lets a subsystem relate to its environment on its own terms.

Social systems are organized around distinctions between system/environment, denoting marked versus unmarked sides of meaningful communication. This allows the possibility of self-reference by indicating what is included and what is excluded from a system. This is an essentially invisible semiotic - like a one-way mirror pressed against another one-way mirror - allowing the system to reduce the complexity of the relationship between itself (internal-reference) and its environment (external-reference). This communicative device makes it possible for social systems to become closed through their very openness. By organizing the way external communication enters itself, a system can maintain its own identity relative to its environment, which may operate according to a different set of communicative codes. The system can become more complex internally by reducing the complexity of that which is deemed outside it. This achievement is for itself. The environment is not actually de-complexified, but the system can now control how it itself reacts to any number of external stimuli and irritations.

Luhmann's epistemology intentionally moves received distinctions around to create novel analytic systems to observe real systems differently. So, for example, the traditional operation of the economic system via a coded distinction between 'payment/non-payment' can be distinguished by separating it analytically from the political system, which is coded in terms of 'government/opposition'. On the one hand this is a distortion, because the economic and political systems clearly interpenetrate one another synchronically in capitalist societies. But it is not abstraction for its own sake, nor is it ungrounded in reality.

Correspondences between concept and reality can be drawn point for point: for example, between the concept of meaning and the phenomenon of meaning ... The decisive fact is, however, that, in forming systems, science goes beyond such point-for-point correspondences. It does not restrict itself to copying, imitating, reflecting, representing. Instead, it organizes experiences of difference, and with them the acquisition of information, and it develops a complexity of its own adequate to do so. In the process, a reference to reality must, on the one hand be safeguarded. On the other, however, science, especially sociology, should not allow itself to be duped by reality. Viewed in this way, abstraction is an epistemological necessity.

(Luhmann 1995b: li) 
Sociology, for example, is always a subsystem within a subsystem (science), and it is organized according to the binary logics of the latter - not because this logic is necessary (or logical!), but because contingent historical developments have produced the relative autonomy of these systems through their self-organization around the code 'truth/untruth'. The system's operation is the 'de-paradoxicalization' of the code, which must be ignored on the first order to become functional (Luhmann 1988a). By reducing complexity with respect to its environment - that is, other disciplines, discourses and social systems - sociology is able to generate more complex internal rhetorics which become relatively autonomous from society itself (Lybeck 2019a). This mediation - this distortion - must be re-theorised through abstraction to recover the actual systemic operation around the binary code, rather than through motivated action on one side or the other of said code. This is not easy, because we are involved and embedded in the systems we seek to understand. In order to see the way the system works, we need to reorganize our received distinctions to see things - to see ourselves - from the outside.

\subsubsection{Bringing (elite) actors back in}

While Luhmann's systems epistemology provides a significantly improved theoretical basis for understanding the way real, powerful and autonomous systems actually work, it does not provide a direct means through which motivated human agency can be brought back into historical analysis. Thus, using Reed's terminology, Luhmann provides us with no access to the performative level of events (see Figure 1.1). This is especially important for historical analysis, as Weber's methodological individualism effectively demonstrated (Aron 1998). Without taking into account the motivations of actors at some point, it becomes difficult to ground the contingent development of system structure in history. Luhmannians end up speaking in pure abstractions, reproducing in our practices the operational closure we thought we had overcome. On the one hand, systems' autonomous self-reproduction should be accounted for; on the other hand, actors do have some agency, even if systems tend be structured in ways which reduce the capacity of actors to change them. The processual approach to this problem is to temporalize this issue as being one of analytic scale. A more common, simplistic way of 'solving' this problem was to deal with agency through reference to differential access to 'resources' (Giddens 1979) - that is, structures are hierarchies of power that are contexts for agency, which in turn reproduce the structures. Yet, this structuration approach - like the related, and equally anthropocentric, 'practice' approach (Knorr-Cetina et al. 2000; Turner 1994) - explicitly rejects the possibility of functional analysis; in other words, these actor/agent-centred theories compel the analyst to avoid study of the very ways in which complex systems ensure their continued self-reproduction and adaptation as systems.

If we return to the essential concepts - self-reference and self-observation we can observe that a 'psychic system' (a human mind) might also mark a 
distinction between one's self and one's environment. The environment might be another person, one's family, the capitalist mode of production, a political party or whatever. These two references allow one the capacity to control one's own identity relative to the environment through narratives (see also White 2008). The environment comes to exist for us: our particular self. Stories, as organized memories, tell us whether we identify with the environment to a lesser or greater degree. The narrative makes it possible to synthesize any number of events by connecting them across time as part of the same external identity. This simplification provides the internally referenced 'self' more room for complexity as it is able to establish links to other environments, for example, other people sharing similar narratives and expectations.

While the analogy is reduced here to an identifiable human being to provide a helpful example, one must recognize that social systems are not reducible to human actors and can exist independently of them. The actor is an element within a social system, which consists of elements and relations. These systems, in turn, exist as elements within other social systems. They are fractals (see also Abbott 2001a). Furthermore, the principle of 'double-contingency' indicates that the system does not consist of an ego adapting to an alter and a system, but, rather, there are always two or more actors doing this at the same time (Luhmann 1995b; Parsons 1937). The system is the emergent stability that human actors are habitualised to accomplish extremely quickly, if not synchronically. There is no moment in which there is an actor entering a system. The system and the actor emerge together. Furthermore, it is entirely conceivable that actors are actually participating in different systems with different sets of norms at the same time. For example, a lawyer might be on his cell phone with a client while checking out groceries, thereby participating in the legal system and the economic system at the same time. His communications, not the man as an embodied individual, enter both systems, which are organized around unique sets of distinctions: 'payment/non-payment' in the case of the economy and 'legal/illegal' in the case of law (Moeller 2006).

But the major significance of Luhmann's systems epistemology - often overlooked - is that the whole operation changes in modernity because of writing. Writing allows social interactions, and therefore social systems, to emerge without face-to-face interaction. An interaction between author and critic occurs when the critic opens a text. All elements in the system (ego, alter, situation, etc.) become changed in the process of this type of emergence, and yet the author may have never met the reader, who may or may not know the context in which the communication was written. 'Writing makes it possible to store communication, independent of the living memory of the interactive partners, indeed even independent of the interaction' (Luhmann 1995b: 87). The achievement of writing within genres with particular styles, structures and objects of discourse allows social systems to emerge virtually within human minds so they can persist across time and space. No actor can appeal to these systems without re-engineering their thoughts into the communicative form. 
In a non-literate society, actors could be reflexive and incursive within social systems. With the advent of mechanically-produced mass communication, humans and social systems become reflexive and incursive. By encouraging the differentiation of coded-information, modern societies have initiated a partially automatic production of communication so that social systems not only can, but do, interact behind the backs of human agents. A human does not have to look at, or execute, a computer code for it to act on her behalf.

The mental image of an agent, or group of agents, in control of society is an old-fashioned image recalling hierarchy, religious tradition and discreet classes. But this applied to an era of minimal societal control - a 'weakanticipatory' system (Leydesdorff 2006). As Mann so effectively demonstrated, early modern monarchs lacked 'infrastructural power' (Mann 1986). This power came with new organizational forms, especially nation states and industrial capitalism: the so-called 'dual revolution' of bourgeois politics and economics (Giddens 1985; Hobsbawm 1969). But, Gouldner and Parsons suggested there was a third revolution, a more general iteration of the university revolution discussed in Chapter 1, which was not observed at the time of its emergence because it was the position from which the other two revolutions were observed: the communications revolution (Gouldner 1982a; Parsons and Platt 1974). 'The communications revolution was the revolution that was not only the seen-but-unnoticed revolution, it was a revolution in seeing that took time to see' (Gouldner 1982a: 195). The change which took place with the emergence of public communication, written to influence 'generalized others' within modern societies, was the fount from which ideologies sprung (see also Mead 1964; Silva 2008).

Luhmann indicated that this change, which defines modernity tout court, amounted to an overall movement toward second-order observation within every social system; so that science is now observed through publication counts, art through observations of form rather than content, politics through public opinion polls, economics through market prices and so forth (Luhmann 1998). Observations on the first order use distinctions, but do not establish contingency for the observer's relative standpoint (Luhmann 1993a). Observations on the second order produce a sharp reduction in the complexity of the world of possible observations, which, paradoxically, also means the generation of more complexity and more possibilities. 'Observations of the second order are the operative basis for the structural differentiation of certain social functions systems' (Luhmann 1998: 57). The advent of coded communication provided the opportunity to functionally differentiate tasks to develop a strong-anticipatory system (Leydesdorff 2006). In a functionally differentiated system of communication sorted according to discrete codes relevant to particular systems - e.g., economy, state, medicine and so on - relevant tasks can be handled within organized sectors, each with their own internal complexity. The interactions between the subsystems could be anticipated at the level of subsystems themselves without ever having to reach those 'actors' ostensibly perched at the top of the societal pyramid (see also Martin 2009). 
And yet, the way this modern system is organized does indicate that certain actors remain positioned in more 'powerful' positions. That is, regardless of the functional organization of autonomous systems according to differentiated logics, some actors (or psychic systems, if you will) are better able to understand and act in relation to these logics (see also Mouzelis 2008; Etzioni 1968). Certain actors are able to see organizations as organizations - that is, on the second order - and these actors sometimes embed powerful institutions with rules and structures intentionally. Actors must learn to become agents within such a world. Some, like the lawyer in the grocery store, are qualified and empowered to participate in more than one system. These actors are able to convert their positions across systems boundaries, and, indeed, elites straddling different systems are the typical agents who recalibrate dis-equilibrated systems intentionally in their interest, as can be observed particularly in times of crisis (Padgett and Powell 2012). It is precisely actors' knowledge of the system which allows them to envision it as a structure and, accordingly, to (self)-organize it to their liking. In other words, while Luhmann's statement 'there are systems' is true - there are also elites.

Once we ground our analysis in systems as well as elites, two observations come into view. First, the systems' bias toward observing power as a primarily 'collective' form of power in Mann's sense can be replaced by reintroducing distributive power. Recall the definition of the collective mode of power $(\mathrm{A}+\mathrm{B}$ over $\mathrm{C}$ ) originated in Parsons's systems-analytical critique of $\mathrm{C}$. Wright Mills's zero-sum account of the power elite (Parsons 1957; Mills 1999). Similarly, Luhmann emphasized the way in which expectations of power differentials condition the possibilities of decisions and actions for both the weaker and stronger party, and therefore "power increases with freedom on both sides, and, for example, in any given society increases in proportion to the alternatives it creates' (Luhmann 1982: 113). Furthermore, contrasting himself explicitly against Gouldner's 'norms of reciprocity' (1960), Luhmann reminds the sociologist that, while brutal, violent, hierarchical control still exists, the vast majority of power relations in modern society have been channelled into legal rational practices; just as Mann says, 'political force is evoked as a ritualized, machine-like, rule-governed and nonviolent constraint' (Mann 2012a: 13).

In contrast, recognition of elites capable of transcending system boundaries reminds us of the historical persistence of traditional, distributive patterns of hierarchy (Mayer 1981). While these hierarchies may be 'decentred' within a functionally differentiated totality or more dependent on status rather than class or party (Shils 1982), there are nonetheless durable hierarchical elite structures which self-reproduce their constitutive elements in modern society namely, through higher education institutions (Bourdieu 1996).

Secondly, the reintroduction of power elites into systems analysis re-establishes the possibility of ideological analysis - a programme Luhmann aggressively resisted due to his conflict with Habermas and the Frankfurt School 'critique of ideology', which he argued 'failed to link up to normal research' 
(Luhmann 2002: 71; 187-93; Habermas and Luhmann 1990; Alexander 1984). Specifically, what I have in mind is an analysis of ideology which is not immediately normatively oriented (and thereby limited), but rather grounds modern ideological systems within dominant classes of people. Such an approach is, in fact, contrary to many sociological theories of ideology, which emphasize the false consciousness of culturally duped and subordinate masses.

Instead, following Abercrombie and Turner (1978), my theoretical orientation indicates that the most important ideological system in terms of the macro-organization of social power is the ideological organization of dominant elites. 'In fact it is typically the case that subordinate classes do not believe (share, accept) the dominant ideology which has far more significance for the integration and control of the dominant class itself' (Abercrombie and Turner 1978: 153). Christianity in the Middle Ages, for example, was not effective because it duped the masses, but rather because it regulated the norms between state elites. In this sense, the ideological consciousness of subordinated classes becomes relatively insignificant within a research question seeking to understand the integration of ideology within large structures of power (with, of course, the significant exception of powerful and conscious social movements from below). If complex social systems have developed to the point where such agency from below is effectively neutralized, then it is all the more important to locate ideological power where relative autonomy continues to obtain - that is, among elites with decision-making, non-decision making and ideological power (Lukes 2004).

\subsubsection{Universities, distinctions and justifications}

Second-order discourses covering the fields of economics, politics and culture that is, economic science, political science, humanistic scholarship and so forth enable increased autonomy for those New Class elites claiming jurisdiction over these discourses, and, concomitantly, the actual autonomy of these differentiated systems from one other. However, as economics, politics and culture become more autonomous, they paradoxically become more dependent and interrelated - that is, interdependent, as Elias reminds us. This is most visible today within the knowledge-based economy, defined by Etzkowitz and Leydesdorff (1996) as the 'triple-helix' or government-university-industry complex. This model of a self-organized system of innovation highlights a dual-layer of institutions and functions shaping the expectations and behaviour of the three subsystems economy, science and state - which respectively manage the functions of (a) wealth generation, (b) novelty generation and (c) control of a and b locally for the retention and reproduction of the system as a whole (Leydesdorff 2006: 43).

The Luhmannian triple-helix model captures the increased complexity within these interactions between state, market and academy, noting that covariations in each have been stabilised through durable selection mechanisms in a process of 'mutual shaping', or co-evolution (Leydesdorff 2006: 45). 
Scientific innovation is an 'incursive' process through which novelty is produced automatically as an end in itself (see also Berman 2011). Meanwhile, selection from the market, government or scientific discourses reflects a recursive operation, which enables the possibility of 'anticipation' within the incursive system.

The observable units of analysis can be considered as footprints of the communications that have served us hitherto. The organization of communications develops along trajectories that have been institutionalized and codified for historical reasons. Institutionalization and stabilization are historically observable, whereas codification can be considered as providing meaning to some meanings but not to others. Therefore, the latter operation is part of an incursive process of cultural evolution.

(Leydesdorff 2006: 72)

The triple-helix thus provides a highly adaptable, yet ultimately conservative system of incursive innovation within relatively stable expectations relating to selection. In other words, despite the triple-helix's insatiable appetite for novelty, no one expects system failure (as evident, for example, in the failure of economists to predict the 2008 financial crisis) (Galbraith 2010; Harvey 2010). Furthermore, since the stabilisation occurs on the secondorder, history itself can be rewritten after the fact from the perspective of hindsight and new socially constructed codifications (see also Fuchs 2005). Thus, actual system failure can be literally written out of the picture as a basis of future expectations.

Here the temporal dimensions of meaningful communication become particularly visible. Since systems are identified with their most durable elements (structures), stabilisation of what these structures are - e.g., capitalism, the ecological environment, globalization, Nature, etc. - become established within second-order codifications so that the future can be managed (or resisted). The most durable common reference point for social systems is 'Nature', whose physical laws appear stable across billions of years (see also Elias 1987a).

One way to establish expectations that are relatively fixed over time is to relate them to something that is not itself an event, that is, cannot in the strict sense itself be expected. One can project identities onto which one can attach expectations, and expectations can be factually ordered by ascription to things that remain identical. One thereby establishes connections and distinctions.

(Luhmann 1995b: 313)

A distinction, a reference, is made in a situation to those things which are expected to be there as given - those things that have always been there, that have the least risk of becoming something else. In the final analysis, these 
temporal distinctions become grounded and organized within histories, especially linear narratives.

To return to Luhmann's conception of communication: meaning can be analytically broken down into three dimensions: factual, temporal and normative (Luhmann 1995b: 86). Distinctions are made within the province of the factual dimension, while normative values establish which distinctions are most appropriate, as in, which distinctions are 'right' or 'wrong', 'good' or 'bad' within a particular situation. Without a reduction of possible distinctions according to valuations of relevance, science and, indeed, knowledge and communication themselves would become impossible.

However, I argue here that, when organized into systems of social power, these factual and normative dimensions become durable distinctions and justifications. Distinctions include demarcations along the factual dimension of meaning, including reified status distinctions (Bourdieu 1984). Justifications are durable, organized norms that establish social legitimacy, and they are most important for elites themselves. Actors and institutions relate themselves to these distinctions and justifications, which are grounded in some variant of history and which provide narratives upon which identities can be temporarily stabilised or disrupted. Knowledge of the historical past, in turn, enables the delimitation of expectations for the future without which social action would be impossible.

Again, to highlight the specificity of organized ideology versus partially conscious ideas and practices, I reframe Luhmann's factual, temporal and normative dimensions of meaning in terms of the organization of (a) distinctions, (b) history and (c) justifications, as illustrated in Figure 3.3. Thus, ideology at the systems level can be defined as: meaningful combinations of socially-recognized distinctions and justifications.

Recalling Gouldner's definition of the culture of critical discourse (CCD), the New Class's linguistic variant emphasizes a particular modality of justification - one which does not recognize the speaker's authority and strives to be self-grounded. Communication in modern societies should ideally have

\begin{tabular}{|ccc|}
\hline $\begin{array}{c}\text { Generally } \\
\text { (Luhmann) }\end{array}$ & $\begin{array}{c}\text { When } \\
\text { Organised } \\
\text { (Lybeck) }\end{array}$ \\
\hline Factual & I & Distinctions \\
Temporal & I & History \\
Normative & I & Justifications \\
\hline
\end{tabular}

Figure 3.3 Dimensions of meaning.

Source: Luhmann 1995b. 
reasons; they should, in principle, be justifiable (see also Habermas 1981, 1971). In other words, communication should exhibit some level of theoreticity. Again, this is not an abstraction, but it is reflective of the historical institutionalization of the revolution in communication and education - that is, the historically unique system of 'public education'.

This system is characterized by the fact that (a) it is education away from the home and thus away from close parental supervision; (b) it is education mediated by a special group of New Class, 'teachers', whose role invites them to take the standpoint of the collectivity as a whole, and who train students to believe that the value of their discourse does not depend upon their differing class origins, that it is not the speaker but the speech that is to be attended; (c) All public schools, therefore, are schools for a linguistic conversion, moving their charges away from the ordinary languages of their everyday lives and moving them toward the CCD.

(Gouldner 1979: 44)

Educational institutions are thus ideological conversion vehicles through which the scientific modality of distinction and justification is learned (see also Bernstein 1973). Relating these observations to Mann's IEMP model, schools are the institution through which the modern ideology of technology is organized and obtains social power. Universities are the epicentre of this ideological system, including the elite perches within university systems - now hierarchically ranked according to second-order metrics counting research publications (Geiger 1985).

In their new institutionalist 'macro-phenomenological' analysis of an emergent world society, Meyer and Bromley recently argued that 'schooled individuals' invest organizations with certain rationalized features, including attribution of sovereignty, autonomy and boundedness (Meyer and Bromley 2013). All the while, these organizations are increasingly dependent on external environments, becoming sprawling structures reflecting inconsistent agendas. Though Mann has argued that Meyer's 'world society' perspective is unspecific regarding the institutional locus of this new form of ideological power (Mann 2012b: 7), this is simply not the case: the unprecedented expansion of higher education has produced discourses of 'scientization' and human rights and empowerment discourses, which contribute to an overall increase in organization in general (Frank and Meyer 2007; Meyer 1977; Meyer et al. 2007; Schofer and Meyer 2005).

The expansion of higher education is sociospatially transcendent insofar as it affects all forms of IEMP power, increasing collective power. As immanent morale, existing distributive power structures are reinforced by converting other sources of ideological power into institutionalized ideologies and rationalized procedures. Subaltern ideological agendas become organized in the spaces between existing dominant institutions (Eyal 2012). In their very self-description, as 'bipartisan', 'non-profit' or 'non-governmental', these organizations affirm the 
binary communicative codes of politics and economics (Luhmann 2002; Seidl and Becker 2006), thereby positioning themselves outside the logics (and responsibilities) of power. This decreases the disruptive influence of ideological power on economic, political and military power, and is, thus, interpreted as a decline of ideology.

Mann argues that these non-governmental organizations are dependent upon and do not change the dominant structures of capitalism, nation-states or American empire. But, this should indicate a successful management of the ideological contradictions between these three increasingly autonomous and unwieldy powers. Just as Christianity resolved several contradictions within the declining Roman Empire, so does the ideology of science and human rights resolve the tensions emerging from the contemporary proliferation of disorganization, risk and unaccountability in the wake of functional differentiation and greater complexity.

Though the work of Meyer et al. (2007) highlights the relationship between higher education, cultural rationalization and organization, thereby demonstrating the gap in Mann's account of modern ideological power, they unfortunately root the emergence of scientization and human rights discourse too late historically. Correctly noting the acceleration of these forms of cultural rationalization during the Cold War, they nonetheless neglect the extensive institutional prehistory of science and higher education, presenting the emergence of world society as a brand-new phenomenon. We are thus left with a gap between around 1800 (when Mann notes the decline of ideology) and 1945 (when Meyer begins his world society analysis). As noted in Chapters 1 and 2, few sociologists of higher education adequately cover this period, relying on the historical assumptions of previous generations of scholars. The result is the mainstream assumption of a decline of ideology during the 19th century rather than recognition of a new form of ideological organization rooted in the modern research university. Communicatively this involves the ideology of technology and the culture of critical discourse, which insist on self-grounded statements; the anti-elitist elitism of the disinterested New Class; and the systemic ignorance of the ideology of science by the schooled individuals who carry and embed this ideology in powerful, rationalised organizations. No wonder a large proportion of the body politic resents the unaccountable power of experts (Clemens 2017; Cramer 2016).

The emergence and extension of the so-called 'knowledge-based economy' is the accumulated advance of what I have called the 'academization process' of modern societies. This process contributes to three broad changes within advanced (post-) industrial societies:

a upgrading of social status now occurs through obtaining education credentials, enabling the capitalization of knowledge and the maximization of New Class autonomy;

b truth claims tend to be externalized in objects rather than subjects, generating an increased prominence of the research function of the university 
over the teaching, learning and ideological functions of the university (Lybeck 2018b); and

c the denial of subjective or elite authority, including among elites themselves.

Triple-helix scholars highlight the actually growing significance of scientific research within contemporary political economies but capture only the level of analysis preferred by science policy experts, administrators and government ministries - that is, the research function of the university. In fact, Parsons and Platt in the American University (1974) provided a more useful schema, which recognized the research function of the university as dominant insofar as it integrates with the broader cognitive complex of modern societies; but they also included in their model three additional functions, including general teaching of the citizenry, professional skills training and ideological services, defined as a contribution to the 'general cultural definition of the situation as distinguished from more particularized knowledge' (Parsons and Platt 1974: 6). Figure 3.4 reproduces the AGIL model of the American university.

The university is, in fact, a sociologically unique phenomenon in that it is highly differentiated, but it is also held together as a 'kind of bundle' (Parsons and Platt 1974: 349). The specialization of knowledge within the disciplines exists beside broad combinations of functions divided across the general categories: 'arts' and 'sciences'. These core disciplines are, in turn, bundled with professional education, combining to generate a general valorization of 'cognitive rationality' at the level of the university as a whole. That cognitive rationality is a value shared by modern society at large explains the continued material support for a relatively inefficient institution.

Parsons argued that the university was the principal institutionalized frame for both humanistic learning and scientific investigation. The scientist shares within the humanities 'the function of educating the primary elite elements of the oncoming generation in the society'. He continued,

In so far as the doctrine is upheld that in general the 'leading men' of the society should be educated men in the modern sense, their elite status

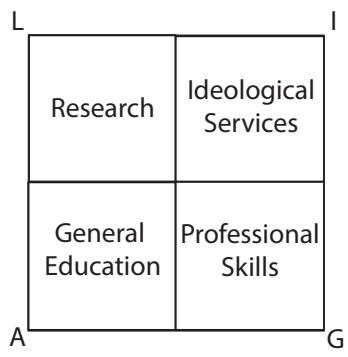

Figure 3.4 AGIL model of the American university.

Source: Parsons and Platt 1974. 
carries with it commitment to a value-system of which the values of the scientist, and the valuation of his activities and their results, form an integral part. This integration of science, both with the wider cultural tradition of the society, and with its institutional structure, constitutes the primary basis of the institutionalization of scientific investigation as part of the social structure.

(Parsons 1951: 342)

Thus, through the education of modern society's primary elite elements, the values of science come to be inculcated within the general value pattern of culture and society. By providing the primary basis through which cognitive rationality and value-neutrality become integrated within social organization - in other words, rationalization - the university, accordingly, stands for Parsons as 'the most critical single feature of the developing structure of modern society' (Parsons and Platt 1974: vi).

\subsection{Science/ideology}

\subsubsection{The operative code of the university and ideological system}

Before returning to Parsons and Platt's four-function model, I wish to isolate and elaborate my core theoretical argument in relation to the discussions above and the organization of university systems as ideological systems. That is: the distinction between sciencelideology is the operative code of the university system.

The general theory of ideology, defined as organized distinctions and justifications which increase along a spectrum of relative intellectualization, establishes that science is the most systematic and organized modality of ideological organization. Science (more precisely, Wissenschaft in German, meaning 'organized knowledge') provides rules for marking distinctions within the factual dimension as well as normative expectations that such distinctions are justified in accordance with the 'reality' of objects rather than the interests of subjects (see also Elias 1971a). This encourages a conflation, or sublimation, of particular interests into concepts, which leads to an overall increase in abstraction and generalization so that concepts are broad enough to accommodate proliferating complexity (see also Münch 2001, 2012). In this way the interests of the New Class are externalised from themselves and self-grounded in the 'reality' of their objects or 'cases'.

We have seen that this ideology of technology contributes to the ascendance of an academized system of innovation which is both adaptive and conservative; enables the functional differentiation of society; and enables the capitalization of knowledge, the transcendence of system boundaries and the autonomy of New Class elites. However, the modality of this ideology, which emphasizes the self-groundedness of statements - especially claims to power also encourages the externalization of elite authority. Thus, modern society is 


\section{4}

The ideological organization of systems

characterized by an extremely unusual situation in which New Class elites have proliferated according to an ideological logic which does not allow them to recognize themselves as elites. Their objectively privileged position must be ignored, in part through more-or-less automatic, habitualised reproduction of communications about privilege.

Within the theory of the academization process I am developing here, this tension between elitism and self-groundedness is the fundamental contradiction of the New Class, and, indeed, of knowledge-based capitalism. As opposed to the old contradictions of capitalism - between classes, relations, means of production and so on - the contradiction of the New Class is internally situated within the class itself; between the interest of capitalizing on acquired knowledge designated through status distinctions (degrees), and the mode of justification which discourages subjective recognition of any form of justified elite authority insofar as all statements must be self-grounded. In short, the ideological 'problem' or 'paradox' of the New Class is that they are elites who have no means through which they can justify their elite authority. The ideological 'solution' to this contradiction is to externalise ideology as something that applies elsewhere - in 'society'. New Class actors do not consider themselves as 'interested' since their dominant interest is the projection of 'disinterestedness' (Bourdieu 1984).

The emergence of sociology as a discourse emphasizing objectivity and value-neutrality becomes essential for Gouldner's interpretation of the ideological organization of modern knowledge-based capitalism. As noted in Chapter 2 above, in attempting to understand the contemporary cultural lag between 'Parsonsianism' [sic] and society, Gouldner suggested the origins of sociology occurred in the wake of the French Revolution and frustration within the Counter-Revolution, which contributed to the emergence of St. Simonian Positivism in France (Gouldner 1970: 98). Ever since, sociology has revolved around two central axes. Having been spawned by a declassed nobility in France circa 1820, the new axis was organized around Marxism and socialism. These two waves (Positivism and Marxism) were then synthesized within the classical phase of Durkheim and Weber. Next, the axis shifted to Structural-Functionalism and the Parsonian synthesis. The 'coming crisis' in the 1970s was thus explained as amounting to another shift of axes, which would result in fragmentation. ${ }^{2}$

Recalling Gouldner generalized from the special case of sociology to the New Class of professionals and academics writ large, his analysis of sociologists as among the most grotesquely deluded of New Class elites helps us understand the way the binary code between science/ideology functions:

Such objectivity is not neutrality, but alienation from self and society; it is an alienation from a society experienced as a hurtful and unlovable thing. Objectivity is the way one comes to terms and makes peace with a world one does not like but will not oppose; it arises when one is detached from the status quo but reluctant to be identified with its critics, detached from 
the dominant map of social reality as well as from meaningful alternative maps. 'Objectivity' transforms the nowhere of exile into a positive and valued social location; it transforms the weakness of the internal 'refuge' into the superiority of principled aloofness. Objectivity is the ideology of those who are alienated and politically homeless.

(Gouldner 1970: 105)

Indeed, sociologists figure as a guild of guardsmen at the gate of the university walls, managing the distinction between science and ideology.

'Ideology' is not just a cognitive object of sociology but is also its claimed boundary ... This boundary between ideology and sociology, then, is not some long-forgotten outpost that the march of intellectual empire has left behind unwatched. Ideology is not some acned condition that sociology outgrows in its maturity. It remains, rather, a boundary wall that is manned, watched and recurrently repaired.

(Gouldner 1982a: 10)

Sociologists, like other scientists, regularly engage in what Thomas Gieryn (1983) described as 'boundary work', in which valid truths are distinguished from the work of amateurs: truth/untruth (see also Lamont and Molnár 2002). But this concerted effort takes on a special character when sociology is interpreted as the study of ideology by ideologists. Marx was among the earliest social scientists to establish this boundary, 'for Marx, ideology was failed science, not authentic science. Implicit in his critical rejection of ideology was an image of true science that was to be a standard. Those failing to measure up were "ideologies" and "ideologues" (Gouldner 1982a: 9; emphasis in original).

In this way, sociology closes itself off from its external environment, including other disciplines, for example, neoliberal economics (ideology) and biology (Science). Sociology also distinguishes itself from the world outside academia which is understood in terms of the ideological influences of the media, religion, business culture and so forth. To the extent that these values are represented within sociology, they are done through the epistemological language of critical sociology or through translation of public values as data (surveys, ethnographies, interviews, focus groups, etc.). These techniques establish narrow bridges of access to an objectified public, which allow the discipline to remain open to assessment of norms while, at the same time, closing itself off to develop complex rhetorics internally, simulating 'fragmentation'.

By maintaining the boundary between science and ideology, sociology both disguises and reflects the ideological organization of the entire university. The very identification of ideology with culture outside the academy's walls reflects the difference between the organized culture of the academy and that which it cannot control, or understand within the language of CCD. Universities' ability to ignore their own culture as culture is achieved to the extent institutional structures protect the university system from outside forces, 
enabling academics to follow their own symbolic hierarchies and canons relatively autonomously. Academics are cultural capitalists who, since they are also the primary consumers of the product, misrecognize their effective control of the production of legitimate, authoritative ideology, thus providing the necessary ignorance on the unmarked side of the distinction separating truth/untruth, knowledge/ignorance, science/ideology.

This distinction became salient during the modern era when the concept of 'ideology' emerged with a negative connotation, allowing 'science' (especially social science) to conceive of itself as truth because it was not 'ideology'. Because science is an ideology that intentionally does not recognize itself as such, and because this ideology has secured state-backed authority in the institutional setting of the modern university, the normative functioning of ideology has become inverted so that power can now be justified without reference to the status of individuals. Rather, power is ideally empirically grounded in 'facts'. Facts are therefore valued in themselves, and the fact/ value distinction is conflated. Luhmann's general systems approach becomes focused and specified onto a 'middle range' in accord with Gouldner's hermeneutic-historical interpretation of the concurrent rise of ideology and social science. Sociology is not simply another discipline among many, but rather emerges out of the core historical dynamics transforming 19th-century societies - the third revolution in communication and education - that is, the academization process (Gouldner 1970, 1979, 1982a). Though Luhmann's analysis of the system of scientific communication (research) frames this operation in terms of 'truth/untruth', the principles of distinction marking and self-reference become clearly visible once the ideological binary 'science/ ideology' is established and related to the same field of communication.

For truth, the matter is clear. We have interpreted it as a code, that is, as an intrinsically self-referential difference between truth and untruth. In the case of reference, a distinction must be made between self-reference (internal reference) and external reference. Both sides of this distinction are given only together with their respective opposites.

(Luhmann 2002: 65; emphasis in original)

The theoretical reformulation via sociological abstraction enables analysis of the unity of the distinction rather than particular designations projected from one side or another. Recognition of the science/ideology code encourages us to see that what is science is that which is not ideology; that this is, in fact, the means through which science actually functions as ideology; and that finally, this is the reason why science fails to see itself as ideology.

As an operative code for the university, and this particular ideological order, both ideology and science claim to relate to empirical reality - the establishment of what is 'true' therefore becomes a space through which theory and practice combine, conflate, cycle and revive discursively. On the one hand, commitment and social investment in research may indeed encourage increased accumulation 
of objective knowledge of reality, particularly of natural and technologically accessible reality. However, from the perspective of the ideological, rather than the scientific system, the consolidation of that which is 'true' means a necessary increase of that which is designated as 'untrue', namely: 'ideology'.

Luhmann (1998) described this condition of modernity as an 'ecology of ignorance'. The proliferation of research and 'science' in social organization does not imply an increased penetration of actual rationality and objective knowledge in society. For example, a company or state may be intentionally organized to prevent knowledge of irresponsible practices from reaching the purportedly 'responsible' executive. Knowledge becomes a liability. Indeed, insurance against 'risk' as bundled uncertainty indicates a need to calculate and determine tolerable levels of ignorance (about the future) so that decisions can be made (or not made) to maximise opportunities or avoid threats (Luhmann 1993b). Such procedures amount to an externalisation of responsibility. Indeed, the clientelistic relations characteristic of the technocratic and professional elements of the New Class enables the capitalization of expertise via provision of the service of diagnosis, inference and treatment - that is, access to learned abstract principles and paradigms (Abbott 1988). Yet, it is the clients or agents who ultimately enact these programmes and ultimately assume responsibility for outcomes, despite their potential ignorance of the reasons behind their collective action.

Gouldner describes these New Class actors as 'pragmatic nihilists':

They are capable of emancipating men from old shibboleths, but they are emancipators who know no limits. Their emancipation has a side effect: cultural destructiveness, anomie. The cultural dissolution they bring is precisely that always entailed by the culture of critical discourse, which commonly alienates persons from tradition.

(Gouldner 1979: 52)

Unlike academics, professionals and technocrats draw authority from the stability of scientific paradigms - they are 'normal scientists' in the Kuhnian sense (Kuhn 1962). Humanistic intellectuals employed within the academy draw authority from their faculty in deconstructing and criticising such paradigms, on factual, normative, or historical grounds. These are, however, controlled demolitions - firewalled within the ivory tower and peer-reviewed journals understood only amongst specialist communities familiar with the associated jargon, theoretical fields and rules of argumentation.

In order for ideologies not produced internally - that is, outside the academy - to re-enter the authoritative discourse of the academic community, they must first establish the scientificity of their claims. Such ideologies must first become self-grounded. Hence, 'intelligent design' is today framed as a more valid scientific standpoint for biological analysis, rather than as an assumption grounded in the traditional authority of the Christian church. Marxism re-entered the academy in the 1960 s by reasserting its scientific validity in 
contrast to the 'ideological' academic sociology of Parsons and modernization theorists. The latter, in turn, redefined (that is, self-referenced) ideology as only that which obtains within leftist 'utopian' movements (Shils 1958; Ben-David 1977).

\subsubsection{Toward a systems-process analysis}

We are now in a position to link Luhmann's analysis to Abbott's analysis of the chaos of disciplines (2001a), which, he argued, develop synchronically and diachronically according to 'self-similar' fractal patterns and cycles. Elsewhere, I have drawn on Abbott's analysis of professions and disciplines to highlight the special role of the university (or academic profession) within the system of professions insofar as academia is the only profession that functions as both system and environment for knowledge claims (Lybeck 2019a).

In a footnote, Abbott dismissed the similarities between his own position and that of systems theorist, Luhmann, who is said to operate at a level of abstraction far above his own (Abbott 2001a: 167n7). While Abbott cannot be faulted for reserving energy for the elaboration of his own theory, I nonetheless identify several compatibilities between the two perspectives. First, each attributes considerable significance to variations in temporality; second, each recognizes the structural significance of indexical, context-dependent distinctions; and, third, each recognizes the contingent recombination of subjective and objective meanings via abstraction (Abbott 2001b; Luhmann 1995b: 278-356).

Combining the two theorists' work generates the possibility of historicising the promise of Luhmann's general systems theory - a universal framework which claims to encompass all of sociology's potential topics - by including itself as part of the reality it studies. An historical sociology of sociology would not produce universal knowledge but could cut across existing distinctions to provide an explanation for the historical existence of a discipline which has dedicated itself to research into everything and nothing in particular at the same time. Sociology is here understood as a self-referential discipline organized around irresolvable fractal distinctions; as functional elements nested within broader systems - science, university, profession, capitalism and so on, as in Figure 3.5.

Providing an explanation for social science's 'indexical' character, Abbott noted that many discursive divisions recapitulate themselves within. For example, age-old methodological distinctions between 'quantitative/qualitative' or 'pure/applied' sociologies are indexically reproduced within their respective wings: e.g., a 'qualitative' quantitative wing versus a 'quantitative' quantitative wing, as in Figure 3.6.

These distinctions provide a means through which each of us (think we) understand the similarities and differences between others' points of view. As Abbott explained, a fractal distinction 'generates endless misunderstandings 


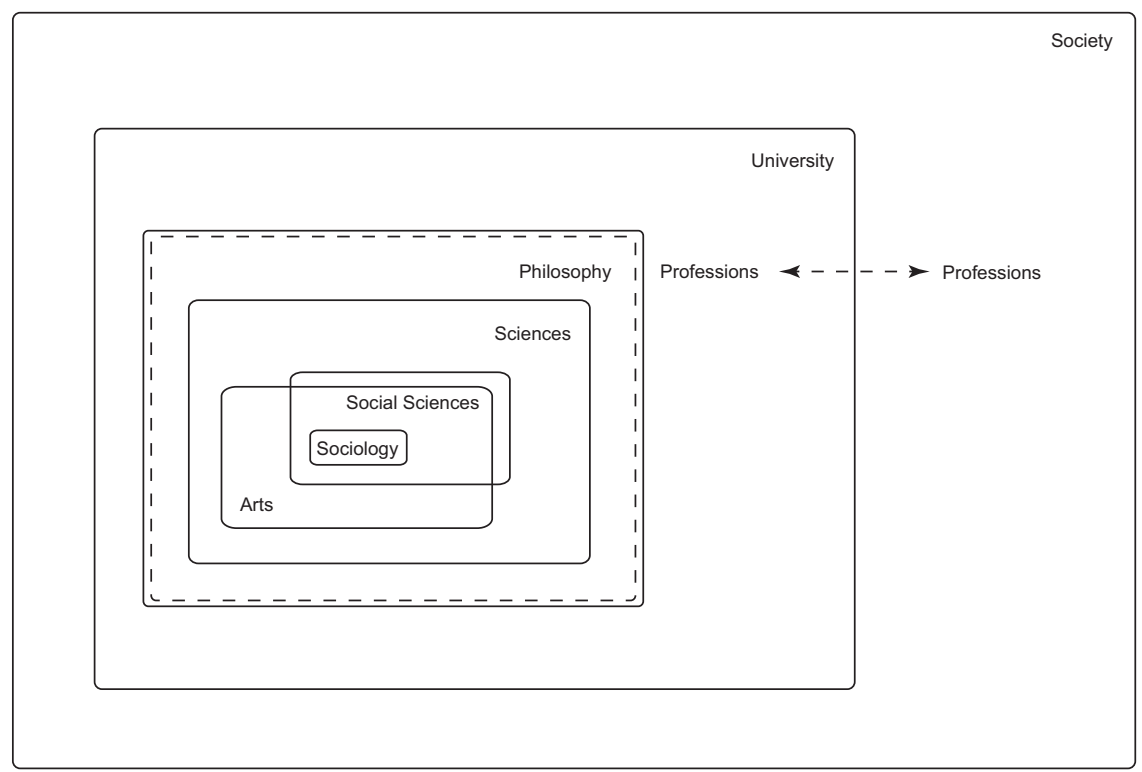

Figure 3.5 Nested subsystems of knowledge.

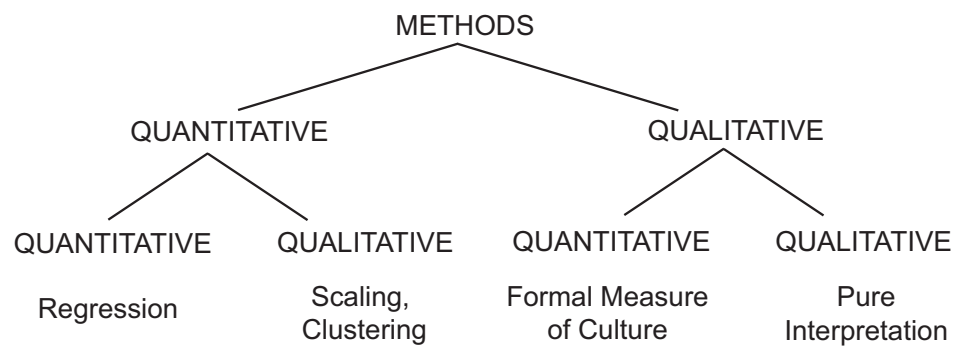

Figure 3.6 Fractal distinctions in sociological methods.

Source: Abbott 2001a: 11.

and provides a disturbingly powerful tool for nonsubstantive argument. All of these characteristics arise from the relational character of fractal distinctions, which makes them generate a clear local structure that replicates a hazy larger one' (Abbott 2001a: 13).

These synchronic, indexical divisions - self-similar on both the micro and macro levels - are mobilised through time. First, these kinship-like splittings are grounded within lineages of descent - so, a given approach will trace a history back to, say, Marx, Weber or Simmel to justify their contemporary theory and method as bona fide. This is especially important within sociology, which is unable to exclude any object ('location' in ecological terminology) as being outside the purview of sociological research. 
Sociology, in short, is irremediably interstitial. In fact, this interstitiality undergirds sociology's claims as a general social science, claims not necessarily justified by its contributions in theory, method or substance. Rather, sociology's claim as the most general social science rests on its implicit and fuddled claim that no form of knowledge [about society] is alien to it.

(Abbott 2001a: 6)

Situated between the arts and sciences, sociology recapitulates the broader relation between the natural sciences and humanities. This interstitial quality consigns sociology to an eternal recurrence in which key concepts are lost and refound under different names.

Abbott attributed this perennial renaming of core objects of sociological interest to fractal cycling, the second temporal element in his model of disciplinary splitting. Unlike knowledge-based professional training, which recapitulates structural differentiation in parallel to culturally 'pure' patterns, chaotic disciplines tend to engage in intense conflict resulting in 'sterile' lines becoming 'remapped' onto a version of the ascendant line, as in Figure 3.7.

These cycling cultural patterns proceed through time, non-dialectically, setting victorious, temporary stabilisations up for future falls when the veritable contradictions of enemy occupation are rediscovered and renamed. This is due to the need for victorious terminologies to account for many of the core assumptions of the alien turf they effectively demolished. Abbott used the example of conflict sociology, which labelled their opponents 'consensus theorists' before trampling them during the course of the 1970s. When outflanked by rational-choice individualists, the Neo-Marxist conflict theorists were forced to defend the normativism they originally rejected. Conflict theory became the only representative of consensualism in the face of a

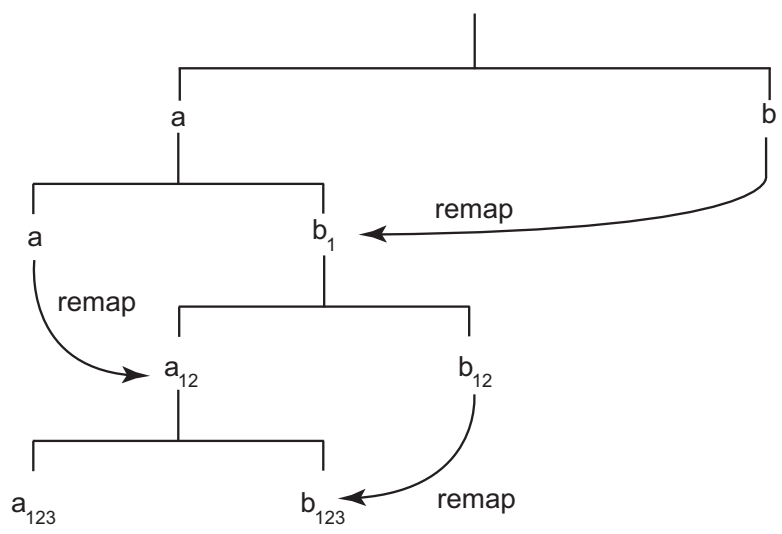

Figure 3.7 Fractal cycling.

Source: Abbott 2001a: 23. 
redoubled neo-utilitarianism and neoliberalism, the very forces Parsons repudiated via his voluntaristic theory of action recognizing the significance of value-integration (Parsons 1937; Parsons and Shils 2001). These shifts tend to occur in generational waves as young scholars Oedipally murder their elders due to the reward structures of the academic profession. Abbott admitted this patterned generational change, or 'slip-clutch', does embody a form of dynamism,

even if that change is organized in a regular succession whereby the young build their careers on forgetting and rediscovery, while the middleaged are doomed to see the common sense of their graduate school years refurbished and republished as brilliant new insight.

(Abbott 2001a: 148)

Yet, the persistent churning of these fractal cultural distinctions only appears chaotic, since the remarkably stable structural home of disciplines remains unmoved. The appearance of chaos belies an underlying stability and order at the level of the university as a whole. Abbott noted the dually institutionalized 'basket structure' of American academia is stabilised at both the department level and through national disciplinary associations (Abbott 2001a: 126-29). A suite of core disciplines are reproduced isomorphically according to the broad categories of undergraduate college majors fractally mirrored in divisions amongst major journals, conferences, advocacy groups and so forth. Academic professionals preserve reputations in each - department and discipline - thereby obtaining a diffuse, decentred authority. Whilst new majors like comparative literature or linguistics very occasionally emerge, in general, the disciplinary structure of the American academy has remained remarkably consistent for the past century.

With reference to Luhmann, we can point to an objective limit within the object of study which sociology claims jurisdiction over. By studying ideology from a position which considers ideology to be its own boundary, we can see that sociology projects its environment internally and is doomed to reproduce the fractal cycling around objects sort of related to ideology - in Abbott's words, 'an archipelago of particular subject matters' (Abbott 2001a: 140) without coming closer to providing authoritative professional advice or stable knowledge about those objects. Sociology's jurisdiction becomes subjective authority over the impossibility of objective knowledge about society.

Luhmann explained this condition in terms of the (non-)object of study society - and the historical refusal/impossibility for the discipline to recognize the inherent circularity of its engagement with its object.

Sociology has hitherto failed to address this problem with the necessary stringency and consistency. It has hence failed to produce anything approaching an adequate theory of society. Toward the end of the 19th century, any integration of a description of society into its object tended 
to be seen as 'ideology' and, as such, rejected. On this basis, the raising of sociology to the academic status of a strict science would have been inconceivable.

(Luhmann 2012: 3)

Classical sociology sought to establish itself as a science of social facts as opposed to opinions, value judgments or ideological prejudices, but could never resolve its own existence as a social fact.

Though the classical thinkers, Durkheim, Weber, Simmel and others, went a long way in trying to resolve the paradox of communication about society in society, the breakdown of the classical synthesis led to such oppositions as structuralist/processualist, domination/conflict, affirmative/critical and so on. We have encountered these sorts of distinctions in Abbott, but note Luhmann's explanation:

Since maintaining a position within such 'frames' required confrontation with the contrary position and thus the inclusion of exclusion, opting for one side rather than the other was always infected with paradox, and to unfold paradox through controversy was convincing only where it made political sense. Given the inherent dynamism of the political system, this has proved less and less convincing, even though intellectuals have continued to play such games.

(Luhmann 2012: 4)

Just as in Abbott's analysis of the conflict theorists occupying the enemy turf of the consensualists, Luhmann described the generation of confrontation and the inclusion of the contrary position through self-referential exclusion. This inclusion is then inverted and reprojected on the next wave, since the only resolution to the paradox is the normative and political game. One projects the accusation of ideology upon one's opponents shutting down the debate on non-substantive terms. Following the American creed, everyone 'agrees to disagree'.

Relating this to the many distinctions Abbott noted within sociology - quantitative/qualitative, constructivist/realist and so on - a special case should be made of his distinction between politicians/moralists (Abbott 2001a: 197-232). Politicians inhere 'transcendent' qualities to particular groups (e.g., the workingclass, female gender, oppressed minorities, etc.), while moralists more often blame the 'system' for social inequality. Both include the mixing of value judgments with scientific ones. This normative distinction is the actual site of sociology's systematic conflations, providing the space for ethical and political criticisms to become mediated and interpreted within the language of science (even when scientistic ideals are rejected). Furthermore, Abbott's description accounts for the remapping and fractal cycling in Figure 3.7: 'Both the Politicians and the Moralists see returning - within their own arguments - the positions that they vehemently deny vis-à-vis the other side, the fractal thus moves to yet another level' (Abbott 2001a: 200). 
Were sociology a profession with practical utility, the moving up moral levels of abstraction along three dichotomies - social/individual, equality/inequality and is/ought - could generate inferential insight. But, in practice, the two sides talk past each other. Instead, a ritualistic circling around the contradictions of thought and action, freedom and determination manifest themselves either in contradictory instruction - as when a linguistic relativist corrects her students' grammar - or when politically motivated scholars represent their discourses as the salvation of external organizations or vague 'publics' while remaining behaviourally inert. However, precisely because sociology has no clear professional outlet - because it so rarely is asked or is able to provide practical advice - the discipline is free to talk amongst itself. This is not to say the discipline does not provide valid knowledge via research, but only that it has no clear mechanism to translate findings into non-mediated results.

Note that it is not necessary for the discipline or the university to accomplish anything resembling consensus - for this is not the way binary codes work. Rather, binary codes must be ignored on the first order to provide standpoints for designations of external environments for systems interested in expanding internal complexity. As in the legal system - organized around the code 'legal/illegal' or 'just/unjust' - the ideological system's operation is nothing less than the constant 'de-paradoxicalization' of the code.

To deal with the question whether the distinction between justice and injustice is being used justly or unjustly would lead the system into paradoxes ... the observation of paradoxes, something which occurs, for example, in the application of the code itself, blocks the system's observation and description, even though at the same time the observer must concede that the system's own autopoiesis is not blocked by the paradox. In other words, the system can simultaneously both be observed and not be observed as a paradoxical system. The observer must then transform this self-paradoxicalization in a quality of his object by asking how the system de-paradoxicalizes itself.

(Luhmann 1988a: 149-50)

To observe the 'justness' of the code itself leads to the so-called 'third question', which cannot be resolved within the internal logic of the system since a third position represents an inherently relative standpoint on the second-order (Luhmann 1988b). Thus, from within an ideological system organized around science/ideology, one cannot substantively assert whether science is actually non-ideological, as the modernization theorists asserted, or whether science is ideological, as critics on the left and Christian right have asserted. Evaluation of such claims would presuppose assumption of a standpoint on one or the other side of the code. What can be observed, however, is the way in which the system operates; that is, how institutional structures and communicative discourses reflect and sustain the production of both science and ideology. For each emerges synchronically and relationally as foils for one another - just as antibodies and viruses would not exist 
without each other. And yet, as a social system, science in the university is engaged in constant acts of purification. How does the university system develop science internally while projecting ideology externally?

The university is a space in which the conflations between science/ideology can be parsed and debated authoritatively or ignored. The division of the disciplines - what Elias called 'scientific establishments' - is the core structural element enabling and conditioning this process. Indeed, this is the primary contribution of world-systems analysis to our understanding of the way divisions of knowledge support the ideological superstructure of knowledgebased capitalism. By providing the conditions for the autonomous reproduction of complexity, universities have allowed disciplines and professions to become operationally 'closed systems' that are nonetheless open to their environments. However, an equally important division of knowledge occurs at the boundary between the professional and philosophical disciplines. Here, as Abbott noted in his sociology of professions, professional education produces new techniques while rationalizing professional knowledge into textbooks, thereby justifying professionals' work amongst publics and audiences.

Extending Abbott and Gouldner's generalization from sociology, a fractal science/ideology distinction can be observed to be distributed across academic disciplines. The natural sciences, for example, are not compelled by their objects to confront ideological concerns, whereas the humanities are more likely to deal with questions of norms and values (Becher and Trowler 2001). One could conceive of this as a spectrum running from physics to comparative literature, for example, with each discipline representing a differentiation of the overall distinction. But, if we closely examine the disciplines' internal organizations, one finds the science/ideology distinction recast within. In biology, for example, there are 'normal' scientific scholars and others more interested in the meanings of life (Meloni 2012). Other scientists, like Richard Dawkins, are engaged in 'ideological services' on behalf of atheism through the representation of 'Science' as Truth. The science/ideology distinction is therefore indexical, dependent on context, as in Figure 3.8. The system

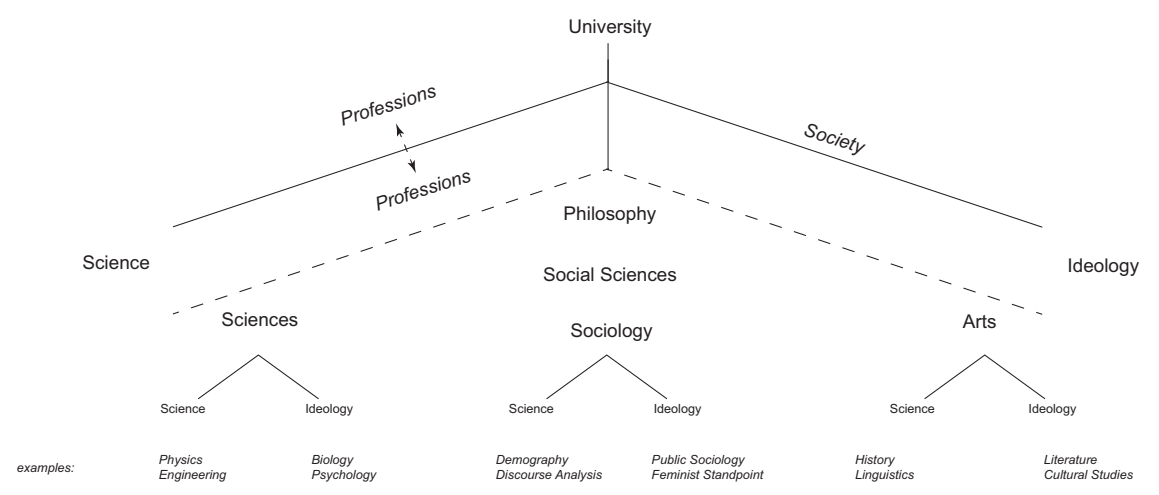

Figure 3.8 Fractal divisions of science/ideology. 
boundary is produced throughout the system by and through written texts, actors, practices and so on.

However, as Parsons and Platt indicated, a generalized, 'bundled' identity of 'the university' becomes essential to the unity and evolution of a global university system, conserving an authoritative centre of/for abstract knowledge covering what would otherwise appear as a complex, differentiated range of functions, discourses, opinions, networks and actions. This is achieved due to the simplification of the university's purpose - often reduced to 'Humboldtian ideals' reflecting the unity of research and teaching (Ash 2006). This core mission is, in effect, a foundation myth - a metanarrative. Despite its historical inaccuracy, the myth of Humboldt provides the historical ground upon which the temporal dimension of meaning is sustained. Thus, historically grounded, the university is communicatively bundled as a series of differentiated functions, despite variation and fragmentation within.

We can return to Parsons and Platt's four-function model in the American University (1974), which provided a useful schema recognizing the research function of the university as dominant insofar as it integrated with the broader cognitive complex of modern societies, but also included three additional functions: general teaching of the citizenry, professional skills training and ideological services (Parsons and Platt 1974: 6). In Figure 3.9, I disregard the AGIL logic and adapt these functions along simpler lines according to the axes research/teaching and internallexternal.

With reference to the above, one can highlight the relationship between the science/ideology code and the 'idea of the university'. Recall the Humboldtian ideals emphasized by the modernization theorists and others: the university does not have four functions, but rather two: research and teaching. However, the four-function model suggests that affirmation of these two Humboldtian

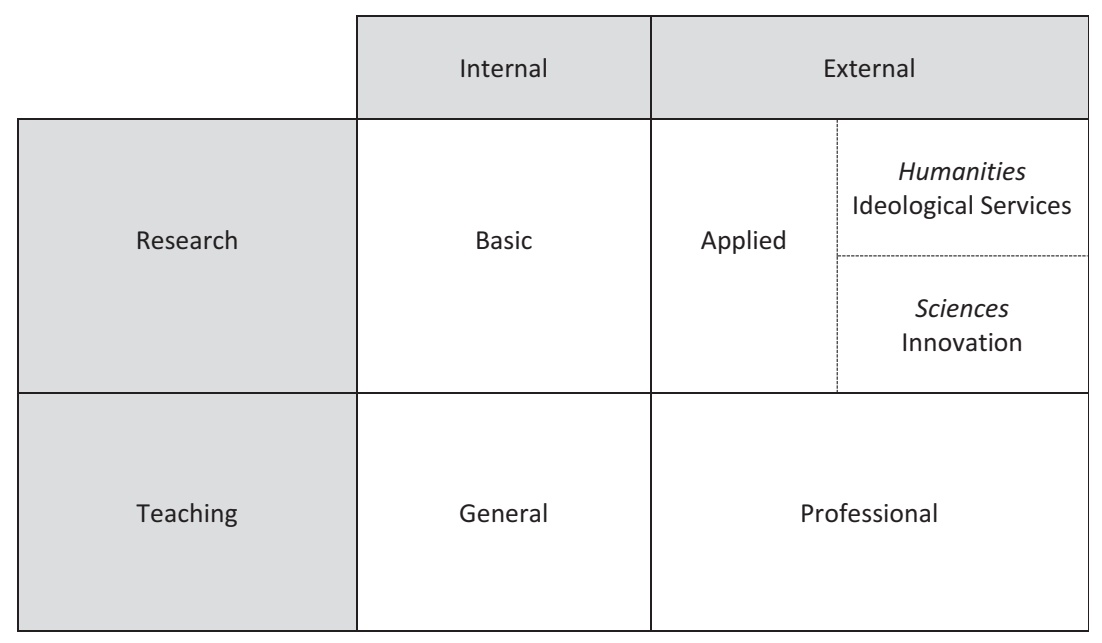

Figure 3.9 Four functions of the university. 
ideals have different meanings within different contexts. For example, the UK government's current emphasis on 'impact' seems to apply to the 'research' function of the university (Bozeman and Sarewitz 2011; Kearnes and Wienroth 2011). But, what these bureaucrats really seem to want is 'applied' rather than 'basic' research. Resource managers in the state and funding councils seek economic output relative to their inputs of resources. Similarly, when external criticism of the university is levelled at the uselessness of certain disciplines, this implies that 'general' teaching should be replaced by more professional, skills-oriented training.

From the other (internal) side, the ideals of teaching and research are expressed again, but now the defence affirms the importance of generalist, liberal education for the development of democratic citizens and publics (Nussbaum 2010). Alternatively, scientists, historians and classicists could affirm the pursuit of basic research: 'knowledge for its own sake' (Rees 2012). The basic structure of this mode of argumentation is achieved because academics within the core disciplines have rarely occupied the lower-right quadrant of the table (professional training). Instead, their professional training as graduate students occurs within the upper-left (basic research) quadrant. Academics are therefore the only profession which can, theoretically, justify themselves in terms of basic research and teaching alone.

This perennial back-and-forth between academics and external powers has not resolved the structural tensions between the university and society, nor has it resolved the science/ideology code. It has, however, achieved a common commitment to the values of 'research' and 'teaching' as essential components of the university recognized by all parties. At the same time, however, neglect of the internal/external distinction generates an attribution of 'pure' research and teaching, which is to be distinguished from the 'interested' applications within the professions and applied sciences. The latter, 'interested' activities are more likely to be deemed 'ideological' among members of the academy, while the former maintain the purity of 'science'.

Lest we think this benefits only the academics, we should consider the example of a professional consultant with a degree in public policy or economics who provides structural-adjustment plans to governments (Fourcade 2009; Mitchell 2005). This elite's authority comes from university credentials, which indicate acquired knowledge of 'pure' economics. Without this connection to the 'pure' centre, professionals would be less justified in performing their practices of diagnosis, treatment and inference. This often ignored aspect of university education - professional skills training - is, in fact, the primary means through which scientific ideology penetrates modern societies and changes the organization of the world. As Parsons noted,

In so far as the doctrine is upheld that in general the 'leading men' of the society should be educated men in the modern sense, their elite status carries with it commitment to a value-system of which the values of the scientist, and the valuation of his activities and their results, form an 
integral part. This integration of science, both with the wider cultural tradition of the society, and with its institutional structure, constitutes the primary basis of the institutionalization of scientific investigation as part of the social structure.

(Parsons 1951: 342)

Thus, through the education of modern society's primary elite elements, the values of science come to be inculcated within the general value pattern of culture and society. In other words, science does not become the dominant ideology of modern society because of scientists' actions - but, rather because, in general, professionals - the New Class - depend on the stability of 'science' to trade on their educationally acquired cultural capital. This is why universities are the institutional centre of this ideological system - not necessarily because science and/or ideology are produced in any particular way, but because the system requires a purifying referent, a 'core' or 'centre' in Shils's terminology, through which the New Class (and increasingly a range of other classes) obtain their status and authority. The 'idea of the university' is not merely an idea - it is a central, yet fundamentally diffuse, locus of ideological social power. 'The University' is where modern ideological power is organized (or, rather, systematically disorganized), not unlike religions of the past.

For this education-based professional system to have been achieved historically, particularly during the course of national federalization and the centralization of authority transcending state and local borders, common recognition of academic credentials and reputation needed to be secured. In Germany and France, this accreditation system was maintained by the state (Anderson 2004; Bourdieu 1996; McClelland 1980). In the United States, a much more decentralized and more self-organized system of reputational standards emerged (Abbott 2001a; Ben-David 1977). The communicative closure of this open system has now been achieved on the second-order through rankings of research publications. These rankings were originally designed to observe research as an indirect measure of the quality of teaching, but they are now sought worldwide as ends in themselves (Geiger 1985). Regardless of the value or productivity of research itself, from the angle of the system of professions, the objective validity of research excellence as expressed in rankings has provided a justification for the hierarchical authority of both institutions at the top of the university system and their graduates. Harvard and Yale graduates are deemed (or, rather, deem themselves) the best people to run the economy and state because Harvard and Yale produce the best scientific research.

While New Left critics challenged Parsons's valorization of modern professionalism, accusing him of being an apologist and conservative ideologue for advanced industrial society, these critics misrecognize their own location in the institutional structure of the academy. That is, critical humanists in the philosophical faculty challenged Parsons's idea of professionalism as an ethical basis for social inequality without adjusting the actual institutional 
expansion of professional training and the over-credentialization of New Class elites. Indeed, the critical challenge to the elitist university during the 1960s, in paradoxical effect, reinforced the very isolation of ivory-tower discourse from society by asserting the autonomy of the university as a basis for social critique (Jewett 2012), resulting in the abstract linguistic acrobatics of what passes for 'theory' in humanistic disciplines. Meanwhile, the proliferation of New Class professional actors has only expanded, despite their increasing inability to justify their intellectual authority.

\subsection{Conclusion}

These brief examples highlight some ways in which the paradoxes of the science/ ideology code are actually materialized within societies. These materializations are not necessarily predictable, but they are systematic and discernible through systems analysis. The theory provides a model through the university can be better understood and directs our attention to particular regions and functions of the university system which are presently ignored, despite their considerable significance in the organization of social power.

In particular, the professional faculties figure as a significant basis of knowledge interest, since it is through professionals that academic philosophical discourses enter social organization as cultural rationalization. Only by grasping the patterned meaning of forms of valorization or critique from different perspectives, inside or outside the university, can we understand the way statements might obtain functions opposite of their intention. For example, the rhetoric of 'open access' propounded with quasi-anarchist motives by academics interested in 'public' impact has been used by governments to justify the expansion of the for-profit 'sub-prime' higher education sector (McGettigan 2013). One needs a new theoretical language from which the actual double meaning of the concept 'open access' can be criticised without affirming or denying the normative validity of the intent. Luhmann's systems theory coupled to Gouldner's New Class analysis provides a simplified heuristic - the 'science/ideology' code which can aid orientation to these complicated communicative patterns.

Finally, deconstructing sociology and the university's excretion of ideology as something external to itself provides an opportunity to re-engage with the many theories of ideology which suggest a decline in traditional authority. As the discussion of Mann above suggests, this macro-sociological transformation is better understood as a replacement of one type of ideology with another. Communication addressing traditional authority has been replaced by second-order observations which allow the deflection of interests into durable concepts and objects. The paradox of contemporary ideological organization is that it is organized around a critique of ideology - by definition denying that it is an ideology. And yet, this ideological organization can be observed to be highly successful in sublimating traditional values and critique into institutionalized ideologies. The only visible powers become those which are self-represented as such - politics, economics and military power. That 
ideology no longer appears to have an influence on these organizations, in fact, indicates the relative success of the science/ideology code. Second-order communication disguises the New Class actors who enact and organize power, most importantly disguising themselves from themselves.

\section{Notes}

1 In this sense, the 2012 US election between Mitt Romney and Barack Obama was perhaps the first election between the two factions of the New Class: 'non-ideological', 'neoliberal' consultant versus 'radical' law professor cum community organizer. Each was educated, of course, at Harvard professional schools.

2 At the time, Gouldner predicted the paradigm might be replaced by either symbolic interactionism, phenomenology or rational-choice theory. All things considered, the prediction was not far off the mark at the turn of the millennium, in light of the prevalence of these three modes of research in subsequent decades, to say nothing of their synthesis within the Bourdieusian doxa of the present (Alexander 1995). 


\section{Paradoxes of the academization process \\ Foreign and classical language education since 1864}

\subsection{Introduction}

Contemporary higher education (HE) in Britain has been a consumerist affair since student choice was put 'at the heart of the system' in 2011 (Department for Business Innovation and Skills 2011). This marketization followed upon decades-long neoliberal trends in American and global HE, which extended universities' function as an occupational clearinghouse: students' choice of degree courses is assumed to be related to career aspirations (Arum and Roksa 2011; Holmwood 2014; Slaughter and Rhoades 2009). Yet, such expectations of rational career-accounting prove mythical if we consider the declining uptake of modern foreign languages in English-speaking countries. Despite the obvious occupational skills multilingualism offers graduates in a globalized economy (Conteh and Meier 2014), fewer and fewer university consumers opt to study foreign languages (HESA 2016).

To assess and explain this decline in foreign language study, narrow focus on the contemporary neoliberal university is abandoned here to reflect on a longer-term trend - an 'academization process' with origins in 19th-century efforts to widen participation in secondary education. In 1864, the Clarendon Commission responded to criticisms made by industrial elites against the perceived aristocratic 'elitism' of public schools. The traditional curriculum organized around classical 'grammar' was compelled to give way to instruction in more 'useful' forms of knowledge, especially modern foreign languages. Indeed, the conflict between classics versus modern 'useful' subjects remained a central axis upon which conservative and progressive educational policy was debated until well into the 1970s. Because these debates ostensibly involved secondary schools, it is easy to miss the legacy of this history, which bears directly upon contemporary higher education.

Viewed from the vantage of the long-term academization process, the contemporary decline in foreign language study can be understood as an artefact of the longer trend wherein an ascendant middle class displaced the holistic curriculum of the old regime in favour of more specialized forms of knowledge. This manifested itself within the university as a jurisdictional struggle between the pre-existing clergy at the centre of curriculum and a new academic class of more

DOI: $10.4324 / 9781351017558-4$ 
secular and liberal humanist academics. The displacement of clergy from the centre of university study occurred over the course of centuries, but embedded certain logics and rhetorics into modern higher education discourse, including counterintuitive links between widening access/anti-elitism, scientific/technical scholarship and women's education.

\subsection{The crisis of contemporary foreign language admissions}

First, let us consider the immediate object of interest: declining foreign language study at university level. According to HESA statistics (2016), uptake in these subjects was down 16 per cent since 2008/2009, a period which otherwise witnessed considerable growth in HE-sector enrolment. This decline was paradoxical insofar as the skills obtained through language study are amongst the most sought after in a globalized economy, especially as Europe remains the UK's primary trade partner, with or without 'Brexit'.

As the 2009 HEFCE review of foreign language instruction in universities indicated, one major cause of the emerging crisis in language study was the government's making foreign language study non-compulsory in secondary schools in 2004 (Worton 2009). According to the 2002 Green Paper which led to this decision, foreign languages were the most frequently requested 'optout' or 'disapplication' subject in state secondary schools (Department of Education and Skills 2002). In other words, state schools did not have the teachers or resources to teach a core subject and regularly applied to not be required to teach the subject on this basis. By removing the requirement, the school exceptions could become the rule - though the government assured students would still be 'entitled to access' these subjects if they chose.

Meanwhile, under OFSTED and league table pressures to ensure high Alevel marks, schools were encouraged to discourage students from opting for foreign language examinations since these are harder to master. This has resulted in a considerable disparity between independent and state school provision in the subject-area (ISC 2015). In 2015, nearly 25 per cent of the 10,328 students taking A-level French were from independent schools; a proportion that was similar in German and Spanish. This, in turn, has resulted in 28 per cent of university students in modern foreign languages hailing from independent schools.

Indeed, according to admissions data on Oxford University's website (2016), state school students regularly apply to the most oversubscribed subjects (economics, medicine, law, etc.), while independent school leavers skew the ratios in less oversubscribed subjects, including languages, classics and music. This confounds universities' efforts to widen participation in HE insofar as, as Reay (2016) notes, 'the problem of social class in higher education has not gone away, rather it has transmuted from one of restricted access to one of "who goes where". While the massification of British universities has continued apace since 2001 when New Labour set the target of 50 per cent of school leavers entering HE, much of this expansion has gone into non-Russell 


\section{Paradoxes of the academization process}

Group universities, especially for students from more disadvantaged backgrounds. This led to further government intervention in the Russell Group to expand its efforts to widen participation further - investing another £11 million on top of the existing $£ 254$ million for scholarships, fee waivers, bursaries and outreach activities for 2017/18 (Russell Group 2016).

But, as indicated by the lack of uptake amongst state school leavers, foreign language study does not appear to be a problem that lends itself to remediation according to prevailing access agreements at Oxbridge or the Russell Group generally. This is due to a broader misrecognition of the underlying dynamics and mechanisms that produce uneven advantages, which are nonlinear and thus cannot be redressed through simple tokenistic re-proportioning at the interface between school and university.

Consider: critiques are regularly levelled against the 'elitism' of an educational system in which 53 per cent of senior diplomats have been privately educated compared to 7 per cent of the public as a whole (SMCPC 2014). But, what is to be done when the proportion of university students pursuing a relevant subject at university (28\%) nearly matches the proportion of independent school students in the subject $(25 \%)$ ? The overall disproportion will inevitably continue unabated until requirements for university admission remove the expectation of prior study in the language - a condition which is already well under way at universities - to encourage non-privately educated students of disadvantaged backgrounds to pursue subjects they have not previously been provided access to. But, what if students still have no interest in pursuing a difficult and often frustrating subject that they have had little, if any, exposure to?

Indeed, we can see a starker indicator of this problem in other undersubscribed subjects at Oxford. According to the university's admissions data, of the 98 students accepted to read classics in 2015, 71 were independently educated. Disproportionate? Yes. Yet, only 79 students from state schools even applied. To reach a condition of parity (50/50), Oxford would have to accept 60 per cent of the state school applicants in this subject. To reach a figure comparable to the population at large (7\% privately educated) within a similar cohort size (98), classics would have to accept all of the state school applicants plus recruit an additional 12, while excluding all but seven of the 162 privately educated applicants. It is easy to see that such elite culling would be impractical in a subject like classics, which few state school students have been introduced to. Yet, a similar, if less severe, condition is evident in the decline of modern foreign languages.

These proportions and similar dynamics are not, in fact, an accident of recent history - the unintended consequences of a 2004 budget cut in secondary education provision. Indeed, the fates of modern foreign languages and classics have been linked since the emergence of modern education as such. Attending to this history will cast the current crisis in a new light - one that highlights that the history of modern education has always been a history of expanding access to education. This expansion progressed in iterated 
opposition to requirements perceived to be 'elitist' and 'exclusive' at the time. In response to such progressive forces, requirements were removed, thereby converting core knowledge into mere subject material - the 'specialized' provinces of academic disciplines, where the centrality of teaching and learning could be displaced in favour of 'research', 'transferable skills' and, now, increasingly 'impact'.

The paradox of this long-term 'academization process' is that, although we have succeeded in widening participation in HE, not only has the broad, shared knowledge of earlier traditions been lost in the acid wash of progressive antielitism; but, indeed, the value of the educational credentials conferred to everwidening populations has been debased, resulting in ever-widening social inequality in the wake of expanded university education.

\subsection{Classical vs. modern education in the mid-19th century}

In Culture and Anarchy, Matthew Arnold, writing in the late 1860s, pushed backed against those critics who identified 'culture' with a 'smattering of the two dead languages of Greek and Latin', noting their contention:

The culture which is supposed to plume itself on a smattering of Greek and Latin is a culture which is begotten by nothing so intellectual as curiosity; it is valued either out of sheer vanity and ignorance, or else as an engine of social and class distinction, separating its holder, like a badge or title, from other people who have not got it.

(Arnold 2006: 32)

Challenging this widespread sentiment, which today echoes in Bourdieusian chambers, Arnold recommended instead a true culture: the 'disinterested' effort 'to see things as they really are, to see how worthy and divine a thing is' (Arnold 2006: 23). It was the role of the critic, and the teacher, to identify and profess that which was timeless, universal and good within historical and contemporary societies (Arnold 1864). His social idea was that the men of culture were the true agents of equality - by diffusing the best human civilization had to offer. He further demonstrated the practical 'utility' of this within policy:

Culture [would be] a great help out of our present difficulties; culture being a pursuit of our total perfection by means of getting to know, on all the matters which most concern us, the best which has been thought and said in the world, and, through this knowledge, turning a stream of fresh and free thought upon our stock notions and habits, which we now follow staunchly but mechanically.

(Arnold 2006: 5)

Culture was then associated with bookish pedants, but it need not be. He noted the manner in which, for example, education policy in Germany - which did 


\section{Paradoxes of the academization process}

strive toward the lofty ideals of Kultur, Bildung and Wissenschaft-managed to distribute intellectual, moral and scientific knowledge more widely across Central European society. It was the focus on quality, rather than quantity, technology or rank which pushed German education ever higher in the world's estimation.

We can situate Arnold's message and motivations in the context of education policy debates occurring during the 1860s. Perhaps no other decade witnessed as much discussion, upheaval and reform in British education though this was largely directed at the level of secondary schools, rather than at the university level, as would be the case later in the century with the advent of 'redbricks' (Whyte 2015). The culmination of this process was the Endowed Schools Act of 1869, which had been preceded by the Public School Act of 1868, which had, in turn, been instigated by criticisms made by the Clarendon Commission of 1861-64. Driven by Liberal politicians, reformers and, notably, social scientists working under the auspices of the National Association for the Promotion of Social Science (Social Science Association) founded in 1857, the reforms amounted to a widespread extension of the purposes of and participation in education (Goldman 2002). Among the most unexpected elements in the Endowed Schools Act was provision for girls' education at a time when the public call for such equality was limited to academic and nascent-suffragist circles (Fletcher 1980).

Thus, the decade in which Arnold - then, Inspector of Schools - felt compelled to defend 'culture' against its enemies was one in which access to secondary education was expanding apace, resulting in reform of endowed grammar schools, public schools and the foundation of new grammar schools for girls.

But, of course, the issue of widening participation was not then exclusive to women's education, and, indeed, Cambridge failed to formally recognize women's exam marks until 1948. In fact, the greatest motivation behind the Clarendon Commission and subsequent reforms was removal of restrictions inhibiting the participation of the middle classes in what were essentially latemedieval institutions: first the public schools and later the endowed grammar schools. Thus, it is worth recounting here the actual structure of medieval European education prior to modernization (see Durkheim 2013).

The first thing to note is the primary religious function: education, secondary and university, was primarily oriented toward the training of the clergy, and secondarily to the training of the 'learned professions', medicine and law. In 1830, half of all undergraduates from Oxford aimed to become parsons and one-third were parsons' sons. A tertiary function, which emerged during the Renaissance era, involved the socialization of errant aristocratic sons, whom Arnold would later call the 'Barbarian' class. Putting such nobles in close proximity to poor pastors' sons reading for a theology degree would encourage greater austerity of manners and, perhaps, some enlightenment amongst the upper classes. Through this process, schools and universities obtained subsidy for their endowments, which were otherwise stipulated in 
charters to provide for the welfare and education of poor children (read: parish priests) on behalf of the public interest. However, over the course of the 16th-18th centuries, the aristocratic socialization function increasingly came to the fore, so that it was a badge of honour to be educated in a public school. It was also during this period, beginning in the late-16th century, when classical Greek was introduced in England as part of a more humanist tradition promoted by Erasmus and centred on the individual, which also retained an emphasis on manners, civility and behaviour (Bywater 1919; see also Elias 2000).

Still, the ancient public schools and universities were by no means the best appointed of institutions at the turn of the 19th century. Buildings were inadequate, libraries musty, wells and kitchens fetid and underserviced. Oxford was considered a 'laymen's church' without the exalted sense of itself it developed across the century. Many of the higher faculties of Theology, Law and Medicine were folding outside leading colleges like Christchurch (Brock and Curthoys 1997). Classics was often the only course of study every college could provide. Prospective students might wander from one gate to another seeking an audience with the Master or Principal, being interviewed until accepted or not. Thirty-five per cent of students were graduates of the nine 'Clarendon' schools, and many would have been admitted according to geographically delineated endowments and scholarships. In 1842, an anonymous graduate eviscerated the state of things in a pamphlet called 'Oxford Unmasked':

What shall we say of the Classical lectures, but that they are the most desultory, imperfect and useless conceivable? ... It is neither a classical nor a religious education we object to, but the mistaken, expensive, imperfect, useless, nay, childish and mischievous mode in use at Oxford.

(Richards 1842: 24-26)

Increasingly, critics challenged both the elitist exclusivity of Oxbridge and the unthinking archaism of a curriculum organized around dead languages and rote memorisation. Why? Firstly, many school charters stipulated that these 'grammar schools' were required to teach Latin and Greek. Further, the ancient universities - Oxford and Cambridge - required near fluency in both languages for entry into higher education, and, thus, classics were a prerequisite to access the learned professions. In 1794, the president of Corpus Christi College, Oxford, responded to a friend's query regarding whether his son might fare well as a candidate having studied only common school books.

It is difficult to form any conjection of the modes of Book Examination that the Electors Seven in number besides the President will adopt, as Each Gentleman separately takes the Candidate to himself; and usually I believe tries him in authors he has not read as well as in those which he has; So as to put out of sight all attempt at preparation for the Day. But 
above all, of the greatest importance is a proficiency in Composition, which indeed is the best Test of good Abilities. Should your Son be so fortunate as to have been led on properly in this way, he will account in it with us; as well as (what is of still much more consequence) in any station of Life to which he may be called. ${ }^{1}$

Classical study was deemed necessary to 'sharpen the mind', a position common across the Britain, but Oxford was unique in asserting classics as the only mind sharpener. This status extended to those members of the established church and establishment classes whose rites of passage were conferred via Oxbridge. Thomas Macaulay, arguing in Parliament about reforming the East India Company asserted:

It is said, I know, that examinations in Latin, in Greek and in mathematics are no tests of what men will prove to be in life. I am perfectly aware, that they are not infallible tests; but that they are tests I confidently maintain. Look at every walk of life - at this House - at the other House - at the Bar - at the Bench - at the Church - and see whether it be not true, that those who attain high distinction in the world are generally men who were distinguished in their academic career.

(HC Deb 10 July 1833, 3s xix 526)

Mid-century, the retention of classical language instruction in Britain was such that when the Clarendon Commission asked Edward Balston, the headmaster of Eton what measures were being done to 'keep up' English and French at his school, he replied: 'none at present except through the ancient languages' (Shrosbree 1988: 54).

For several reasons, British universities managed to gradually adapt to a new, modern curriculum as demanded by liberals. Drawing on an articulate, yet liberal conservatism expressed by Burke, Coleridge, Copleston and others, they very intentionally preserved humanistic and holistic elements of the classical curriculum, while also allowing new modes of study. In particular, as in Germany, English resistance was particularly directed against the French Enlightenment model of encyclopaedic knowledge, which had set itself in opposition to Aristotelian logic and metaphysics. This was associated with vulgar materialism, particularly amongst the established church of England (since Scotland and Ireland had different religious establishments - complicating matters to say the least). As historical sociologists Mayrl and de Swaan have noted, religious competition has tended to lead to mass expansion of education as well as a secularisation of knowledge (Mayrl 2016; Swaan 1988). In Britain, these were differentiated across the nation - and region, with considerable north/south divisions in England as well. But, because this was a long and generally top-down process - emanating not simply from Oxford, but even more specifically, from two dining tables sat across from one another at Oriel College (Brock and Curthoys 1997) - this meant a well-articulated 
alternative to non-conformist, middle-class attempts to change the curriculum were developed and implemented largely by the noetic liberals, rather than Oxford-Movement High-Church conservatives. Across the century, these selfdirected reforms drew further upon the emerging insights of German idealists, who also affirmed the value of classics, though for different reasons.

Arnold, who repeatedly addressed the conflict between 'non-conformists' and 'establishment' religions, noting that the former were associated more with the industrial middle classes, or 'Philistines' in his terminology. These were associated with utilitarianism, and running throughout their criticism levelled against the archaism of the classical education was a challenge to the alleged idleness of the Old Regime classes that had been swept away in more 'modern' societies like France and America. In England, retention of a purely classical education only served the forces of tradition and conservatism, keeping Britain back from the inevitable forces of progress, industry and social equality. Critique of aristocratic privilege, indeed, had a long pedigree amongst the European middle classes, as Gouldner noted:

The middle-class standard of utility developed in the course of its polemic against the feudal norms and aristocratic claims of the 'old regimes', in which the rights of men were held to be derived from and limited by their estate, class, birth or lineage: in short by what they 'were' rather than by what they did ... Developed in the course of its struggle against the nobility, the ideology of usefulness was in part a residual concept: the useful was that which the nobility was not.

(Gouldner 1970: 62)

Rather than express their own self-interest - their goal to enter and control positions of power, notably the public purse - the bourgeoisie generalized their grievances as a 'public interest' in universal standards of 'utility'. These standards were, in fact, exceedingly limited in their narrowness on those aspects of the self and culture which contributed to the technical and economic growth of market society, aspects which the middle classes felt the aristocracy did not embody due to their unearned 'privileges'.

In time, these bourgeois ethics would be assimilated into state and society, but not without changing the habits and behaviours of the aristocracy itself, which became more 'productive' and 'useful', as David Cannadine and others have noted (Cannadine 1990; Mayer 1981). In fact, rather than a straightforward decline of the aristocracy in the 19th century, we can see the emergence of a new upper class consisting of productive aristocrats earning money in mining, imperial projects and finance while mixing with the new middle classes that aped the aristocratic culture in a manner often perceived to be vulgar. Few sociologists today recognize Norbert Elias's observation that 'men of the robe' - in other words, learned professionals - had earlier represented the middle classes in the Old Regime (Elias 2000: 324). Yet, these professionals relied on their state-sanctioned special privileges as much as the 


\section{Paradoxes of the academization process}

landed aristocracy (Bourdieu 1996). Thus, the elimination of privilege, enacted by the French Revolution and later extended throughout the 'modern' world, amounted to a displacement of the meaning of professional qualifications: from one in which access to the learned professions was restricted according to the ecclesiastical expectations of the church, to a new basis adhering to those deemed most useful to the bourgeois state. It was this revolution which middle-class, utilitarian reformers sought to institute within the public school system and, later, the endowed grammar school establishment, but ultimately with a shifting of the established church's stranglehold on university education.

Again, it is worth recalling what these schools were for: in particular, we should note why they were called 'grammar' schools. Of course, one needs to understand grammar to learn any foreign language - whether French, Latin or Greek. This instruction was the first of seven elements within the medieval curriculum: the 'trivium', which preceded the 'quadrivium' learned at university (Durkheim 2013). The trivium provided students with an understanding of grammar, logic and rhetoric. It was understood that by learning grammar - any grammar - one would learn how language works and how to receive written and spoken information, which would, in turn, be processed through logic and converted into speech through rhetoric, as in a religious sermon. Thus, understanding and mastery of language were deemed essential, for example, in order to understand the logic of propositions: how creation of a subject and predicate also implies certain forms of causality or generalizability, or it contributes to certain rhetorical strategies for persuasion.

Particularly during the humanist era, there were multiple reasons why classical languages were preferred, since it was understood that one could best learn these rules by creating a distance between one's own vernacular and that of a foreign tongue. After all, we each learn our language during childhood, but we do not learn the rules governing it, as anyone who has felt the pangs of English grammar drills can relate.

By focusing on the classics, including Greek philosophers and Latin historians, students were exposed to an entire civilization's worth of thinkers grappling with the very problems of logic and rhetoric in the trivium, or arithmetic, geometry, music and astronomy covered in the quadrivium. Not only the intellectual questions, but also the social and moral questions which confronted Cicero, Tacitus, Plato and Herodotus could be drawn upon to provide students with perspective on an entire social order: how it worked or did not work, how it shifted and why it changed or declined. Via the medium of the classics, students engaged with every aspect of social and philosophical questions, from which they could better evaluate their own role in contemporary history.

Undoubtedly, by the 1850s the public schools and endowed grammar schools had their flaws, and many likely resembled the caricatures of pedantic schoolmasters surrounded by dusty books. But, it was not sufficient for the utilitarians to simply challenge the delivery of the curriculum. Rather, their 
position was that the entire classical curriculum should be replaced, or at the very least supplemented, by modern forms of study, including science and modern foreign languages; for these would be deemed more 'useful' within contemporary commerce, diplomacy and cultural exchange.

Henry Sidgwick, writing in 1867 , expressed the many reasons why a classical education was unnecessary insofar as modern foreign language study could accomplish the same and more (Sidgwick 1968). First, he noted, there is no reason why Greek and Latin should go together 'like Siamese twins': students could learn just as much by reading Sanskrit, Hebrew or other dead languages, if difficulty and deadness were deemed necessary conditions. Secondly, Sidgwick noted that, although classicists were staunch defenders of a 'liberal education', they had taken to defending the 'professional utility' of their instruction, not unlike contemporary humanities professors who note the 'transferrable skills' such subjects provide on the job market today. But Sidgwick stated:

the advantages are found to be unequally distributed among the different professions ... Greek is of use (we may say indispensable) to clergyman: Latin to lawyers and learned men. The other infinitesimal fragments of utility may be disregarded for our present purpose.

(Sidgwick 1968: 301)

Thus, the question was, in fact, reducible to the value of a 'liberal education' and to what extent this was dependent on classical study 'as the best introduction to the study of Philology, as including the best instruction in the universal principles of Grammar, and as indispensable to a real knowledge of English and of other modern languages' (Sidgwick 1968: 301). Here Sidgwick acknowledged the importance of understanding 'universal grammar' for a philosophical understanding of logic. Further, he acknowledged the difficulties of mastering these necessary grammatical distinctions within one's mother tongue. But here, the utilitarian resorted to the pragmatics of instruction insofar as 'nine-tenths' of the students' time is devoted to rote memorization, and the advantages of universal grammar would be much increased if the student were to learn French instead (because it was easier).

Sidgwick also acknowledged the value of philology, which classical study provided, for understanding the historical development of language. But this is merely a specialized subject on a par with - nay, of lower rank importance compared to - sciences like 'Physics, Chemistry, Astronomy, animal and vegetable Physiology' and so forth, which have had the greater influence on 'the material welfare of the human race' (Sidgwick 1968: 302-303). And, since we could not possibly include all the sciences in a general education curriculum, it seems those satisfying 'mere curiosity' should be left to the specialists rather than occupy the core of a secondary school education.

The last point upon which Sidgwick argued against the necessity of the classics was on their contribution to appreciation of literature; in other words, 
the content of the classics as well as their influence on later European culture in the works of Milton and Shakespeare, for example. One could not understand the intellectual milieu or meaning of great works if one did not understand the classical references and allusions. Here again, he points to the pragmatics: 'for the general reader, who has no wish to go so deep, classical knowledge does not do much more than save some trouble of referring to dictionaries and histories, and some ignorance of quotations' (Sidgwick 1968: 304). After all, are there not plenty of obscure references within (then) contemporary Victorian fiction? We should therefore pick up classical allusions from contextual clues and hazy understanding as we do when reading novels. Indeed, for the purposes of general edification, students would be just as well appointed from study of English literature as of classical texts.

Thus, the moral philosopher concluded that classics, while a significant body of enquiry that should not be lost entirely, should nonetheless be relegated to the status of a specialized discipline. In its place, the necessary functions of instruction in universal grammar, philology and literary edification would be replaced by modern foreign language instruction and, perhaps, a course in English literature; in others words, today's 'humanities' or 'arts' disciplines.

But note: firstly, Sidgwick did not deny the need for some basic, core competencies in grammar, logic and rhetoric. He merely suggested these could be more easily delivered by means of foreign language and other humanistic study. Secondly, by relegating the classics education, deemed only 'necessary' for a clerical office, he displaced the primacy of religious instruction at both secondary and university level, thereby making the profession of clergyman a 'specialized' profession within a field now open to other middle-class occupations.

The critique of classics, thus, not only removed the difficult and demanding standards of 'elitist' schools and universities on behalf of the middle-class students wishing to enter educational establishments in greater numbers; it removed the old learned professions' special authority (and, by extension, that of classically trained aristocrats and gentry) within the traditional political order. Thus, the replacement of classical education with modern foreign languages opened the gates of the ivory tower for middle-class children and middle-class values. The resulting shift from a traditional to a modern education system, by extension, contributed to a new, more 'modern' society.

Yet, as Arnold recognized in real time while witnessing the shift from his official position as inspector of schools, the manner in which middle-class 'Philistines' generalized their complaints against dusty classicism would not translate into a democratisation of knowledge. Rather, such values, emphasizing what one did and what use one had on the market, rather than what culture one had obtained, would 'debauch' both the middle classes and those who would enter education in their wake:

Only the middle classes are told they have done it all with their energy, self-reliance and capital, and the democracy are told they have done it all with their hands and sinews. But teaching the democracy to put its trust 
in achievements of this kind is merely training them to be Philistines to take the place of the Philistines whom they are superseding.

(Arnold 2006: 49)

By dismantling the barriers excluding them from powerful positions, and by smashing the classical edifice while paying lip service to retained 'equality of access' to classical research, utilitarian reformers not only swung open the college gates, they lowered and changed the standards of what it meant to be educated, cultured and professional. In her final work, George Eliot similarly despaired at what she perceived to be this 'debasement of the moral currency':

This is what I call debasing the moral currency: lowering the value of every inspiring fact and tradition so that it will command less and less of the spiritual products, the generous motives which sustain the charm and elevation of our social existence - the something besides bread by which man saves his soul alive. The bread-winner of the family may demand more and more coppery shillings, or assignats, or greenbacks for his day's work, and so get the needful quantum of food; but let that moral currency be emptied of its value - let a greedy buffoonery debase all historic beauty, majesty, and pathos, and the more you heap up the desecrated symbols the greater will be the lack of the ennobling emotions which subdue the tyranny of suffering, and make ambition one with social virtue.

(Eliot 1879)

Eliot's and Arnold's critiques of middle-class philistinism would inspire members of generations then and since to resist the erosive impact on standards amidst the expansive tide, including many of the contemporary educational reformers, like John Percival, who was instrumental in founding the redbrick University of Bristol and, earlier, Clifton College, which combined both classical and modern language study in sixth form to great effect (Arkwright 1901; Temple 1921). Indeed, Oxford and Cambridge, while allowing exceptions within natural science admissions for other foreign languages as their second or third language, retained Latin as compulsory until well into the 20th century as an indication of some exposure to a liberal, classical education at secondary school. Because of these entrance expectations, Latin and Greek continued to be taught at public schools as well as the state-funded 'grammar schools' within the tripartite system of education adopted after World War II.

Still, by 1959 , Cambridge was compelled to drop Latin as a compulsory entrance requirement. Candidates could choose either Latin, Greek, German or Russian as one of two foreign languages. In a 1962 commission established by Oxford to review their admissions procedures, the only objection came from one fellow, MacDonald: 
I do not regard mere usefulness as one of the main factors to be considered in education. It is, however, not only useful, it is essential that scientists should have an understanding of the functions, nature and structure of language, and in my opinion, the best means to achieve this understanding in most English schools is at present the study of Latin. ${ }^{2}$

He went on to explain that perhaps, in future, foreign-language textbooks could be developed that incorporated the vast range of rhetorical, grammatical and logical elements that had been passed down for centuries as part of the Classical curriculum, but until that had happened, entrance examinations should not be made less difficult simply to encourage students - from both disadvantaged backgrounds and the natural sciences - to enrol.

At both institutions, those in favour of the changes noted the greater 'utility' of German or Russian in diplomacy or medicine. As reported in the Sydney Morning Herald (Anon 1959), Sir Cyril Hinshelwood, the Chemistry professor who introduced the resolution at the Regent House said: 'I am perfectly convinced that Latin is safe and that for generations to come it will be one of the favourite options of large numbers of people'. And so we come full circle to the disproportion of both classics and foreign language study in independent schools, and by extension elite universities.

\subsection{Neoliberalism and the cultural arbitrary}

As noted above, a persistent decline in foreign language study characterises contemporary university enrolments. While critical scholars might be inclined to blame this trend on the 'neoliberal' forces of marketization, this cannot account for the problem insofar as no market rationality seems to steer students into a subject which engenders a range of 'transferable' and 'marketable' skills within a globalized economy. Rather, we have seen that, from a processual point of view, the decline in foreign language uptake was the result of the removal of this form of instruction within secondary schools responding to university entrance requirements. In fact, the impulse to do so was precisely to widen, not limit, participation and access to university. Once removed from the bulk of maintained schools, independent schools disproportionately retained this instruction in foreign languages, and leavers of these schools remain much more likely to apply to elite universities for advanced study in these fields. Indeed, the disproportion is even greater with regard to classics, insofar as public schools are more likely to retain the requirements dating back to the medieval period - though updated, of course, to also include more 'modern' subjects in science, modern languages, computing and so on.

Yet, the qualitative advantages of this broader level of instruction is lost in the persistent criticism of these schools' intrinsic 'elitism': their conferral of unfair 'privileges' and 'arbitrary' cultural capital. Whereas, as Bourdieu and Passeron (1990) themselves noted, although there is a correlation between 
training in Greek and Latin and the acquisition of cultural capital, this was potentially conferred via a 'better' education:

If students who have done Latin and Greek are distinguished by their verbal ease, this is because they have selected themselves (or been selected) by reference to an image of the hierarchy of the sections of secondary schooling in order to lay claim an entry into a section which the system reserves for its elite and which attracts to itself the teachers most likely to turn these good pupils into the very best pupils.

(Bourdieu and Passeron 1990: 83)

Yes - this is a question of resources - but ONE of those resources is the holistic, rounded curriculum itself. Meanwhile, across the channel, Bourdieusian scholars in Britain admit only tentatively and inconclusively that: it is possible that private schools may instil cultural capital in pupils' (Sullivan 2001: 909).

The field of educational research, while understanding the mechanisms and uneven distribution of cultural capital and its effects on social reproduction, concludes that the best means of redressing this inequality is to eliminate 'elitist' barriers which make more disadvantaged students less inclined toward participation in higher education (Crozier et al. 2008; Graham 2013; Reay et al. 2005; Stich 2012). For example, Reay (2016) chastises Oxbridge for not admitting enough students on free school meals or from low-participation neighbourhoods, noting that her own university admitted only 3.1 per cent from the latter target rather than their benchmark of 4.8 per cent. But consider: Cambridge's first-year intake was 3,449, meaning a bullseye would benefit the circumstances of precisely 59 individuals. These students might hail from the 'precariat' class, which recent estimates suggest amounts to a population of 9,615,000 (Savage et al. 2013). It is most unlikely these few dozen students will transform the British class structure. Further, if universities confer cultural capital, rather than simply objectifying privilege, these 59 students would become middle- and upper-class actors at the end of the process. This will only accentuate the distance between their class of origin and their class of destination insofar as they will be middle class, not working class, upon conferral of degree. That class position will, in turn, be reproduced intergenerationally - as their children will likely also be middle-class professionals.

Indeed, we should consider the origins of our particular, contemporary discourse of widening participation during the period within the longer academization process, during which the beneficiaries of a widened state grammar school system entered university. By 1965, nearly a century after the Clarendon Commission concluded its investigation into public schools, the Crosland Report determined that such schools had become exclusively middle class in orientation (King 1968). Such elitism and exclusion was deemed unacceptable, so these schools should be better integrated into the state 
system, which was undergoing its own transformation as grammar schools became either comprehensive or privately endowed. The Crosland investigation noted that public schools were not only socially exclusive, they were restrictive in terms of 'ability', and were highly gendered: three of the 273 schools investigated were coeducational. The commission recommended that these schools must take on students of mixed ability and mixed class structure as well as give equal representation to girls. This reflected a new, second phase within the progressive expansion of education: since equality of access did not result in equality of results, it was deemed most important that educational intakes and enrolments match the demographic patterns of society at large. This reflected a new interest in middle-class modes of representation - schools and other organizations became representational utopias - wherein, ideally, the percentages of different groups in society would be proportionally distributed.

The first phase of the academization process involved the transition from a medieval university to a modern, elite university. This successfully established a connection between a university education and access to positions of power in business, politics, professions and cultural institutions. Initially, higher education was restrictive in terms of access, especially in terms of ethnicity, class and gender. This exclusivity was subject to critique, most notably from middle-class women, but increasingly from representatives of the working class, ethnic minorities and other excluded groups. The ideal of universities was now to obtain a relatively proportional 'mirror' of the demography of society. Failure to live up to these ideals results in more or less constant critique since the throughput drivers and outcomes are rarely addressed. In fact, such critiques of universities as elitist institutions, where graduates are mere individuals simultaneously embodying both unearned privileges and technical skills, reproduce the middle-class argument against the Old Regime in the first phase of the academization process. In other words, the contemporary critique of privilege is an exceptionally middle-class behavioural habit. Subsequent reforms to universities do not adequately engage in the actual world beyond the academy - the 50 per cent of school leavers who do not attend higher education, for example. Rather, these groups are imagined according to the utopian ideas that middle-class - more precisely, New Class - academics and professionals have about themselves. The embedding of these discourses in coursework, and even more so within extramural and residential activities, reflects the ascendant New Class groups' desire to reform the curriculum in their image.

This largely impacts only the discursive dimension of ideological power identified by Reed, as it addresses only the level of second-order observation identified by Luhmann. Graduates become experts in reproducing certain forms of statements and ideas surrounding difficult topics such as racism, sexism and homophobia. But, these statements, on their own, do not remove those phenomena from society.

A deep paradox results from this retained anti-elitist elitism, which compels students and academics to deny the possibility that educational advantages 
could be earned. For, as enrolments expanded and diversified, the institutional structure of the modern university did not fundamentally shift. University degrees remained a narrow bridge of access to social positions, so greater inclusion of diverse populations effectively converted these disadvantaged students into members of a more diverse New Class of academics and professionals. This social mobility benefits individuals, but it does not benefit the other members of groups who are not so educated. Thus, expansion of higher education in the second wave exacerbates, rather than mitigates, inequality, as the hierarchy of ranked universities replaces mere access to university.

Indeed, the anti-elitist elitism of the New Class becomes increasingly untenable as more and more young people obtain higher-education credentials, assuming large amounts of student debt in the process. Meanwhile, overcredentialization leads to precarious job prospects in a range of professions, including academia itself, where adjunct jobs are being largely filled with women - not necessarily, I would argue, because of their gender (though certainly much discrimination is experienced on a day-to-day level). Rather, this disproportion is the result of the inclusion of women (and other excluded groups) occurring after the massification of the university was well underway. These cohorts are overrepresented within the overcredentialed 'academic proletariat'.

This pattern is compounded and reinforces the bifurcation between the research and teaching functions of the academic profession. An underclass of adjunct lecturers and graduate students - held in limbo for years on 'studentships' and, in effect, prolonging their economic adolescence - work for little pay and with little job security, performing the larger part of instruction to ever-widening student bodies. Meanwhile, older researchers obtain high salaries, are rewarded with considerable perks and travel the world delivering talks and receiving prizes at high-profile, international conferences.

Whereas the first phase of the academization process displaced the clergy with a range of specialized professional and academic curricula, this did nothing to displace the elitist structure of higher education. The tiered structure remained; in fact, this hierarchy would become ever wider as the interim tier of grammar schools was eliminated, leaving independent and comprehensive schools on two unequal tiers gaping across a chasm of genuine privileges (resources and capital: economic, cultural, social, symbolic). In the 1990s, the similar dual structure at university level was dismantled by renaming polytechnics as 'universities': forcing these institutions to compete within a single, rank-ordered cohort ostensibly pursuing the same higher educational goals. Today, as the same sociological critics regularly note, the majority of disadvantaged students entering university in recent decades are enrolling in these former polytechnic, post-92 universities, which occupy the lower tiers of the HE hierarchies.

The result of such efforts to widen participation has not, and will not, result in a transformation of the social-class structure of the United Kingdom (Goldthorpe 2013). Indeed, insofar as 50 per cent of students, at best, will 


\section{6}

enter higher education, predominantly in the lower tiers, current efforts to widen participation may only exacerbate inequalities by producing a new hierarchy: those with degrees and those without. Such a process has already taken place within the United States over the course of three to four decades, such that demographers now identify membership in the American 'working class' with whether or not an individual has a college degree. This is how political scientists identify such strong correlations between Donald Trump's current popularity with both the 'working class' and the 'poorly educated'. Similar proportions could be drawn with reference to the recent 'Brexit' vote, which was more popular amongst those who had not obtained HE credentials (The Economist 2016). Indeed, the Brexit/Remain divide (52/48) is likely indicative of the new structure of British politics organized around education versus the lack thereof - one that is mirrored globally as Piketty (2018) recently observed.

Meanwhile, by ensuring that universities at every level are neither elitist nor exclusive, access agreements diminish the very qualities which would provide incoming students with the resources they are sent to university to obtain. As the case of foreign languages demonstrates, entrance requirements have steadily diminished for centuries, affecting all students, not only those with ability and potential but lacking means. Where once Latin and Greek were replaced with a baseline of Latin and another foreign language, now there is no foreign language requirement at all. The academic field of languages, now a specialized subject rather than a core requirement, steadily diminishes in enrolment and is forced to compete by becoming more popular: often by offering cultural studies courses in English or showing sub-titled films. As students have become consumers, university 'providers' have to reckon with the fact that difficult subjects and requirements put them at a disadvantage. Students are less likely to enrol. And, the first cohort Oxford and Cambridge adapted to bent over backwards for - were the natural scientists in the 1960s.

Today, amongst critical university scholarship, such conditions and crises of the humanities are regularly blamed on the all-pervasive trends of "neoliberalism': the ever-creeping expansion of market rationality in cultural institutions where it does not belong (Eagleton 2010; Heller 2016; Smyth 2017). But, as Nietzsche (2015) noted during Germany's own phase of widening participation, the expansion and dissemination of education knowledge goes hand in hand with the narrowing and weakening of knowledge:

For various reasons, education is supposed to reach the widest possible circle - such is the demand of the first tendency. But then the second tendency expects education to give up its own highest, noblest, loftiest claims and content itself with serving some other form of life, for instance, the state.

(Nietzsche 2015: 15)

This condition of 'anti-education' was the result of the state's establishment of mass education as the only means through which one could enter the civil 
service. The demand for universal education necessitated a broadening of the criteria through which teachers were accredited. This group then redefined and narrowed the definition of 'culture' according to their own sensibilities, resulting in a more 'mediocre' content, which, on the one hand, diminished the 'aristocratic' content of a properly classical education (which Nietzsche, like Arnold, admitted no longer existed even amongst the philologists), while, on the other hand, the populace was alienated from their own culture and spirit. All were forced into an equally middling, 'levelled' culture, which was not so much the lowest common denominator, but a contentless purgatory in which everyone was equally dissatisfied and unintimidated, if otherwise powerless and slavish. Sounds like 'neoliberalism' to me.

Tracing the history of the classics and modern language instruction in Britain, the state was less involved - certainly at Oxbridge - so here the removal of barriers and entry of the middle classes did not immediately draw teachers and students into the homogeneity of the state. Rather, religious establishments provided the social boundaries throughout the 19th century. To understand the development of the academization process in Britain, we must accordingly grasp the history of religion and the stakes of religious conflicts. These did not always occur in relation to higher education, but might come up in secondary school reform or issues surrounding professional jurisdiction. Through this long, slow process, education more dramatically and flexibly accommodated the narrow bourgeois values and 'utility' of market society. In generalizing the bourgeois complaints against the aristocracy in terms of the 'uselessness' of a classical education, such holistic forms of study were thereafter disdained as a form of 'elitism', even as more middle-class students obtained this education. By the 1960s, with the public schools again under attack, this elitism was challenged by the very students who benefited from this very education, just as Sidgwick had obtained a classical education before declaring it unnecessary.

But note, during the second wave of expansion, this anti-elitist critique was not always levelled by working class actors themselves. Rather, public school (and grammar school) exclusivity was challenged often by the educated middle classes themselves as self-appointed representatives of the 'public interest'. As Gouldner noted about this 'New Class' of academics and professionals: 'the paradox of the New Class is that it is both emancipatory and elitist. It subverts all establishments, social limits, and privileges, including its own' (Gouldner 1979: 84). For, unlike the previous century's challenge to aristocratic privileges made by the middle class in its own interest, in recent decades the subversion of middle-class privilege has been made by the middle classes themselves.

The discourses surrounding widening participation have been developed, shaped and promulgated within universities by professional academics studying and theorizing the conditions of inequality, then extending those critiques as critiques of their own institutions. Recognizing that they are themselves implicated within the very structures they criticize - which are 
'neoliberal', 'racist', 'sexist' and so forth - contemporary academics then insist that their own house be put in order. They therefore insist universities admit more women; black, Asian and minority ethnic (BAME) students; working-class actors and so forth. But, perhaps this is most important, not as a means of obtaining social justice, but as a means of justifying their own existence.

Consider: successive governments since New Labour's 'education, education, education' pledge have expanded university education at an astonishing pace, reproducing the rutted conditions which took America decades to settle into (Newfield 2011). But, every one of these expansions and 'marketizations' has been coupled to a package of widening access. In 2004, the Office for Fair Access (OFFA) was established to ensure universities invested in reaching targets for underrepresented groups in higher education. As student fees were trebled in $2011, £ 1,000$ of the additional $£ 6,000$ was to be spent on scholarships and widening participation offices at universities. Remaining critical of the 'neoliberalization' of the university in years since, most academics have been sated by lip service paid to disadvantaged students and are prepared to take fees from tens of thousands of middle-class students provided a sufficient - and more or less specific - number of non-traditional students were allowed into Oxbridge.

All of this has been accomplished with the greatest of haste: a remarkable achievement of modern 'neoliberal' university administration. Recent reports indicate that, since 2011, the proportion of BAME students attending Russell Group universities has increased so it now matches the proportion of nonwhite population in the UK at large (Russell Group 2016). Of course, these may not necessarily be BAME students from the most disadvantaged backgrounds, since these could just as easily be Asian, black or other non-white students who attended independent schools. But, the targets were reached quickly and easily - by simply selecting those members of the population with the required demographic characteristics.

All the while, in a zero-sum game, by necessity those with undesirable characteristics are deselected. At Oxbridge, one metric includes a target ratio $(64 / 36)^{3}$ of state versus independent schools, a condition which has changed the much derided 'coaching' strategies at places like Eton: high ability but poor 'scholarship boys' (still admitted, as ever, under the school's chartered mission) now ensure their personal statements include reference to their humble origins. Otherwise, the 'contextual data flag' indicating 'ETON' at the top of the UCAS form could diminish their chances at interview. Having participated in such interviews and admissions panels, and having attended workshops instructing faculty to 'beware' of interview 'coaching' in order to reach access targets, I have seen first-hand the level of prejudice levelled at 'posh' students with RP accents; at the same time, I have observed patronising remarks about potential 'access' candidates, who might be deemed 'a double whammy' if they are both black and poor. I have also heard colleagues' first-hand horror stories of students more or less let in 
via patronage networks that remain informally in place as they did 200 years ago. All the while, the largest state school feeder to Oxbridge has become Hills Road Sixth Form, where the majority of Cambridge academics send their own children. These students, of course, are ideal insofar as they bump up the state/independent ratio and are, accordingly, most welcome whether they were 'coached' or not. Such are the conditions engendered by setting targets on the second-order of metrics rather than on substance.

\subsection{Conclusion}

My intention in this chapter has not been to discourage the continued efforts to widen participation to demographic groups which are underrepresented in higher education, but merely to adopt a detached perspective to see why progress is not as forthcoming as we claim to want. The analysis highlights some of the complexities and ambiguities of the project of widening participation or encouraging 'diversity', which may not necessarily be a good in and of itself. We should perhaps focus more on the practical and performative effects of these institutional policies - e.g., in the actual uplift of entire disadvantaged communities. As American sociologist Shamus Khan (2010) observed at his old boarding school, St. Paul's, what has emerged from affirmative action policies in such institutions is a new elite, which might be more 'diverse' in one direction, but equally homogeneous and entitled in another.

More importantly, as the case of modern foreign languages highlights, the standards and content of what is deemed a 'top' education should not be sacrificed in order to obtain 'progress' as quickly as possible. Such was Arnold's position as inspector of schools: while committed to the ideal of universal education, it was nonetheless essential that the education remain 'the best'. Otherwise, we debase the moral currency; we offer more and more degrees to wider and wider groups while deflating their value. Further, we do so in a thoroughly patronizing manner, as we will see in the next chapter - for example, by offering to lower standards for BAME, working-class and disabled students on the premise that there are no means by which they could be brought up to existing higher - though perhaps reformed - standards through mutual, committed effort and education.

Neither should all efforts to retain these standards be deemed 'elitist' in and of themselves. Indeed, we, as academics, should reflect more on the charge of 'elitism' that was a central element within a very middle-class ideology during the long-term academization process: an ideology that succeeded in smashing the gates of the ivory tower in the mid-Victorian era, and a bourgeois ideology that we regularly reproduce through our discourses and instruction and, perhaps most paradoxically, even when we think we are being most 'critical'. In so reflecting, we might further grasp that we are the ideological centre of the 'neoliberal' university: its beating heart and soul. 


\section{Notes}

1 Letter from Dr John Cooke, Principal Corpus Christi College, Oxford to H.P. Whyndan, June 1794. Cooke papers, Corpus Christi College archives. B14/5/1.

2 'Entrance to Oxford \& Cambridge: A Report by the Universities of Oxford and Cambridge', 1960. Oxford University Archives AD 1/18/1-19.

3 As indicated within Cambridge's OFFA access agreement for 2017/18. See https:// www.offa.org.uk/agreements/University $\% 20 \mathrm{of} \% 20$ Cambridge $\% 201718$.pdf. 


\section{Women and higher education \\ Two ideas of equality in 19th-century Britain}

\subsection{Introduction}

The general history of 19th-century women's higher education (HE) in Britain, America and beyond has been well documented, especially since the 1970s, when feminist academics recovered the forgotten histories of women's participation in institutions of higher learning (Dyhouse 2006; Graham 1978; Parker 2015). Much of this work, quite sensibly, focuses on historical events occurring within women's colleges and explores the slow progress women made in gaining recognition within historically male universities. These include the ways students and faculty organized themselves in dormitories, classrooms and student societies; the subjects in arts and sciences women were taught and learned; the ways examinations were organized and the ways women's college leaders lobbied degree regulators to accept and confer the qualifications earned. These histories also link the struggle for women's recognition in $\mathrm{HE}$ and society to wider political contexts, including suffragism and first-wave feminism in the second half of the 19th century as well as the legacy of so-called 'blue stockings' during the Enlightenment, who registered early demands for education and respect amongst elite salon circles (Carruthers and Wanamaker 2015; Eger 2010; Gordon 1990; Kose et al. 2016; Richardson and Willis 2001; Van Wingerden 1999).

This chapter has a different purpose, namely, to reconsider the central influence the movement for women's HE had on the overall trajectory of higher education during and after the 19th century. Accordingly, the known history of women's HE will be drawn on, not for itself or to add particularly new knowledge to this history, but for what it can tell us about the way modern HE, generally, has developed within the modern era. As noted in Chapter 1, this interest in women's HE is one element within my theory of the 'academization process' which has taken place since around 1800 in core European and American nations. Whereas past narratives explaining the rise of HE emphasized the significance of industry, science and technology (BenDavid 1971; Parsons and Platt 1974; Wallerstein et al. 1996), I suggest science was only one of five major causes, the others being:

DOI: $10.4324 / 9781351017558-5$ 
a changes in elite class structure;

b displacement of Theology and religion in curricula;

c imperialism; and

d changing roles of women and children.

In exploring these issues surrounding women's HE, I am accordingly fleshing out here the ways in which cause (d) had an impact on the processual development of HE in general. The growth and institutionalization of women's HE was also interacting with the factors above. Because of this, certain aspects of women's HE, including particularly the tension between different ethical ideals of equality, were embedded in the logic of the academization process. I conclude by noting that we can still see these effects and logics today as we continue to widen access and participation to HE to historically excluded groups, suggesting that revisiting what I call the 'Girton-Newnham debate' is well worth pursuing for analytic, historical and normative purposes.

\subsection{The priority of women's higher education in Britain}

To track the significance of debates surrounding women's HE in Britain, we need to note the processual conditions out of which these debates emerged. While linked across the second half of the 19th century with suffragism and equality of women in legal and political spheres, we should recall that during the first half of the century democracy and suffrage had not yet been extended to every male. Reform Acts in 1832, 1867 and 1884 did not lead to universal male suffrage, which was only achieved after World War I. While women's suffrage campaigns grew in force after 1884, the right to vote was not obtained until 1928. This meant that, in the Georgian and early Victorian context, women, like the majority of British subjects, needed to lobby their political representatives through indirect mechanisms, social networks and persuasion, rather than electioneering. Within elite social circles, many women, including the Blue Stocking Circle from the 1750s, were effective political operatives (Chalus 2000, 2005; Eger 2010). Still, the debate surrounding the rights of men and women in the wake of the French Revolution raised the question to a matter of public concern. Mary Wollstonecraft's Vindication of the Rights of Women (1792) remains a classic text, of course. And, as middle-class utilitarianism aged from the generation of James to J.S. Mill, we see the latter applying the logical conclusions of his philosophy to argue no distinction exists between women and men, wherein the former should be able to participate equally in the public sphere. By the 1840s, Mill's popularity contributed to a younger generation of (male) scholars, intellectuals and professionals committed to the cause of women's equality. The concentration of Millian advocates in elite universities, particularly at the University of London and Cambridge, meant the 'women's question' was debated widely amongst high society. 
Of course, Mill's liberalism was also characterised by other features, including advocacy of social science of an Anglicised positivist sort (Lewisohn 1972). Also, within the context of imperialist discussions around the Irish question, Mill's $O n$ Liberty (1859) articulated a vision of what we would today call the 'marketplace of ideas', which would lead to better truth claims. Still, this required proper education and knowledge to participate in said marketplace. At this time, the British Empire established the non-denominational Queen's Universities of Belfast, Maynooth and Galway in Ireland (1849), only to find the Tractarian leaders of the conservative Oxford Movement involved in the founding of University College Dublin (1854) to preserve a Catholic, traditional, humanistic and liberal (in the curricular, rather than political, sense) education. To this day, Newman's 'idea of the university' as one removed from the ends of work and technical skills informs our sense of what makes HE distinct from other forms of education (Collini 2012; Newman 1996). In fact, both Mill's and Newman's conceptions of what universities are for amount to left and right iterations of the New Class position of the emerging cohort of academics and professionals - Mill's being closer to the bourgeois values of realism and empiricism, and Newman's drawing on a more aristocratic disdain for spiritless materialism, a standpoint later rearticulated by Matthew Arnold, John Ruskin, George Eliot and others, including many of the women advocating for equal access to HE.

Indeed, it was through the social science associations in London and beyond where women, including Emily Davies, Barbara Bodichon and others, found common cause with a range of politicians, philanthropists and other reformers. One of the earliest social problems related to women's education that led to action and institutionalization involved the poor condition of governesses, leading to establishment of the Governesses' Benevolent Institution (GBI) in 1843, which was also linked to the establishment of Bedford College (1849), now a part of Royal Holloway, University of London. In 1866, W.B. Hodgson, an examiner at the University of London, presented his findings from having systematically reviewed the cases registered at the GBI leading women to become governesses in need. In every instance, the cause for these otherwise well-educated women's descent into the dependent teaching positions familiar to readers of Brontë's Jane Eyre (1847) was a man's mismanagement of money. Coming from families of means, negligent fathers or brothers led their families into destitution, and without further options for employment beyond needlework or domestic service, educated women's only choice was to enter teaching for those well-to-do families who could afford it. They remained, however, entirely dependent and precarious. The social scientists resolved to promote a two-fold solution to undo this unfair and irrational waste of women's purpose through no fault of their own. Channelling the general bourgeois ideal of utility, Hodgson suggested: 'it is needful that idleness should cease to be regarded as the happiest destiny of women' (Hodgson 1869). Whereas, hitherto only women planning to enter teaching pursued examinations, he felt every woman should be prepared - that is, educated. Thus, the first intervention was to remove the stigma of women's 
education - often thwarted by family disdain and gendered expectations. George Eliot captured this dynamic in The Mill on the Floss (1860), wherein the Tulliver family bends over backwards to secure their brutish son Tom's place at university, while ignoring the clear giftedness and intelligence of his sister, Maggie. Indeed, Hodgson expressed the same sentiment Eliot scorned in what passed for education and intelligence in her gender in 'Silly Novels by Lady Novelists' (1856) when he suggested:

Such a serious, and solid, and practical training would itself go far to banish the aimless frivolity, the idleness, the vain display, the mental vacuity and ennui, the wastefulness of time and money, the dreamy sentimentalism which afflicts so many young women of the upper class, and to create instead, an intelligent interest in the world's progress, an ennobling desire to be helpful thereunto.

(Hodgson 1869)

The second intervention would work in concert with the new input of education for women, namely the expansion of professions into which educated women could be employed. Such work was already ongoing within the Society for Promoting the Training of Women (SPTW) founded in 1859 by Jessie Boucheret in response to an article by Harriett Martineau in the Edinburgh Review. Expanding occupational opportunities would result in genuine independence and the capacity for women to free themselves from the degeneracy of irresponsible men. The premise throughout these campaigns is one of equality of being, such that anyone who believes women are inferior was mistaken. Rather, there was a clear recognition that socialisation into what we would today call 'patriarchy' limited women from seeking education and, further, limited their progressing without adequate support - particularly in maths. Lastly, reforming these goals and expectations through an increase of suitable professional occupations would encourage women to rise to the occasion and occupy their fair and equal position in society. While many of these figures were advocates for women's suffrage, in principle, none of these reformers planned to wait for the vote and, instead, focused on the economic, social and cultural interventions they could make within the constraints of their time. By 1886, the SPTW could claim victory for turning teaching into a true profession requiring a systematic course of study. ${ }^{1}$ They also contributed to a massive expansion of employment roles, from three to four careers to over 70, including bookkeeping, decorative arts, lithography, book binding and fashion design. The last of these was a particular achievement for those who initially wondered 'why should bearded men be employed to sell ribbon, laces, gloves and the dozen other trifles of a haberdasher's shop?', only to realise the negative response was due to lack of arithmetic to work out customers' bills. ${ }^{2}$ Similarly, upon the advent of the telegraph, the SPTW strongly advocated for the employment of women as telegraph operators, which translated into further occupational footholds in the wake of the telephone at the helm of vast electrical switchboards. 
Among the cohorts of social scientists, reformers and campaigners involved in these initiatives was Emily Davies, who would go on to found Girton College, Cambridge, in 1869. In a paper presented to the Social Science Congress in 1862, Davies argued that women should aim toward employment in the prestigious medical profession at a time when greater attention was directed toward Florence Nightingale's efforts to establish a separate nursing profession. Davies's argument characteristically responded to common criticisms of her proposal. First, that women should not work. Davies noted that women already work hard and called for redistribution of the 'apportionment of mental and physical labour as relatively distributed between men and women'. ${ }^{3}$ Others point to particular physical limits and ailments women suffered from, including hysteria, which Davies turned back on itself by noting: 'Many ladies are sickly and hysterical, not, strictly speaking from want of work, but from the want of some steady occupation, sufficiently interesting and important to take them out of themselves'. ${ }^{4}$ Others say women are inferior, but there is no actual evidence for this. Finally, many argue work would involve a loss of social position for upper class women, which is why Davies felt the learned profession of medicine would be ideal, since it would involve no such trade-off. In any case, as in the haberdasher's example above, many women would prefer doctors of their own sex for certain health issues. She contended, however, that ultimately it was necessary to first change the opinion of parents, who should begin to imagine their daughters in such work and begin educating them to the high standards expected of these professions. Such was the education she and colleagues, including Barbara Bodichon, Lady Stanley, Dorothea Beale and others, endeavoured to provide at Hitchin and Girton.

\subsection{The Girton-Newnham debate}

From the 1860 s to the end of the century, Davies and other reformers lobbied and secured access for women to higher education, although the culmination of full recognition by historically male institutions like Oxford and Cambridge arrived late indeed, in 1920 and 1948, respectively. During the course of this movement, two identifiable positions were adopted by reformers, reflecting two conceptions of equality. The first, represented by Davies and Girton College, asserted an absolute rejection of any idea that women were ontologically unequal to men, and thus there should be no reason - or suggestion - that women were unable to attain and even exceed the accomplishments of men. The second, represented by Ann Clough, Henry Sidgwick and other founders of Newnham College, Cambridge, established in 1872, sought to maximize the participation of women in $\mathrm{HE}$ and recommended practical considerations and accommodations be applied to adjust entry requirements to enrol and involve more women.

In each instance, the significance of entry examinations were paramount. Indeed, Davies realised early on that although her ultimate goal was redistribution 
of women across the entire range of professions, she needed to first begin with reform of higher education and, before that, reform of secondary school and examination preparations. From the 1860s, she and others had lobbied the University of London to allow women to sit their examinations, but to no avail. Because women could not access the local examinations that established qualifications to enter university, they needed to first lobby the local examination boards in Cambridge and Oxford. The chronology of this is significant, since these exams had only been introduced in 1862 as part of the general middle-class reforms toward meritocratic admission across a wider population and geography. These discussions put Davies and others into correspondence with leaders in general education reform circles, including those surrounding Henry Acland, Frederick Temple and their families networked around the Southwest, Oxford and the establishment church and state in and around London. Subtle political distinctions of the time matter in this instance, since these were veterans of an earlier generation of liberals, who sought to reform and modernize church, schools and universities without losing traditions and valuable heritage derived from historical and classical scholarship. At Oxford, this camp was known as the 'Noetics', in contrast to the Tractarians, or Oxford Movement, who represented, in a sense, the next, more Romantically and 'high church' conservative generation. The Noetics recognized the value in reform, and aligned themselves with aspects of the ascendant middle-class liberalism - seeing the valorization of Scottish and London universities claiming the spirit of the age and not wanting to fall behind. Initially, examinations began to be held for fellowships, not studentships, although both were similarly linked to specific endowments, often with geographical stipulations to ensure parish priests across national regions could send their sons to Oxford and Cambridge. As was typical of liberal reformers, like Trollope's John Bold in The Warden (1855), legal efforts were made to remove the 'dead hand' of history to ensure deeds and trusts could be put to most efficient contemporary usage. This meant examinations became increasingly significant to determine who was best qualified for particular roles as fellows or scholars. As Acland explained to Davies, the way they achieved institutionalization of local examinations was simply by doing it - holding a test in Exeter to determine the best candidate - then demonstrating the value to other colleges. He recommended Davies and her campaigners do the same.

With examinations already being conducted and available, the issue was not in constructing the tests, but in marking them as Oxford or Cambridge would. They therefore needed to secure the participation of existing (de facto male) academics to voluntarily read the examinations submitted by women. In the first sitting for Cambridge, 32 out of the 40 girls who sat failed, overwhelmingly due to the mathematics sections. In other institutions, campaigns continued, with Durham opening their local exams in 1866; at Oxford, a petition with 999 signatories was registered demanding they open up their exams to women. In 1869, the University of London established a 'special examination for women'. Meanwhile, the Schools Enquiry Commission of 1864, populated by many of the social scientists surrounding these and other 
reform campaigns, provided a systematic and damning overview of the entire state of British education (Fletcher 1980). Particularly remarkable was that, right from the start, the cause of women and girl's education was addressed as needing reform as much as that of boys. This led to rapid reconfiguration of the educational landscape, although state intervention was exceedingly limited until late in the century. One of the only major additions came from the inspection system led, essentially, by Matthew Arnold himself, who traveled from school to school to assess the provision of education across religiously differentiated voluntary schools (Black 1987; Connell 2002). Here he developed his opinions regarding the philistinism of the middle-class 'non-conformist' schools, especially in the North of England, where technical and industrial education left out much of what was best in human culture, resulting in a dullness and thoughtlessness in students. Arnold and others advocated for a more professional training for teachers, and this was an era in which many teacher's colleges were founded for this purpose.

By 1869, Davies pushed towards foundation of what would become Girton College, initially in Hitchin in Hertfordshire, then in Girton village, approximately 2.5 miles from Cambridge. A redbrick building organized around a corridor system - to leave open a plan B as a hospital - Girton's mistress and faculty committed themselves to educating their girls to the highest standard. By 1870, Cambridge had been convinced to not only allow access to entrance examinations, but to previous years' exam scripts: that is, for women to determine what degree they could expect (if they were allowed). Again, they relied on willing examiners committed to the cause. In the first round, five women from Hitchin took the exams with four obtaining first-class marks, and one receiving a second class. A considerable achievement, not just for the students themselves, but as a demonstration that there was no fundamental difference between women and men in terms of potential performance in academic work. By 1880, the college shocked the nation when a Girton student matched the score of the 8th 'wrangler' in the impossible Mathematics Tripos, effectively registering herself as among the most gifted mathematicians in the world. In the meantime, Oxford and Cambridge merged their local examinations in 1873, and from the start allowed girls to sit these. It was, however, up to the colleges themselves to determine what to do with these scores, which effectively left the interpretation of results to the women's colleges, Girton and Newnham at Cambridge, the latter founded in 1871 by Ann Clough.

The story, background and ethos of Newnham was different than Girton's, although in the broader cause of advocating for women's HE, their leaders worked together more often than not. However, it is these differences within the movement for women's HE that are interest to us here. Firstly, Clough's work to educate women was based largely in the north of England and had been ongoing since at least 1867, establishing the North of England Council for Promoting the Higher Education of Women (NECPHEW). The sister of one of the last and most well-regarded Romantic poets, Arthur Clough, Ann 
moved back to Liverpool after his premature death to educate his children. Inspired by the events she witnessed in London earlier in the decade, Ann established an organization of a range of women (and men) interested in drawing visiting scholars to hold public lectures in Manchester, Leeds, Liverpool, Bury and other northern cities. This not only provided considerable momentum for the cause of women's education in the region, but led to the foundation of the University Extension movement when a young lecturer, James Stuart, accepted an invitation to speak, discovering a hitherto considerable and unmet demand for higher learning across the nation (Goldman 1995). As these links between NECPHEW and Oxbridge developed further in subsequent years, the ostensive purpose for the meetings was drawn more clearly towards the professionalization of teaching and preparation for the Oxbridge exams. Still, although much earlier history of the university extension movement focused on the education of working-class men, in fact, the overwhelming majority of attendees were women.

Meanwhile, just as at Oxford, internal disputes regarding how much liberalism and modernization should be accommodated, Cambridge in the 1850s was undergoing the slow generational shift toward what Rothblatt called the 'revolution of the dons' (Rothblatt 1981). In effect, this amounted to a formalisation and professionalization of younger college fellows as academics rather than as clergy or general establishment figures. It was led by figures including J.R. Seeley, Henry Jackson, Henry Sidgwick and others, who were interested in what we would today call historical sociology supplemented by what would be established there a generation later as Moral Sciences. Building on their own education in public schools, including especially Rugby after the Noetic reforms of Thomas Arnold, Frederick Temple and others, these scholars drew in-house the tutorial work provided by Tripos exam coaches working along the King's Parade. The group emphasized the relational dynamics between teacher and students, conceiving of the college fellowship as a corporation working together like an athletic team (organized sport, of course, also became popular at this time) (Elias and Dunning 2008). Among the most radical and outspoken of these internal reformers was Sidgwick, who, as discussed in Chapter 4, was relevant to the academization process as one of the leading advocates for the rejection of the classical curriculum in favour of a more 'useful' humanities course of studies organized around modern foreign languages and science, both natural and social (Sidgwick 1968). In 1869, inspired by others adopting similar moral stances, including Arthur Clough before his death, Sidgwick resigned his lectureship at Trinity College due to his unwillingness to subscribe to the 39 Articles of the Church of England. This left Sidgwick in self-employment as a tutor, yet he was still linked to an internal scholarly network with the colleges. As a dedicated Millian, he had long advocated for the cause of women's equality, and he became involved in the establishment of Newnham College on Parker's Piece. Following correspondence with Ann Clough, he recommended she take up the role of mistress. It soon became apparent, however, that the needs of 
women - especially those travelling from the north of England to Cambridge - were very different from those of male bachelors. The college leaders also soon encountered the same issue Girton faced in terms of entrance examinations, particularly concerning untrained students' relatively poor performance in mathematics. Sidgwick recommended an intermediate set of exams which would be easier for women, who should not be expected to perform at the same level as males without prior training.

This premise, however, revolted Davies, who felt women should be held to the same standards as men (Winstanley 2009). Here we can see quite starkly the two approaches to widening access and participation which would characterize the next century and a half: (1) the Girtonian ideal of equality of the sexes, with the expectation that academic standards must be upheld, versus (2) the Newnham ideal that equality of the sexes should be achieved through handicapping of individuals - in effect, lowering the standards in order to encourage greater participation. In fact, it is precisely this tension between two ideals of equality which has been central to the entire unfolding of the academization process ever since.

For, if the history of education is the history of expanding access to education, there has always remained a tension between widening participation and 'standards'. Are those standards 'arbitrary' - the result of the dominant class, gender, profession, religion's monopolization of what is considered 'true' and 'good' knowledge? In this case, we can merely change those standards to accommodate the enrolment and participation of historically excluded groups. But, what if these are not merely arbitrary standards? What if, as in the case of the changes to classics discussed in the previous chapter - we 'debase the moral currency', as George Eliot suggested?

Indeed, Davies, Eliot and others associated with the expansion of women's $\mathrm{HE}$, and education generally, were instrumental in articulating the precise value of traditional education even while seeking to break through the artificial barriers that excluded them from entry, not only into education, but social, professional and public life in general. Theirs was an expectation of equality of humanity - both human individuals and the species and culture as a whole. They were as concerned to preserve and update the social fund of knowledge as they were interested in transforming it.

Thus, in returning to and recovering this debate as it occurred within the first phase of the academization process, we can revisit more complex discussions and trade-offs being considered in ways we simply no longer do now that we are well into the second phase of the academization process. There is undoubtedly much more to consider, explore and untangle on this issue, as with the other five causes identified in the general theory outlined in Chapter 1. At present, we might simply observe that adopting this long-term processual perspective opens up new lenses through which we can reinterpret both the past and the present. We might even consider whether we can recover useable, discarded aspects of earlier funds of knowledge for use in the future. The Girton-Newnham debate is one such central question we might ask ourselves anew. 
140 Women and higher education

\section{Notes}

1 'History of the Society for Promoting the Training of Women.' Box 8/9, Society for Promoting the Training of Women. Girton College Archive, Cambridge.

2 Ibid.

3 'Medicine as a Profession for Women.' Box 11/4, Personal Papers of Sarah Emily Davies, Girton College Archive, Cambridge.

4 Ibid. 


\section{6 'Without any reason for being' Interdisciplinarity at the 1904 World's Fair}

\subsection{Introduction}

\subsubsection{Sociologists confront interdisciplinarity}

Within sociology a range of scholars have engaged with the current fashion for interdisciplinarity sweeping universities in America and, via imitation, worldwide. Recently, Jacobs's In Defense of Disciplines (2014) noted that, in fact, the much derided 'silos' of academic disciplines organized around departments and majors encourage and engender plenty of interdisciplinary discussion and innovation, whereas examples of interdisciplinary departments, e.g., area studies, just as often become segmented and siloed once institutionalized. Interdisciplinarity is often imposed from agents external to disciplines themselves, and Lamont's (2010) study of interdisciplinary grant committees reveals these to be, in fact, sites of disciplinary 'boundary work'.

Indeed, as Abbott (2001a) described, calls for interdisciplinarity have been fairly consistent throughout the entire history of disciplinarily organized universities: 'there was no long process of ossification; the one bred the other almost immediately ... Interdisciplinarity presupposes disciplines' (Abbott 2001a: 132, 135). Noting the advantages of disciplines within the 'basket-structure' of the American university, Abbott suggested these 'problem-portable' forms of knowledge thrive, whereas the 'problem-oriented' interdisciplinary studies result in duplicative redundancies and are otherwise dependent on specialized disciplines to generate theories and methods. Abbott seems to suggest a form of stable chaos emerges out of the operational closure of disciplines surrounded by the persistent, buzzing 'noise' of interdisciplinarity.

Other important sociological engagements with interdisciplines draw on the work of Bourdieu, particularly with reference to the notion of 'fields', which might obtain greater or lesser degrees of 'autonomy' or 'heteronomy' vis-à-vis external powers. Recent examples of this line of research can be found in Münch (2014), Steinmetz (2017) and others interpreting the strategic competition of disciplinary actors or the influence of national boundaries while noting the significance of differentials in power or capital, which produce a range of forms of interdisciplinarity. In other words: not all

DOI: $10.4324 / 9781351017558-6$ 
interdisciplinarity is equal, and, as in any strategic game, there are winners and losers.

The last group of scholars worth mentioning here are the "new sociologists of ideas', especially Camic and Gross (2004), who insist on situating explorations of certain ideas and intellectuals within historical context (Hauchecorne and Ollion 2009). These scholars draw on Abbott, Bourdieu, Collins (1998) and others to emphasize 'practices' and 'local' factors in the development of ideas. One example of this form of study includes Camic and Xie's (1994) explanation of the statistical turn within sociology as part of a broader interdisciplinary movement occurring at Columbia University in the early 20th century. ${ }^{1}$ However, there are several problematic assumptions latent within the STS (science, technology and society) and 'Cambridge School' approaches new sociologists of ideas draw upon methodologically. The exaggerated turn toward 'localism' and 'practices' has led to a narrow 'contextualization' of the development of ideas within the circumscribed boundaries of the elite American university campus. This results in a relative neglect of changing dimensions of power - as Bourdieu would have understood - while also neglecting the patterned changes between what Abbott called the 'linked ecologies' of universities, state and professions (Abbott 2005b). Lastly, there is no means through which ideas might beget ideas - sociological form is emphasized over content - and, thus, the new sociology of ideas amounts to a kind of hyper-materialist base/superstructure model, wherein the 'base' is an academic's social network (or 'actor-network', in similar ANT approaches).

In other words, there is no compelling reason why the new sociology of ideas should be pursued here to study interdisciplinarity, rather than simply following Abbott's and Bourdieu's course. That said, the actual theoretical perspective employed here will be Norbert Elias's sociology of knowledge (Elias 1971a, 1971b, 2007) as elaborated in Chapter 1 and further below (Lybeck 2019b). Elias's process model can be used to incorporate aspects of Bourdieu's and Abbott's theories, while situating interdisciplinarity within the context of long-term historical trends, thereby synthesizing and transcending the approaches noted above.

\subsubsection{Norbert Elias and the sociology of knowledge}

Elias is best known for his study of the 'civilizing process' (2000), but his early career began as an assistant for Karl Mannheim at the University of Frankfurt. He was thus familiar with the sociology of knowledge tradition developed by Mannheim (1985) during the interwar period; later in life Elias returned to these themes within his investigation of 'involvement and detachment' within social research (Elias 2007). Despite general appreciation of Elias's work in this book, few scholars have applied his sociology of knowledge as an extension of the tradition running back to Mannheim through to Berger, Gouldner and, indeed, Bourdieu - what the new sociologists of ideas call the 'old sociology of knowledge'. 
This is unfortunate insofar as Elias replaces problematic distinctions, especially the irreconcilable dualism between 'subjectivity' and 'objectivity', which he suggested was a hold-over from philosophy and epistemology. According to Elias, the sociology of knowledge began initially, though incompletely, in Marx's studies of ideology. Elias suggested we should replace this Marxian philosophical dualism with a spectrum running from 'subject-oriented' forms of knowledge to more 'object-oriented' forms of knowledge (Elias 1971b). He later replaced these with the terms 'involvement' and 'detachment'.

Once identified as a spectrum with greater or lesser degrees of involvement or detachment, the sociologist of knowledge can do at least three things. First, one can recognize no knowledge is ever completely subjective or completely objective, each involves a bit of both. Second, one can observe a long-term trend, beginning in early modern artists' experiments with perspective, which encouraged greater emphasis on grasping 'objective' forms of knowledge. This was most effective within what is now called 'science', and thus our idea of 'objectivity' presumes scientific knowledge is the model for knowledge in general (Daston and Galison 2007). Third, by noting this longterm trend, one can observe knowledge is processual: it develops as a 'social fund', not as a property single individuals or subjects confront as an object with sense-perception alone; rather, knowledge is a property of groups, including disciplinary configurations, which may be more oriented toward objective or subjective forms of knowledge. For example, among the weaknesses of sociology is the tendency to emphasize subjective forms of knowledge - e.g., ideologies, beliefs, false consciousness, 'culture', values and so forth - while neglecting more objective, historical forms of social knowledge which could be grasped were we more oriented to the 'detached' pole.

Further, Elias provided a process-ontology to account for why different forms of knowledge can be grasped 'scientifically', insofar as natural history has a much greater duration relative to the more rapidly developing transformations occurring at the sociological level across several generations and the individual level across a single lifetime (Elias 1983). Thus, scholars have argued that Elias provided a 'central theory', which could unite various forms of natural and social scientific knowledge (Quilley and Loyal 2005). This chapter does not elaborate the precise content of what this knowledge would look like, but merely points to the possibility to suggest that this form of interdisciplinarity would be markedly different from the form prevailing today.

\subsubsection{Strong vs. weak interdisciplinarity}

Indeed, it is taken for granted today that interdisciplinarity implies a relativist form of transaction amongst equals: various disciplinary actors exchange ideas across borders generating new, innovative knowledge about particular problems or problem areas. As Abbott noted, these interactions rarely produce new 'problem-portable' knowledge, theories or methods. And, though 
Bourdieusians acknowledge the relative power differentials between fields and actors, the fact remains that 'interdisciplinarity' rarely implies either a total colonization and abolition of competing disciplinary fields, or a reorganization of the system of disciplines around a totalizing, logical or functional order.

The era of competing jurisdictional wars passed off long ago with the foundation of the modern university and its stock roster of majors and departments. Indeed, my own work suggests that the initial institutionalization of the university in 19th-century Germany and America largely conditioned the subsequent development of academic knowledge (and hence why new sociologists of ideas are incorrect to focus too narrowly on the internal, local context within the university to the exclusion of longer-term factors) (Lybeck 2016).

I call this contemporary form of interdisciplinarity 'weak' in contrast to the 'strong' interdisciplinarity suggested by Elias's central theory of natural, sociological and individual processes. Other forms of 'strong' interdisciplinarity can be drawn from the critical realist tradition begun by Bhaskar (2008), meaning a philosophical or sociological attempt to determine the ontology of entities in general, which, by extension, implies a range of 'levels' or 'strata', which, in turn, correspond with different sciences and disciplines. In other words, 'strong interdisciplinarity' implies a certain 'unity of knowledge', unlike the various problemoriented interdisciplines characteristic of the contemporary university.

With the noted exceptions aside - which have by no means overturned the disciplinary order, nor do they appear poised to do so in future - the idea of strong interdisciplinary appears to be a very old-fashioned idea today. Thus, as in the previous chapter, we can return to earlier debates to see if alternative possibilities open up on our horizon. I will now turn to discussion of the St. Louis World's Fair of 1904 as a moment reflective of the historical break from an earlier era of strong interdisciplinary toward the contemporary environment of weak interdisciplinarity. This is just before the shift from the first phase to the second phase of the academization process. After briefly introducing the fair, particularly its Congress of Arts and Sciences organized by German émigré professor Hugo Münsterberg, the chapter will highlight the controversy surrounding the arrangement of disciplines across the Congress Hall. Historians of ideas (Coats 1961) have suggested this controversy reflected a debate between a European 'idealist' versus an American 'pragmatist' idea of the unity of knowledge - or lack, thereof - however, I will suggest a nascent 'third way' was, in fact, evident at the time. Our reflection over certain lessons from the 1904 experience might help us better address the contemporary issues surrounding interdisciplinarity today.

In particular, I will suggest that, although pragmatists were likely correct in dismissing the arrogance of the congress organizers (as it turns out, they did not unify knowledge in the end!), the subsequent shift from strong to weak interdisciplinarity has benefitted the object-oriented disciplines more than the subject-oriented disciplines. Hence, the oft noted crisis of the humanities and the shift of universities toward STEM can be put into better historical context. 


\subsection{The division of disciplines at the 1904 St. Louis World's Fair}

\subsubsection{The Louisiana Purchase Exposition in context}

The 1904 Louisiana Purchase Exposition in St. Louis was in many ways the end of an era: the last World's Fair of the kind characteristic of the 19th century. At the same time, the Fair reflected the nascent transfer of economic, political, cultural and scientific power from Europe to America in the 20th century. Among the centrepieces of the expo was the Congress for Arts and Sciences organized by Hugo Münsterberg. The German émigré professor made it his mission to reject the randomness of subjects evident at the 1900 Paris Exposition, which appeared, to him, to have been 'scattered without any reason for being' (Münsterberg 1903). Munsterberg determined to organize the plan of the Congress to reveal the 'neglected idea of the unity of truth'.

In the Atlantic Monthly, Münsterberg boldly laid out his programme for the organization of the Congress Hall, which was split into seven divisions, further split into 25 departments, which were further subdivided into 130 sections. He declared,

The necessary condition would be a plan in which every possible striving for truth, every theoretical and practical science would find its exact place; as a matter of course, such a plan would have no similarity with chance combinations of the university catalogue. It must be really a plan which brings the inner relations of all branches of knowledge to light. The very existence of such a ground plan which would give to every section its definite position in the whole system would bring the unity of knowledge strongly to consciousness.

(Münsterberg 1903)

Münsterberg deemed the exposition a rare opportunity for scientists to disengage from their specialized research to present the unity of knowledge to the public, recovering the original values of the university envisioned by Humboldt (cf. Ash 2006). Indeed, Münsterberg envisaged the Congress would serve as the 'world's university', and his plan sought to replace the apparently random distribution of specialized disciplines on American university campuses with a more orderly, logical arrangement of knowledge.

The divisions would be organized around distinctions between, initially, physical and mental sciences, and then general and particular sciences within each. At the threshold between physical and mental knowledge, one could add a distinction between 'purposes' and 'phenomena', thus necessitating separate studies of physical and mental purposes: with individual phenomena treated by the 'normative' sciences and their institutionalized forms - e.g., law, literature, education, etc. - by the 'historical' sciences. This resulted in a four-field division of the 'theoretical' or pure sciences - physical, mental, normative and historical - to which a fifth division on 'practical sciences' was 
added insofar as what we would today call 'applied' sciences, which necessitated a synthetic, rather than analytic, orientation to knowledge; these sought to connect 'facts' with 'ends'. The practical sciences were correspondingly split into three: utilitarian, regulative and cultural sciences - according to the 'ends' of these applications, respectively: material welfare, harmonization of human interests and 'perfection'. The result was seven divisions into which more recognizable departments were then allocated.

In addition to the logical ordering, which reflected Münsterberg's bias toward psychologism - putting psychology at the centre of the pure mental sciences - there were several practical considerations which equally informed Münsterberg's proposal; not least was his goal to attract European scholars to the fair, highlighting the 'coming of age' for American scholarship (Coats 1961). Most important of these Old World cohorts were German academics, who in the 19th century had represented the leading edge of advanced scholarship (Lybeck 2016). As early as 1900, David Francis, president of the World's Fair Company, obtained an audience with Kaiser Wilhelm II, highlighting the fact that St. Louis was a city with a high proportion of GermanAmericans (Lützeler 2005). ${ }^{2}$ The Kaiser had recently been awakened to a 'Teutonist' ideology and mustered his ministry to prepare a blockbuster contribution to the 1904 World's Fair. ${ }^{3}$ The government would send the leading (traditional, not modern) artists of the day along with its leading scholars to participate in the Congress of the Arts and Sciences, all in an international effort to 'unite the German tribes', including German-America.

Thus, Münsterberg secured acceptance of invitations extended to scholars including Max Weber, Ferdinand Tönnies, Karl Lamprecht, Ernst Troeltsch, Heinrich Waldeyer and hundreds besides, who would travel to America to speak on topics requested by the Congress organizers. This would ensure that the goal of the unity of knowledge - and the avoidance of specialized topics could be maintained. Further, as the Congress provided honoraria plus travel expenses, the unity of knowledge approach avoided any suggestion of American materialism; that is, the European experts were not seen to have been somehow 'bought out'.

Finally, Münsterberg was keen to avoid any 'missionizing' arrogance on the part of the Europeans. He wanted them to attend in a spirit of mutual respect and recognition that American scholarship had come of age. The irony, of course, was that he had to artificially construct a schema of 'pure sciences' to resemble the European field, thereby distorting the more pragmatist American scholarship ongoing particularly in the American Midwest, especially Chicago.

\subsubsection{John Dewey's critique of the Münsterberg plan}

The Midwestern pragmatist criticism of Münsterberg's presentation of the Congress organization in the Atlantic was expressed immediately by John Dewey (1903) in Science. Dewey noted that, while the Congress obviously 
needed some divisions, there was a profound arrogance evident in the organizers' presupposition that they had struck upon the actual proper organization and unity of knowledge.

We learn from the article that contemporary intellectual life is officially decreed by the committee to have got beyond materialism, positivism, psychologism, indeed beyond any scheme in which the mental and physical sciences are coordinated with each other ... We are told that each department is to have an address on the historical development of its own line of work in the last century.

(Dewey 1903)

A symmetrical ground plan, based on intellectual standards, in clearly presented.

The divisions being based upon the distinction, first between 'purposes' and 'phenomena', and then between such purposes and phenomena as hold good for the individual and those which are more than individual in quality. There is we learn a radical gulf between purposes and phenomena. Purposes 'are not to be explained but to be interpreted'; they represent values which are to be appreciated, not described; they are to be approached by teleological not by causal methods. The student of art, history, literature, politics, jurisprudence, education, is, we are told, occupied with matters of this sort.

(Dewey 1903)

Once established and laid into the ground plan of the Congress, there could be no further room for debate; once stationed in their various stalls, participants were constrained and delimited in their communication. Further, as James Angell (1905) noted, the resulting discussion could only recapitulate the pre-existing knowledge of specialisms, presumably through a dry historical retelling of insights gained in the course of the 19th century, adding nothing substantively new for the 20th century. The unity of knowledge would not be revealed insofar as scholars were not engaged in mutual problems; neither were they or the public made aware of the way specialized scientists actually conceived of and comported themselves in their everyday work within a range of institutions. Dewey noted: 'the essential trait of the scientific life of to-day is its democracy, its give-and-take, its live-and-let-live character' and further 'unity' emerged naturally out of open enquiry, as evident in the double-barrelled names of new sciences, including astrophysics, physical chemistry, geo-physics, etc. - what we would today call 'interdisciplinarity' (Dewey 1903: 276; see also Reuben 1996: 176-79).

While Dewey's articulation of disdain was representative of a number of scholars offended by the arrogance of Münsterberg and the committee members, and, though he justified this grievance on substantive intellectual and 
academic grounds, it is interesting to note here that, in doing so, Dewey redefined 'unity' as a particular, situated outcome rather than a condition of the totality of knowledge as a whole. Unity was something which occurred when physicists and chemists collaborated: an achievement of interaction, rather than a pre-existing condition or systemic order, which could be 'reflected' in a master-plan. Dewey was not simply criticizing Münsterberg's plan, but any plan. This would necessarily imply a particular brand of metaphysics, and since this could be contested by rival schools, any plan organized on principles other than what workaday scientists do would be unacceptable. In this sense, Dewey evidently had no qualms with the 'randomness' of either the average American university campus or the Paris Expo of 1900, which Münsterberg (1903) suggested had been 'scattered without any reason for being'. For the pragmatist: unity, like truth, was not a static, fixed condition, but rather an organic outcome of active enquiry. Any attempt to fix this would be invalid, and so only relativist, open-ended enquiry could be deemed 'true', fair, representative and, ultimately, democratic.

Here we see the articulation of the 'weak' interdisciplinarity which would characterize 20th-century academia: no particular discipline, view or set of distinctions took precedence over another. Scholars worked on a range of problems, and these findings may or may not have relevance to others. The role of interdisciplinarity is to bring these researchers together so new, organic compounds might emerge; disciplinary knowledge could thus be 'unified' with that of another, but only for a particular purpose with a particular utility within a particular context. In this sense, the 'unity of knowledge' is a temporary achievement, neither an end in itself nor, indeed, even an 'objective' possibility.

Across the 20th century, Dewey's more democratic vision for the meaning of scholarship and education obtained a greater influence. This relativist, weak version of interdisciplinarity was important not only in encouraging the achievements of double-barrelled subjects like astrophysics, but also, in denying the possibility of a total unity of truth, every discipline could be understood to be 'equal' in relation to the others. No one form of knowledge took precedence over the others. This paved the way for the massification of higher education, which would take place during the 20th century as more and more students entered university (Trow 1972). Specialized subjects could pursue their research autonomously. Biology did not need to update itself in relation to the latest developments in philosophy; evolutionary psychology need not account for paradigm shifts in anthropology. Only within the inevitably limited interfaces of interdisciplinary 'problem' studies would these insights interact, sometimes, but by no means always, feeding back into the disciplinary silos. Theories and methods could be applied, but no discipline could fundamentally challenge the autonomy of a neighbouring field - even when, as in the case of economics during the neoliberal period, the discipline's underlying assumptions were visibly and highly problematic; further, owing to the discipline's professional integration with financial markets, these 
errors contributed directly to a global financial crisis in 2008 (Galbraith 2010).

Thus, whereas Dewey was undoubtedly correct in highlighting the flaws in Münsterberg's metaphysical schema, perhaps there are limits to the pragmatist, weak form of interdisciplinarity. Dewey, like contemporary advocates of interdisciplinarity, appears to have a faith in the inherent good of live-and-letlive problem-solving. Yet, as Bourdieusian scholars have noted, certain disciplines do have greater power than others; so how can we hold powerful disciplines to account if there is no standard upon which one discipline is supposed to be related to another? The denial of any form of strong interdisciplinarity means the market of ideas will run its course; science is what scientists do; no truth exists independently of the prevailing configuration within siloed, or problem-oriented, scholarly networks.

Paradoxically, this 'democratic' relativism ignores the actually unequal power structures - that disciplines should be equal becomes disciplines are equal. This results in an organization of power across the academic profession which is, on the one hand, diffuse and expansive - any problem can be pursued (provided there is funding to hand) - meanwhile, on the other hand, at a more local, departmental or disciplinary level, knowledge and judgment can be wielded quite authoritatively and, ultimately, conservatively by those with the most social capital. Elias called these 'scientific establishments' (Elias et al. 1982). Disciplines and departments become black boxes, impervious to scrutiny from the outside world, and academics become unaccountable to anyone beyond themselves.

\subsubsection{A 'third-way': Albion Small's action frame of reference}

Whereas Münsterberg's idealist, formal ordering of the sciences proved arrogant - and ultimately ineffective insofar as not every speaker adhered to the prompt, and much of the 'generalist' discussion resulted in a series of dry, historical retellings of 19th-century science - Dewey's pragmatist critique suggested that no 'unity' of knowledge could ever be achieved beyond the local synthetic work of scholars addressing interdisciplinary problems. Yet, I have suggested this weak interdisciplinarity contributes to several problems insofar as a relativist position can occlude and justify the actual power differentials within and between disciplines. Further, the position leaves little room for scholars outside - and perhaps even inside - disciplines to challenge central assumptions, biases and systemic misrecognitions. Thus, perhaps it is not 'siloing', as such, which is a problem, but rather the extent to which 'autonomous' forms of knowledge can proceed unchecked. In other words, perhaps both interdisciplinarity and autonomy are too often assumed to be inherent goods in and of themselves.

To recommend an alternative, we need look no further than the plan for the St. Louis World's Fair, although not the Congress committee's plan in full. Rather, note the particular division recognizing the synthetic 'practical' 
sciences, which connected scientific 'facts' with 'ends'; these included material welfare, harmonization of human interests and 'perfection'. In fact, this section was not conceived as part of Münsterberg's initial plan. Rather, the three sections were added as an accommodation to an entirely separate, second proposal presented to the Congress organizers by the Chicago sociologist Albion Small (Coats 1961: 406).

Small's plan was organized around a conception of the 'unity of life', rather than the 'unity of knowledge'. He challenged the idealist assumption that:

the most real unity in human affairs is the formal unity in logical correlations of abstract categories. This is the scholastic illusion which I am trying to dissipate. The only genuine synthesis which human beings experience is the synthesis of action, and I want a program which will enable us to interpret the correlations which life as a totality is working out, not merely the formal correlations the logician finds convenient in his classifications of the parts of action which he tries to comprehend ... The framework which I propose ... is the actual human process instead of the abstract logical setting of the process, which seems to you [Münsterberg] to be the true perspective.

(quoted in Coats 1961: 406)

On the one hand, Small's plan prefigured Dewey's concern that any metaphysical plan would be unrepresentative of actual scientific work. Indeed, Small was concerned that the Congress, as organized, would display the 'disunity of scientists' rather than the 'unity of science' (Reuben 1996: 177).

Small's scheme was less abstract and academic than Münsterberg's, but more realistic than Dewey's in acknowledging that the world does not turn on the 'pivot of academic science' (Reuben 1996). Among the fallacies reflected in the World's Fair was the notion that progress in science amounted to the progress of society as such. This academic provincialism was, ultimately, the source of its arrogance. Small proposed that, rather than develop a logical unity of knowledge, the congress should be organized around six 'functional' groups reflecting the various purposes to which science is put: health, the production of wealth, the establishment of justice, the discovery of knowledge, the embodiment of aesthetic conceptions and the development of religions.

One might ask where these functional 'ends' derived from. Could not Small be charged with arbitrariness himself? Yet, it is immediately apparent these six groupings reflected six distinct professions, respectively: medicine, 'social economy', law, science, arts and theology. Three of these are the 'ancient' learned professions of the medieval university: theology, medicine and law. The other three reflect the division of academic disciplines: arts, science and social science. In many ways - and to the extent any social structure can be deemed 'natural' - this was a natural division of functions (applicable within that stage of modernity, according to what Elias called 'process universals'). 
Small's plan reflected what academics and professionals $d o$; but transcending Dewey's critique, his divisions also reflected the reasons these particular forms of knowledge are pursued in contemporary society. The disciplines' social function, not their abstract knowledge, determined their proportional representation within the field of arts and sciences.

Indeed, the words of John Ruskin are brought to mind:

Five great intellectual professions, relating to daily necessities of life, have hitherto existed - three exist necessarily, in every civilized nation:

The Soldier's profession is to defend it.

The Pastor's, to teach it.

The Physician's, to keep it in health.

The Lawyer's, to enforce justice in it.

The Merchant's, to provide for it.

(Ruskin 2015: 31)

Ruskin's point, like Small's, was that these professions exist whether we study them or not. Indeed, some appear to be essential to the maintenance of human civilization itself, and they are most unlikely to go anywhere soon. These professions do or do not perform activities to defend, teach, treat, adjudicate and provide for communities in which they work. If these professions fail to perform these, or develop inappropriate forms of knowledge, which in turn leads to injustice, war and disease, this knowledge can be criticized on those grounds. They can be deemed inadequate, not because they are 'untrue', but because they are either 'harmful' or, indeed, 'pointless'.

In Small's plan we can see a sociological, as opposed to philosophical, ordering of the sciences. This retained a strong interdisciplinarity, rooted in the action frame of reference and in the social functions of knowledge, like Parsons's later general theory (Münch 2012). Here, one could imagine that the visiting scholars, if asked to reflect on the 'progress' of their science in the 19th century, would have had to consider the impact of their knowledge on the world. Natural scientists could point to the ways in which discoveries in organic chemistry contributed to new fertilizers or explosives; social scientists could reflect on the way their rationalist forms of knowledge contributed to the better delivery of charity; and so on. Rather than enumerating the frontiers of knowledge, scholars could project new uses of their sciences, including interdisciplinary interactions in the forthcoming 20th century.

If we consider Small's plan in relation to Elias's spectrum running between subject-oriented and object-oriented forms of knowledge, we can note that the action frame of reference would have encouraged scholars in the natural sciences to reflect on the subjective elements of their sciences - to what social ends were these insights put? Whereas, social scientists could use the opportunity to highlight the ways in which their attempts to objectify subjective experiences - for example, the life experiences of Polish immigrants (Thomas 
and Znaniecki 1996) - could contribute to objective efforts at social amelioration. Each would contribute to a potential synthetic discussion regarding the actual contributions of knowledge in general to populations beyond the scientist themselves.

As Abbott (1988: 35-40) argued in relation to the competition between professions over jurisdiction, successful claims delimit the subjective boundaries surrounding objective problems. Whereas much has been made in the new sociology of ideas and related scholarship over the subjective, cultural boundary work occurring within interprofessional competition, the fact remains: there are several identifiable, objective foundations to most professional knowledge. Abbott identifies technological, organizational and natural sources of problems as well as aspects of long-term cultural trends, e.g., private property, which, though technically 'fictitious', are nonetheless durable enough to be treated as 'given' within, for example, accountancy practice.

Because of the subjective and objective factors in determining professional jurisdiction, the role of abstraction becomes significant insofar as 'only a knowledge system governed by abstractions can redefine its problems and tasks, defend them from interlopers and seize new problems ... Abstraction enables survival in the competitive system of professions' (Abbott 1988: 9). Indeed, the application of abstract knowledge can be said to define the distinction between professions and other occupational groups.

And yet, there is an academic profession within the system that is claiming jurisdictional control over abstract knowledge itself (Lybeck 2019a). This dual role - as both subsystem and environment - positions the university in a unique societal position insofar as academic discourse is both the environment for many professional jurisdictional claims, while, at the same time, being an internally differentiated system of disciplines competing for jurisdiction within, as illustrated by Figure 3.9 in Chapter 3. This dual role of the academic profession accounts for the appearance of autonomy, which regardless applies only to the research side of academic work; the side upon which academics measure their own status hierarchies (Lybeck 2018b). In fact, for much of the academic profession - in particular, the humanities and social sciences - the central professional activity is teaching. And, these are the disciplines which are most often deemed 'subjective', even by practitioners. Consider, for example, the range of introductory courses in sociology which ask students whether their subject is 'really' a 'science'; it is a truly absurd question insofar as translation into another language, German, implies science (Wissenschaft) means any organized body of scholarship.

Thus, although the academic profession retains an appearance of autonomy, the profession is embedded within a wider set of objective and subjective relations which are identifiable, i.e., 'objective'. Further, the rise of the academic profession since the late 19th century amounts to an historical trend upon which the contributions of the knowledge produced therein can be evaluated. Had Small's plan been implemented, the various scholars in the arts and sciences at the St. Louis World's Fair could have reflected upon the 
contributions of their knowledge on the world; so too can we evaluate the contributions of contemporary disciplines and, indeed, interdisciplinarity on the wider world. Have these disciplines and interdisciplines contributed to, or inhibited, societal progress?

\subsection{The problems of interdisciplinary disciplines}

For a variety of reasons, the natural sciences have advantages over the humanities in this form of evaluation, which would rate knowledge in terms of its objective practical effects. According to Abbott (2001a: 140), the humanities are not organized around similar sorts of objects: English is organized around texts in the English language, anthropology is organized around the ethnographic method, political science around relationships of power, and economics around an action theory of rational utility maximization. The natural sciences do have aligned 'axes of cohesion' insofar as the levels of analysis between physics, chemistry, organic chemistry and up to, say, experimental psychology reflect hierarchical ontological levels of material reality (Abbott 2001a: 140; see also Bhaskar 2008; Elias 1991). Interdisciplinary research between physicists and geologists addresses different analytic levels of the same objects. These findings tend toward verifiable conclusions, predictions and technologies, unlike humanistic interdisciplinary kitchens cooking mutually allergenic food for thought.

Not only does natural scientific cooperation probabilistically yield more useful results, it also forces a proto-translation from esoteric to exoteric knowledge since disciplinary neologisms inhibit cooperative discussion across analytic levels. This generalist translation of specialist knowledge engenders a preference among external grant-writing agencies to block fund interdisciplinary research (Bastow et al. 2014; Kearnes and Wienroth 2011). Using Elias's spectrum, disciplines which remain more object-oriented are more likely to produce 'useful' technologies and synthetic forms of knowledge. We have seen in Chapter 4 that useful knowledge has been prioritised in many - but not all - areas of academic and professional discourse. But, this is 'usefulness' in an abstract sense, as in the case of economics noted above. Fixation on the numerical proliferation of financial transactions, collateralized debts and GDP were taken to be 'objective' measures of economic growth while the real economy stagnated. Thus, not enough recognition of the subjectivity of value, including economists' own overesteem of mathematical models (Lawson 1997), resulted in a series of systemic blind spots: an ecology of ignorance.

In subject-oriented disciplines, like sociology, cultural phenomena and participant experiences are often treated as inherent 'goods' in themselves; so, 'giving voice' to populations otherwise excluded from 'hegemonic' discourses is considered an appropriate act of 'research': a kind of compensatory factfinding as an end in itself. In this way, 'excluded' forms of knowledge can be 'included'. However, to retain the assumption that all knowledge is equally 'good' (except 'neoliberal' economics), sociologists in recent decades have 
collectively avoided a range of offensive, intolerant views, particularly conservative and right-wing discourses. Accordingly, just as the economists did not see the 2008 crash coming, sociologists were all but oblivious to the rise of Trump, Brexit and similar phenomena in 2016, insofar as these were not elements that factored into their disciplinary 'work'.

Elsewhere, I have argued this flaw in sociology - as in other humanistic disciplines - can be explained in terms of these disciplines' different professional outlets (Lybeck 2019a). Economists, for example, have been charged with explaining and predicting certain aspects of reality - generally, monetary transactions - and have successfully professionalized their discipline so that graduates are (or, perhaps, were) trusted experts on these matters (Berman 2013; Fourcade 2009). Sociologists, on the other hand, have had a long history of missed opportunities to integrate themselves with professional bodies or assert professional responsibility themselves. This was evident in sociology's retreat from social work and social reform in the early 20th century or in its failure to capitalise on the opportunity presented by legal scientists during the 1930s and 1940s (Camic 2007; Schlegel 1995). The exception that proves the rule was the post-war functionalist era, when sociology asserted itself as a potential synthetic, general theory within a modernization paradigm tied to welfare-state domestic and international policies (Gilman 2007). Yet, no sooner was this synthesis articulated than it was challenged from 'below' by the younger, more 'critical' generation asserting a need for less detached, 'value-free' social science and more involved, 'activist' forms of knowledge.

Thus, sociology, like many humanistic disciplines, reverted to a single professional outlet for its knowledge: the academic profession, i.e., teaching and research. As Abbott argued, sociology recapitulates the fragmented, chaotic structure of the university as a whole. And, as Holmwood (2010) critically noted, Abbott paradoxically affirmed the value of this fragmentation within sociology while criticizing the duplicative redundancy of 'problem-driven' interdisciplinarity in the university at large. In fact, the problem of sociology as a subject-oriented form of knowledge is the problem of the university as a whole: it affirms 'open-ended', relativist, 'critical', 'activist' forms of knowledge, while avoiding engagement with readily accessible, knowable objects largely historical in nature - and, further, avoids synthesis. Sociology is a discipline organized around a 'weak' form of interdisciplinarity.

From an alternative 'strong' interdisciplinary standpoint attentive to professional responsibilities and practical effects, we can observe that, like sociology, interdisciplinarity - particularly humanistic interdisciplinarity - has one primary effect on the outside world: the socialization of undergraduates 'schooled individuals', as Meyer and Bromley (2013) put it. Like sociology, many interdisciplines emphasize critical scholarship challenging the hegemonic discourses of patriarchy, white supremacy, heteronormativity and related forms of symbolic domination. Undoubtedly, these have had profound effects on collaborating researchers and students trained in these problem 
areas. Yet, what are the social effects of these lines of enquiry? Which is to say: what are the social effects of these graduates? Indeed, in many ways, society is moving in directions opposite to those advocated by critical scholarship, becoming less tolerant, more closed-minded and chauvinist (Dahms 2017). In the wider world we have seen the emergence of white identity politics, particularly in the Trump campaign, but also evident in the rise of farright parties in Europe. The lack of higher-educational credentials is notable amongst supporters of all of these movements (Becker et al. 2016).

Meanwhile, initially proactive protest movements surrounding Occupy Wall Street and the Arab Spring have retreated into their own silos on social media. Prior to 2016, student groups struggled to obtain formally institutionalized safe spaces in which each particularistic group could pursue their own discourses 'free' from outside interference. In loudly asserting their requirement of 'autonomy', these activities reflected the trajectory of academic scholarship in recent decades: the socialization patterns established by the likes of Michael Burawoy (2005a), whose proposed professional outlet amounted to activist engagement with multiple 'publics'. Using Elias's and Small's strong interdisciplinary perspective, one can highlight the objective failures of much of this activity insofar as social indicators of tolerance and equality are moving backwards, not forwards; each student group and 'public' is having less and less effect on the public and civic life outside the university. ${ }^{4}$

Indeed, this is predictable insofar as each interdiscipline is organized around a different problem, each of which is a different object. ${ }^{5}$ Unlike in the natural sciences, where multi-perspectival engagement with problems produces synthetic knowledge about a given object, which in turn results in technical innovation (in other words, use), which, in turn, reaffirms the value of multiple disciplinary knowledges, within humanistic interdisciplinarity multiple disciplinary actors converge to elaborate critique of a single dimension of society and culture.

Interdisciplinary humanistic scholarship is, thus, oriented toward objects which encourage solidification of the subjective boundaries of that which is deemed socially and culturally important. For women's studies, this implies patriarchy; for African-American studies, this implies racism; for LGBTQ studies, this implies heteronormativity. But, how are these critical insights translated into professional practice? Beyond the socialization of students, or perhaps in highly constrained work in corporate diversity offices, this work amounts to academics' re-engagement with their disciplinary fields of origin: sociology, history, English, political science, psychology, etc. On the one hand, these disciplines are inevitably deemed 'inadequate' in their engagement with the dimension at hand, and, hence, in need of substantial revision. Often, this involves a reconfiguration of the 'canon' to be more inclusive and representative. On the other hand, multiple re-engagements from several interdisciplines at once results in competition amongst each interest group to determine which dimension is, in fact, most important: race, class, gender, sexuality, disability and so on. As with the representative utopia generally as 
discussed in Chapter 4, the goal of a sufficiently diverse department can become an end in itself - and, as with the loss of social funds of knowledge in the past, the last elements to be defended in a discipline are those central insights the interdisciplines take for granted.

As in weak interdisciplinarity in general, each body of disciplinary critics avoids full dismissal of its competitors; in other words, rarely does the LGBTQ scholar deny the problem of white supremacy or capitalism. Rather, each agrees to recognize the 'intersectionality' of these various forms of domination, in effect, retaining pluralism by avoiding the objective question: Which is more damaging in America today, white supremacy or patriarchy? Which is the most urgent problem? What compromises may be necessary in the short-term to achieve these more urgent ends? The result of these re-engagements within a problemportable discipline, like sociology, is consolidation around the common denominator: namely, the disciplinary silo, which is the mutual object of each interdiscipline's critique.

The discipline, and by extension academia in general, becomes defined as 'heteronormative', 'patriarchal', 'white supremacist', 'Eurocentric', 'masculine', 'ableist' and so on. Indeed, it becomes all of these things at once. This not only sidesteps the question of which form of domination is most salient within a particular historical context - and how each has been an emergent sub-process and interdependent dynamic within the long-term academization process; avoiding the 'third question' noted at the end of Chapter 2 further justifies why it is essential that interdisciplinarity persists indefinitely insofar as disciplines appear to be the bastions of middle-class white men. The primary function of these disciplines - e.g., national history - can be redefined as having been centrally motivated to reinforce this dominant group's ideology, rather than as an object-oriented body of scholarship linked to a variety of subjective dynamics at the time - for example, religious controversies or professional challenges, as we encountered in Chapters 4 and 5. Thus, within a weak interdisciplinary system, the greater penetration and reintegration of interdisciplinary critique within the established disciplines results in delegitimization of these very disciplines and their intellectual authority within a field of professions and power. In other words, the anti-elitism characteristic of the New Class occurs at a level of both socialization (individual graduates) but also the collective level of the entire institutional complex -Parsons defined this as 'ideology'. This is not because the critiques are too penetrating or harsh - most are more or less accurate and true that is, 'scientific'; rather, because these problem-driven studies deny the possibility the standard disciplines could be, or have ever been, anything more than the subjective biases of dominant white men, the very knowledge we come to work with and for is defined as ideology itself. In this way, the science/ideology code of the university is weaponised back upon ourselves, resulting in intellectual self-immolation.

Most certainly, insofar as humanistic disciplines address more subjective forms of knowledge relative to the object-oriented natural sciences, many biases can be observed, especially in historic eras when the white male 
demographic ruled the roost. But, these biases can be objectively identified indeed, the interdisciplines have triumphed in discovering them! So, ideally, these inadequate biases could now be replaced with new, reconstructed forms of disciplinary knowledge oriented to new professional outlets and responsibilities. But, this reconstructed knowledge would have less to do with the subjective biases reflective of our social background, and it would instead be more object-oriented and detached. Paradoxically, this would amount to a recommitment to value-neutrality within disciplines even as this value-neutrality is, correctly, identified by critics to have been ideological justification for dominant groups! But, this is a paradox - and, at present, due to our overinvolvement in the field, we are unaware of the ways we 'deparadoxify' the operative code of the university. By recovering a strong - or stronger - interdisciplinarity we cannot hope to overcome the binary logic of the system; but, rather, we can become more aware of and ultimately more in control of the practical effects our knowledge has on ourselves, our institutions and the world beyond the academy (which is not more ideological than we are). In other words, the effect of this understanding should result in a recovery of academic humility.

\subsection{Conclusion}

The history of the St. Louis World's Fair reveals three distinct perspectives regarding what interdisciplinarity might mean. The first, Münsterberg's, highlighted the unity of knowledge as deduced from a logical arrangement of the arts and sciences. While harking back to an earlier Humboldtian ideal in which abstract knowledge, divided into specialized disciplines, could be synthesized and recombined by relating the part to the whole, this ultimately failed in execution. This was the result of practical inconveniences, including the unpreparedness of the scientists themselves to speak over general matters, which resulted in dry retellings of internal disciplinary histories.

Further, the proposal opened itself up to the pragmatist critique of Dewey, which noted the arrogance of the Congress organizers, who deigned to lay out a logical order once and for all. This inevitably neglected the actual activities and practices of scientists, and it predictably failed to produce the promised syntheses. Dewey's weak interdisciplinary vision suggested that only through local problem-solving could 'unity' be achieved in relation to these specific concerns. But, while such interdisciplinary engagements might produce useful technologies and localized syntheses, the broader goal of relating sciences to one another was effectively abandoned. This weak interdisciplinarity was ultimately more reflective of the 20th-century ideals of academic interdisciplinarity, which continue to be evident in university policy today. Indeed, this weak disciplinarity was characteristic of the second phase of the academization process - emphasizing a 'democratic' ideal that encouraged equal participation and access without reforming unequal playing fields.

However, drawing on the theoretical framework of Elias's sociology of knowledge, I have argued that the third proposal offered by Albion Small had 
more potential than was realised at the time. In particular, by arranging the organized bodies of scholarship according to their social functions - especially, the professional functions of knowledge - both natural and social scientific knowledge could be drawn out to reveal the objective, synthetic relationships between knowledge and society. These syntheses would not be constructed out of the academic pretence of that which should be the case, but rather what was the case in terms of actual professional practices and social impacts. Have our merchants delivered more wealth or not? Have our doctors kept us healthy? This focus on professional functional efficacy could have contributed to what I have called a 'strong interdisciplinarity', which engages with the subjective and objective elements within every body of knowledge. This contrasts with the weak interdisciplinary paradigm in which multi-perspectival orientation to problems encourages synthesis within axially aligned STEM subjects - what Dewey would call 'unity' - while discouraging this unity within more humanistic, subject-oriented bodies of knowledge addressing different objects in incommensurable and duplicative ways.

We must recall Elias's assertion that knowledge is not an individual faculty, but rather a resource of groups: a social fund. A strong interdisciplinarity attentive to the functions of knowledge could organize all disciplines toward an identifiable set of ends. Today, these need not be the societal goals Small and Ruskin identified in the 19th century, but could instead be determined through collaborative discussions that are both subject- and object-oriented. These might still include the promotion of health, justice, understanding, security, wealth and others to be determined in collaboration with publics. In addition to their current research, all disciplines could reflect on the ways in which their knowledge has contributed to and been integrated with progress (or regression) in these areas, and how they might better contribute to these ends in the future. These needs would further be differently - yet, organically - arranged depending on regional, social and cultural differences and particularities. What is deemed 'wealth' or 'health' or 'justice' will be different in London, Hull, Riyadh and the Argentine Pampas. Equally, we will encounter increasingly global problems, including climate change as well as issues of global governance, economic organization and public health, which all societies need to respond to and understand. Universities must be at the centre of direct intervention in these processes alongside the market and state.

Even without such a framework in place, one need only briefly imagine what this might look like to see how far from this mark we are in the 21st century after an unprecedented period of mass expansion of education. Today, we are becoming less healthy; injustice prevails in policing, politics and prisons; we have become mutually incomprehensible, less secure, more unequal economically; and our planet is about to burst into flames. Why? We have not adequately accounted for the ecology of ignorance: the increase of knowledge is not simply the solution, it is also a problem. Indeed, contemporary problems require interdisciplinary solutions, but the relativist, weak interdisciplinarity of the Deweyian university is objectively inadequate 
insofar as it has not contributed to progression toward these ends - in part, due to the elitist legacies of the first phase of the academization process, which were democratized in the second without adequate normative reflection. This is our task as we enter the nascent third phase.

The limits of weak interdisciplinarity are evident not only in the inability of more object-oriented disciplines, like science, to solve problems technologically and responsibly, but, in more critical disciplines and interdisciplines, including sociology and the range of 'studies' which have proliferated in recent decades without necessarily improving the conditions of the disadvantaged groups for whom they claim to speak. As societies critical of 'woke' students, 'cancel culture' and suchlike move farther and farther away from the ideas and ideals articulated within these critical discourses, we must obtain a means of pointing to the objective inadequacies of these forms of knowledge in realizing social progress through communication alone. Because these are discursive statements made from an objectively privileged position, which nonetheless constantly calls out 'privilege', we too often fail to see the extent to which our translation from esoteric to exoteric knowledge is alienating and disempowering for a large number of people, including a non-trivial number of individuals from disadvantaged groups themselves. We further do not see how embedding these human-empowerment agendas in organizations via technical, managerial means and metrics further disguises and limits the potential for genuine changes in social consciousness. Whatever their truth content, the weak interdisciplinary environment creates and reinforces conditions of power in which these essentially valid and 'true' discourses fail to articulate with wider systems of power. Objectively observing this as the fact of the matter provides us with a choice: either the discourses or the institutional system requires reconstruction (Dahms and Lybeck 2016).

We can therefore argue that these academic practices have 'failed' - or are failing - and are, accordingly, in need of replacement with a new, sociologically-informed strong interdisciplinarity. This would have neither the character of Münsterberg's arrogant unity of knowledge, nor Dewey's relativist tolerance suggesting science is what scientists do. Rather, in orienting ourselves toward the objective disunity of the social functions of knowledge today, we might someday establish a better, more realistic unification of these specialized disciplines and problem-oriented interdisciplines; this would, in turn, aid in the progressive realization of a better, more functional, tolerant world. This is one possibility for the university of the future: a reflexive, humble, open, yet confident, local and global university that enters a third phase of the academization process with far more self-awareness than was exhibited in the largely unplanned first and second phases. Or not. The third phase will happen with or without our input, but in this instance we are far more likely to continue our more-or-less oblivious contribution to a range of social problems even as we solve great many others. Ultimately, there is no fundamental resolution to the contradictions emanating from the ideological organization of modern society around universities. There will always be 
critics and counter-critiques. But, it is up to us whether we wish to pursue our individual and collective actions with more realistic and effective means of orientation into the problems we claim an interest in fixing. In this way, the gap between our works and deeds, our culture and utility, might lessen if not disappear.

\section{Notes}

1 I have argued elsewhere that, even locally and contextually, Camic and Xie's interpretation is incorrect insofar as political scientist John W. Burgess did not encourage such a movement as they claim. Rather, the interdisciplinary quantitative shift, such as it was, was the consequence of a diffuse generational rejection of Burgess's Germanic idealism. An essential proximate factor was, thus, World War I and the subsequent anti-Teutonism at Columbia and elsewhere. In other words, the 'local' cause was not the cause, the 'context' included world-historical events and ideological biases, and, in any case, there's no archival evidence for the 'cause' the authors do provide, which appears to have been deduced from the simultaneity of the shift in several departments (see Lybeck 2016).

2 Initially, the Prussian civil service was disinclined to participate in the Exposition, having lost considerable sums during the 1893 Chicago World's Fair. Indeed, in general, Germany did not care for the quintessentially 19th-century institution of the world expo. Only one 'colonial exposition' was held, grudgingly, in Berlin in 1896 (Geppert 2010).

3 A full-scale replica of the front of the Charlottenburg Palace would serve as the German House constructed in the centre of the main site of the Expo. Ironically, the emperor's hopes that the baroque palace would be unlike anything the Americans had ever seen were dashed insofar as the Fair was composed entirely of similar neoclassical buildings. While disappointing to the Kaiser's personalist ambitions, the architecture reflected the pre-existing Germanic influences and sensibilities of the organizers and Missourians. The World's Fair site would later be integrated as part of the Washington University campus.

4 The exception here, which proves the rule, is the Black Lives Matter movement, which emerged from both academic and activist movements in response to the rise in police shootings of people of colour. However, the salience of this movement appears to be an effect of the significance and scale of the problem of police shootings; the academic intervention, if anything, appears to have muddied the waters by introducing a range of issues unrelated to policing reform - e.g., Palestinian rights, transgender issues, etc. In other words, the objective social problem drives Black Lives Matter forward, not the academic theorization of white supremacy.

5 It must be noted that there are a range of historical reasons why these 'problemoriented' groups were established as such. Many universities wished to avoid confrontation with disciplines and established, for example, African-American studies separately from disciplines for this reason. It is, thus, by no means my intention to suggest the following critique is somehow the 'fault' of these interdisciplines. Indeed, as noted below, these forms of scholarship should be fully integrated within disciplines, as should have occurred from the start. 


\section{Conclusion}

\section{Reconstructing the academic profession}

\subsection{The paradox}

Having outlined aspects of the academization process theory, we have only reached the stage wherein we have identified a central paradox: never in human history has higher education been so widespread in its reach and global significance. A rough estimate would identify around 2.8 per cent of the world's population as being currently enrolled in tertiary education (UNESCO IIEP 2017). There has been similar growth in academics, support staff, administration and buildings to house and serve these increasing numbers (ACTA and IEG 2017).

At the same time, however, even as the centrality and importance of academic research, teaching and knowledge exchange has grown, the relative status of the academic profession has suffered a precipitous decline. Sure, the occasional naturalist or historian appears in television documentaries; or, the honoured academic judge or respected economist reaches ears in policymaking circles. But, increasingly, these are the exceptions that prove the rule: the authority of experts is under siege by right-wing populism, dissatisfied workers and even other experts and academics with opposed views (Lybeck 2018b).

This paradox of the simultaneous growth and decline of the academic profession's status can lead to a lack of reflection if we fail to observe that universities are not just passive 'victims' of transformations in the global knowledge economy. We are, in fact, perhaps more than any other institution, the producer of those changes critics tend to call 'neoliberalism', 'post-Fordism', 'late capitalism' and so on (Jessop et al. 2008). In other words, what universities experience as the gale of creative destruction emanates from the current figuration of the university system, which I argue is the contradictory synthesis of two types of university: elite and mass.

What this paradoxical university system produces is a contradictory type of graduate - an individualised, status-seeking professional who increasingly mistakes technique for knowledge, and who is expert in deconstructing established truths and authority, including the very authority on which their social status rests. For an 'individualised professional' is almost an oxymoron

DOI: $10.4324 / 9781351017558-7$ 
insofar as professions are collective entities - lawyers, doctors, therapists and, of course, academics themselves. As academics become more and more specialized and individualized within their workplaces, we lose sight of our collective interest in shared, common knowledge, which is not identical to 'common sense'. We believe that our research is 'ours', our degrees are like a deed of property, and we think of knowledge from the epistemic position of the knowing (adult) individual, rather than thinking of knowledge as a social fund, which improves or declines in quality at a supra-individual (Elias 1987a).

Because we have not properly reckoned with the contradictions of a 'mass elite' university, in which nearly 50 per cent of young adults in OECD nations enrol in university (OECD 2018) - meaning the educated 'elite' is nearly the popular majority - we find ourselves paralysed by fears of being too elitist or an impostor or both. We engage in robust critical scholarship that demonstrates we are privileged in the grand scheme of things, and yet we still struggle to pay the bills, including interest on student loans, and we wonder how those non-academic professionals seem to have so much more wealth, leisure and, paradoxically, time to read. We may know we are elites, but how often do we feel empowered?

\subsection{The pinch}

Why has the academic profession been effectively deconstructed in the past few decades, producing these increasingly large cohorts of anxious individualised professionals?

- The New Left - while many would blame contemporary neoliberalism on the New Right (see next bullet below), my interpretation here is that the (recent) trend toward what the sociologist Robert Bellah called 'expressive individualism' began during the 1960s amongst the baby-boomers (Bellah et al. 2007; Bell 1996; Lasch 1991). Initially motivated by just causes, including civil rights, anti-war protests, gender inequality and so forth, this generation's political organization fell short of cultural promises to themselves, including a neo-Romantic, East-meets-West ideal of self-actualisation and 'freedom' defined in sexual terms, on the one hand, but also technological terms, particularly within Silicon Valley utopianism imagining non-hierarchical networks and systems that would allow humans to interact without authority structures or big government bureaucracies. The introduction of expressive individualism within the baby-boomer generation and thereafter has had a number of consequences for social organization (Boltanski and Chiapello 2005); and it was significant in asserting the individual's right to be 'free' to do what they want, especially vis-à-vis welfare-state authority structures, of which professions and universities remained a constitutive part. Thus began our sustained auto-criticism of the very institutions in which we work and from which we obtain income and status. 
- The New Right - While historians of ideas trace the origins of neoliberalism to the meeting of (then oddball) economists and political philosophers at a Swiss hotel (Mirowski and Plehwe 2009; Harvey 2005), we must recall these neoliberal views did not begin their ascendance until the basic mechanisms of Keynesian fiscal management of the state began to malfunction and stagflation - a theoretical impossibility in Keynesian macroeconomics - began to occur. This crisis of expertise happened more or less concurrently across advanced industrial economies beginning in the early- to mid-1970s, pushing the anti-monopolist, anti-tax, subjectivity-oriented and methodologically individualistic views of economists to the forefront of economic policy. Not coincidentally, many professionals' view of themselves preconditioned them to accept this due to the aforementioned changes in expressive individualism amongst the middle classes. From the right, thereafter, neoliberals challenged the collective authority of professions as being self-interested guilds, in which any references to public purpose or social or civic function was mere ideological window-dressing for self-interested, rationally calculating, greedy actors. Again, this was increasingly the way professionals seemed to view themselves.

The rest is history, as we know: the privatisation of public finances began under Reagan in America and Thatcher in Britain, with similar reforms made in their images elsewhere (Slaughter and Rhoades 2009; McGettigan 2013; Newfield 2016). The power of unions was smashed due to the perceived oligarchy structure that stood in the way of efficiency and growth, which was politically effective in terms of eliminating counter-powers in 'old Left' unions and political factions. Universities - and some professions - were also caught up in this anti-monopolist wave: tenure was stripped, academic union rights were diminished and new public administration audits were put in place. Then, as now, these reforms were justified through critical reference to academic elitism, which supposedly held back the participation of wider populations who would otherwise benefit from higher education. Then, as now, academics, left-wing loafers and their arcane subjects were criticised for being useless to both these students and the wider public. The state would have to intervene to undermine academic authority in the students' and the wider public's interests.

What the state accomplished was the opening of the higher education 'market' to other non-academic professionals, namely those trained within business schools who employed management and auditing techniques that were inappropriate for the non-economic sectors colonised by these consultants (still drawing on 'expertise' rooted in university degrees). After decades of this trashing of public services, which has resulted in greater inefficiencies and costs, dramatically increased economic inequality, still stagnating wages and (often disguised) inflation and unemployment, it is not difficult to see why this mode of organizing firms, societies, healthcare, cultural 
and media institutions and universities is undergoing a sustained legitimacy crisis of its own.

We are presently living through an interregnum.

\subsection{Where we are}

The ascent of populism on the left and right, but especially the right, is rooted in a loss of faith in experts. This anti-expert populism was, of course, prefigured in climate denialism, but it has a long tradition going back to evangelical disbelief in Darwinian evolution in the 19th century. Interestingly, in America these populists were also connected to heterodox economic positions, such as the 'free silver' movement and so on. Finally, each political faction (populist and elite) tended to accuse the other of being 'racist' in inconsistent ways, as is common within today's polarised public sphere as well. Thus far, much of the contemporary academic reaction to these claims has taken the form of doubling down: the public is wrong/racist/ignorant and so on. This may be emotionally satisfying, and perhaps factually correct at times, but I argue this reaction misrecognizes several dynamics that, again, are important for us to see as being the result of long-term sociological trends:

- The internal and international migration of students and graduates has led to an evacuation of young people from rural and suburban communities toward metropolitan cities and university towns - this concentrates the knowledge economy in these regions and contributes to demographic statistics showing, for example, that the counties that voted for Brexit are 'older' and 'less educated' (Becker et al. 2016).

- By moving from elite to mass levels of enrolment, we have restructured national class systems around credentials and status. In the US, political scientists now actually measure 'class' according to whether voters do or do not have college degrees.

- As globalised, Schumpeterian states have shifted toward STEM research and innovation while competing for (especially international, especially Chinese) students framed as 'consumers', universities organize themselves isomorphically around the criteria measured in global rankings produced by Times Higher Education, QS, Guardian and other publishers (DiMaggio and Powell 1983 on 'isomorphism'). This channels the mission and purpose of higher education into the individualistic frames noted above, while also further restricting the incentives for universities to function as regional and local institutions.

- As student numbers grow, unregulated development of student accommodation - both purpose-built and multiple-occupancy homes - dramatically impacts housing prices. These pressures on the cost of housing for 'locals' can result in dissatisfaction, displacement and gentrification within metropolitan spaces or segregation of spaces into town and gown (Smith, Sage, and Balsdon 2014). 
- Not only do these economic trends affect 'locals', they also affect earlycareer academics themselves, who can rarely afford to live near their universities, in contrast to their older professional peers, whose equity in nearby housing has increased exponentially. This occurs alongside the casualisation of fixed-term teaching staff and the internal bifurcation of the academic profession into elite researchers and precarious teachers. There are also substantial gendered dimensions to the trend, as is typical of the emergence of any 'semi-profession' (Etzioni 1969; Lybeck 2018b).

- Lastly, discourses surrounding social mobility reinforce the idea that one should aspire to leave one's community not just if one hopes to obtain higher incomes, but if one hopes to participate in society, politics, economics or science at all. This process encourages a more rootless, less attached relationship to one's 'place' and a greater attachment to cosmopolitan ideals.

These are only a few related trends that become more visible from the detached position provided by the academization process theory.

But, we can also consider this emergent structure from the vantage of a pensioner living in an abandoned, deindustrialised town when a politician arrives and says, 'Don't believe the experts - remember how they ruined the economy in 2008? - you know, they never talk about immigration? - they want to tell us we cannot make our own rules? - that our fate is in the hands of global trade and a bunch of faceless bureaucrats in Brussels?' Or: 'Don't believe those intolerant latte-sipping Democrat elitists who want to replace coal with solar power from China - we are going to bring back the mines/ factory/mill that used to be the heart of this town - anyone who tells you we can't is lying - fake news!' From the pensioner's position within the emerging knowledge-economy, the appeal of these messages become somewhat more understandable, if nonetheless ill-informed. However, amongst academics and professionals, is our best reaction to then continue to speak amongst ourselves about how Brexit 'really' is a reaction to post-imperial decline? Or, to continue to hold seminars on campus demanding our regions develop a 'global vision' that fits our university's strategic plans? Or, to suggest that those who believe we can 'take back control' from unaccountable bureaucrats are essentially stupid? Further examples abound, in which few, if any, lessons are being learned about our post-Brexit, post-Trump, post-truth world that is not directed internally within academia/metropolitan/'liberal' spaces and communicative systems.

We might further consider that even within this emergent structure - particularly from vantages other than the 'top' of the hierarchical pyramid of rankings - not all is quite right. Imagine, for example, being a student from a disadvantaged background who has enrolled at a not-so-top-tier institution. One may still have to leave home and become a stranger to both friends 'left behind' and one's peers at university who are not first-generation (Reay et al. 2005). Or, imagine being an academic working in or a professional graduate 
from one of these institutions. The message from the broader professional environment is clear: you remain 'less than'. You may have a degree, but it is 'Mickey Mouse'. You apply for dozens of jobs, but you are competing against graduates from 'top-tier' universities. Accordingly, the job you do have is insecure because you are 'replaceable' - by either new graduates or an as yet uninvented artificially intelligent machine. You may be aware that you are in what anthropologist David Graeber (2018) calls a 'bullshit job'. When not distracted by box sets depicting grotesque violence or reality shows humiliating less fortunate others, one might be 'lucky' enough to attend a dinner party with other professionals and academics. References to abstract theories by Foucault or Butler catch you off guard, since much of one's training was skills-based, technical and professionally oriented. Newspapers talk about automation destroying white-collar work, and one wonders whether one's degree is enough. Does one go on to expensive postgraduate study? If so, do you have learn all about this 'intersectionality' stuff we keep hearing about? Should you migrate to a less expensive region and become a big fish in a smaller pond? Would you too become 'left behind'?

Now imagine the politician who says: 'Do you know all those elitist academics going on about social justice, feminism, transgender and on and on? when will it end? - it's never enough for these people - and they have the nerve to talk about us being "privileged" - Ha!' Wouldn't it be so much more convenient if the source of one's problems lay at the door of those irritating, arrogant, 'virtue-signalling' academic elites? Not only do they seem to control the centre of expertise, culture and power, if one tries to challenge their wisdom, one is accused of being a racist, sexist, privileged white man or similar.

These are just a few points of view that look differently from angles other than the view at the elite centre of the academic profession, which remains highly unequal despite the increase in mass student enrolment. Indeed, as

overcredentialisation makes bachelor's degrees a standard baseline for employment, the more the overall status hierarchy of institutions (i.e., global rankings) determines one's chances of obtaining work and status, as has been well-known within sociology since the 1970s (Collins 1971). As long as the hierarchical structure of higher educational institutions remains the case, any efforts to widen participation within elite universities will fail to improve the condition of the majority of students from non-traditional backgrounds, who will be enrolled at less than top-tiered universities.

\subsection{Reconstruction}

Having deconstructed much of what is taken for granted as the natural structure of higher education in a globalised, knowledge-based economy, it is worth considering what this diagnosis suggests should be done to improve the situation. Taking the last observation first: if the problem is the hierarchical structure of institutions worldwide, what the academic profession can begin to 
do is reassert our collaborative relationships and horizontal, segmental patterns of differentiation. Those of us in more 'elite' institutions might recommend further collaborations with 'lower status' universities, not just in developing countries, as the British government is encouraging through its Global Challenges Research Fund, but within local cities and regions. The recent proposal in Berlin to develop a citywide strategy for Humboldt, Frei, TU-Berlin and Charité medical schools is a promising development in this direction. Indeed, the re-emergence of explicitly 'civic universities' through the UPP Foundation in Britain and the international collaborators I am working with as editor of the new journal Civic Sociology may point us in the direction we need to go in.

To put a fine point on the matter: we need to take responsibility, not just for our science, but for our societies - both those we live in and near, and those that feel 'left behind'. We may think these folks do not understand $\mathrm{x}, \mathrm{y}$ or $\mathrm{z}$; in which case, it is our responsibility to empathise, engage and explain what we think is the 'truth' to folks who may not see the value in what we do. In going through such processes, who knows: maybe some of our most certain truths will change? Maybe together, we can become something new.

While this task might appear difficult in present circumstances, we must recall that the academic profession and university is well over 1,000 years old. Founded as a guild to preserve the quality of degrees, the social value of universities has waxed and waned over the centuries. What is most interesting about the present is the paradox of both centrality, due to the expansion of mass higher education and technological innovation, and the criticism of academics as being out-of-touch elitists. As I have argued in the past, perhaps a return to the idea of universities as self-governing guilds could provide a basis upon which we can reconnect with wider populations (Lybeck 2018b). Immediately this suggestion will strike us as a contradiction: how would reconstructing the 'exclusivity' of guild 'privileges' result in a reengagement with the public? History suggests that universities were not just $a$ guild, but the original guild, upon which all others organized themselves. Other histories suggest unions and artisanal associations were similarly modelled on guilds, especially as privileges were undermined by utilitarian principles of 'free trade'. Indeed, historians have revisited the history of guilds and found that they not only provided the earliest conception of citizenship, but they were transnational (Prak 2018; Hoogenboom et al. 2018). Moving forward we might consider our relationship as academics and professions to more traditional 'trade' and 'craft' guilds, such as Les Compagnons du Devoir and other forms of apprenticeships and non-academic education. The university of the future must interact with everyone as an element of everyday life. This need not involve enrolment on expensive degree courses. Rather, universities, like libraries, must be public resources where we all engage with our collective social fund of knowledge.

After all, the great success story of the 20th- and 21st-century expansion of higher education has been the establishment of a high proportion of 


\section{Conclusion}

university-educated classes. But, have we adequately considered the fates of those without such credentials - both older populations and younger populations who do not immediately go on to further education? Perhaps the current crisis we are facing is, in fact, an opportunity to rethink the role of academic knowledge in contemporary, globalizing (and deglobalizing) societies. But only through rigorous remaking of our theories and practices about what the university is, was and could be can we hold in our hand even the slightest chance of orienting ourselves to an evermore complex and uncertain world. This book has hopefully served its function as a humble start in that direction. 


\section{References}

Abbott, Andrew. 1988. The System of Professions: Essay on the Division of Expert Labour. Chicago, IL: University of Chicago Press.

Abbott, Andrew. 1999. Department and Discipline: Chicago Sociology at One Hundred. 1st edition. Chicago, IL: University of Chicago Press.

Abbott, Andrew. 2001a. Chaos of Disciplines. Chicago, IL: University of Chicago Press.

Abbott, Andrew. 2001b. Time Matters: On Theory and Method. 1st edition. Chicago, IL: University of Chicago Press.

Abbott, Andrew. 2005a. 'Linked Ecologies: Ecologies and Fields'. Andrew Abbott Papers. https://home.uchicago.edu/ aabbott/edited\%20vols.html.

Abbott, Andrew. 2005b. 'Linked Ecologies: States and Universities as Environments for Professions'. Sociological Theory 23 (3):245-274.

Abbott, Andrew. 2016. Processual Sociology. Chicago, IL: University of Chicago Press.

Abercrombie, Nicholas, and Bryan S. Turner. 1978. 'The Dominant Ideology Thesis'. The British Journal of Sociology 29 (2):149-170.

ACTA and IEG. 2017. How Much Is Too Much? Controlling Administrative Costs through Effective Oversight. Washington, DC: American Council of Trustees and Alumni - Institute for Effective Governance.

Adams, Julia, Elisabeth Stephanie Clemens, and Ann Shola Orloff. 2005. Remaking Modernity: Politics, History, and Sociology. Durham, NC: Duke University Press.

Adas, Michael. 1989. Machines as the Measure of Men: Science, Technology, and Ideologies of Western Dominance. Ithaca, NY: Cornell University Press.

Adorno, Theodor. 2003. 'Late Capitalism or Industrial Society? - The Fundamental Question of the Present Structure of Society'. In Can One Live After Auschwitz? A Philosophical Reader. Stanford, CT: Stanford University Press.

Alexander, Jeffrey C. 1984. 'The Parsons Revival in German Sociology'. Sociological Theory (2): $394-412$.

Alexander, Jeffrey C. 1995. Fin de Siècle Social Theory: Relativism, Reduction and the Problem of Reason. London: Verso Books.

Alexander, Jeffrey C. 2003. The Meanings of Social Life: A Cultural Sociology. Oxford: Oxford University Press.

Alexander, Jeffrey C. 2008. The Civil Sphere. New York: Oxford University Press.

Alexander, Jeffrey C., Bernhard Giesen, and Jason L. Mast. 2006. Social Performance: Symbolic Action, Cultural Pragmatics, and Ritual. New York: Cambridge University Press. 
Anderson, R. D. 2004. European Universities from the Enlightenment to 1914. Oxford: Oxford University Press.

Angell, James Rowland. 1905. 'Psychology at the St. Louis Congress'. Journal of Philosophy, Psychology and Scientific Method 2:533-546.

Anon. 1959. 'Latin Dropped By Cambridge as Entrance Need'. Sydney Morning Herald, May 18, 2.

Archer, Margaret Scotford. 1995. Realist Social Theory: The Morphogenetic Approach. New York: Cambridge University Press.

Arkwright, E. H. 1901. 'Modern Languages at Clifton College'. The Modern Language Quarterly (1900-1904) 4 (3):196-197.

Arnold, Matthew. 1864. 'The Function of Criticism at the Present Time.' The National Review.

Arnold, Matthew. 2006. Culture and Anarchy. Oxford: Oxford University Press.

Aron, Raymond. 1998. Main Currents in Sociological Thought. New Brunswick, NJ: Transaction Publishers.

Aron, Raymond. 2001. The Opium of the Intellectuals. New Brunswick, NJ: Transaction Publishers.

Arrighi, Giovanni. 2010. The Long Twentieth Century: Money, Power, and the Origins of Our Times. London: Verso Books.

Arrighi, Giovanni, and Beverly J. Silver. 1999. Chaos and Governance in the Modern World System. Minneapolis, MN: University of Minnesota Press.

Arum, Richard, and Josipa Roksa. 2011. Academically Adrift: Limited Learning on College Campuses. Chicago, IL: University of Chicago Press.

Ash, Mitchell G. 2006. 'Bachelor of What, Master of Whom? The Humboldt Myth and Historical Transformations of Higher Education in German-Speaking Europe and the US1'. European Journal of Education 41 (2):245-267.

Ashby, Eric. 1967. 'The Future of the Nineteenth Century Idea of a University'. Minerva 6 (1):3-17.

Aston, T. H., and C. H. E. Philpin. 1985. The Brenner Debate: Agrarian Class Structure and Economic Development in Pre-Industrial Europe. New York: Cambridge University Press.

Ball, Stephen J. 1990. Foucault and Education: Disciplines and Knowledge. London: Routledge.

Ball, Stephen J. 2013. Foucault, Power, and Education. New York: Routledge.

Baran, Paul A. 1957. The Political Economy of Growth. New York: Monthly Review Press.

Bastow, Simon, Patrick Dunleavy, and Jane Tinkler. 2014. The Impact of the Social Sciences: How Academics and Their Research Make a Difference. Thousand Oaks, CA: SAGE Publications.

Becher, Tony, and Paul Trowler. 2001. Academic Tribes and Territories: Intellectual Enquiry and the Cultures of Disciplines. 2nd edition. Buckingham: Open University Press.

Beck, Ulrich. 1992. Risk Society: Towards a New Modernity. Thousand Oaks, CA: SAGE Publications.

Becker, Sascha, Thiemo Fetzer, and Dennis Novy. 2016. 'Who Voted for Brexit? A Comprehensive District-Level Analysis'. Economic Policy 32 (92):601-650.

Bell, Daniel. 1960. The End of Ideology: On the Exhaustion of Political Ideas in the Fifties. New York: Free Press.

Bell, Daniel. 1996. The Cultural Contradictions of Capitalism. Glencoe, IL: Basic Books. 
Bellah, Robert N., Richard Madsen, William M. Sullivan, Ann Swidler, and Steven M. Tipton (Eds.). 2007. Habits of the Heart: Individualism and Commitment in American Life. Berkeley, CA: University of California Press.

Ben-David, Joseph. 1960. 'Scientific Productivity and Academic Organization in Nineteenth Century Medicine'. American Sociological Review 25 (6):828.

Ben-David, Joseph. 1965. 'The Scientific Role: The Conditions of Its Establishment in Europe'. Minerva 4 (1):15-54.

Ben-David, Joseph. 1971. The Scientist's Role in Society: A Comparative Study. 1st edition. Upper Saddle River, NJ: Prentice Hall.

Ben-David, Joseph. 1972a. American Higher Education: Directions Old and New. New York: McGraw-Hill Book Company, Inc.

Ben-David, Joseph. 1972b. 'The Profession of Science and Its Powers'. Minerva 10 (3):362383. doi:10.1007/BF01556920.

Ben-David, Joseph. 1977. Centers of Learning: Britain, France, Germany, United States. New York: McGraw-Hill Book Company, Inc.

Ben-David, Joseph. 1981. 'The Sociology of Scientific Knowledge'. In The State of Sociology: Problems and Prospects, edited by J. F. Short. New York: Sage Publications.

Ben-David, Joseph, and Randall Collins. 1966. 'Social Factors in the Origins of a New Science: The Case of Psychology'. American Sociological Review 31 (4):451.

Ben-David, Joseph, and Teresa A. Sullivan. 1975. 'Sociology of Science'. Annual Review of Sociology 1:203-222.

Ben-David, Joseph, and Awraham Zloczower. 1961. 'The Idea of the University and the Academic Market Place'. European Journal of Sociology/Archives Européennes de Sociologie 2 (2):303-314.

Berman, Elizabeth Popp. 2011. Creating the Market University: How Academic Science Became an Economic Engine. Princeton, NJ: Princeton University Press.

Berman, Elizabeth Popp. 2013. 'Thinking Like an Economist: The Normative Effects of a Positive Discipline in Two U.S. Policy Domains'. ASAComparative-Historical and Political Sociology Sections Mini-Conference on Capitalism, the Politics of Inequality and Historical Change. New York.

Bernstein, Basil. 1973. Class, Codes and Control, Volume 2: Applied Studies towards a Sociology of Language. London: Routledge \& Kegan Paul.

Bhambra, Gurminder K. 2010. 'Historical Sociology, International Relations and Connected Histories'. Cambridge Review of International Affairs 23 (1):127-143.

Bhaskar, Roy. 2008. A Realist Theory of Science. London: Verso.

Black, Mary E. 1987. 'Matthew Arnold as School Inspector: A Revaluation'. Pacific Coast Philology 22 (1/2):15-21.

Blackbourn, David. 2003. History of Germany, 1780-1918: The Long Nineteenth Century. Malden, MA: Blackwell Publishing.

Blackbourn, David, and Geoff Eley. 1984. The Peculiarities of German History: Bourgeois Society and Politics in Nineteenth-Century Germany. Oxford: Oxford University Press.

Block, Fred, and Matthew R. Keller. 2009. 'Where Do Innovations Come From? Transformations in the US Economy, 1970-2006'. Socio-Economic Review 7 (3):459483.

Block, Fred L. 1994. 'The Ruling Class Does Not Rule'. In The State: Critical Concepts, Volume 1, edited by John Hall (pp. 130-145). New York: Routledge.

Boltanski, Luc, and Eve Chiapello. 2005. The New Spirit of Capitalism. London: Verso. 


\section{References}

Bourdieu, Pierre. 1977. Outline of a Theory of Practice. Cambridge: Cambridge University Press.

Bourdieu, Pierre. 1984. Distinction: A Social Critique of the Judgement of Taste. Cambridge, MA: Harvard University Press.

Bourdieu, Pierre. 1986. 'The Forms of Capital'. In Handbook of Theory and Research for the Sociology of Education, edited by J. G. Richardson (pp. 241-258). New York: Greenwood Press.

Bourdieu, Pierre. 1988. Homo Academicus. Stanford, CA: Stanford University Press.

Bourdieu, Pierre. 1996. The State Nobility: Elite Schools in the Field of Power. Cambridge: Polity.

Bourdieu, Pierre. 2015. On the State. 1st edition. Cambridge: Polity.

Bourdieu, Pierre, and Jean-Claude Passeron. 1990. Reproduction in Education, Society and Culture. Thousand Oaks, CA: SAGE Publications.

Bozeman, Barry, and Daniel Sarewitz. 2011. 'Public Value Mapping and Science Policy Evaluation'. Minerva 49 (1):1-23.

Braudel, Fernand. 1996. The Mediterranean and the Mediterranean World in the Age of Philip II. Berkeley, CA: University of California Press.

Brint, Steven. 1996. In an Age of Experts: The Changing Role of Professionals in Politics and Public Life. Princeton, NJ: Princeton University Press.

Brock, M. G., and M. C. Curthoys, eds. 1997. The History of the University of Oxford: Volume VI: Nineteenth Century Oxford, Part 1. Oxford: Oxford University Press.

Brocke, Bernhard Vom. 1991. 'Friedrich Althoff: A Great Figure in Higher Education Policy in Germany'. Minerva 29 (3):269-293.

Bromley, Patricia, and John W. Meyer. 2015. Hyper-Organization: Global Organizational Expansion. Oxford: Oxford University Press.

Bruch, Rüdiger vom. 2006. Gelehrtenpolitik, Sozialwissenschaften Und Akademische Diskurse in Deutschland Im 19. Und 20. Jahrhundert, edited by B. Hofmeister and H.-C. Liess. 1st edition. Stuttgart: Franz Steiner Verlag.

Burage, Michael. 1993. 'From Practice to School-Based Professional Education: Patterns of Conflict and Accommodation in England, France, and the United States'. In The European and American University Since 1800, edited by S. Rothblatt and B. Wittrock (pp. 142-190). Cambridge: Cambridge University Press.

Burawoy, Michael. 2005a. '2004 ASA Presidential Address: For Public Sociology'. American Sociological Review 70 (1):4-28.

Burawoy, Michael. 2005b. 'Provincializing the Social Sciences'. In The Politics of Method in the Human Sciences: Positivism and Its Epistemological Others, edited by G. Steinmetz (pp. 508-525). Durham, NC: Duke University Press.

Burawoy, Michael. 2008. 'Open the Social Sciences: To Whom and for What?'. Portuguese Journal of Social Sciences 6 (3):137-146.

Burke, Peter. 2000. A Social History of Knowledge: From Gutenberg to Diderot. Cambridge: Polity.

Bywater, Ingram. 1919. Four Centuries of Greek Learning in England: Inaugural Lecture Delivered Before the University of Oxford on 8 March 1894. Oxford: Clarendon Press.

Callon, Michel. 1998. Laws of the Markets. Hoboken, NJ: John Wiley \& Sons.

Camic, Charles. 2007. 'On Edge: Sociology during the Great Depression and the New Deal'. In Sociology in America: A History, edited by C. Calhoun (pp. 225-280). Chicago, IL: University of Chicago Press. 
Camic, Charles, and Neil Gross. 2002. 'Alvin Gouldner and the Sociology of Ideas: Lessons from "Enter Plato"”. The Sociological Quarterly 43 (1):97-110.

Camic, Charles, and Neil Gross. 2004. 'The New Sociology of Ideas'. In The Blackwell Companion to Sociology, edited by J. R. Blau (pp. 236-249). Malden, MA: Blackwell Publishing.

Camic, Charles, Neil Gross, and Michèle Lamont. 2011. Social Knowledge in the Making. Chicago, IL: University of Chicago Press.

Camic, Charles, and Yu Xie. 1994. 'The Statistical Turn in American Social Science: Columbia University, 1890 to 1915'. American Sociological Review 59 (5):773-805.

Cannadine, David. 1990. The Decline and Fall of the British Aristocracy. New Haven, CT: Yale University Press.

Carruthers, Celeste K., and Marianne H. Wanamaker. 2015. 'Municipal Housekeeping the Impact of Women's Suffrage on Public Education'. Journal of Human Resources 50 (4):837-872.

Chalus, Elaine. 2000. 'Elite Women, Social Politics, and the Political World of Late Eighteenth-Century England'. The Historical Journal 43 (3):669-697.

Chalus, Elaine. 2005. Elite Women in English Political Life, c.1754-1790. Oxford: Oxford University Press.

Chriss, James J. 1999. Alvin W. Gouldner: Sociologist and Outlaw Marxist. Aldershot: Ashgate.

Clark, Christopher M. 2006. Iron Kingdom: The Rise and Downfall of Prussia, 16001947. Cambridge, MA: Belknap Press of Harvard University Press.

Clark, William. 2006. Academic Charisma and the Origins of the Research University. Chicago, IL: University of Chicago Press.

Clemens, Elisabeth S. 2017. 'Distrust in Distant Powers: Misalignments of Political and Social Geography in American Democracy'. Items: Insights from the Social Sciences. https://items.ssrc.org/democracy-papers/misalignments-of-political-and-so cial-geography-in-american-democracy.

Coats, A. W. 1961. 'American Scholarship Comes of Age: The Louisiana Purchase Exposition 1904'. Journal of the History of Ideas 22 (3):404.

Collini, Stefan. 2012. What Are Universities For?London: Penguin.

Collins, Randall. 1971. 'Functional and Conflict Theories of Educational Stratification'. American Sociological Review 36 (6):1002-1019. doi:10.2307/2093761.

Collins, Randall. 1979. The Credential Society: An Historical Sociology of Education and Stratification. New York: Academic Press.

Collins, Randall. 1998. The Sociology of Philosophies: A Global Theory of Intellectual Change. Cambridge, MA: Belknap Press of Harvard University Press.

Connell, W. F. 2002. The Educational Thought and Influence of Matthew Arnold. Abingdon: Routledge.

Conteh, Jean, and Gabriela Meier. 2014. The Multilingual Turn in Languages Education: Opportunities and Challenges. Bristol: Multilingual Matters.

Craig, John E. 1984. Scholarship and Nation Building: The Universities of Strasbourg and Alsatian Society, 1870-1939. Chicago, IL: University of Chicago Press.

Cramer, Katherine J. 2016. The Politics of Resentment: Rural Consciousness in Wisconsin and the Rise of Scott Walker. Chicago, IL: University of Chicago Press.

Crozier, Gill, Diane Reay, John Clayton, Lori Colliander, and Jan Grinstead. 2008. 'Different Strokes for Different Folks: Diverse Students in Diverse Institutions Experiences of Higher Education'. Research Papers in Education 23 (2):167-177. 


\section{References}

Dahms, Harry F. 2017. 'Critical Theory, Brexit, and the Vicissitudes of Political Economy in the Twenty-First Century'. In Brexit: Sociological Responses, edited by W. Outhwaite. (pp. 183-192). London: Anthem Press.

Dahms, Harry F., and Eric R. Lybeck, eds. 2016. Reconstructing Social Theory, History and Practice. Vol. 35. Bingley: Emerald Group Publishing Limited.

Dahrendorf, Ralf. 1959. Class and Class Conflict in Industrial Society. 3rd edition. Stanford, CA: Stanford University Press.

Dahrendorf, Ralf. 1969. Society and Democracy in Germany. Garden City, NY: Doubleday.

Daston, Lorraine, and Peter Galison. 2007. Objectivity. Cambridge, MA: Zone Books.

Department for Business Innovation and Skills. 2011. Higher Education: Students at the Heart of the System. CM 8122. London: Department for Business, Innovation and Skills. Retrieved 17 April 2012: http://www.scribd.com/doc/58879994/ 11-944-WP-Students-at-Heart.

Department of Education and Skills. 2002. 14-19: Extending Opportunities, Raising Standards Consultation Document. CM 5342. London: Department for Education and Skills.

Dewey, John. 1903. 'The St. Louis Congress of the Arts and Sciences'. Science 18:275278.

DiMaggio, Paul J., and Walter W. Powell. 1893. 'The Iron Cage Revisited: Institutional Isomorphism and Collective Rationality in Organizational Fields.' American Sociological Review 48 (2):147-160.

Domhoff, G. William. 2010. Who Rules America? Challenges to Corporate and Class Dominance. Boston, MA: McGraw Hill Higher Education.

Durkheim, Emile. 2001. The Elementary Forms of Religious Life. Oxford: Oxford University Press.

Durkheim, Emile. 2013. The Evolution of Educational Thought: Lectures on the Formation and Development of Secondary Education in France. Abingdon: Routledge.

Dyhouse, Carol. 2006. Students: A Gendered History. Abingdon: Routledge.

Eagleton, Terry. 2010. 'The Death of Universities'. The Guardian, 17 December.

Eger, Elizabeth. 2010. Bluestockings: Women of Reason from Enlightenment to Romanticism. Basingstoke: Palgrave Macmillan.

Elias, Norbert. 1971a. 'Sociology of Knowledge: New Perspectives Part One'. Sociology 5 (2):149-168.

Elias, Norbert. 1971b. 'Sociology of Knowledge: New Perspectives Part Two'. Sociology 5 (3):355-370.

Elias, Norbert. 1983. The Court Society. New York: Pantheon Books.

Elias, Norbert. 1987a. Involvement and Detachment. New York: Blackwell.

Elias, Norbert. 1987b. 'The Retreat of Sociologists into the Present'. Theory, Culture \& Society 4 (2-3):223-247.

Elias, Norbert. 1991. The Symbol Theory. Thousand Oaks, CA: SAGE Publications.

Elias, Norbert. 2000. The Civilizing Process: Sociogenetic and Psychogenetic Investigations. edited by E. Dunning, J. Goudsblom, and S. Mennell. Malden, MA: Blackwell Publishing.

Elias, Norbert. 2007. Involvement and Detachment. Dublin: University College Dublin Press.

Elias, Norbert, and Eric Dunning. 2008. Quest for Excitement: Sport and Leisure in the Civilising Process. Dublin: University College Dublin Press. 
Elias, Norbert, Hermínio Martins, and Richard Whitley. 1982. Scientific Establishments and Hierarchies. Dordrecht: Reidel.

Eliot, George. 1879. Impressions of Theophrastus Such. London: William Blackwood \& Sons.

Engels, Frederick. 2005. Ludwig Feuerbach and the End of Classical German Philosophy. Forest Grove, OR: University Press of the Pacific.

Etzioni, Amitai. 1968. The Active Society: A Theory of Societal and Political Processes. New York: Collier-Macmillan.

Etzioni, Amitai. 1969. The Semi-Professions and Their Organization: Teachers, Nurses, Social Workers. New York: Free Press.

Etzkowitz, Henry, and Loet Leydesdorff. 1996. 'A Triple Helix of Academic-IndustryGovernment Relations: Development Models beyond "Capitalism versus Socialism"'. Current Science 70 (8):690-693.

Etzkowitz, Henry, and Loet Leydesdorff. 1998. 'The Endless Transition: A “Triple Helix" of University-Industry-Government Relations'. Minerva 36 (3):203-208.

Evans, Peter B., Dietrich Rueschemeyer, Theda Skocpol, Social Science Research Council (US) Committee on States and Social Structures, Joint Committee on Latin American Studies, and Joint Committee on Western Europe. 1985. Bringing the State Back In. Cambridge: Cambridge University Press.

Ewing, Sally. 1987. 'Formal Justice and the Spirit of Capitalism: Max Weber's Sociology of Law'. Law \& Society Review 21 (3):487.

Eyal, Gil. 2012. 'Spaces between Fields'. In Bourdieu and Historical Analysis, edited by P. S. Gorski (pp. 158-182). Durham, NC: Duke University Press.

Fisher, Irving. 1906. The Nature of Capital and Income. New York: Macmillan.

Fleck, Christian. 2011. A Transatlantic History of the Social Sciences: Robber Barons, the Third Reich and the Invention of Empirical Social Research. London: Bloomsbury Academic.

Fletcher, Sheila. 1980. Feminists and Bureaucrats: A Study in the Development of Girls' Education in the Nineteenth Century. Cambridge: Cambridge University Press.

Flexner, Abraham. 1994. Universities: American, English, German. Piscataway, NJ: Transaction Publishers.

Fligstein, Neil. 1993. The Transformation of Corporate Control. Cambridge, MA: Harvard University Press.

Fligstein, Neil, and Doug McAdam. 2015. A Theory of Fields. Oxford: Oxford University Press.

Fourcade, Marion. 2009. Economists and Societies: Discipline and Profession in the United States, Britain, and France, 1890s to 1990s. Princeton, NJ: Princeton University Press.

Fowler, Bridget. 2015. 'Lucien Goldmann's Key Sociological Problems and His Critical Heritage: From the Hidden God to the Hidden Class'. In Sociological Amnesia: Cross-currents in Disciplinary History, edited by A. Law and E. R. Lybeck (pp. 105-124). Aldershot: Ashgate.

Frank, Andre Gunder. 1989. 'The Development of Underdevelopment (1966)'. Monthly Review 41 (2). doi:10.14452/MR-041-02-1989-06_4.

Frank, David John, and John W. Meyer. 2007. 'University Expansion and the Knowledge Society'. Theory and Society 36 (4):287-311.

Frickel, Scott, and Neil Gross. 2005. 'A General Theory of Scientific/Intellectual Movements'. American Sociological Review 70 (2):204-232.

Fuchs, Stephan. 2001. 'Beyond Agency'. Sociological Theory 19 (1):24- 40. 


\section{References}

Fuchs, Stephan. 2005. Against Essentialism: A Theory of Culture and Society. Cambridge, MA: Harvard University Press.

Galbraith, James K. 2010. 'Why Innovation in Economics Should Build on Success: The Case of the Financial Crisis'. Journal of Innovation Economics 1 (5):167-178.

Galbraith, John Kenneth. 1978. The New Industrial State. Boston, MA: Houghton Mifflin.

Gale, Trevor, and Bob Lingard. 2015. 'Evoking and Provoking Bourdieu in Educational Research'. Cambridge Journal of Education 45 (1):1-8.

Gascoigne, Robert Mortimer. 1987. A Chronology of the History of Science, 14501900. New York: Garland Publishing.

Geiger, Roger. 1985. 'Hierarchy and Diversity in American Research Universities'. In The University Research System: The Public Policies of the Scientists, edited by A. Elzinga and B. Wittrock. Stockholm: Almqvist \& Wiksell.

Geiger, Roger L., ed. 2013. The Land-Grant Colleges and the Reshaping of American Higher Education. 1st edition. London: Routledge.

Geiger, Roger L. 2014. The History of American Higher Education: Learning and Culture from the Founding to World War II. Princeton, NJ: Princeton University Press.

Geiger, Roger L., Nathan M. Sorber, and Christian K. Anderson, eds. 2017. American Higher Education in the Postwar Era, 1945-1970. New York: Routledge.

Gellner, Ernest. 1983. Nations and Nationalism. Vol. 9. Ithaca, NY: Cornell University Press.

Geppert, Alexander C. T. 2010. Fleeting Cities: Imperial Expositions in Fin-de-Siècle Europe. 1st edition. Houndmills: Palgrave Macmillan.

Giddens, Anthony. 1979. Central Problems in Social Theory: Action, Structure, and Contradiction in Social Analysis. Berkeley, CA: University of California Press.

Giddens, Anthony. 1985. The Nation-State and Violence: A Contemporary Critique of Historical Materialism. Berkeley, CA: University of California Press.

Gieryn, Thomas F. 1983. 'Boundary-Work and the Demarcation of Science from NonScience: Strains and Interests in Professional Ideologies of Scientists'. American Sociological Review 48 (6):781-795.

Gilman, Nils. 2007. Mandarins of the Future: Modernization Theory in Cold War America. New edition. Baltimore, MD: Johns Hopkins University Press.

Go, Julian. 2013. 'Sociology's Imperial Unconscious: The Emergence of American Sociology in the Context of Empire'. In Sociology and Empire: The Imperial Entanglements of a Discipline, edited by G. Steinmetz (pp. 83-105). Durham, NC: Duke University Press.

Goldman, Lawrence. 1995. Dons and Workers: Oxford and Adult Education since 1850. New York: Clarendon Press.

Goldman, Lawrence. 2002. Science, Reform, and Politics in Victorian Britain: The Social Science Association 1857-1886. Cambridge: Cambridge University Press.

Goldstein, Joshua S. 1988. Long Cycles: Prosperity and War in the Modern Age. New Haven, CT: Yale University Press.

Goldthorpe, John H. 2013. 'Understanding - and Misunderstanding - Social Mobility in Britain: The Entry of the Economists, the Confusion of Politicians and the Limits of Educational Policy'. Journal of Social Policy 42 (3):431-450.

Gordon, Lynn D. 1990. Gender and Higher Education in the Progressive Era. New Haven, CT: Yale University Press. 
Gorski, Philip S. 2006. 'Mann's Theory of Ideological Power: Sources, Applications and Elaborations'. In An Anatomy of Power: The Social Theory of Michael Mann, edited by J. A. Hall and R. Schroeder. New York: Cambridge University Press.

Gorski, Philip S. 2013. Bourdieu and Historical Analysis. Durham, NC: Duke University Press.

Gouldner, Alvin W. 1960. 'The Norm of Reciprocity: A Preliminary Statement'. American Sociological Review 25 (2):161-178.

Gouldner, Alvin W. 1964. 'Anti-Minotaur: The Myth of Value Free Sociology'. Social Problems 9:199-213.

Gouldner, Alvin W. 1970. The Coming Crisis of Western Sociology. New York: Basic Books.

Gouldner, Alvin W. 1979. The Future of Intellectuals and the Rise of the New Class: A Frame of Reference, Theses, Conjectures, Arguments, and an Historical Perspective on the Role of Intellectuals and Intelligentsia in the International Class Contest of the Modern Era. New York: Seabury Press.

Gouldner, Alvin W. 1982a. The Dialectic of Ideology and Technology: The Origins, Grammar, and Future of Ideology. Oxford: Oxford University Press.

Gouldner, Alvin W. 1982b. The Two Marxisms: Contradictions and Anomalies in the Development of Theory. Oxford: Oxford University Press.

Graeber, David. 2018. Bullshit Jobs: A Theory. New York: Simon \& Schuster.

Graham, Claire. 2013. 'Discourses of Widening Participation in the Prospectus Documents and Websites of Six English Higher Education Institutions'. British Journal of Sociology of Education 34 (1):76-93.

Graham, Patricia Albjerg. 1978. 'Expansion and Exclusion: A History of Women in American Higher Education'. Signs: Journal of Women in Culture and Society 3 (4):759-773.

Gross, Neil. 2009a. 'A Pragmatist Theory of Social Mechanisms'. American Sociological Review 74 (3):358-379.

Gross, Neil. 2009b. 'Proposal to Edit Sociological Theory'. Retrieved 3 April 2012: http://www.asanet.org/images/journals/docs/pdf/proposals/neil_gross_proposal.pdf.

Gross, Neil. 2018. 'Pragmatism and the Study of Large-Scale Social Phenomena'. Theory and Society 47 (1):87-111.

Habermas, Jürgen. 1970. 'Technology and Science as "Ideology"'. In Toward a Rational Society (pp. 81-122). Boston, MA: Beacon Press.

Habermas, Jürgen. 1971. Knowledge and Human Interests. Boston, MA: Beacon Press.

Habermas, Jürgen. 1981. The Theory of Communicative Action, Vol. I: Reason and the Rationalization of Society. Boston, MA: Beacon Press.

Habermas, Jürgen, and Niklas Luhmann. 1990. Theorie Der Gesellschaft Oder Sozialtechnologie. Was Leistet Die Systemforschung?Frankfurt: Suhrkamp.

Habinek, Jacob. 2010. 'State-Building and the Origins of Disciplinary Specialization in Nineteenth Century Germany'. UC Berkeley: Recent Work. https://escholarship. org/content/qt7jv0b9s3/qt7jv0b9s3.pdf.

Hall, John A., and Ralph Schroeder. 2006. An Anatomy of Power: The Social Theory of Michael Mann. Cambridge: Cambridge University Press.

Hamerow, Theodore S. 1958. Restoration, Revolution, Reaction: Economics and Politics in Germany, 1815-1871. Princeton, NJ: Princeton University Press.

Harding, Sandra G., ed. 2004. The Feminist Standpoint Theory Reader: Intellectual and Political Controversies. New York: Routledge. 
Harvey, David. 1989. The Condition of Postmodernity: An Enquiry into the Origins of Cultural Change. Oxford: Blackwell.

Harvey, David. 2005. A Brief History of Neoliberalism. Oxford: Oxford University Press.

Harvey, David. 2010. The Enigma of Capital: And the Crises of Capitalism. New York: Oxford University Press.

Hauchecorne, Mathieu, and Étienne Ollion. 2009. 'What is the New Sociology of Ideas? A Discussion with Charles Camic and Neil Gross.' Transeo Review 1. Retrieved: https://web.archive.org/web/20140424210055/http://www.transeo-review. eu/What-is-the-new-sociology-of-Ideas.html.

Heilbron, Johan. 1995. The Rise of Social Theory. Cambridge: Polity.

Heller, Henry. 2016. The Capitalist University: The Transformations of Higher Education in the United States, 1945-2016. London: Pluto Press.

HESA. 2016. 'Students in Higher Education 2014/15.' Higher Education Statistics Agency.

Hobsbawm, E. J. 1969. The Age of Revolution: Europe 1789-1848. New York: Praeger Publishers.

Hodgson, Naomi, Joris Vlieghe, and Piotr Zamojski, eds. 2020. Post-Critical Perspectives on Higher Education: Reclaiming the Educational in the University. Cham, Switzerland: Springer International Publishing.

Hodgson, William Ballantyne. 1869. The Education of Girls; and the Employment of Women of the Upper Classes Educationally Considered: Two Lectures. 2nd edition. London: Trübner \& Co.

Holmwood, John. 2010. 'Sociology's Misfortune: Disciplines, Interdisciplinarity and the Impact of Audit Culture'. The British Journal of Sociology 61 (4):639-657.

Holmwood, John. 2014. 'From Social Rights to the Market: Neoliberalism and the Knowledge Economy'. International Journal of Lifelong Education 33 (1):62-76.

Holton, Robert J. 1981. 'Marxist Theories of Social Change and the Transition from Feudalism to Capitalism'. Theory and Society 10 (6):833-867.

Hoogenboom, Marcel, Christopher Kissane, Maarten Prak, Patrick Wallis, and Chris Minns. 2018. 'Guilds in the Transition to Modernity: The Cases of Germany, United Kingdom, and the Netherlands'. Theory and Society 47:255-291.

Inglis, David. 2014. 'What Is Worth Defending in Sociology Today? Presentism, Historical Vision and the Uses of Sociology'. Cultural Sociology 8 (1):99-118.

ISC. 2015. 'Independent Schools Protect "Vulnerable" Modern Languages at A Level'. Independent School Council. https://www.isc.co.uk/media-enquiries/news-press-relea ses-statements/independent-schools-protect-vulnerable-modern-languages-at-a-level.

Jacobs, Jerry A. 2014. In Defense of Disciplines: Interdisciplinarity and Specialization in the Research University. Chicago, IL: University of Chicago Press.

Jameson, Fredric. 1991. Postmodernism, or, The Cultural Logic of Late Capitalism. Durham, NC: Duke University Press.

Jessop, Bob. 1995. 'The Regulation Approach, Governance and Post-Fordism: Alternative Perspectives on Economic and Political Change?'. Economy and Society 24 (3):307-333.

Jessop, Bob, Norman Fairclough and Ruth Wodak. 2008. Education and the Knowledge-Based Economy in Europe. Rotterdam: Sense.

Jewett, A. 2012. 'The Politics of Knowledge in 1960s America'. Social Science History 36 (4):551-581.

Joas, Hans. 1996. The Creativity of Action. Chicago, IL: University of Chicago Press. 
Kant, Immanuel. 1992. The Conflict of the Faculties. Lincoln, NE: University of Nebraska Press.

Kaspersen, Lars Bo, and Norman Gabriel. 2013. 'Survival Units as the Point of Departure for a Relational Sociology'. In Applying Relational Sociology: Relations, Networks, and Society, edited by F. Dépelteau and C. Powell (pp. 51-81). New York: Palgrave Macmillan.

Kearnes, Matthew, and Matthias Wienroth. 2011. 'Tools of the Trade: UK Research Intermediaries and the Politics of Impacts'. Minerva 49 (2):153-174.

Khan, Shamus Rahman. 2010. Privilege: The Making of an Adolescent Elite at St. Paul's School. Princeton, NJ: Princeton University Press.

King, Lawrence Peter, and Ivan Szelenyi. 2004. Theories of a New Class: Intellectuals and Power. Minneapolis, MN: University of Minnesota.

King, Ronald. 1968. 'The Public Schools Commission: First Report*'. Social Policy \& Administration 2 (4):277-283.

Knorr-Cetina, Karin, Theodore R. Schatzki, and Eike von Savigny, eds. 2000. The Practice Turn in Contemporary Theory. 1st edition. London: Routledge.

Kocka, Jurgen, and J. Allan Mitchell, eds. 1993. Bourgeois Society in 19th Century Europe. Oxford: Berg Publishers.

Kolko, Gabriel. 1977. The Triumph of Conservatism: A Reinterpretation of American History, 1900-1916. Reissue. New York: The Free Press.

Konrad, Gyorgy, and Ivan Szelenyi. 1979. The Intellectuals on the Road to Class Power. New York: Harcourt.

Kose, Esra, Elira Kuka, and Na'ama Shenhav. 2016. 'Women's Enfranchisement and Children's Education: The Long-Run Impact of the US Suffrage Movement'. IZA: Institute of Labor Economics.

Koselleck, Reinhart. 2002. The Practice of Conceptual History: Timing History, Spacing Concepts. Stanford, CA: Stanford University Press.

Kuhn, Thomas S. 1962. The Structure of Scientific Revolutions. Chicago, IL: University of Chicago Press.

Kuhn, Thomas S. 1972. 'Review of Ben-David's Scientist's Role'. Minerva 10 (1):166187.

La Vopa, Anthony J. 1990. 'Specialists against Specialization: Hellenism as Professional Ideology in German Classical Studies'. In German Professions, 1800-1950, edited by K. Jarausch and G. Cocks (pp. 27-45). New York: Oxford University Press.

Lamont, Michèle. 2010. How Professors Think. Reprint. Cambridge, MA: Harvard University Press.

Lamont, Michèle, and Virág Molnár. 2002. 'The Study of Boundaries in the Social Sciences'. Annual Review of Sociology 28 (1):167-195.

Lasch, Christopher. 1991. The Culture of Narcissism: American Life in the Age of Diminishing Expectations. New York: W.W. Norton.

Lash, Scott, and John Urry. 1987. The End of Organized Capitalism. 1st edition. Cambridge: Polity.

Latour, Bruno. 1993. We Have Never Been Modern. Cambridge, MA: Harvard University Press.

Latour, Bruno. 2004. Politics of Nature: How to Bring the Sciences into Democracy. Cambridge, MA: Harvard University Press.

Lawson, Tony. 1997. Economics and Reality. London: Routledge. 
Lee, Richard E., and Immanuel Wallerstein. 2005. Overcoming the Two Cultures: Science vs. the Humanities in the Modern World-System. Boulder, CO: Paradigm.

Leopold, David. 2007. The Young Karl Marx: German Philosophy, Modern Politics, and Human Flourishing. Cambridge: Cambridge University Press.

Levinger, Matthew Bernard. 2000. Enlightened Nationalism: The Transformation of Prussian Political Culture, 1806-1848. Oxford: Oxford University Press.

Lewisohn, David. 1972. 'Mill and Comte on the Methods of Social Science'. Journal of the History of Ideas 33 (2):315-324.

Leydesdorff, Loet. 2006. The Knowledge-Based Economy: Modeled, Measured, Simulated. Boca Raton, FL: Universal Publishers.

Lipset, Seymour Martin, and Everett Carll Ladd. 1972. 'The Politics of American Sociologists'. American Journal of Sociology 78 (1):67-104.

Luhmann, Niklas. 1974. Soziologische Aufklärung / Niklas Luhmann. Bd. 1, Aufsätze Zur Theorie Sozialer Systeme. Opladen: Westdeutscher Verlag.

Luhmann, Niklas. 1982. Trust and Power. New York: John Wiley \& Sons Inc.

Luhmann, Niklas. 1988a. 'Law As a Social System'. Northwestern University Law Review 83:136-150.

Luhmann, Niklas. 1988b. 'The Third Question: The Creative Use of Paradoxes in Law and Legal History'. Journal of Law and Society 15 (2):153-165.

Luhmann, Niklas. 1993a. 'Deconstruction as Second-Order Observing'. New Literary History 24 (4):763-782. doi:10.2307/469391.

Luhmann, Niklas. 1993b. Risk: A Sociological Theory. New York: A. de Gruyter.

Luhmann, Niklas. 1995a. Das Recht der Gesellschaft. Frankfurt am Main: Suhrkamp Verlag.

Luhmann, Niklas. 1995b. Social Systems. Stanford, CA: Stanford University Press.

Luhmann, Niklas. 1998. Observations on Modernity. 1st edition. Stanford, CA: Stanford University Press.

Luhmann, Niklas. 2002. Theories of Distinction: Redescribing the Descriptions of Modernity. Stanford, CA: Stanford University Press.

Luhmann, Niklas. 2012. Theory of Society, Vol. 1. Stanford, CA: Stanford University Press.

Lukács, György. 1971. History and Class Consciousness: Studies in Marxist Dialects. London: Merlin Press.

Lukes, Steven. 2004. Power: A Radical View. Basingstoke: Palgrave Macmillan.

Lützeler, Paul Michael. 2005. 'The St. Louis World's Fair of 1904 as a Site of Cultural Transfer: German and German-American Participation'. In German Culture in Nineteenth-century America, edited by L. Tatlock and M. Erlin (pp. 59-86). Rochester, NY: Camden House.

Lybeck, Eric. 2015. 'History of the Concept of "Geist/Spirit"'. In International Encyclopedia of the Social and Behavioral Sciences, edited by J. D. Wright (pp. 666-670). Oxford: Elsevier.

Lybeck, Eric. 2016. 'Progressive Sociology, Conservative Universities: Tracing the Legacies of German Legal Science in American Social Science'. Doctoral Thesis, University of Cambridge, Cambridge.

Lybeck, Eric. 2017. 'Comparative-Historical Sociology as Professional Practice'. Human Figurations 6 (2).

Lybeck, Eric. 2018a. 'Reconstructing the Academic Profession'. On Education: Journal for Research and Debate 1 (3). https://doi.org/10.17899/on_ed.2018.3.5. 
Lybeck, Eric. 2018b. 'The Coming Crisis of Academic Authority'. In From Crisis to Social Change: Towards Alternative Horizons, edited by T. Geelan, M. Hernando, and P. Walsh. (pp. 53-66). Basingstoke: Palgrave.

Lybeck, Eric. 2018c. 'The French Revolution in Germany and the Origins of Sociology'. Historická Sociologie 10 (1):27-46.

Lybeck, Eric. 2019a. 'Ajurisdiction'. Theory and Society 48 (1):167-191.

Lybeck, Eric. 2019b. Nobert Elias and the Sociology of Education. London: Bloomsbury Academic.

Mandel, Ernest. 1975. Late Capitalism. London: NLB.

Mann, Michael. 1984. 'The Autonomous Power of the State: Its Origins, Mechanisms and Results'. European Journal of Sociology/Archives Européennes de Sociologie 25 (02):185-213.

Mann, Michael. 1986. The Sources of Social Power: Volume 1, A History of Power from the Beginning to A.D. 1760. New York: Cambridge University Press.

Mann, Michael. 1993. The Sources of Social Power: Volume 2, The Rise of Classes and Nation-States, 1760-1914. New York: Cambridge University Press.

Mann, Michael. 1994. 'In Praise of Macro-Sociology: A Reply to Goldthorpe'. The British Journal of Sociology 45 (1):37-54.

Mann, Michael. 2008. 'Infrastructural Power Revisited'. Studies in Comparative International Development 43 (3-4):355-365.

Mann, Michael. 2012a. The Sources of Social Power: Volume 3, Global Empires and Revolution, 1890-1945. Cambridge: Cambridge University Press.

Mann, Michael. 2012b. The Sources of Social Power: Volume 4, Globalizations, 19452011. Cambridge: Cambridge University Press.

Mannheim, Karl. 1985. Ideology and Utopia: An Introduction to the Sociology of Knowledge. San Diego, CA: Harcourt Brace Jovanovich.

Mannheim, Karl. 1986. Conservatism: A Contribution to the Sociology of Knowledge. London: Routledge, Chapman \& Hall.

Marcuse, Herbert. 1991. One-Dimensional Man: Studies in the Ideology of Advanced Industrial Society. Boston, MA: Beacon Press.

Marginson, Simon, and Mark Considine. 2000. The Enterprise University: Power, Governance and Reinvention in Australia. Cambridge: Cambridge University Press.

Martin, John Levi. 2003. 'What Is Field Theory?'. American Journal of Sociology 109 (1):1-49. doi:10.1086/375201.

Martin, John Levi. 2009. Social Structures. Princeton, NJ: Princeton University Press.

Martin, John Levi. 2011. The Explanation of Social Action. Oxford: Oxford University Press.

Marx, Karl, and Friedrich Engels. 1970. The German Ideology: With Selections from Parts Two and Three, Together with Marx's 'Introduction to a Critique of Political Economy'. London: Lawrence \& Wishart.

Mayer, Arno J. 1981. The Persistence of the Old Regime: Europe to the Great War. New York: Pantheon Books.

Mayrl, Damon. 2016. Secular Conversions: Political Institutions and Religious Education in the United States and Australia, 1800-2000. Cambridge: Cambridge University Press.

McClelland, Charles. 1980. State, Society and University in Germany 1700-1914. Reissue. Cambridge: Cambridge University Press.

McGettigan, Andrew. 2013. The Great University Gamble: Money, Markets and the Future of Higher Education. London: Pluto Press. 


\section{References}

Mead, George Hebert. 1932. The Philosophy of the Present. Chicago, IL: The Open Court Company.

Mead, George Herbert. 1934. Mind, Self \& Society, edited by C. W. Morris. Chicago, IL: University of Chicago Press.

Mead, George Herbert. 1964. On Social Psychology: Selected Papers. Chicago, IL: University of Chicago Press.

Meloni, Maurizio. 2012. 'On the Growing Authority of Neuroscience for Political and Moral Theory: Sketch for a Genealogy'. In Neuroscience and Political Theory: Thinking the Body Politic, edited by F. Vander Valk (pp. 25-49). London: Routledge.

Mennell, Stephen. 1998. Norbert Elias: An Introduction. Dublin: University College Dublin Press.

Merton, Robert K. 1938. 'Science and the Social Order'. Philosophy of Science 5 (3):321-337.

Merton, Robert K. 2002. Science, Technology \& Society in Seventeenth-Century England. New York: Howard Fertig.

Merton, Robert King. 1957. Social Theory and Social Structure. Glencoe, IL: Free Press.

Meyer, John W. 1977. 'The Effects of Education as an Institution'. American Journal of Sociology 83 (1):55-77.

Meyer, John W., John Boli, George M. Thomas, and Francisco O. Ramirez. 1997. 'World Society and the Nation-State'. The American Journal of Sociology 103 (1):144-181.

Meyer, John W., and Patricia Bromley. 2013. 'The Worldwide Expansion of "Organization"'. Sociological Theory 31 (4):366-389.

Meyer, John W., Francisco O. Ramirez, David John Frank, and Evan Schofer. 2007. 'Higher Education as an Institution'. In Sociology of Higher Education: Contributions and Their Contexts, edited by P. J. Gumport (pp. 187-221). Baltimore, MA: The Johns Hopkins University Press.

Mills, C. Wright. 1999. The Power Elite. New York: Oxford University Press.

Mirowski, Philip, and Dieter Plehwe. 2009. The Road from Mont Pèlerin: The Making of the Neoliberal Thought Collective. Cambridge, MA: Harvard University Press.

Mitchell, Timothy. 2005. 'The Work of Economics: How a Discipline Makes Its World'. European Journal of Sociology/Archives Européennes de Sociologie 46 (02):297-320.

Moeller, Hans-Georg. 2006. Luhmann Explained: From Souls to Systems. Chicago, IL: Open Court.

Morrish, Liz, and Helen Sauntson. 2019. Academic Irregularities: Language and Neoliberalism in Higher Education. Abingdon: Routledge.

Mouzelis, Nicos. 1994. 'In Defence of "Grand" Historical Sociology'. The British Journal of Sociology 45 (1):31-36. doi:10.2307/591523.

Mouzelis, Nicos P. 2008. Modern and Postmodern Social Theorizing: Bridging the Divide. Cambridge: Cambridge University Press.

Mumford, Lewis. 1963. Technics and Civilization. New York: Harcourt.

Mumford, Lewis. 1973. The Condition of Man. New York: Harcourt Brace Jovanovich.

Münch, Richard. 1992. 'The Production and Reproduction of Inequality: A Theoretical Cultural Analysis'. In Theory of Culture, edited by R. Münch and N. J. Smelser (pp. 243-264). Berkeley, CA: University of California Press. 
Münch, Richard. 2000. The Ethics of Modernity. Lanham, MD: Rowman \& Littlefield Publishers.

Münch, Richard. 2001. The Ethics of Modernity: Formation and Transformation in Britain, France, Germany, and the United States. Lanham, MD: Rowman \& Littlefield.

Münch, Richard. 2012. Theory of Action (Routledge Revivals): Towards a New Synthesis Going Beyond Parsons. New York: Routledge.

Münch, Richard. 2014. Academic Capitalism: Universities in the Global Struggle for Excellence. New York: Routledge.

Münsterberg, Hugo. 1903. 'The St. Louis Congress of Arts and Sciences'. Atlantic Monthly 91:671-684.

Murphy, Mark. 2013. Social Theory and Education Research: Understanding Foucault, Habermas, Bourdieu and Derrida. 1st edition. Abingdon: Routledge.

Newfield, Christopher. 2011. Unmaking the Public University: The Forty-Year Assault on the Middle Class. Cambridge, MA: Harvard University Press.

Newfield, Christopher. 2016. The Great Mistake: How We Wrecked Public Universities and How We Can Fix Them. Baltimore, MD: Johns Hopkins University Press.

Newman, John Henry. 1996. The Idea of a University. New Haven, CT: Yale University Press.

Nietzsche, Friedrich. 2015. Anti-Education: On the Future of Our Educational Institutions. New York: New York Review of Books.

Nipperdey, Thomas. 1998. Deutsche Geschichte 1800-1866: Bürgerwelt Und Starker Staat. München: Beck.

Nussbaum, Martha Craven. 2010. Not for Profit: Why Democracy Needs the Humanities. Princeton, NJ: Princeton University Press.

OECD. 2018. Education at a Glance. OECD iLibrary. https://www.oecd-ilibrary.org/ education/education-at-a-glance_19991487.

Ortolano, Guy Samuel. 2005. The 'Two Cultures' Controversy: C. P. Snow, F. R. Leavis, and Cultural Politics in Post War Britain. Ann Arbor, MI: UMI.

Oxford University. 2016. 'Undergraduate Admissions Statistics 2015 - University of Oxford'. University of Oxford. Retrieved 13 September 2016: https://www.ox.ac.uk/a bout/facts-and-figures/admissions-statistics/undergraduate?wssl=1.

Padgett, John F., and Walter W. Powell. 2012. The Emergence of Organizations and Markets. Princeton, NJ: Princeton University Press.

Palmer, R. R., and Joel G. Colton. 1965. A History of the Modern World. New York: McGraw-Hill.

Paolucci, Paul. 2009. Marx's Scientific Dialectics: A Methodological Treatise for a New Century. Chicago, IL: Haymarket Books.

Pareto, Vilfredo. 2003. The Mind \& Society: The Early Sociology of Culture: Theory of Residues, Vol. 4, edited by K. Thompson. London: Routledge.

Parker, Patsy. 2015. 'The Historical Role of Women in Higher Education'. Administrative Issues Journal 5 (1):3-14.

Parsons, Talcott. 1934. 'Some Reflections on "The Nature and Significance of Economics"'. The Quarterly Journal of Economics 48 (3):511-545.

Parsons, Talcott. 1937. The Structure of Social Action. Vols. 1 and 2. New York: Free Press.

Parsons, Talcott. 1951. The Social System. Glencoe, IL: Free Press.

Parsons, Talcott. 1957. 'The Distribution of Power in American Society'. World Politics 10 (1):123-143. 
Parsons, Talcott. 1999. The Talcott Parsons Reader, edited by B. S. Turner. Malden, MA: Blackwell.

Parsons, Talcott, and Gerald Platt. 1974. American University. Cambridge, MA: Harvard University Press.

Parsons, Talcott, and Edward Shils. 2001. Toward a General Theory of Action: Theoretical Foundations for the Social Sciences. New Brunswick, NJ: Transaction Publishers.

Petrina, Stephen, and E. Wayne Ross. 2014. 'Critical University Studies: Workplace, Milestones, Crossroads, Respect, Truth'. Workplace: A Journal for Academic Labor (23):62-72.

Piketty, Thomas. 2018. 'Brahmin Left vs Merchant Right: Rising Inequality and the Changing Structure of Political Conflict'. World Inequality Database: Working Paper Series. http://piketty.pse.ens.fr/files/Piketty2018.pdf.

Poggi, Gianfranco. 2000. Forms of Power. Cambridge: Polity Press.

Polanyi, Michael. 2000. 'The Republic of Science: Its Political and Economic Theory'. Minerva 38 (1):1-21.

Postone, Moishe. 2010. 'Theorizing the Contemporary World: Robert Brenner, Giovanni Arrighi, David Harvey'. In Political Economy and Global Capitalism: The 21st Century, Present and Future, edited by R. Albritton, B. Jessop, and R. Westra (pp. 7-24). London: AnthemPress.

Poulantzas, Nicos. 1969. 'The Problem of the Capitalist State'. New Left Review 58 (1):67-78.

Prak, Maarten. 2018. Citizens without Nations: Urban Citizenship in Europe and the World, c.1000-1789. Cambridge: Cambridge University Press.

Prebisch, Raúl. 1959. 'Commercial Policy in the Underdeveloped Countries'. The American Economic Review 49 (2):251-273.

Prigogine, Ilya. 1997. The End of Certainty: Time, Chaos and the New Laws of Nature. New York: Free Press.

Putnam, Hilary. 1981. Reason, Truth, and History. Cambridge: Cambridge University Press.

Quilley, Stephen, and Steven Loyal. 2005. 'Eliasian Sociology as a "Central Theory" for the Human Sciences'. Current Sociology 53 (5):807-828.

Raeff, Marc. 1975. 'The Well-Ordered Police State and the Development of Modernity in Seventeenth- and Eighteenth-Century Europe: An Attempt at a Comparative Approach'. The American Historical Review 80 (5):1221-1243.

Rafferty, Edward C. 2003. Apostle of Human Progress: Lester Frank Ward and American Political Thought, 1841-1913. Lanham, MD: Rowman \& Littlefield.

Rashdall, Hastings. 1895. The Universities of Europe in the Middle Ages: Vol. 2, Pt. 1 - Italy, Spain, France, Germany, Scotland, Etc. Oxford: Clarendon Press.

Reay, Diane. 2016. 'Social Class in UK Higher Education: Still an Elephant in the Room'. In Routledge Handbook of the Sociology of Higher Education, edited by J. E. Cote and A. Furlong (pp. 131-141). Abingdon: Routledge.

Reay, Diane, Miriam E. David, and Stephen Ball. 2005. Degrees of Choice: Social Class, Race and Gender in Higher Education. Sterling, VA: Trentham Books Ltd.

Reed, Isaac Ariail. 2011. Interpretation and Social Knowledge: On the Use of Theory in the Human Sciences. Chicago, IL: University of Chicago Press.

Reed, Isaac Ariail. 2013. 'Power: Relational, Discursive, and Performative Dimensions'. Sociological Theory 31 (3):193-218. 
Rees, Martin. 2012. University Diversity: Freedom, Excellence and Funding for a Global Future. London: Politeia.

Reimann, Mathias. 1989. 'Nineteenth Century German Legal Science'. Boston College Law Review 31 (4):837-897.

Reuben, Julie A. 1996. The Making of the Modern University: Intellectual Transformation and the Marginalization of Morality. Chicago, IL: University of Chicago Press.

Richards, Alfred Bate. 1842. Oxford Unmasked: Or, An Attempt to Describe Some of the Abuses in That University; Dedicated, Without Permission, to Sir Robert Peel, Bart. London: E. Wilson.

Richardson, Angelique, and Chris Willis. 2001. The New Woman in Fiction and Fact: Fin-de-Siècle Feminisms. Basingstoke: Palgrave Macmillan.

Ringer, Fritz K. 1979. Education and Society in Modern Europe. Bloomington, IN: Indiana University Press.

Rosenberg, Hans. 1958. Bureaucracy, Aristocracy, and Autocracy: The Prussian Experience, 1660-1815. Cambridge, MA: Harvard University Press.

Rothblatt, Sheldon. 1981. The Revolution of the Dons: Cambridge and Society in Victorian England. Cambridge: Cambridge University Press.

Rüegg, Walter. 2004. A History of the University in Europe: Volume 3, Universities in the Nineteenth and Early Twentieth Centuries (1800-1945). Cambridge: Cambridge University Press.

Ruskin, John. 2015. Unto This Last. Milan: John Ruskin.

Russell Group. 2016. OFFA Access Agreements 2017-18. Russell Group. https://rus sellgroup.ac.uk/news/offa-access-agreements-2017-18.

Sachse, Arnold. 1928. Friedrich Althoff und sein Werk. Berlin: E.S. Mittler.

Salmi, Hannu. 2008. Nineteenth Century Europe: A Cultural History. Malden, MA: Polity Press.

Savage, Mike, Fiona Devine, Niall Cunningham, Mark Taylor, Yaojun Li, Johs Hjellbrekke, Brigitte Le Roux, Sam Friedman, and Andrew Miles. 2013. 'A New Model of Social Class? Findings from the BBC's Great British Class Survey Experiment'. Sociology 47 (2):219-250.

Scheppele, Kim Lane. 1994. 'Legal Theory and Social Theory'. Annual Review of Sociology 20:383-406.

Schlegel, John Henry. 1995. American Legal Realism and Empirical Social Science. Chapel Hill, NC: University of North Carolina Press.

Schofer, Evan, and John W. Meyer. 2005. 'The Worldwide Expansion of Higher Education in the Twentieth Century'. American Sociological Review 70 (6):898-920.

Schott, Thomas. 1993. 'The Movement of Science and of Scientific Knowledge: Joseph Ben-David's Contribution to Its Understanding'. Minerva 31 (4):455-477.

Schroeder, Ralph. 2007. Rethinking Science, Technology, and Social Change. Stanford, CA: Stanford University Press.

Schumpeter, Joseph. 2008. Capitalism, Socialism, and Democracy. New York: Harper Collins.

Schumpeter, Joseph Alois. 1939. Business Cycles: A Theoretical, Historical, and Statistical Analysis of the Capitalist Process. London: McGraw-Hill Book Company, Inc.

Seidl, David, and Kai Helge Becker. 2006. 'Organizations as Distinction Generating and Processing Systems: Niklas Luhmann's Contribution to Organization Studies'. Organization 13 (1):9-35. 
Seidl, David, and Dennis Schoeneborn. 2010. 'Niklas Luhmann's Autopoietic Theory of Organisations: Contributions, Limitations, and Future Prospects'. University of Zurich, Institute of Organization and Administrative Science (IOU) Working Paper No. 105. SSRN ELibrary. https://papers.ssrn.com/sol3/papers.cfm?abstract_id= 1552847.

Sewell, William Hamilton. 2005. Logics of History: Social Theory and Social Transformation. Chicago, IL: University of Chicago Press.

Shils, Edward. 1955. 'The End of Ideology?'. Encounter 5:52-58.

Shils, Edward. 1958. 'Ideology and Civility: On the Politics of the Intellectual'. The Sewanee Review 66 (3):450-480.

Shils, Edward. 1962. 'Editor's Introduction'. Minerva 1 (1):5-17.

Shils, Edward. 1982. The Constitution of Society. Chicago, IL: University of Chicago Press.

Shils, Edward. 1989. 'The Modern University and Liberal Democracy'. Minerva 27 (4):425-460.

Shils, Edward. 2006. A Fragment of a Sociological Autobiography: The History of My Pursuit of a Few Ideas, edited by S. E. Grosby. New Brunswick, NJ: Transaction Publishers.

Shrosbree, Colin. 1988. Public Schools and Private Education: The Clarendon Commission, 1861-64, and the Public Schools Acts. Manchester: Manchester University Press.

Sidgwick, Henry. 1968. 'Henry Sidgwick on Classics and Classicists'. Arion: A Journal of Humanities and the Classics 7 (2):298-308.

Silva, Filipe Carreira da. 2008. Mead and Modernity: Science, Selfhood, and Democratic Politics. Lanham, MD: Lexington Books.

Skocpol, Theda. 1977. 'Review: Wallerstein's World Capitalist System: A Theoretical and Historical Critique'. The American Journal of Sociology 82 (5):1075-1090.

Slaughter, Sheila, and Larry Leslie. 1997. Academic Capitalism: Politics, Policies, and the Entrepreneurial University. Baltimore, MD: Johns Hopkins University Press.

Slaughter, Sheila, and Gary Rhoades. 2009. Academic Capitalism and the New Economy: Markets, State, and Higher Education. Baltimore, MD: Johns Hopkins University Press.

Small, Albion W. 1924. Origins of Sociology. Chicago, IL: University of Chicago Press.

SMCPC (Social Mobility and Child Poverty Commission). 2014. 'Elitist Britain?'. www.gov.uk. https://assets.publishing.service.gov.uk/government/uploads/system/up loads/attachment_data/file/347915/Elitist_Britain_-_Final.pdf.

Smith, Darren P., Joanna Sage, and Stacey Balsdon. 2014. 'The Geographies of Studentification: "Here, There and Everywhere"?'. Geography 99 (3):116-127.

Smyth, John. 2017. The Toxic University: Zombie Leadership, Academic Rock Stars and Neoliberal Ideology. London: Palgrave Macmillan.

Snow, C. P. 2012. The Two Cultures. Cambridge: Cambridge University Press.

So, Alvin Y. 1990. Social Change and Development: Modernization, Dependency, and World-Systems Theories. Thousand Oaks, CA: SAGE Publications.

Sperber, Jonathan. 2013. Karl Marx: A Nineteenth-Century Life. New York: W. W. Norton \& Co.

Standing, Guy. 2011. The Precariat: The New Dangerous Class. London: Bloomsbury Academic.

Steinmetz, George. 1997a. 'German Exceptionalism and the Origins of Nazism: The Career of a Concept'. In Stalinism and Nazism: Dictatorships in Comparison (pp. 251-284). New York: Cambridge University Press. 
Steinmetz, George. 1997b. 'The Myth of an Autonomous State: Industrialists, Junkers, and Social Policy in Imperial Germany'. In Society, Culture, and the State in Germany, 1870 1930, edited by G. Eley (pp. 257-318). Ann Arbor, MI: University of Michigan Press.

Steinmetz, George. 1999. State/Culture: State-Formation after the Cultural Turn. Ithaca, NY: Cornell University Press.

Steinmetz, George. 2004. 'Odious Comparisons: Incommensurability, the Case Study, and "Small N's" in Sociology'. Sociological Theory 22 (3):371-400.

Steinmetz, George. 2013. Sociology \& Empire: The Imperial Entanglements of a Discipline. Durham, NC: Duke University Press.

Steinmetz, George. 2017. 'Field Theory and Interdisciplinarity: History and Sociology in Germany and France during the Twentieth Century'. Comparative Studies in Society and History 59 (2):477-514.

Stevens, Mitchell L., and Ben Gebre-Medhin. 2016. 'Association, Service, Market: Higher Education in American Political Development'. Annual Review of Sociology 42 (1):121-142.

Stich, Amy E. 2012. Access to Inequality: Reconsidering Class, Knowledge, and Capital in Higher Education. Lanham, MD: Lexington Books.

Streeck, Wolfgang. 2017. 'The Return of the Repressed'. New Left Review (104):5-18.

Sullivan, Alice. 2001. 'Cultural Capital and Educational Attainment'. Sociology 35 (4):893912.

Swaan, A. de. 1988. Care of the State: Health Care, Education, and Welfare in Europe and the USA in the Modern Era. Oxford: Oxford University Press.

Swartz, David. 1997. Culture \& Power: The Sociology of Pierre Bourdieu. Chicago, IL: University of Chicago Press.

Taylor, A. J. P. 1946. The Course of German History: A Survey of the Development of Germany since 1815. New York: Coward-McCann.

Taylor, Barbara. 2011. 'The Demise of the Asylum in Late Twentieth-Century Britain: A Personal History'. Transactions of the Royal Historical Society 21:193-215.

Taylor, Peter, Michael Hoyler, and David Evans. 2008. 'A Geohistorical Study of "The Rise of Modern Science": Mapping Scientific Practice Through Urban Networks, 1500-1900'. Minerva 46 (4):391-410.

Temple, William. 1921. Life of Bishop Percival. London: Macmillan \& Co.

The Economist. 2016. 'A Tale of Two Cities'. The Economist, February 20.

Therborn, Göran. 1976. Science, Class, and Society: On the Formation of Sociology and Historical Materialism. London: NLB.

Therborn, Göran. 1977. 'The Rule of Capital and the Rise of Democracy'. New Left Review 1 (103):3-41.

Thomas, William Isaac, and Florian Znaniecki. 1996. The Polish Peasant in Europe and America: A Classic Work in Immigration History, edited by E. Zaretsky. Champaign, IL: University of Illinois Press.

Thompson, John B. 1995. The Media and Modernity: A Social Theory of the Media. Stanford, CA: Stanford University Press.

Tilly, Charles. 1984. Big Structures, Large Processes, Huge Comparisons. New York: Russell Sage Foundation.

Tilly, Charles. 1990. Coercion, Capital, and European States, AD 990-1990. Cambridge, MA: Blackwell.

Trow, Martin. 1972. 'The Expansion and Transformation of Higher Education'. International Review of Education/Internationale Zeitschrift Für Erziehungswissenschaft/Revue Internationale de l'Education 18 (1):61-84. 
Turner, Stephen. 1994. The Social Theory of Practices: Tradition, Tacit Knowledge, and Presuppositions. Chicago, IL: University of Chicago Press.

UNESCO IIEP. 2017. Six Ways to Ensure Higher Education Leaves No One Behind. Paris: UNESCO International Institute for Education Planning.

Van Wingerden, Sophia A. 1999. The Women's Suffrage Movement in Britain, 18661928. Basingstoke: Palgrave Macmillan.

Veblen, Thorstein. 1924. The Theory of the Leisure Class: An Economic Study of Institutions. New York: B. W. Huebsch.

Wagner, Peter. 2008. Modernity as Experience and Interpretation. Malden, MA: Polity Press.

Walker, Mack. 1998. German Home Towns: Community, State, and General Estate, 1648-1871. Ithaca, NY: Cornell University Press.

Wallerstein, Immanuel. 1971. The University Crisis Reader. 1st edition. New York: Random House.

Wallerstein, Immanuel. 1974. The Modern World System, Vol. I: Capitalist Agriculture and the Origins of the European World-Economy in the Sixteenth Century. New York: Academic Press.

Wallerstein, Immanuel. 1980. The Modern World System, Vol. II: Mercantilism and the Consolidation of the European World-Economy, 1600-1750. New York: Academic Press.

Wallerstein, Immanuel. 1989. The Modern World System, Vol. III: The Second Era of Great Expansion of the Capitalist World-Economy, 1730-1840s. San Diego, CA: Academic Press.

Wallerstein, Immanuel. 1990. 'Culture as the Ideological Battleground of the Modern World-System'. In Global Culture: Nationalism, Globalization and Modernity, edited by M. Featherstone. Thousand Oaks, CA: SAGE Publications.

Wallerstein, Immanuel. 2001. Unthinking Social Science: The Limits of NineteenthCentury Paradigms. 2nd edition. Philadelphia, PA: Temple University Press.

Wallerstein, Immanuel. 2004a. The Uncertainties of Knowledge. Philadelphia, PA: Temple University Press.

Wallerstein, Immanuel. 2004b. World-Systems Analysis: An Introduction. Durham, NC: Duke University Press.

Wallerstein, Immanuel. 2011. The Modern World-System IV: Centrist Liberalism Triumphant, 1789-1914. 1st edition. Berkeley, CA: University of California Press.

Wallerstein, Immanuel, Calestous Juma, Evelyn Fox Keller, Kocka Jurgen, Dominique Lecourt, V. Y. Mudimbe, Kinhide Mushakoji, Ilya Prigogine, Peter J. Taylor, and MichelRolph Trouillot. 1996. Open the Social Sciences: Report of the Gulbenkian Commission on the Restructuring of the Social Sciences. Stanford, CA: Stanford University Press.

Weber, Eugen. 1976. Peasants Into Frenchmen: The Modernization of Rural France, 1870-1914. Stanford, CA: Stanford University Press.

Weber, Max. 1958. 'Science as a Vocation'. Daedalus 87 (1):111-134.

Weber, Max. 1968. Economy and Society: An Outline of Interpretive Sociology, edited by G. Roth and C. Wittich. Berkeley, CA: University of California Press.

Weber, Max. 2008. Max Weber's Complete Writings On Academic and Political Vocations, edited by J. Dreijmanis. New York: Algora Publishing.

Weisz, George. 1992. The Emergence of Modern Universities in France, 1863-1914. Princeton, NJ: Princeton University Press.

Wellmon, Chad. 2015. Organizing Enlightenment: Information Overload and the Invention of the Modern Research University. Baltimore, MD: Johns Hopkins University Press. 
Whimster, Sam. 2017. 'Max Weber's Roman Agrarian History: Jurisprudence, Property, Civilisation.' In Recht als Kultur? Beiträge zu Max Webers Soziologie des Rechts, edited by W. Gephart and D. Whitte (pp. 229-277). Frankfurt/Main: Vittorio Klostermann.

White, Harrison C. 2008. Identity and Control: How Social Formations Emerge. Princeton, NJ: Princeton University Press.

Whitehead, Alfred North. 1925. Science and the Modern World: Lowell Lectures, 1925. New York: Macmillan Company.

Whitehead, Alfred North. 1930. Process and Reality: An Essay in Cosmology; Gifford Lectures Delivered in the University of Edinburgh during the Session 1927-28. New York: Macmillan.

Whyte, William. 2015. Redbrick: A Social and Architectural History of Britain's Civic Universities. Oxford: Oxford University Press.

Winstanley, Denys Arthur. 2009. Later Victorian Cambridge. Cambridge: Cambridge University Press.

Worton, Michael. 2009. Review of Modern Foreign Languages Provision in Higher Education in England. Issues paper 41. London: HEFCE.

Wright, Erik Olin. 1985. Classes. London: Verso.

Zeitlin, Maurice. 1974. 'Corporate Ownership and Control: The Large Corporation and the Capitalist Class'. American Journal of Sociology 79 (5):1073-1119.

Zeitlin, Maurice. 1984. The Civil Wars in Chile, or, The Bourgeois Revolutions That Never Were. Princeton, NJ: Princeton University Press.

Zeitlin, Maurice. 1989. The Large Corporation and Contemporary Classes. New Brunswick, NJ: Rutgers University Press.

Zimmerman, Andrew. 2012. Alabama in Africa: Booker T. Washington, the German Empire, and the Globalization of the New South. Princeton, NJ: Princeton University Press. 


\section{Index}

Note: Figures are indexed with italic page numbers.

18th-century 4, 39-40, 47 concerns about the proliferation of books 8; networks of scientific practice 42

19th-century 9, 27, 49-50, 56; efforts to widen participation in secondary education 110; networks of scientific practice 41; Newtonian worldview 57; and the political economic situation of the university in America 51

Abbott, Andrew 10-13, 17, 22, 24, 52, 64, 98-102, 104, 141-3, 152-4; analysis of professions and disciplines 98; and the development of 'linked ecologies' 11; and processual metaphysics 81 ; remapping and fractal cycling 102; and the sociology of professions and disciplines 13

abstractions 11-12, 82, 90, 93, 98, 103, 152 ; levels of 14,98 ; principles of natural law 58, 97; pure 83; sociological 96 academic 12, 20, 40, 95, 98, 101, 125, 148,165 ; curricula 125 ; humility 157 ; professions 3, 11-12, 20, 22, 98, 101, $125,127,149,152,154,161-2,165-7$ academics $20,22,50,52,54,63-5,71-3$, 75, 96-7, 106, 108, 124-5, 127-9, 161-3, 165-7; contemporary 128; elitist 166; feminist 131; liberal humanist 111; middle-class 75 'academization process' $1,5,10,20-2$, 24-5, 75, 79, 91, 94, 96, 110-32, 138-9, 144, 157, 159; long-term 110, 129, 156; multidimensional 4; theory 3, 161, 165

Acts and Regulations: Endowed Schools Act 1869 114; Public School Act 1868 114; Reform Acts 1832, 1867 , 1884132
Adams, Henry 51

administrators $1,31,44,92$

admissions data $111-12,121$

African-American studies 155, 160

Age of Revolutions 4

agents 5, 85-6, 97, 113, 141

AGIL model of the American university 92

Air Force and National Science

Foundation 52

Althoff, Friedrich 50-1

'Althoff system' (university policy) 51

American University 92, 105

analysis 3-5, 9, 13-14, 18-19, 21-6, $30-1,33,36-40,43-5,53-4,83,86-8$, 90-2, 96-8, 175-7; biological 97;

functional 83; historical 57, 83, 175 , 177; institutional 53; internationalized 33 ; levels of 92,153 ; rationalist 53 ; systems-process 98

Angell, James 147

Anglophone sociology 80

Annales School 33

anti-elitism 113, 156

anti-elitist elitism 62, 91, 124-5

antibodies 80, 103

approaches in the sociology of science 27

aristocracy 2, 19, 47, 59, 63, 117-18, 127

Arnold, Matthew 113-14, 117, 120, 127, 133, 137

Arnold, Thomas 138

Arrighi, Giovanni 25, 37, 53

Association for the Promotion of Social Science (Social Science Association) 114,133

asylums 12

Atlantic Monthly 145

Austro-Hungarian Empire 20 
authority 2, 12, 20, 31, 47-8, 52, 57-9, $62,66,72-4,97,107,161$; academic $62,64,163$; aristocratic 62; central 30; collective 163; hierarchical 59, 107; intellectual 51, 108, 156; legal 47; political 67-8; psychiatric 12; religious 28, 67; state-backed 96; theological 28 autonomy 9, 22, 43, 45-7, 72, 74, 87, 90, $93,108,141,148-9,155$; academic 52, 57,66 ; appearance of 152 ; institutionalized 48 ; of science $28,56,81$ autopoietic systems $79-80$

Balston, Edward 116

BAME (black, Asian, minority ethnic) students 128-9

'Barbarian' classes ('aristocratic sons') 114

Beale, Dorothea 135

Bedford College (part of Royal Holloway, University of London) 133

behaviour 12, 19, 21, 24, 27, 78, 80-1, $87,115,117,124$

behaviourists 13

Ben-David, Joseph 7, 20, 24-32, 37-8, 40-1, 43-6, 48-50, 53-7, 64, 64n2; account of the movement of natural scientists as the historical basis for knowledge development 8 ; analysis of the scientist's role in society 25-6, 38, 44; and his mentor Edward Shils produce an historical account of modern higher education in 19th-century Germany 7, 22, 30, 54-6, 64-5, 74, 76, $86,98,101,107$; and the historical interpretations of the evolution of scientific disciplines 25 ; model of centers of learning 33; natural scientists as the centers of learning 38; paradigmatic success story 44 ; sociology of science 38 ; and the three groups revolutionizing higher education in France, Germany and England 31; and world-systems analysis (WSA) position 26, 43

Berlin 40-1, 48, 51, 160n2, 167

Berman, Elizabeth Popp. 9

Bildungsbürghertum (educated German bourgeoisie) 45, 61

biotechnology 9

Bodichon, Barbara 133, 135

Bonn 40

Boucheret, Jessie 134

Bourdieu, Pierre 4, 21, 71-2, 122, 141-2

bourgeois classes 19, 21, 55, 63, 117

bourgeois values 127,133
Braudel, Fernand 33

'Brexit' 111, 154, 164-5

Brint, Steve 73-4

Britain see United Kingdom

Bromley, Patricia 5, 90

buildings 1, 115, 137, 160-1

Burawoy, Michael 56, 155

bureaucrats 44, 61, 63, 106

business schools 49,163

Cambridge University 32, 114-15, 121, $123,126,132,135-9$

campaigns 132, 134-7, 155; for the education of women 134-6; women's suffrage 134

Cannadine, David 117

capital 14, 33-4, 38, 40, 71-2, 76, 120, 125,141 ; accumulation of $34-5,39$; economic $71-2$; institutionalized 71 ; social 149; symbolic 14

capitalism 6-7, 10, 18, 21, 23, 33, 53-4, $56,68,70-2,88,91,94,98,156$; academic 9; global 7; implied 33; industrial 9, 85; knowledge-based $57,66,94,104$

capitalist system 3, 24, 33-4, 37-8, 43, $53,55,57,82$

capitalists $22,33,43,51,60,76$

Carnegie Commission on Higher Education 31

Catholic education 133

CCD see culture of critical discourse censorship 47, 60, 63-4

centers of learning $24-5,29,31,38,40$;

Ben-David's model of 33; professional training in 50; scientific 38, 40; shifting between national university cores and peripheries 11

chaotic determinism (Prigogine) 37

Charles VI 33

Charlottenburg Palace 160

chemistry $119,122,147,151,153$

Chicago School 10

Chicago University 51-2, 146

Chicago World's Fair 1893160

children 2, 24, 72, 115, 123, 129, 132, 138

China 28, 165

churches $59,63,73,116,118$

city-states $34,37,53$

civic universities 8, 20, 167

Clarendon Commission 1864 110, 123

'Clarendon' schools 115

classes 61-3, 69, 73-4, 76, 86, 94, 107, 117, 123-4, 155, 164; academic 110; 
bourgeois 19, 21, 55, 63, 117; business 51; capitalist 73; conflicts 74 ; dominant 4, 87, 139; economic 68; intellectual 19; lower 63,75 ; ruling 64,73 ; social 63 , 111; structures 2, 24, 124; subordinated 87; university-educated 168

classics (subject) 110-12, 115-20, 122, 127,139

clergy $2,20,24,110-11,114,119-20$, 125,138

Clifton College, Bristol 121

Clough, Ann 135, 138

Clough, Arthur 137-8

Cold War 91

colleges 25, 32, 101, 115, 121, 126, 130-1, 133, 135-40, 164; Bedford College 133; Corpus Christi College 115; Girton College 135, 137, 139; Newnham College 137, 139; Oriel College 116; technical 31; Trinity College 138; women's 131, 137 communication $80,82,84-5,88-90,94$, 96, 102, 108, 147, 159; coded 85; external 82; mechanically-produced mass 85 ; in modern societies 89 ; public 85; scientific 96; social 80

competition 7, 17, 29-30, 38, 40, 51, 68, 152, 155; imperial 2; institutionalizing 46 ; interprofessional 11,152 ; religious 116; strategic 141

conflicts $1,11,18,46-7,61,86,110,117$; academic 18; personal 47; professional 47; religious 127

conservatism $34,62,68,117$

control 32, 35, 51, 72, 75, 82, 84-5, 87, $95,157,166$; authoritative 79 ; distributive 75 ; hierarchical 86 ; jurisdictional 152; minimal societal 85

Corpus Christi College, Oxford 115

Counter-Revolution 59, 63, 94; see also French Revolution

credentials 32, 72, 76, 91, 106-7, 113, 125-6, $155,164,168$; academic 107; educational 113; higher-education 125,155

crises $34,37-8,65,86,111-12,126,163$, 168; emerging 111; financial 11, 88, 149 ; sustained legitimacy 164 ; systemic 37; terminal 36

critical scholarship 154-5, 162

critics 3, 69-70, 84, 94, 103, 113, 115,

157,160 ; administering surveys to sociologists to demonstrate their leftleaning 70 ; disciplinary 156 ; sociological 125; who identify 'culture' with a 'smattering of the dead languages

Greek and Latin' 113

critiques $57,108,112,117,120,124,127$, 155-6, 160; contemporary 124, 176; scientific 67 ; systems-analytical 86 cultural capital 71-3, 123; academic 71; acquired 107; arbitrary 122 ; institutionalized 71 ; objectified 71

culture $1,4,21,24-5,71-3,87,89,91$, 93, 95, 97, 99, 113-14, 117, 127; academic 24; aristocratic 47, 117; business 95; of critical discourse 72, 74; human 137; organized 95

curriculum 110, 116, 118; classical 25, 116, 119, 122, 138; general education 119, 136; middle-class attempts to change the 117; and the New Class groups' desire to reform the 124; organized around dead languages and rote memorisation 115

\section{Darwin, Charles 3}

Davies, Emily 133, 135-7, 139

Dawkins, Richard 104

democracy 19, 56, 120, 147

democratisation 4-5, 22, 25, 120

departments 101, 141, 144-5, 147, 149, 160; diverse 156; governmental 51; interdisciplinary 141 ; university 52 Dewey, John 146-50, 157-8

dimensions $13-15,17,26,67,80,89$, 155; factual 89, 93; of IEMP power 67 ; of meaning 89 ; normative 89 ; performative 13-14, 16; sociological 16; temporal 15-16, 88, 105

disadvantaged backgrounds 112, 122, 128,165

disciplinary 141, 143, 154-5; associations 52; configurations 143; developments 11; neologisms 153; silos 148, 156; specialization $20,44,120,141,145$, 157, 159; splitting 100

disciplines $11,13,52,66,82-3,95-6,98$, $101,103-4,106,141,144-5,148-9$, 151-8, 160; academic 18, 37, 104, 113, 141,150 ; chaotic 98,100 ; contemporary 153 ; critical 159 ; humanistic 108, 154; object-oriented 144, 159; problem-portable 156; professional 50; scientific 25; specialized 20, 44, 120 , 141, 145, 157, 159; subject-oriented 144,153

discourses 13, 15, 17, 82-4, 87, 90, 94, 103, $105,124,127,129,155,159,165$; 
academic $56,108,152$; authoritative 97 ; communicative 15, 103; conservativeprogressivist 20; contemporary 123; critical 72-3, 89, 91, 97, 159; empowerment 90; human rights 91 ; ideological 17; philosophical 28; professional 153; rational 76 ; right-wing 154 ; scientific 40 , 88; sociological 80

distribution 135, 145; differentiated 52; of German university students over the faculties and subject areas, 1830-1914 (in rounded percentages by column) 49; relational 14; uneven 123

divisions $18,35,37,52,54,58,101,104$, 145-7, 150-1; disciplinary 35, 52, 56; four-field 145; political 18; structural 55 doctrines $6,60,68,92,106$

Durham University 136

Durkheim, Emile 6, 94, 102 dynamics $2-3,9,20,25,53,112$, 164; cultural 4; long-term processual 19 ; longer-term power 22; macrosociological 3, 13, 19; relational 138; subjective 156

ecologies 11-12, 20, 142, 169

economics $17,34,49,52,62,67,85,87$, 91, 106, 108, 111, 148, 153, 165; knowledge of 'pure' 106; and market prices 85 ; neoliberal 95,153

economists 9, 36, 51, 88, 126, 153-4, 161,163

economy 5, 84-5, 87, 107, 165; capitalist 3 , 38; globalized 110-11, 122; knowledge-based 180

Edinburgh Review 134

education $6,21,35,45-6,90,111-12$, 114-16, 120-2, 126-9, 133-5, 137-9, 147-8, 170, 172-8, 180-3; advanced 71; classical 117, 119-21, 127; general 29, 92; German university 29; history of 139 ; institutions $6,71,75-6,79,86$, 90, 166; language 110; liberal 31, 106, 119; modern 112-13; non-academic 167; professional 52, 64, 92, 104; public $72,90,173$; reformers 121 ; religious 115 ; secondary $25,61,110,114$, 119; women's 111, 114, 133, 138

Elias, Norbert 117, 142; analysis of the civilizing process 21,23 ; conception of knowledge 16; figurational sociology 18,157

Eliot, Charles 51, 121, 139

Eliot, George 121, 133-4, 139 elites $51,59,61,63,66,72,83,86-7,89$, $92,94,123,132,161-2,164$; academic 166 ; bureaucratic 63 ; and class structure 132; colonized Alsatian 50; economic 63; emerging 20; industrial 110 ; intelligent 56 ; knowledgeable 61 ; professional 54; status of 6, 92, 106; wealthy 45

elitism 32, 62, 75, 94, 110, 112, 122-3, 127, 129; academic 163; of humanistic Oxbridge tutors 57; new 62

elitist 51, 113, 126-7, 129, 162; academics 166; barriers 123; Bildungsbürgertum disdain for utilitarianism 61; legacies 159; schools 120; universities $1-2,108,122,124,132,166$

employment 133-5, 166, 178

Endowed Schools Act 1869114

Engels, Friedrich 5, 175

engineers $59,69,74$

England 31, 40, 43, 63, 115-17, 137-9; educational reform 32; and literature 120; and schools 122; see also United Kingdom

enrolment 125-6, 139, 164, 167; contemporary university 122 ; expanding university 44; HE-sector 111; mass student 166

environment 169 ; academic 21 ; contemporary 144 ; cultural 52,78 ; interdisciplinary 159; professional 166 equality $58,63,113-14,124,132,134-5$, 139,155 ; ideas of 131 ; social 117 ; women's 132,138

establishments 8, 11, 43, 50, 52, 116, 118 , 120 religious 116-17, 127, 136; state's 126

Eton School 116, 128

Europe 1, 4, 28, 35, 38, 40, 61, 111, 145, 155 ; cultural landscape of 32,120 ; early 19 th-century 21 ; education systems 32,114 ; guild system 52 ; medieval 28; and the middle classes 117; scholars 146

Evans, David 38

evolution 3, 6, 9, 25, 37, 53, 66, 105; biological 15; cultural 88; historical 75 examinations 116, 136-7, 139; civil service 8; entrance 122, 135, 137, 139; local 136-7

expansion $61,90,108,111-12,125-8$, 134, 139; 21st-century 167; colonial 34; economic 37

experts $56,71,124,161,164-5,169,172$; autonomous social scientific 56 ; 


\section{Index}

educated 20; power of 91; science policy 92 ; trusted 154

faculties 1, 36, 46-7, 49, 57, 66, 97, 131, 137; higher 46-7, 49; legal 26, 47, 49, 55; philosophical 20, 46-7, 49-50, 57, 107; professional 50, 64

families 84, 121, 133, 136

financial crises 11, 88, 149

Foucault, Michel 21, 166

four functions of the university 105

fractal cycling $100,101-2$

fractal distinctions 11, 98, 99; between 'hard' and 'soft' forms of science 11; generating endless misunderstandings 98; relational character of 99 ; in sociological methods 99

fractal divisions of science and ideology 104

fractals $84,101-2$

'fragmentation' 94-5, 105, 154

France 19-20, 24, 29, 31, 55, 59, 63, 117; and 'centers of learning' moving from Britain 25; and the conjunctural historical differences between professional systems in 64; and contests between differing conceptions of the nation 63; declassed nobility in 94; dependent upon Paris as the only access point to the outside world 40; domestic institutions 34; and the emergence of St. Simonian Positivism 59, 94; evaluation procedures opening social access to higher education 31 ; German-speaking countries responding to the imperial invasion of 20; impact of the French Revolution on higher education 24; investing in higher education 43; and the new social sciences as projects of a 'dispossessed aristocracy' 59; and the 'noblesse de robe' identifying with the rationalization interests 19 ; and the overturning of the courtly tier 62 ; promotion of special schools in 31 ; recognition and securing of academic credentials and reputation 107; and the shift of centers to Germany in the 19 th century 31 , 40; state-sponsorship securing a stable basis of finance and authority 31

Francis, David 146

'Franco-British rivalry' 34, 40

Franco-Prussian War 50
Frankfurt School 86

French Revolution 8, 20, 23-4, 31, 34, $60,94,118,132$; contours and effects of the 4; and the emergence of German idealism in parallel to the 5; and the emergence of the university in the aftermath of the 64; interpreted as the end phase of the Franco-British rivalry 34 ; leads to the ideological reconfiguration of the capitalist system 34 ; and the occurrence of sociology in the wake of the 94; and the turn towards 'democracy' 19

\section{GBI see Governesses' Benevolent} Institution

Gebre-Medhin, Ben 9, 21

gender 16, 124-5, 134, 139, 155; female 102 ; inequality 162 ; troubles 75

general education 29, 92, 119, 136

'geoculture' 34-5

geopolitics 25, 34

German Romanticism 59

Germanists 48, 60, 62, 64

Germany 8, 24-5, 29, 31, 38, 40, 43-4, $55-6,61,64,107,116,126,160$; 19thcentury $7,55,144$; academics 24,50 , 146; and the 'academization process' 20; aiming for the ideals of Kultur, Bildung and Wissenschaft in education policy 113; developed an 'educated' bourgeoisie called Bildungsbürghertum 45; and the civil code 50; development of legal sciences in 26; develops the modern university system according to a scheme articulated by Kant 20; enthusiasm for Naturphilosophie 27; and the French Revolution 62; and the model as the primary contribution to the global university system 32; model assimilated into British and American universities 55; and the movement of centers of knowledge to the United States from 30; and the novel institutional growth of the university occurring in 43; philosophers and scholars promoted the movement for reform in 31 ; and the reactionary Vormärz period in 58; and the removal of the universities' ecclesiastical and financial bases following Napoleon's invasion of 43; sets the standard of what academic knowledge should be in the 19th century 11; and the settling of US 
academics and reformers in 50; and the Sonderweg assumption that Germany was an aberrant nation 55; state reform in 44; and the success of science in the 19th century due to a decentralized university system 29 ; and the thinness of the educated civil service 62 ; and the undermining of all guild privileges in 44; and the university being the product of a form of liberal conservatism, or conservative liberalism 20; and the university revolution in 40; and Wallerstein focuses on the historical methods developed in 36 ; where the university enabled rational social reform without requiring either revolution or popular participation 24

Giddens, Anthony 4, 83, 85

Gilman, Daniel Coit 51

Girton College, Cambridge 135, 137, 139 global capitalism 7

global rankings 164, 166

globalization 18, 88

globalized economy 110-11, 122

goals 3, 46, 51, 117, 134, 146, 156-7; higher educational 125; societal 158

Göttingen 40, 47

Gouldner, Alvin 13, 17, 20, 22, 59, 63, 66-7, 70-6, 79, 85-6, 90, 94-7, 117, 127,177 ; account of the ideology of technology and the emergence of the New Class 70; analysis of sociology as ideology 71; analysis of the university and the New Class 59, 79, 108; attempts to connect French Positivism to German Romanticism 59; interpretation of the ideological organization of modern knowledge-based capitalism 94; supports the New Class as a unity of academics and professionals 73; understanding of scientific ideology 79

Governesses' Benevolent Institution 133 graduate schools 25,51

graduates 1, 6, 8, 52, 61, 107, 110, 115, $124,154-5,161,164-6$

grammar schools $114-15,118,121,124$ 5, 127; see also public schools

Great Britain 12, 29, 40; see also United Kingdom

Greek 113, 115-16, 118-19, 121, 123, 126; ancient 61; classical 115; philosophers 28,118

Gross, Neil 142 groups $16,30-1,67,70,85,124-5,127$, $129,138,142-3,158$; disadvantaged

159; excluded 124-5, 132, 139;

functional 150; New Class 124; problem-oriented 160; professional 49

growth 1, 5-6, 27-30, 33-4, 42-4, 53-6,

111,117 ; economic $1,117,153$;

historical 30; institutional 43; of the 'scientific community' 42

guild privileges $44-5,52,54$

guilds $95,163,167,178$

Gulbenkian Commission 56

Gymnasium 61, 63

Habermas, Jürgen 70, 86-7, 90

Habinek, Jacob 44

Hamerow, Theodore 50

Harvard University 51

health 52, 72, 150, 158; see also public health

hegemonic 4, 14, 33-4, 37-8, 40, 53, 63, 153-4; aspirants 40; assumptions 14; centers 37-8; discourses 153-4; domination of the West 4

hegemony 33, 38, 63

Heine, Heinrich 5

Hellenism 61-2

hermeneutics 13-14

heteronormativity $154-5$

hierarchies 57, 81, 83, 85-6, 123, 125; distinctions 54, 75; new 126; pyramid 165 ; status 152, 166; symbolic 96

higher education 5-9, 20-1, 31-2, 43, 45-6, 90-1, 123-9, 131-40, 163-4, 166-7, 172-4, 176, 178, 181-4, 186-7; contemporary 110 ; credentials 76 ; German 43; revolutionizing of 31; systems 24, 31; underrepresented groups in 128

historians 2, 4, 21, 58, 106, 144, 161, 163, 167 ; analyzing the way technology is used as a 'measure of men' 21; conservative Romantic 61; Latin 118; Theodore Hamerow 50; of universities 8 ; value-neutral 50

historical 142, 144, 156; accounts 7, 49, 56 ; assumptions 91 ; data 3,53 ; development $25,37,83,119,147$; dynamics 21 ; events 17,131 ; inaccuracy 105 ; materialism 4; materialists 13; particularities $49,55,58,64$; records 56 , 58; research 36,61 ; retellings 147,149 ; scholarship 3, 64; sites 28; sociology 3 , $8-10,21-2,66,98,116,138$ 
history $2-3,7,9-10,12-13,15,47-9$, $53-7,60-1,88-9,110,112,127,131$, 140-1, 167; contemporary 118 ; of expanding access to education 112 , 139; human 161; internal disciplinary 157; legal 50, 180; national 156; natural $15-16,143$; recent 112 ; sociological 15-16; of universities 3, 10

Hobsbawm, E.J. 4

Hodgson, W.B. 133-4

Holmwood, John 154

Holy Roman Empire 47-8, 62

human interests 146, 150, 177

human minds $83-4$

human rights $5,90-1$

humanists $35-6,87$

humanities 35-6, 47, 49, 54, 56, 92, 100, $104-5,120,126,139,144,152-3$

humans $17,58,77,80,85,162$

humility, academic 157

ideals $30,43,56,77-8,106,139,159 ; 20$ thcentury 157; civilized 21 ; cosmopolitan 165; ethical 132; fragmented 78; of Wilhelm von Humboldt 46, 55, 105

identity 30, 80, 82, 84, 89; 'bundled' 105; collective 77 ; external 84 ; intersectional 75; scientific 7, 54

ideological 63, 92, 104-5; analysis 86; authority 65,70 ; centre of the 'neoliberal' university 129 ; commitments 27; consciousness 87 ; contradictions 91; development 66; functions 43, 92; justification for existing political, military and economic institutions and classes 69; organizations $35,66,76,79$, 87, 91, 93-5, 108, 159; orientations 57; power 14, 17, 21, 67-9, 82, 87, 90-1, 107, 124; superstructure 7, 9, 104; systems $65-109$

ideologies 14, 17, 27, 34, 55, 63, 66, 68-70, 74, 76-9, 85, 90, 95, 97, 108; institutionalized 14, 17, 69-70, 90, 108; and scientific theories 69, 78-9; secular 34 ideologues 75, 78, 95, 107

ideology $12,14,17-18,60,63,65-71,73$, 75-9, 87, 89, 95-8, 101-4, 107-9, 143, 156; anti-modern 59; authoritative 96; bourgeois 129 ; conservative 60 ; critique of $70,73,86,108$; decline of 65 , 71, 91; deflationary 70; dominant 87, 107, 156; general and special 78 ; modern 65, 70, 76, 90; non-scientific 27; religious 70; of technology 66, 70,
91,93 ; theories of 69,108 ; theory of

76, 93; traditional 66, 71

IEMP model of power 14, 66-7,

69-70, 90

ignorance 79, 96-7, 113, 120; systematic 66, 79; systemic 91

In Defense of Disciplines 141

incomes 63, 71-2, 74, 162, 175

individualism $68,162-3,171$

industrial societies 5,91

industrialisation $4-5,13,22$

industry $20,22,63,117,131$

inequality $10,123,125,127,182,187$; economic 163; exacerbating 126; social $102,107,113$

injustice $63,75,103,151,158$

institutionalization $12,26,31,35,43,54$, $77,79,88,93,107,132-3$; achieving

136; compounding 30 ; historical 90 ; initial 144; social 13

institutionalized ideologies 14, 17, 69-70, 90, 108

institutions $1,3,7-8,11,14-15,17$, 29-30, 66-8, 79, 81-2, 86-7, 89-90, $125,161-2,166 ; 19$ th-century 160 ; central 12, 66, 79; cultural 124, 126; disenchanted 14, 69; economic 69; elitist 124, 167; ideological 17; inefficient 92; late-medieval 114; new 51, 55; political 60,181 ; privileged 32; traditional 69

instruction 110, 118-20, 122, 125, 129; classical language 116; foreign language 111, 120; modern language 127; religious and public 46, 120

integration $12,78,82,87,93,101,107$; political 21, 44; professional 148

intellectuals 51, 62, 71, 73-4, 102, 132, 142

intelligence 17, 134

interdisciplinarity $141-4,147-9,153-4$, 156-7, 178, 187; academic 157; and contemporary issues surrounding 144; humanistic 154-5; situating within the context of long-term historical trends 142 ; strong 144, 149, 151, 158; study of 142 ; weak $143-4,149,156-9$

interdisciplinary 3, 144, 148, 160; disciplines 153; grant committees 141; humanistic scholarships 155; interactions 151; problems 149; research 153; solutions 158

interdisciplines 153, 155-7, 159-60; characteristic of the contemporary university 144; emphasizing critical scholarship 154; organized around a 
different problem, each of which is a different object 155; sociological engagements with 141

interests $2-3,9,11-12,19-20,24,55,59$, $62,72,74-5,93-4,108,111-12,160$, 162 ; analytic 17 ; bourgeois 21,63 ; competitive 43 ; economic 72 ; mercantile 33; particular 72-3, 93; public 115, 117, 127, 163; sociological 100

interpretations 4, 6, 25, 33, 39, 47-8, 94, 96, 99, 137, 160, 162, 179, 184, 188;

contemporary 13 ; hermeneutichistorical 96; new historical 25; structural-functionalist 6

Ireland 116, 133; see also United Kingdom

Italian city-states 37,53

Italy 40; see also Renaissance Italy

Jacobs, Jerry A. 141

Johns Hopkins University 51

jurisdiction $47,52,101,152$; professional 46,152 ; scientific 44

jurists $47-50,57-8,62-4$

justice 57, 103, 150-1, 158; see also social justice

Kaiser-Wilhelm-Gesellschaft (now called the Max Planck Society) 46

Kaiser-Wilhelm-Universität 50, 57

Kant, Immanuel 20, 46-8, 57-8, 64

Keynesian fiscal management of the state 163

Keynesian macroeconomics 163

Khan, Shamus 129

Kleindeutsch German Empire 60, 64

knowledge 4, 10-11, 16, 27-32, 35, 71-2, 89, 97, 99-100, 139, 141-3, 145-6, 148-54, 156-9, 161-2; abstract 2, 12, $105,151-2,157$; academic 11, 52, 144 , 168; accumulation of $3,28,94,106$; advanced 11; capitalization of 54,91 , 93; classical 120; disciplinary 148, 157; divisions of $35,54-5,104$; economy 7 , 161, 164-5; mental 145; nested subsystems of 99 ; objective $53,97,101$; organized 82,93 ; physical 145 ; preexisting 147; professional 11, 52, 104, 152; scientific 26-7, 30, 32, 44, 114, 143, 171,185 ; social functions of 143,151 , 158-9, 173, 184; sociology of 13, 27, 142 ; specialist 73,153 ; traditions of 27 , 142; unity of $44,144-8,150,157$ knowledge-based capitalism 57, 66, 94, 104

knowledge-based economy 180

knowledge-based status structure 54

Kuhn, Thomas 26, 53

La Vopa, Anthony J. 61

languages $16,33,95,102,111-12,115$, 118-19, 122, 126, 152; classical 118; dead 113, 115, 119; foreign 110-11, $118,120-2,126$; study of $110-12,122$

'late capitalism' 4, 161

Latin 113, 116, 118-19, 121-3, 126

law 5, 20, 46-52, 57-60, 62, 64, 84, 111, $114-15,145,150$; faculties 47-8; local state 47 ; natural 47-8, 58-60, 63

lawyers 5-6, 58, 84, 86, 119, 151, 162 lecturers 45, 125, 138; see also professors left-wing politics 72

legacies $6,22,25,31,110,131$

legal scholars $48,50,55,62$

legal science $26,48-50,59,154$; divided into sub-divisions 48; German 20, 48; historical 57, 62

LGBTQ scholars 156

Liberal politicians 114

liberalism 34-5, 62, 68, 138; ascendant middle-class 136; conservative 20; and John Stuart Mill 133

liberals $18,35,43,116,136$

London 38, 40, 133, 136, 138, 158

Louisiana Purchase Exposition 1904145

Luhmann, Niklas 57-8, 66, 79-81, 83, $85-6,89,96-8,101-2,124$; analysis of the system of scientific communication 96; and the sociologists 86 ; systems approach 79, 86; systems epistemology 83-4; systems theory 14,108 ; theory of autopoietic systems 79

Mann, Michael 3-4, 13-14, 22, 66-70, $74,76,79,85-6,90-1,108$; account of the decline of ideology in the 19 th century 71 ; believes ideology derives from the human need to find the ultimate meaning in life 68; criticised by representatives of the culturalist 'third-wave' for the neglect of ideological power 68; and the IEMP model of power 14, 66-7, 69-70, 90; neglects science in modern social organizations 69

Mannheim, Karl 13, 60, 62, 69, 142 
markets 9, 15, 22, 45, 52, 54, 69, 87-8, 120, 149, 158, 163; capitalist 4; core 33; professional labor 71

Martineau, Harriett 134

Marx, Karl 5, 75, 95, 99

Marxism 70, 73, 94, 97, 143, 177

mathematics 116, 137, 139

Maturana, Humberto 80

Max Planck Society 46

Mead, George Herbert 13

media 95, 164

medicine 20, 46, 49, 85, 111, 114-15,

$122,135,140,150$

mental sciences 145-6

Merton, Robert 81

Meyer, John W. 90-1, 154

micro-technologies 69

middle classes 19, 32, 59, 114, 117-18, 120, 123-4, 127, 137, 156, 163, 183; arguments against the Old Regime 124; bourgeois 2, 59, 74; capitalist 19; educated 45, 127; industrial 117; occupations 120; and privilege 127; students $75,120,127-8$; utilitarianism 132

military $17,64,66-9$

Mills, John Stuart 132-3

Mills, Wright 86

Minerva 7, 64

model 7, 13, 22, 32, 35, 43, 53-6, 81, 87, $92,100,108,143$; center-periphery 31 , 41,55 ; competitive 29-30, 55; compounding system 53 ; four-function 93 , 105; historical 61; hyper-materialist base/superstructure 142; systemic 53 'modernity' (concept) 169, 178, 180, 183-4, 186-7

modernization theorists $6-7,11,20,56$, $70,98,103,105$

modernization theory $33,55-6$

MT see modernization theory

Münsterberg, Hugo 144-8, 150, 157, 159 music 111,118

Napoleon 31, 33, 43, 45

nation-states $4,18,34,91,176,181-2$

National Science Foundation 52

nations $23-5,33,40,45,55,60,63-4$, 116, 137-8; aberrant 55; advanced industrial 21; civilized 151; Western European 63; young 32

natural law 47, 59-60, 63; abstract principles of 58; the juridical faculty since Christian Wolff aspire to ground their authoritative decisions in 47-8; shift towards 58

natural sciences 7, 32, 35-6, 44, 47, 50, 54, 100, 104, 122, 151, 153, 155; experimental 57; object-oriented 156

natural scientists $7,35,38,44,46,50,57$, 126,151

nature $47-8,53,57-8,76-7,88,122,154$; observable 53 ; state of 58,60

Naturphilosophie 27

NECPHEW see North of England

Council for Promoting the Higher

Education of Women

neo-Marxism 18

neoliberalism 18, 75, 101, 122, 126-8, 161-3

neopragmatists 13

nested subsystems of knowledge 99

networks 15, 40-2, 44, 129, 132, 136, $138,142,149,162$; 18th-century 40 ; non-hierarchical 162; patronage 44 , 129; scholarly 138,149

New Class 2, 20, 64, 70-6, 79, 87, 89-91, 93-4, 97, 107-9, 124-5, 127, 156; of academics and professionals 62, 94, 125; ascendant 17; disinterested 91; factions 71; groups 124; ideology 76; of intellectuals and intelligentsia 74; power 17; retention of the means of production and consumption of cultural capital 72, 163; worldview 20

New Left 65, 74, 107, 162

New Right 162-3

Newnham College, Cambridge 137, 139

Newtonian science 57

Newtonian worldview 36-7

Nietzsche 126-7, 183

Noetic reformers (known as 'Noetics') 136, 138

non-Russell Group universities 111-12

North of England Council for Promoting the Higher Education of Women 137-8

OFFA see Office for Fair Access

Office for Fair Access 128

Old Regime 59, 62-3, 117, 124, 181

Old World 32, 146

On Liberty 133

organic chemistry 151, 153; see also chemistry

organisms $22-3,60$

organizations $11,14-15,25,28,31,65$, 67, 86, 88-91, 93, 106, 108-9, 145, 147, 149; authoritative 75; collective 77; economic 158; external 29, 103; 
functional 76, 86; global 11; internal 104; military 67; non-governmental 91; rationalised 91; rules 70 ; social 26 , 43, 70, 80, 93, 97, 108, 162

Oriel College 116

Oxford University 32, 112, 114-16, 121, $135-8$

Padua 38-41

Palace Promoting the Training of Women 160

paradigms 27, 97, 109, 180; mainstream sociological 74 ; weak interdisciplinary 158

Paris Expo 1900148

Parsonianism 18, 94; see also neo-Marxism

Parsons, Talcott 6, 17, 30, 66-7, 74, 76-9, 84-6, 92-3, 98, 101, 105-7, 114, 151, 156; articulates the view that mass higher education is 'the most critical single feature of the developing structure of modern society' 6; distinguishes between the personal ideology of the individual and the ideology of a collectivity 77; emphasizes the ability for actors to work together for shared ends 67; and idea of professionalism 107 ; and the valorization of modern professionalism 107

patent law 9

patriarchy $134,154-6$

patronage networks 44, 129

philology 47, 49, 119-20

philosophers 28, 31-2, 44, 46-7; likeminded 46; neo-humanist 43; political 163

philosophical 5, 20, 27-8, 45-50, 54, 57-8, 77, 104, 107-8, 118-19, 143-4, 151 ; arguments 54 ; autonomy 48 ; disciplines 104; inspiration 48; motivation 45; understanding 119

philosophy $3,20,29,44,47-8,57,62,77$, $99,104,132,143,148$; of organism 22; pure 47; speculative 28

Polanyi, Michael 26

policies 76, 129, 154; economic 163, 170; institutional 129; political 76; progressive educational 110

political economy 25, 34, 52, 71, 92

political interests $62,73,76$

political science $52,87,153,155$

political scientists 126,164 politicians 2, 20, 22, 51, 102, 133, 165-6, 176; corrupt 20; Liberal 114; moralists 102

politics $3,17,36,61-2,67,70,85,87,91$, $108,124,147,158,165$; bourgeois 85 ; influenced by cultural dynamics 4 ; white identity 155

populations $1-2,8,20-1,79,112,123$, $125,128,136,152-3,163,167$; expanding 45,113 ; non-white 128 ; older 168; world's 5, 161; younger 168

Postone, Moishe 53

power $12-17,20,22,44-5,56-7,67,72-$ $3,75,85-7,91,96,108-9,141-2,149$, 159; capitalist 33; collective 69, 82, 90; distributive 69,86 ; economic 40 ; elites 86; external 46, 106, 141; hierarchical 67,75 ; infrastructural $68,70,85$; military $67,91,108$; networks 15 ; political 66-8; solar 165; sources of 14,67 practices 13-14, 27-8, 32, 68, 76-8, 83, 86, 89, 97, 105-6, 142, 157-9, 168; academic 72,159 ; intersubjective 13 ; political 77; professional 155, 158, 180 pragmatics $119-20$

pragmatists $144,146,148-9$

privileges $19,32,45,62,94,117-18,122$, $124-5,127,159,167$; guild 167; historical 58; objectifying 123; professorial 44; state-sanctioned special 117 processual 4, 12, 18, 83, 143; development 11,132 ; theory 10 productivity $65,71-2,107$ professionals $2,17,20,22,52,54,71-3$, $94,97,106-8,124-5,127,132-3,163$, 165-6; educated 19; ethical 56; knowledge 11, 52, 104, 152; middle-class 123; non-academic 162-3; outlets 103 , 154-5, 157; status 31 , 49; training 5, 29, 31, 44, 49-50, 64, 100, 106, 108, 137

professions 11-13, 52, 73-4, 98-9, 103-4, 106, 119-20, 124-5, 134-6, 139-40, 142, 151-2, 156, 162-3, 167; academic 3, 11-12, 20, 22, 98, 101, 125, 149, 152, $154,161-2,165-7,180$; core 2 ; intellectual 151; learned 61-2, 114-15, 118, 120, 135, 150; medical 135; nursing 135; sociology of 73,104 ; specialized 120 ; system of 11-12, 52, 98, 107, 169 professors 29, 32, 44-7, 50, 53, 57, 109, $119,122,144-5$; bureaucratic appointees of the state 45; German 32; humanities 119; and the 'Humboldtian 
myth' 46; law 47, 57; and their guild privileges 45 ; university 45,50

propaganda 51

Prussia 40, 44-5, 48, 160; borders 40; control 44; and King Frederick William III 48; reform movement $45,51,55$

public health 2, 158

Public School Act 1868114

public schools $90,110,114-15,118$, $121-4,127,138$

rankings (research excellence) 107, 165

Reay, Diane 111, 165

reference $48,54,56-7,73,77,79,82-4$, $96,123,126,128,149,151,163,166$; classical 120; critical 163; external 96; frame of 30,177 ; historical 3 ; internal 96; primary 77

Reform Acts 1832, 1867, 1884132

reformers 48, 50, 114, 133-5; enlightened aristocratic 55; internal 138; liberal 136 reforms $31-2,35,44-6,50,58,114,124$, 136-7, 163, 176; contemporaneous state 44; educational 46; general middle-class 136; institutional 46; legal 64; liberal 45; policing 160; progressive 20 ; secondary school 127,136 ; selfdirected 117; specialist 43

regions $32,44,116,138,164-5,167$

relations $11,16-17,22,28,59-60,74,77$, $81,84,86,93-4,100,148,151-2,157$; clientelistic 69,97 ; collaborative 167 ; government-business 51 ; institutional 79; internal 34; social 14; structural 38 ; subjective 152; synthetic 158 religious $2,7,14,28,46,62,70,77-8,95$, 107, 114, 127, 132, 150; competition 116; controversies 156 ; education 115 ; establishments 116-17, 127, 136

Renaissance 6, 25, 53, 56, 114

representation $57,65,104,124$; collective 60, 77; equal 124; proportional 151 research $1,3-4,8,15,20,38,92,96-8$, $103,105-7,109,113,153-4,158,162$; academic 161; basic 44, 106; classical 121 ; comparative 58 ; findings 45 ; function 32, 91-2, 105; publications 90,107 ; questions 87 ; social 80,142 ; universities 66,79

resources $2,14,30,45,83,106,111,123$, $125-6,158$

Restoration 59, 62, 74, 177

revolution 4, 20, 177-8, 181; antisystemic 56 ; communications 85 ; contemporaneous British Industrial 4; democratic 1, 9, 34-5; dual 4-5, 9, 13, 19, 21, 85; French 8, 20, 23-4, 31, $34,60,94,118,132$; triple 4-5, 9-10, 18,22

risk $2,10,20,88,91,97,180$

Roman law 47-8

Romanists 48, 60, 62

Romantics 59-60

Rome 61

Rothblatt, Sheldon 138

Royal Holloway College, University of London (previously called Bedford College) 133

Ruskin, John 151, 158

Russian Empire 20, 74

Russian language 121-2

scholars 3-5, 9, 13-14, 26-7, 29, 31, 44-6, 62-3, 68, 132, 136, 138, 141-3, 146-9, 151-2; critical 122; disqualified 17; humanistic 50; legal 48, 50, 55, 62; LGBTQ 156; motivated 103; postcolonial 4; young 101

scholarship 44, 62, 112, 115, 128, 148, 152, 156, 158, 160; academic 155; advanced 146; classical 61, 136; critical 154-5, 162; scientific/technical 111; university 126

schools 18, 36, 61, 90, 111-12, 114, 116, $118,120,122-4,128-9,136-7$; academic capitalism 9; Annales School 33; boarding 129; 'Clarendon' 115; comprehensive 125; Eton 116, 128; independent $111,122,128$; medical 167; modern 6; non-conformist 137; private 123 ; professional 51,109 ; rival 148; specialized 31 ; students $1,6-8$, 45-6, 61, 72, 74, 110-12, 115, 118-20, $122-9,137-8,147-8,152,154-5$, 163-6; technical 46

Schools Enquiry Commission 1864136 science 1-2, 24-33, 35-41, 43-4, 53-7, 65-6, 69-71, 75-9, 81-3, 91-3, 95$100,102-4,106-8,142-6,149-52$; 19 th-century 149 ; academic social 74 ; applied 106, 146; biological 80; cultural 146; economic 87; growth of 28-9, 43, 53-6, 70; historical 34-5, 49, 145; and ideology $65-6,70,75,77-8$, 95, 103; medical 2; modern 55, 147, 187; new social 59, 100; physical 147; political 52, 87, 153, 155; practical 145-6; pure 29, 46, 145-6; theoretical 
28,77 ; value-free social 154 ; valueneutral 28

Science, Technology and Society scholars $3-4,8,18,142$

scientific community 30 , 42; conceptualizations of 'paradigms' and the 27; growth of the 42; and Michael

Polanyi's work emphasizing the 26 scientific knowledge 26-7, 30, 32, 44, $114,143,171,185$

scientific practice $40,43,77 ; 18$ th-century networks of 42 ; 19th-century networks of 41

scientific research 29, 41, 46, 64, 92, 107

scientific roles $28-31,53,55,171$

scientific theories and ideologies 69, 78-9 scientists 6-7, 25-8, 30, 35-6, 38-40, 44, $46,55,57,69,71,93,106-7,157,176$; individual 28; legal 49, 59, 154; political 126,164 ; proto-social 51 ; role in society 8, 25-6, 28, 30-1, 38, 53; specialized 147; value-neutral 56; workaday 148 Scotland 116; see also United Kingdom secondary schools 17, 110-11, 114,

$121-2,136$

sex issues 135,139

Shils, Edward 7, 22, 30, 54-6, 64-5, 74, $76,86,98,101,107$

Sidgwick, Henry 119-20, 127, 135, 138-9

Small, Albion 150-2

social equality 117

social inequality 102, 107, 113

social justice $1,5,128,166$

social networks 132,142

social power $5,9,13,66,70,79,82,87$, 89-90, 107-8; autonomous 69-70;

dimensions of 16; IEMP model of 66 ; sources of 66-7, 69, 181

social reformers $24,57,154$

social sciences 18, 26, 35-7, 49-51, 54,

56-7, 59, 77, 81, 96, 98-9, 104, 114, 150,152

social scientists $37,56-7,65,70,95,114$, $133,135-6,151$

social structures $10,16,30,67-8,81,93$, 107,150

social systems $57,87,104$

socialism 68,94

society $3-6,18-19,25-6,30-1,53-5,58-$ 9, 82-3, 92-4, 99-102, 106-8, 124,

$134,155,158-9,167-8$; aristocratic 32 ; bourgeois 59,179 ; capitalist 82 ; communist 58; contemporary 113 , 151; functionally-differentiated 75, 79; human 15; industrial 5, 59, 91, 107; medieval 1 ; modern $1,3,5-7,56,63$, 65-7, 70, 73, 76-7, 85-6, 89, 91-3, $105-7,117,120$; problems of 65,71 ; reforms 20; scientist's role in $8,26,29$, 38,171 ; student 131 ; theory of 10 , 101, 180; traditional 73

Society for Promoting the Training of Women 134, 140

sociological 11, 53, 144, 151, 169; abstraction 96; approaches 26; dimensions 16; discourses 80; engagements 141 ; interests 100 ; methods 99 ; positivism 59; theories 13,87

sociologists $2,4,13,25,50-1,57,70,80$, 86, 91, 94-5, 117, 141, 143, 153-4; classical 5-6; contemporary 57; critical 7, 12, 20; historical 4, 15-16; political 4, 9; post-war 76

sociology $3,15,18,20,28,52,71,79$, 82-3, 94-6, 98-104, 141-3, 152-6, 159,166 ; academic 70, 98; comparative-historical 9, 180; critical 95; deconstructing 108; figurational 21; institutionalist 28; of knowledge 26-7, 142-3; new 13, 17, 142, 152, 178; origins of 74, 94, 186; political 13, 21-2, 67 ; processual 10, 15, 22, 169; of science 26,27

specialization $31,44,92$; disciplinary 20 , 44, 120, 141, 145, 157, 159; of knowledge within the disciplines 92

SPTW see Palace Promoting the Training of Women

St. Louis World's Fair 1904 144-5, 149, 152, 157

St. Simonian Positivism in France 59, 94 state 4, 6-7, 9-12, 14-15, 19-20, 32-3, $43-50,52,57-8,67-9,72,87,106-7$, $126-8,163$; authority 45,51 ; bourgeois 118; bureaucracy 45,64 ; constitutional 58; education-based 55; nation 82,85 ; progressive 51; reformers 48; and school students 1, 6-8, 45-6, 61, 72, 74, $110-12,115,118-20,122-9,137-8$, $147-8,152,154-5,163-6$

status structure (knowledge-based) 54 STEM research and innovation 164

STS see Science, Technology and Society scholars

students $1,6-8,45-6,61,72,74,110-12$, $115,118-20,122-9,137-8,147-8$, 152, 154-5, 163-6; aristocratic 47; disabled 129; disadvantaged 123, 125 , 


\section{Index}

128; educated 112; graduate 106, 125; non-traditional 128; non-white 128 ; university $111-12$; untrained 139 studies 3-4, 6, 15, 18, 36, 98, 101, 104, $138,141,143,145,148,155-6$, 159-60; African-American 155, 160; classical 116, 119; cultural 15, 36; historical comparativists 10 ; scholarly 15 ; women's 155

subjects $7,54,58,91,93,111-12$, 118-19, 122, 124, 126, 131, 143, 145, 152, 158; A-level French 111; aligned STEM 158; colonial 21; modern 122; oversubscribed 111; traditional 44; transcendental 16; universal 75 suffragism 131-2

systems $15,27,29-32,34,37-8,40-1$, 48-9, 53, 78, 80-4, 86-90, 96, 98, 102-5, 144-5; abstract 54; accreditation 107; aristocratic protection 19; authoritative 28; autonomous 83,86 ; autopoietic 79-80; closed 82, 104; communicative 80,165 ; competitive 152; complex 79, 83; decentralized 30 ; economic 82, 84; educational 107, 112, 120; geopolitical 67; higher education 24, 31; ideological 65-109; legal 57-8, 84,103 ; psychic $80,83,86$; scientific 97; self-organized 54, 87, 107; single 25, 30, 33, 37; social 57, 87, 180, 183; strong-anticipatory 79,85 ; taxation 19; university 5, 8, 20, 31, 65-6, 90, $93,95,104,107-8,161$; weak interdisciplinary 156

\section{taxation 19}

teachers $29,44,72,90,111,113,123$, 127, 137-8; non-elite 13; public school 74 ; secondary school $61-2$; and students $1,6-8,45-6,61,72,74,110-12$, $115,118-20,122-9,137-8,147-8$, $152,154-5,163-6$

teaching $8,32,43,56,64,92,105-7,113$, $120,133,138,152,154,161$; advanced 1-2; discipline 47; exercises 49; fixedterm staff 165; general 92, 105-6; positions 133 ; unifying 61

technology 1-2, 4, 8, 21, 24, 55, 65-6, 69-71, 79, 90-1, 93, 114, 131, 153, 157; mass communications 40 ; science underpinning 39; and society 142

Temple, Frederick 136, 138 temporal dimensions and corresponding dimensions of social power 16 tensions $1,28,59,62-3,70,91,94,106$, $114,120,122,132,138-9,142,144$; social 59; structural 106

theology 2-3, 46-7, 49, 132, 150

Times Higher Education 164

tradition 26, 48, 52, 58, 70, 97, 108, 117, 121, 142, 188; academic capitalism 9; authority 108 ; bourgeois class 45 ; cultural 93, 107; political order 120; selfreferential 26

traditional religion 70

training $5,8,11,49,75,114,121,123$, 166; professional skills 92, 105-6; scientific 47

transformations $124-5,161$; institutional 26, 43; macro-sociological 108; political 1

Trinity College, Dublin 138

triple-helix complex 5, 21, 87-8

truth $12,16,35,44-5,57,78-9,96,104$, 145, 148-9, 167; claims 91, 133; content 32, 159; established 161; intersubjective 56; valid 95

tuition fees $1,25,45,128$

'two cultures' (C.P. Snow) 7, 35, 37, 57

unemployment 46, 163

unification (economic and political) 44 , $58,60,159$

unions 163,167

United Kingdom 4, 8, 20, 24-5, 32, 40, $55,64,110,116-17,123,127,131-2$, 163,$167 ; 17$ th-century 43 ; 18 th century $39 ; 19$ th-century 38,131 ; class structure 123; education 114, 137; elite schools 54; politics 126; scientific societies 56; universities 111,116

United States 25, 29-30, 32, 34, 40, 50-1, $54-5,65,107,126$; decentralized 53; and the emergence of affirmative policies 129; and the ideal science system in the decentralized 53; post-war 56; recent surge in evangelical influence in American power 65; and the rise of the New Left during the 1960s and 1970s 65 universities 1-12, 17, 24-6, 29-32, 43-4, 46-7, 49-51, 62-4, 74-5, 90-3, 103-8, $110-12,122-8,154-65,167-75$; 19thcentury 56; accredited 44; advanced 51; ancient 32, 115; autonomous 55; Cambridge University $32,114-15,121,123$, 126, 132, 135-9; Chicago University 51-2, 146; civic 8, 20, 167; contemporary 9, 144; Durham University 136; elitist 
1-2, 108, 122, 124, 132, 166; extended function of 110; four functions of the 105; German 7-9, 12, 25, 43-4, 47, 49-50, 54, 56; global 159; group 128;

Harvard University 51; Johns Hopkins University 51; Kaiser-WilhelmUniversität 50, 57; liberal 12; lower status 167; male 131; modern 1-2, 20, 24, 31, 47, 51, 96, 125, 144; modern German 63; modern research $38,55,71,76,91,188$; non-Russell Group 111-12; Oxford University $32,112,114-16,121,135-8$; redbrick 121; Russell Group 112, 128; systemic evolution of 24-64; top-tier 166; Trinity College 138; United States 25, 53, 55, 92, 141; University College Dublin 133, 174; University of Berlin 48; University of Bonn 50; University of Bristol 121; University of Chicago 7, 51-2, 146; University of Frankfurt 142; University of London 132-3, 138

university students $1,6-8,45-6,61,72$, $74,110-12,115,118-20,122-9$, $137-8,147-8,152,154-5,163-6$ university systems $5,8,20,31,65-6,90$, 93, 95, 104, 107-8, 161; decentralized 29; global 32, 105; growing 22; massified 2; national 52; paradoxical 161 upper classes 40, 114, 117, 134

value-integration 101 values $12,14,55-6,68-72,77-8,90,92-3$, $95,104,106-7,117,119-21,136,143$, 153-5; bourgeois 127, 133; heuristic 66; middle-class 120; public 95; social 28, 30, 74, 167; traditional 108; universal 24 Varela, Francisco 80

Vindication of the Rights of Women 132 violence 19,72

vom Stein, Karl 20, 45-6, 48, 61 von Hardenberg, Karl 45, 48, 61 von Humboldt, Wilhelm 46, 61, 105, 145 ,

167; hired by Karl vom Stein to run the state's Section for Religion and Public Instruction 46; ideals 46, 55, 105; intention in unifying teaching and research as a means of preserving the modern authority of secondary school teachers. 61; neo-humanist philosopher 43;
University of Berlin 48; vision of teacherresearchers 46

von Savigny, Eike 62, 64

voting 132,134

Wallerstein, Immanuel 33-9, 43, 49, 53-7, 131

The Warden 136

wars and diseases 151

Wars of Liberation 61

Wars of Unification 58, 60

wealth $72,150,158,162$

Weber, Max 47, 94, 99, 102

welfare-state 154

Whitehead, A.N. 22

Whyte, William 8

Wollstonecraft, Mary 132

women $36,63,75,125,128,131-9$;

19 th-century 131 ; changing roles of 24, 132; educated 133-4; employment of 134, 178; and equality 132 , 138; and higher education 131-40; middle-class 124; planning to enter teaching 133; special examination for 136; suffrage campaigns 134; upper class 135 ; young 134

work $2-4,10-12,15,30,33,38-9,71-2$, 75, 95, 98, 131, 133-5, 141, 154, 156; academic 137, 152; archival 49; empirical 38; scientific 150; tutorial 138; white-collar 166

workers 74, 161

working classes $20-1,75,123-4,126-7$

workplaces of leading scientists, 16th-19th centuries 39

world-systems analysis 24-6, 33, 35, 37-8, 40, 45, 50, 53-6, 104, 188; challenges the triumphalist modernization theory of political economic development 33; explains the compounding growth of a single system across centuries 33 ; neo-Marxist 24; as outlined by Immanuel Waller-stein and Giovanni Arrighi 25

World War I 9, 55, 132, 160

World War II 45, 52, 65, 121

World's Fair 1904 141, 145-6, 150, 160

WSA see world-systems analysis 


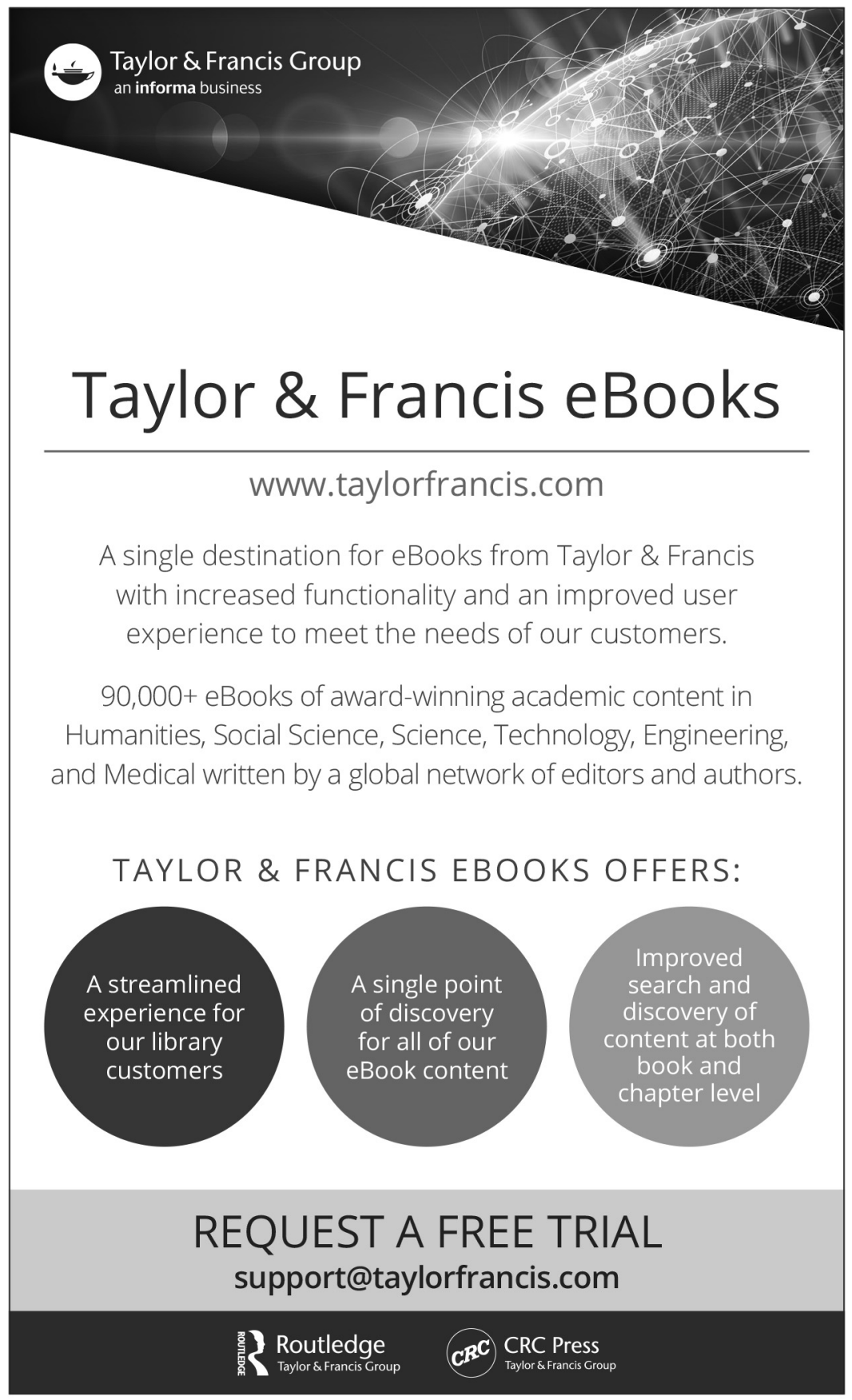

